\title{
Management of structure and productivity of boreal and subalpine forests
}

Edited by

SUNE LINDER

Department of Ecology and Environmental Research, Swedish University of Agricultural Sciences, Sweden

SEPPO KELLOMÄKI

Faculty of Forestry, University of Joensuu, Finland 


\section{Preface}

This issue of Studia Forestalia Suecica contains some of the papers presented during a IUFRO workshop on "Management of Structure and Productivity of Boreal and Subalpine Forests". The workshop was a mixture of lectures and excursions, during which the participants travelled from the lowlands of Central Finland to the forest limit in Northern Sweden. The emphasis of the workshop was on the biological and environmental constraints on forest yield in managed boreal and temperate forests. During such a short meeting it is impossible to cover more than a few aspects of the functioning of forest ecosystems. The four main areas selected were forest genetics, forest structure, nutrition and environmental stress. The problems associated with scaling-up basic knowledge from the level of organs to trees and ecosystems were also discussed.

Forests cover more than a third of the land surface of the earth, and are almost equally distributed between the temperate and the tropical regions. In the temperate regions, forest and woodland account for approximately $40 \%$ of the total land area. The forests of the boreal zone, together with temperate forests of the northern hemisphere, form the main base for the world's current timber and pulp production. Forests and other wooded land thus constitute the largest component of current and future land use in terms of area, and play an important part in the global carbon balance. The role of managed forest as a carbon sink or source, as well as the possibility of increasing carbon sequestration in forest ecosystems through silvicultural practices, is therefore a new and important area of research for forest scientists.

Managed forests cover a range from plantations, in which management includes all silvicultural activities, through natural forest managed for wood production, to natural forests simply exploited for timber products.

Factors regulating biomass production concern the physical and biological processes controlling carbon gain and partitioning. These processes are the same in high-yielding as in low-yielding stands, as well as in different species. Specific site conditions, in terms of climate and fertility determine, however, actual biomass production.

To be able to understand and evaluate the potential effects of natural and anthropogenic environmental changes on the future structure, biomass production and yield of managed forests, it will be necessary to predict both the short-term responses of the forest to altered climate, disturbance and silvicultural practices, and the effects on long-term sustainable site productivity and biodiversity. The long-term emphasis will require that conceptual advances be made in our capacity to characterise the sustainability and resilience of ecosystems in response to altered rates of input, loss and cycling of carbon, water and mineral nutrients.

The papers presented during the workshop demonstrated convincingly how current silvicultural practices may have both positive and negative effects which last longer than a rotation. However, they also indicated how practices which have a sound scientific base can provide management tools which guarantee the sustainable use and stability of our forest ecosystems.

Financial support for the workshop was provided by the Academy of Finland, the Finnish Ministry of Agriculture and Forestry, "Fonden för skogsvetenskaplig forskning", "Cellulosaindustrins Stiftelse", the Royal Swedish Academy of Agriculture and Forestry, the Swedish Council of Forestry and Agricultural Research and the National Swedish Environment Protection Board. The support given by these bodies is gratefully acknowledged. We wish also to thank our friends and colleagues for their excellent help in refereeing the individual papers.

Uppsala and Joensuu, December 1993

Sune Linder Seppo Kellomäki 


\section{Contents}

McKeand, S.E. \& Bridgewater, F.E.

Provenance and family variation for juvenile growth characteristics of Pinus taeda L. and the impact on early selection for growth, 5

Beets, P.N. \& Kimberley, M.O.

Genotype $\mathrm{x}$ stocking interactions in Pinus radiata: productivity and yield implications, 11

Shibata, O.\& Ando, Y.

Growth of Betula and Abies trees and their productivity at different altitudes in the subalpine zone, 21

Banks, J.C.G. \& Paton, D.M.

Low temperature as an ecological factor in the cool-temperate eucalyptus forests, 25

Waring, R.H., Runyon, J., Goward, S.N., McCreight, R., Yoder, B. \& Ryan, M.G.

Developing remote sensing techniques to estimate photosynthesis and annual forest growth across a steep climatic gradient in Western Oregon, USA., 33

Stenberg, P., Smolander, H. \& Kellomäki, S.

Description of crown structure for light interception models: angular and spatial distribution of shoots in young Scots pine, 43

Flower-Ellis, J.G.K.

Dry-matter allocation in Norway spruce branches: a demographic approach, 51

Nordmeyer, A.H. \& Ledgard, N.J.

Above-ground biomass, productivity, and nutrients in 15-year-old stands of Ponderosa pine, Corsican pine, Douglas fir, and European larch in the Craigieburn Range, New Zealand, 75

Malcolm, D.C. \& Ibrahim, K.G.

Nutrient:productivity relations in plantation-grown Sitka spruce in Scotland, 87 



\title{
Provenance and Family Variation for Juvenile Growth Characteristics of Pinus taeda L. and the Impact on Early Selection for Growth
}

\author{
STEVEN E. McKEAND \\ Cooperative Tree Improvement Program, Department of Forestry, North Carolina \\ State University
}

\section{FLOYD E. BRIDGEWATER}

USDA Forest Service, Department of Forestry, North Carolina State University

\begin{abstract}
McKeand, S.E. \& Bridgewater, F.E. 1993. Provenance and family variation for juvenile growth characteristics of Pinus taeda L. and the impact on early selection for growth. In Management of structure and productivity of boreal and subalpine forests (ed. S. Linder \& S. Kellomäki). Studia Forestalia Suecica 191. 94 pp. ISSN 0039-3150, ISBN 91-576-4822-0.

Stem elongation in first-and second-year Loblolly pine (Pinus taeda L.) seedlings has reliably predicted 8- to 12-year heights of half-sibs in Atlantic Coastal Plain provenances. However, stem elongation traits may not be useful for early selection with other provenances. For western provenances, shoot dry weight at $4-6$ months is used to predict field performance, but dry weight has not been a good predictor for the Atlantic Coastal provenances.

A study with 13 to 16 open-pollinated families from each of five provenances was established to test for differences among them for early selection. Ranks of stem elongation traits for the five provenances were as expected with the southern and lower coastal plain sources growing the fastest. Heritabilities for most traits in most provenances were moderate to high. Elongation traits were most strongly related to 5-year heights of older half-sibs in other trials for the Atlantic Coastal, Middle-Upper Gulf, and Marion County, Florida provenances, but the relationships were weaker for the Lower Gulf and the Gulf Hammock, Florida provenances. Thus, there is evidence that early selection based on first- and secondyear stem elongation traits may be effective only for certain provenances of Loblolly pine.

Key words: genetic gain, heritability, juvenile-mature correlation, shoot elongation, tree breeding, tree improvement.

Steven E. McKeand ${ }^{1}$ and Floyd E. Bridgwater ${ }^{2}$.

${ }^{1}$ Cooperative Tree Improvement Program and ${ }^{2}$ USDA Forest Service, Department of Forestry, P.O. Box 8002, North Carolina State University, Raleigh NC, 27695-8002, USA.

MS. received 11 November 1992

MS. accepted 7 January 1993
\end{abstract}

\section{Introduction}

Stem elongation in first- and second-year Loblolly pine (Pinus taeda L.) seedlings has reliably predicted 8-12 year field performance in eastern North Carolina (NC) and South Carolina (SC) provenances (Williams, 1987; Bridgwater, 1989; and Li, McKeand \& Allen, 1989, 1991). While other juvenile traits have been evaluated, stem elongation appears to be the most reliable and most easily assessed trait for early selection.

The utility of stem elongation for early selection has not been demonstrated for other prov- enances, and it is possible that other provenances will not behave in the same way. For example, total stem dry weight at 4-6 months is being used in the operational breeding program of the Western Gulf Cooperative with provenances from west of the Mississippi River (Lowe \& van Buijtenen, 1989). However, dry weights have not been good predictors of field performance of older siblings in studies of the NC provenance (Williams, 1987; Li et al., 1991).

Since breeding and testing trees in a traditional, long-term tree improvement program 
is very expensive, the ability to screen selections before they are placed into breeding populations would be very valuable. For breeders to use early selection as a screening tool, a reliable and repeatable early selection method for the breeding populations is required.

The objective of the study is to evaluate the use of stem elongation traits as a method of early selection for families from five provenances of Loblolly pine.

\section{Materials and methods}

Open-pollinated seeds of 13 to 16 families from each of five provenances in the southeastern United States were planted in the trial (Table 1). These same families from the Atlantic Coastal (ACP), Marion County (MC), Gulf Hammock $(\mathrm{GH})$, and Lower Gulf ( $\mathrm{LG}$ ) provenances were previously planted in a series of six tests established in 1982 and 1983 by members of the University of Florida Cooperative Forest Genetics Research Program and the North Carolina State University - Industry Cooperative Tree Improvement Program (Anonymous, 1988). The Middle-Upper Gulf (MUG) families had been planted as series of three trials in central Alabama and Georgia in 1984 (Anonymous, 1990).

Seeds for the present study were sown in a greenhouse in Raleigh, North Carolina $\left(35^{\circ} 47^{\prime} \mathrm{N}, 78^{\circ} 42^{\prime} \mathrm{W}\right)$ in early November, 1988 and seedlings were grown in RL Super Cells ${ }^{\mathrm{R}}$ $\left(164 \mathrm{~cm}^{3}\right)$ until they were outplanted $13-15$ March 1989 near Georgia-Pacific's (G-P) nursery at Cedar Springs, Georgia $\left(31^{\circ} 10^{\prime} \mathrm{N}\right.$, $85^{\circ} 3^{\prime} \mathrm{W}$ ) and at International Paper Company's (IPCo) Southlands Experiment Forest near Bainbridge, Georgia $\left(30^{\circ} 54^{\prime} \mathrm{N}, \quad 84^{\circ} 36^{\prime} \mathrm{W}\right)$ (Fig. 1). A randomized complete block design with 36 blocks of single-tree plots of 72 families was used at each location. Thus, a total of 72

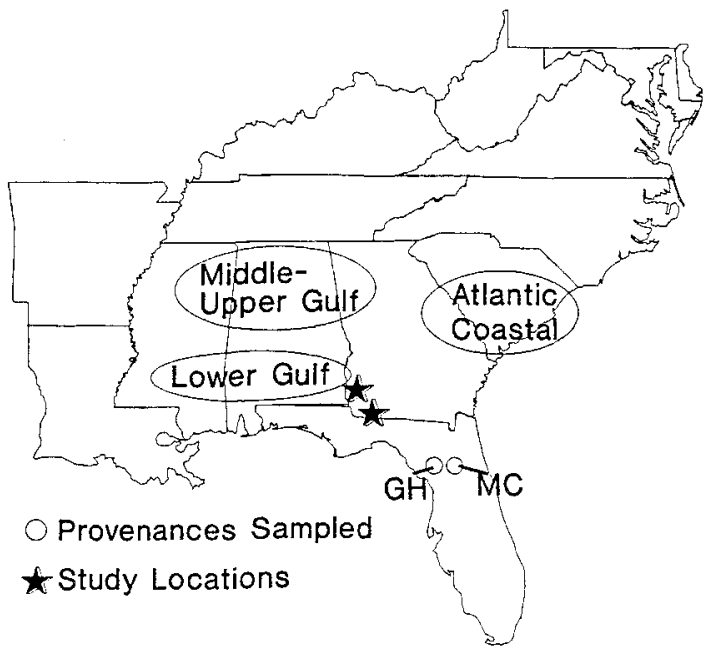

Fig. 1. Map of the southeastern United States showing the general location of the five provenances and the location of the two field sites. GH is Gulf Hammock, Florida and MC is Marion County, Florida.

seedlings were planted per family. The trees were planted at a spacing of $1.3 \times 1 \mathrm{~m}$ at G-P and $1 \times 1 \mathrm{~m}$ at IPCo to minimize block sizes. No cultural treatments were imposed on the trees except that tip moths (Rhyacionia sp.) were controlled with periodic insecticide applications, and competing vegetation was controlled with periodic herbicide applications.

After the first growing season, height to the end of the free growth cycle and total stem height were measured (free growth being defined as the developmental progression from hypocotyl emergence to the first terminal bud (Sweet \& Bollmann, 1976). After two growing seasons, total height was measured again, and the lengths for first- (excluding free growth) and secondseason elongations were calculated. The number of growth cycles or flushes was counted after both growing seasons. (A cycle is commonly referred to as a flush or internode in reference to stem growth. In Pinus, each is typically characterized by a zone of sterile cataphylls,

Table 1. Provenances of loblolly pine used in the study

\begin{tabular}{lll}
\hline Provenance (Code) & Latitude range & Longitude range \\
\hline Atlantic Coastal Plain (ACP) & $32^{\circ}-34^{\circ} \mathrm{N}$ & $79^{\circ}-83^{\circ} \mathrm{W}$ \\
Marion County, Florida (MC) & $28^{\circ} 50^{\prime}-29^{\circ} 20^{\prime} \mathrm{N}$ & $81^{\circ} 30^{\prime}-82^{\circ} 30^{\prime} \mathrm{W}$ \\
Gulf Hammock, Florida (GH) & $29^{\circ} 00^{\prime}-29^{\circ} 20^{\prime} \mathrm{N}$ & $82^{\circ} 20^{\prime}-83^{\circ} 00^{\prime} \mathrm{W}$ \\
Lower Gulf Coastal Plain (LG) & $31^{\circ}-32^{\circ} \mathrm{N}$ & $86^{\circ}-89^{\circ} \mathrm{W}$ \\
Middle-Upper Gulf Coastal Plain (MUG) & $32^{\circ}-34^{\circ} \mathrm{N}$ & $83^{\circ}-89^{\circ} \mathrm{W}$ \\
\hline
\end{tabular}


subtended by a zone of secondary needles, and a whorl of branches (Van Den Berg \& Lanner, 1971)).

Family and provenance means across the two planting sites were calculated for each trait. A11 statistical analyses were conducted using the GLM and VARCOMP (Type I sums of squares) procedures in SAS (SAS Institute Inc., 1985). To estimate the significance levels for provenance effects in the analyses of variance (Table 2), an approximate $F$-test (Satterthwaite, 1946) was used. Genetic and environmental components of variance were estimated for each provenance separately. The variance among open-pollinated families within each provenance was assumed to estimate one-quarter of the additive genetic variance (Falconer, 1989), and individual tree heritabilities for each provenance were calculated as:

$$
h^{2}=\frac{4 \sigma_{F}^{2}}{\sigma_{F}^{2}+\sigma_{F L}^{2}+\sigma^{2}}
$$

where: $\sigma_{\mathrm{F}}^{2}=$ variance among families $\sigma_{F L}^{2}=$ variance due to family by location interaction

$$
\sigma^{2}=\text { variance among trees within a family }
$$
within location

Standard errors of each $h^{2}$ estimate were calculated using methods of Becker (1984). Family mean (product-moment) correlations between variables measured in the early selection trial and the five-year field heights from the older field trials were calculated for each provenance. Family mean correlations are usually conservative estimates of genetic correlations. If environ-

Table 2. Form of the analysis of variance used in

\begin{tabular}{|c|c|c|}
\hline Source & $\begin{array}{l}\text { Deg. of } \\
\text { freedom }\end{array}$ & Expected mean squares ${ }^{1}$ \\
\hline Location & 1 & \\
\hline Blocks (L) & 69 & \\
\hline Provenance & 4 & $\begin{array}{l}\sigma^{2}+b \sigma_{\mathbf{L x F}(\mathrm{P})}^{2}+1 \mathrm{~b} \sigma_{\mathrm{F}(\mathrm{P})}^{2} \\
+\mathrm{f} \sigma_{\mathrm{B}(\mathrm{L}) \mathbf{x} \mathbf{P}}^{2}+\mathrm{bf} \sigma_{\mathbf{L x P}}^{2}+1 \mathrm{lbf} \theta_{\mathrm{P}}^{2}\end{array}$ \\
\hline $\operatorname{LxP}$ & 4 & $\sigma^{2}+b \sigma_{L x F(P)}^{2}+f \sigma_{B(L) x P}^{2}+b f \sigma_{L X P}^{2}$ \\
\hline $\mathrm{B}(\mathrm{L}) \times \mathrm{P}$ & 276 & $\sigma^{2}+f \sigma_{B(L) x P}^{2}$ \\
\hline $\mathrm{F}(\mathrm{P})$ & 67 & $\sigma^{2}+b \sigma_{L_{x F(P)}^{2}}^{2}+1 b \sigma_{F(P)}^{2}$ \\
\hline $\mathrm{LxF}(\mathrm{P})$ & 67 & $\sigma^{2}+b \sigma_{\mathrm{LxF}(\mathrm{P})}^{2}$ \\
\hline $\mathrm{B}(\mathrm{L}) \times \mathrm{F}(\mathrm{P})$ & 4562 & $\sigma^{2}$ \\
\hline Corr. total & 5050 & \\
\hline
\end{tabular}
the overall analyses

${ }^{1}$ Provenances were considered as fixed effects, all others as random effects. ments are uncorrelated, the estimates are the same.

The ideal method to compare different stem elongation traits in different provenances for their potential as early selection traits would be to compare the correlated response (Falconer 1989) at rotation age from selecting on the different juvenile traits:

$C R=i_{J} h_{J} h_{M} r_{J \cdot M} \sigma_{P_{M}}$ where:

$C R=$ correlated response at rotation age from selecting at juvenile ages

$i_{J}=$ selection intensity for juvenile trait

$h_{J}=$ square root of heritability for juvenile trait $h_{M}=$ square root of heritability for mature trait $r_{J \cdot M}=$ genetic correlation between juvenile trait and mature trait

$\sigma P_{M}=$ phenotypic standard deviation of mature trait.

However, we do not have estimates of $h_{M}$ and $\sigma_{P_{M}}$ and we have only the family mean correlations between juvenile traits and 5-year heights, not the genetic correlation between juvenile and mature traits. We used the product of $h_{J}$ and $r_{J \cdot 5 y r}$ to determine which stem elongation traits have the most potential for early selection. These products were also compared among provenances to determine which provenances would likely be responsive to early selection.

\section{Results and discussion}

At both test sites, growth and survival (97\%) were excellent after two growing seasons. Provenances differed significantly $(p \geq 0.01)$ for total height, stem elongation, and number of growth cycles (Table 3 ), and rankings were as expected based on other provenance studies with Loblolly pine (Kraus, Wells \& Sluder, 1984). The Florida provenances grew the most and had the most cycles in both years, followed by the Atlantic Coastal, Lower Gulf, and the Middle-Upper Gulf provenances.

There were very large differences estimated for the degree of genetic control for the different traits (Table 4). Individual tree heritabilities were very high for the Middle-Upper Gulf provenance and were intermediate for most of the other provenances. There were small differences in growth among the families in the Marion Co. provenance, with $h^{2}$ values of only 0.09 and 0.15 
Table 3. Provenance means for total height, stem elongation, and number of growth cycles. Range of family means within each provenance is in parentheses

\begin{tabular}{|c|c|c|c|c|c|}
\hline Trait & $\begin{array}{l}\text { Marion } \\
\text { Co, FL }\end{array}$ & $\begin{array}{l}\text { Gulf Ham. } \\
\text { FL }\end{array}$ & $\begin{array}{l}\text { Atlantic } \\
\text { Coastal } \\
\text { Plain }\end{array}$ & Lower Gulf & $\begin{array}{l}\text { Middle-Upper } \\
\text { Gulf }\end{array}$ \\
\hline \multicolumn{6}{|l|}{ Height $(\mathrm{cm})$} \\
\hline Yr 1 & $\begin{array}{l}85.3 \\
(81-92)\end{array}$ & $\begin{array}{l}85.2 \\
(73-96)\end{array}$ & $\begin{array}{l}70.4 \\
(61-79)\end{array}$ & $\begin{array}{l}61.3 \\
(50-68)\end{array}$ & $\begin{array}{c}54.0 \\
(45-69)\end{array}$ \\
\hline Yr 2 & 241.2 & 242.8 & 211.2 & 190.9 & 175.6 \\
\hline \multicolumn{6}{|l|}{ Stem elong. (cm) } \\
\hline Yr $0-1$ & $\begin{array}{l}53.2 \\
(48-60)\end{array}$ & $\begin{array}{l}52.5 \\
(40-62)\end{array}$ & $\begin{array}{l}39.1 \\
(27-50)\end{array}$ & $\begin{array}{l}30.6 \\
(23-38)\end{array}$ & $\begin{array}{l}26.3 \\
(20-40)\end{array}$ \\
\hline Yr $0-2$ & 209.1 & $\begin{array}{l}210.0 \\
(179-226)\end{array}$ & $\begin{array}{l}179.9 \\
(154-206)\end{array}$ & 160.2 & 148.0 \\
\hline Yr $1-2$ & 155.5 & 157.1 & 140.3 & 129.3 & 121.4 \\
\hline \multicolumn{6}{|l|}{$\begin{array}{l}\text { No. of growth cycles } \\
\text { Yr } 1\end{array}$} \\
\hline Yr 1 & $\begin{array}{c}3.9 \\
(3.5-4.7)\end{array}$ & $\begin{array}{c}3.9 \\
(3.0-4.4)\end{array}$ & $\begin{array}{l}2.8 \\
(1.8-3.5)\end{array}$ & $\begin{array}{l}2.1 \\
(1.7-2.7)\end{array}$ & $\begin{array}{l}1.8 \\
(1.1-2.9)\end{array}$ \\
\hline Yr 2 & $\begin{array}{c}4.9 \\
(4.5-5.3)\end{array}$ & $\begin{array}{l}5.0 \\
(4.6-5.6)\end{array}$ & $\begin{array}{c}4.6 \\
(4.3-5.2)\end{array}$ & $\begin{array}{c}4.4 \\
(4.1-4.6)\end{array}$ & $\begin{array}{c}4.1 \\
(3.6-4.5)\end{array}$ \\
\hline
\end{tabular}

Table 4. Individual tree heritability estimates and standard errors in parentheses for different provenances for total height, stem elongation, and number of growth cycles

\begin{tabular}{llllll}
\hline Trait & $\begin{array}{l}\text { Marion } \\
\text { Co, FL }\end{array}$ & $\begin{array}{l}\text { Gulf Ham. } \\
\text { FL }\end{array}$ & $\begin{array}{l}\text { Atlantic } \\
\text { Coastal } \\
\text { Plain }\end{array}$ & Lower Gulf & $\begin{array}{l}\text { Middle-Upper } \\
\text { Gulf }\end{array}$ \\
\hline $\begin{array}{lllll}\text { Height } \\
\text { Yr 1 }\end{array}$ & $0.09(.05)$ & $0.44(.17)$ & $0.44(.16)$ & $0.42(.17)$ & $0.93(.31)$ \\
Yr 2 & $0.11(.06)$ & $0.49(.18)$ & $0.58(.20)$ & $0.45(.18)$ & $0.80(.28)$ \\
Stem elongation & $0.15(.08)$ & $0.40(.16)$ & $0.53(.18)$ & $0.35(.14)$ & $0.75(.27)$ \\
Yr 0-1 & $0.10(.06)$ & $0.49(.18)$ & $0.64(.21)$ & $0.42(.17)$ & $0.71(.25)$ \\
Yr 0-2 & $0.11(.06)$ & $0.32(.13)$ & $0.37(.14)$ & $0.21(.10)$ & $0.44(.18)$ \\
Yr 1-2 & $0.46(.17)$ & $0.55(.20)$ & $0.59(.20)$ & $0.33(.14)$ & $0.84(.29)$ \\
No. of growth cycles & $0.30(.12)$ & $0.37(.14)$ & $0.47(.17)$ & $0.10(.06)$ & $0.53(.21)$ \\
Yr 1 & & & & &
\end{tabular}

for total height and stem elongation, respectively, in both the first and second year. The range of heritability estimates for the Atlantic Coastal provenance was very similar to values reported by Li et al. (1991) for height and firstyear stem elongation in a greenhouse $\left(h^{2}=0.37\right.$ to 0.73 ) for families from North Carolina (a slightly more northern provenance, $34^{\circ}-37^{\circ} \mathrm{N}$, $76^{\circ}-79^{\circ} \mathrm{W}$, than was used in the current study). For second-year stem elongation in a nursery, heritabilities from 0.36 to 0.54 were found for the North Carolina families ( $\mathrm{Li}$, Williams, Carlson, Harrington \& Lambeth, 1992). No variance component estimates have been reported for these traits for the other provenances used in our study.

There was an interesting trend in the heritability values for the annual height increment in the first and second years. The $h^{2}$ estimates for stem elongation from year 1 to year 2 decreased can average of 0.15 from the $h^{2}$ for stem elongation in the first year. Apparently, the environmental variation was higher or family variation was lower for cyclic growth in the second year as compared to the first year. This was also suggested by the lower $h^{2}$ values (average decrease $=0.20$ ) for the number of growth cycles in the second year.

The family mean correlations with the 5-year field data (Table 5) were less variable than the heritability estimates. For second year height, the age-age correlations of family means ranged from 0.42 for the Gulf Hammock, Florida provenance to 0.85 for the Middle-Upper Gulf provenance. These moderate to strong correlations of total height and stem elongation with 5-year 
Table 5. Family mean correlations between 5-year field height for different provenances with total height, stem elongation, and number of growth cycles in the early selection study

\begin{tabular}{|c|c|c|c|c|c|}
\hline Trait & $\begin{array}{l}\text { Marion } \\
\mathrm{Co}, \mathrm{FL}\end{array}$ & $\begin{array}{l}\text { Gulf Ham. } \\
\text { FL }\end{array}$ & $\begin{array}{l}\text { Atlantic } \\
\text { Coastal } \\
\text { Plain }\end{array}$ & Lower Gulf & $\begin{array}{l}\text { Middle-Upper } \\
\text { Gulf }\end{array}$ \\
\hline \multicolumn{6}{|l|}{ Height } \\
\hline $\operatorname{Yr} 1$ & 0.43 & 0.34 & 0.44 & $0.53+$ & $0.85^{*}$ \\
\hline $\begin{array}{l}\text { Yr } 2 \\
\text { Stem elongation }\end{array}$ & $0.65^{*}$ & 0.42 & $0.59+$ & $0.49+$ & $0.85^{*}$ \\
\hline \multicolumn{5}{|l|}{ Stem elongation } & \\
\hline Yr $0-2$ & $0.55^{*}$ & 0.38 & $\begin{array}{l}0.40 \\
0.58+\end{array}$ & 0.45 & $0.85^{*}$ \\
\hline Yr $1-2$ & $0.58^{*}$ & 0.43 & $0.61+$ & 0.41 & $0.77^{*}$ \\
\hline No. of growth cycles & -001 & -0.03 & $058+$ & 0.41 & $0.83 *$ \\
\hline Yr 2 & -0.17 & 0.07 & 0.43 & 0.48 & $0.67^{*}$ \\
\hline
\end{tabular}

*, significant at $P \leqslant .05$ and $P \leqslant .10$, respectively.

heights for all the provenances, especially in the second year, indicated that families were ranked with some degree of certainty at two years of age in our study. While there was a trend for the second-year heights to be more strongly correlated to 5-year field data than first-year heights, there was no advantage in using stem elongation versus total height. Apparently the "noise" from the free-growth cycle (e.g. maternal effects; Williams, 1987) at the time of planting had little influence on the correlations, especially after two growing seasons.

The number of growth cycles correlated very well with 5-year heights for the Middle-Upper Gulf provenance and was intermediate for the Atlantic Coastal and Lower Gulf provenances. There was no correlation for the two Florida provenances.

The ability to use stem elongation traits to predict later field growth appears to have differed among provenances. When the index of
$h_{J} \times r_{J \cdot 5 y r}$ was used to compare the provenances (Table 6), early selection among families from the Middle-Upper Gulf provenance would be the most effective because of the high heritabilities and age-age correlations for height. Early selection in the Atlantic Coast provenance should result in greater gains than early selection in the Lower Gulf and the two Florida provenances. The age-age correlations for the Marion County provenance were comparable to the correlations for the Atlantic Coastal and Middle-Upper Gulf provenances. However, the low heritabilities for height and stem elongation for the Marion County provenance suggest that early selection among families will be only marginally effective. For the Gulf Hammock and Lower Gulf families, both the heritabilities and age-age correlations were moderate, suggesting that early selection will not be as effective as for the Atlantic Coastal and Middle-Upper Gulf provenances.

Table 6. Product of the square root of juvenile trait heritability and family mean correlations between 5 -year field height for different provenances $\left(h_{J} \times \mathrm{r}_{J \cdot 5 y r}\right)$ for total height, stem elongation, and number of growth cycles in the early selection study

\begin{tabular}{lcclll}
\hline Trait & $\begin{array}{l}\text { Marion } \\
\text { Co, FL }\end{array}$ & $\begin{array}{l}\text { Gulf Ham. } \\
\text { FL }\end{array}$ & $\begin{array}{l}\text { Atlantic } \\
\text { Coastal } \\
\text { Plain }\end{array}$ & Lower Gulf & $\begin{array}{l}\text { Middle-Upper } \\
\text { Gulf }\end{array}$ \\
\hline Height & 0.13 & 0.23 & 0.29 & 0.34 & 0.82 \\
Yr 1 & 0.22 & 0.29 & 0.45 & 0.33 & 0.76 \\
Yr 2 & 0.05 & 0.15 & 0.35 & 0.27 & 0.72 \\
Stem elongation & 0.17 & 0.27 & 0.46 & 0.29 & 0.72 \\
Yr 0-1 & 0.19 & 0.24 & 0.37 & 0.19 & 0.51 \\
Yr 0-2 & -0.01 & -0.02 & 0.45 & 0.24 & 0.76 \\
Yr 1-2 & -0.09 & 0.04 & 0.29 & 0.15 & 0.49 \\
No. of growth cycles & & & & & \\
Yr 1 & & &
\end{tabular}




\section{Conclusions}

Early selection for total height after two years in the field is a useful tool for reducing numbers of families that must be evaluated for longer times in larger field trials in the Atlantic Coastal Plain and Middle-Upper Gulf regions. Other methods for early selection must be developed for other provenances of Loblolly pine, unless data nearer harvest age from the older field trials change this conclusion. These field trials will be measured through rotation age and the longterm relationships with these juvenile measures will be evaluated to determine the value of early selection using stem elongation and height measurements on one- and two-year-old trees.

\section{References}

Anonymous, 1988. Thirty-second Annual Report. North Carolina State University - Industry Cooperative Tree Improvement Program. Raleigh, NC. $60 \mathrm{pp}$.

Anonymous. 1990. Thirty-fourth Annual Report. North Carolina State University - Industry. Cooperative Tree Improvement Program. Raleigh, NC. 20 pp.

Becker, W.A. 1984. Manual of quantitative genetics, 4th ed. Academic Enterprises, Pullman, WA. 188 pp.

Bridgwater, F.E. 1989. Shoot elongation patterns of loblolly pine families selected for contrasting growth potential. Forest Science 36, 641-656.

Burdon, R.D. 1977. Genetic correlations as a concept for studying genotype- environment interaction in forest tree breeding. Silvae Genetica 26, 168-175.

Falconer, D.S. 1989. Introduction to quantitative genetics. Essex, England: Longman Scientific \& Technical. $438 \mathrm{pp}$.

Kraus, J.F , Wells, O.O. \& Sluder, E.R. 1984. Review of provenance variation in loblolly pine (Pinus taeda L.) in the southern United States. In Provenance and genetic improvement strategies in tropical forest trees (ed. R.D. Barnes \& G.L. Gibson), 281-317. Commonwealth Forestry Institute, Oxford, England and Forest Research Centre, Harare, Zimbabwe.

Li, B., McKeand, S.E. \& Allen, H.L. 1989. Early selection of loblolly pine based on seedling shoot elongation characters. In Proceedings 20th Southern Forest Tree Improvement Conference, Charleston, SC. 228-234.

Li, B., McKeand, S.E. \& Allen, H.L. 1991. Seedling shoot growth of loblolly pine families under two nitrogen levels as related to 12-year height performance. Canadian Journal of Forest Research 21, 842-847.

Li, B., Williams, C.G., Carlson, W.C., Harrington, C.A.

\& Lambeth, C.C. 1992. Gain efficiency in short-term testing: experimental results. Canadian Journal of Forest Research 22, 290-297.

Lowe, W.J. \& van Buijtenen, J.P. 1989. The incorporation of early testing procedures into an operational tree improvement program. Silvae Genetica 38, $243-250$.

SAS Institute Inc. 1985. SAS/STAT Guide for Personal Computers, Version 6 Edition. Cary, NC. 378 pp.

Satterthwaite, F.E. 1946. An approximate distribution of variance components. Biometrics Bulletin 2, $110-114$.

Sweet, G.B. \& Bollman, M.P. 1976. Terminology of pine shoot growth. New Zealand Journal of Forest Science 6, 393-396.

Van Den Berg, D.A. \& Lanner, R.M. 1971. Bud development in lodgepole pine. Forest Science 17, 479-486.

Williams, C.G. 1987. The influence of shoot ontogeny on juvenile-mature correlations in loblolly pine. Forest Science 33, 411-422.

\section{Acknowledgements}

This study was funded by members of the North Carolina State University - Industry Cooperative Tree Improvement Program and the United States Forest Service. We particularly appreciate the assistance provided by Georgia-Pacific Corporation and International Paper Company with the establishment and management of the trials. 


\title{
Genotype x stocking interactions in Pinus radiata: productivity and yield implications
}

\author{
P.N. BEETS and M.O. KIMBERLEY \\ Forest Research Institute, Rotorua, New Zealand
}

\section{Abstract}

Beets, P.N. \& Kimberley, M.O. 1993. Genotype $x$ stocking interactions in Pinus radiata: Productivity and yield implications. In: Management of structure and productivity of boreal and subalpine forests (ed. S. Linder \& S. Kellomäki). Studia Forestalia Suecica 191. 94 pp. ISSN 0039-3150, ISBN 91-576-4822-0.

A trial comprising a mixture of clones and seedlings of $P$. radiata was planted in 1973 on a highly productive, ex-pasture site in New Zealand. Rooted cuttings of six clones were planted in mixture with seedlings in a stand stocked at 2200 trees ha $^{-1}$, and subsequently thinned to give four final stockings $\left(60,180,550,2200\right.$ trees $\left.^{-1}\right)$. Plot trees were measured for height, stem diameter at breast height, and height and stem diameter at the base of the green crown in 1990, at stand age 17 years.

Significant genotype $\mathrm{x}$ stocking interactions were evident for most traits. For tree size traits, one clone dominated at higher tree stockings both in total height and diameter at breast height $(d b h)$. In contrast, two clones which were gradually being suppressed at higher stocking levels ranked equally, in terms of $d b h$, with the fastest growing clone in stands at the lower stocking levels. A major proportion of the interaction for $d b h$ was accounted for by the linear relationship between growth rate and the logarithm of stocking, with different slopes for different clones.

Estimates of environmental and genetic variance in $d b h$ were obtained for each stocking, based on the variance within clones and between seedlings. With reducing stocking, environmental variance was found to decrease while genotypic variance increased. Broadsense heritability estimates for $d b h$ increased with decreasing stocking.

Key words: Genetics, productivity, clonal forestry, silviculture, thinning, tree health, competition.

P. N. Beets and M. O. Kimberley Forest Research Institute, Private Bag 3020, Rotorua, New Zealand

MS. received 4 November 1992

MS. accepted 7 January 1993

\section{Introduction}

New Zealand's Pinus radiata D. Don plantations are usually highly productive and intensively managed. Improvement of growth and form traits is an important component in their silvicultural management. Planting of improved genotypes at low densities, and pruning and thinning to low stockings are typical practices aimed at reducing stand establishment costs while increasing the size and value of the logs. Tree selection for breeding or thinning requires information on the relative performance of genotypes at a range of stockings.

In tree improvement programmes the assessment of relative performance of genotypes is costly, and for both practical and economic reasons, testing would ideally be undertaken early in the rotation and using a limited amount of space. This is being achieved by accelerating tree growth through weed control, fertilising, planting at high stocking densities, and then assessing tree performance on the basis of early height growth (R. D. Burdon, pers. comm.). Choice of optimal testing-age has received attention for a number of traits and is commonly taken into consideration in tree improvement programmes; early versus late performance is expressed by the age-age correlation (Sziklai, 1974). However, stocking effects have not been satisfactorily addressed, with available information on genotype $\mathrm{x}$ stocking interactions in tree species both limited and inconclusive.

Campbell \& Wilson (1973) observed that for Pseudotsuga menziesii (Mirb.) Franco there is insufficient information to determine if genotype 
$\mathrm{x}$ stocking interaction is a serious problem. Their experiment on family performance assessed at a range of stockings (1, 3, 5, 7 inches apart) showed that genotype $x$ stocking interaction evident in their data at age 3 years resulted from changes in trait variance at different stockings. The interaction was not evident after the data were transformed, and no significant changes in rank were found. Given that the range of stockings in commercial forests is usually small, they concluded that genotype $\mathrm{x}$ stocking interaction in $P$. menziesii was unlikely to affect selection accuracy.

Total genotypic, environmental, and interaction variances can be estimated more precisely using clones (Burdon \& Shelbourne, 1974). The role of stocking, as a source of interaction variance, needs to be determined but few clonal studies have incorporated a range of tree stockings (Fries, 1984), and the testing age has sometimes been too early (Hattemer, Andersson \& Tamm, 1977). An additional problem has been physiological aging of clonal material, which is associated with the method of vegetative propagation. Historically, this has resulted in poor performance of cuttings in comparison with seedlings (Pawsey, 1971), making the study of competitive interactions difficult. To avoid physiological aging, cuttings can be taken from very young parent material and the genotypes subsequently maintained in a more juvenile state through the practice of hedging (Bolstad \& Libby 1982).

Inaccurate selection would occur if productivity, quality, and health traits become apparent only later in life or under particular environmental conditions. Accurate selection then requires testing to be undertaken under appropriate conditions. Cannell (1982), working with juvenile trees, found that families rank differently in performance depending on the amount of competition. Ideally, rankings should be accurate for performance at final stocking and at the end of the rotation.

A genotype $x$ stocking interaction implies that some genotypes may grow differently depending on the amount of competition. Growth processes, such as photosynthesis, respiration, allocation, nutrient uptake, and translocation, are linked with tree structure (e.g. height, diameter, leaf area distribution), and depend ultimately on genetics and the environment (Dixon,
1990). Because stocking is known to have large consequences for growth and product quality, particularly on fertile sites, more research into genetic aspects of stocking and competitive interactions is called for (Morgenstern, 1982).

An opportunity to obtain relevant information was provided in a trial set up in the central North Island of New Zealand in 1973. Rooted cuttings of Monterey pine clones interplanted with seedlings were included in the design. The development of the clonal material in comparison with seedling-origin material was assessed at stand age 17 years. The objectives of the study reported here were to i) examine the effects of genotype, stocking, and their interaction on growth of Monterey pine, and ii) compare performance variability in clones with that in non-clonal material at a range of stockings.

\section{Materials and methods}

\section{Site description and experimental material}

The trial was established at the 35 ha Puruki Catchment, which is part of the Purukohukohu Experimental Basin. This basin is located in the central North Island of New Zealand, where a major proportion of NZ's plantation forests are located. Puruki is a highly productive, expasture site with a current annual stem volume production rate exceeding $50 \mathrm{~m}^{3} \mathrm{ha}^{-1} \mathrm{yr}^{-1}$ in closed canopy stands (Beets \& Brownlie, 1987). Foliar analysis indicates that nutrients are generally in adequate supply but magnesium $(0.08-0.10 \%$ of dry weight) and boron (11$12 \mathrm{ppm}$ ) levels are in the marginal range, with some variation in tree nutritional status evident within the catchment. A more complete description of previous land-use, soil, climate, and plantation history has been given by Beets \& Brownlie (1987).

After uniformly spraying with herbicide to kill pasture plants, the catchment was planted with 1-year-old climbing-select (a largely unimproved standard used by the NZFRI) $P$. radiata seedlings in 1973 at a stocking rate of 2200 trees $\mathrm{ha}^{-1}(2.4 \times 1.8 \mathrm{~m}$ spacing $)$. In three areas totalling $1.2 \mathrm{ha}$, every third seedling in every third row was replaced with a rooted cutting from one of six clones (FRI Clone Nos. 448, 450, 451, $454,455,456)$. The size of the planting stock 
was not recorded, but one year after planting the clones averaged $78 \mathrm{~cm}$ (range $58-113 \mathrm{~cm}$ ) and seedlings $65 \mathrm{~cm}$ (range $18-131 \mathrm{~cm}$ ), based on trees measured in the unthinned control plot.

An equal number of ramets of each clone was planted in a fully random sequence. The clonal areas were deliberately sited on the most level terrain available in the catchment so that the areas would be comparable in terms of aspect and slope. One area fell entirely within the stand subsequently thinned to 180 trees $\mathrm{ha}^{-1}$, while the other two areas were each split between two stocking levels $(60 / 550$ and $550 / 2$ 200). The bounded measurement plots installed in these areas, which comprised seedling-origin material interplanted with clonal material, differed in size $(0.33,0.27,0.40,0.17$ ha at the $60,180,550$ and 2200 trees $\mathrm{ha}^{-1}$ stocking levels, respectively). The clones had been identified with a labelled peg placed next to each ramet, but in some cases the labels were missing. Live ramets next to unlabelled pegs were identified from morphological and chemical (terpene composition) profiles we developed for each clone. Mortality data were considered too unreliable to include in this paper.

This set of clones was originally propagated from one-year-old seedlings selected at random from open-sown nursery beds (Jackson, Gifford \& Hobbs, 1973). The physiological age of the rooted cuttings at time of planting at Puruki is uncertain. The cuttings were collected from hedges derived originally from seedlings, as documented in Knight (1978), to minimise possible effects of physiological aging.

\section{Stand management}

The plantation was pruned to $2.2 \mathrm{~m}$ height and repeatedly thinned to give four final crop stock- ing levels as documented in Table 1. The thinning regimes were designed to provide information for the following canopy conditions: (i) The unlimited condition of continuous open growth (at 60 trees ha $^{-1}$ in Tahi subcatchment); (ii) The limited condition of canopy closure (at 2200 and 550 trees ha $^{-1}$ in Rua subcatchment); (iii) An intermediate condition of successive open growth followed by canopy closure (at 180 trees $\mathrm{ha}^{-1}$ in Toru subcatchment).

Clones were normally favoured when selecting trees to remove during thinning operations, unless a ramet was noticeably deformed owing to wind damage. The special consideration given to clones was overlooked when stands were thinned in 1983 and 1984. In those years tree selection was based on quality and spacing criteria, as was always the case for the seedling-origin material. Straight trees free of forks and with small branches and healthy crowns were favoured, with tree size and spacing of secondary importance. The on-site selection ratio for seedling origin material varied markedly with the thinning regime; $1: 1,1: 4,1: 12$, $1: 36$ for unthinned to heavily thinned stands, respectively, and some improvement in seedling performance at lower stocking levels might therefore be expected.

\section{Measurement of tree growth and health}

The clonal plots were measured in 1990 at stand age 17 years. Table 2 gives the number of live ramets of each clone and of seedling-origin trees measured at each stocking level. Stem diameter at breast height ( $d b h$, at $1.40 \mathrm{~m}$ above ground) and height of clonal and seedling-origin trees were measured to indicate tree growth rate. The following additional measurements and obser-

Table 1. Nominal pruning and thinning regime in Puruki catchment. All stands were nominally planted at 200 trees $h a^{-1}$ in 1973

Thinning year and stocking

\begin{tabular}{|c|c|c|c|c|c|c|c|c|}
\hline \multirow[b]{2}{*}{ Stand } & \multirow[b]{2}{*}{$\begin{array}{l}\text { Pruned, } \\
\text { Year }\end{array}$} & \multirow[b]{2}{*}{$\begin{array}{l}\mathrm{Ht} \\
(\mathrm{m})\end{array}$} & \\
\hline & & & Year & $\begin{array}{l}\text { Trees } \\
\mathrm{ha}^{-1}\end{array}$ & Year & $\begin{array}{l}\text { Trees } \\
\mathrm{ha}^{-1}\end{array}$ & Year & $\begin{array}{l}\text { Trees } \\
\mathrm{ha}^{-1}\end{array}$ \\
\hline Tahi & 1979 & 2.2 & 1979 & 550 & 1983 & 180 & 1987 & 60 \\
\hline Toru & 1981 & 2.2 & 1981 & 550 & 1984 & 275 & 1988 & 180 \\
\hline Rua & 1980 & 2.2 & 1980 & 550 & - & - & - & - \\
\hline Cont $^{a}$ & - & $\ldots$ & - & - & - & - & - & - \\
\hline
\end{tabular}

${ }^{a}$ Unpruned and unthinned control stand is within Rua subcatchment. 
vations were made of factors likely to influence tree growth.

The size and configuration of trees surrounding the clonal trees were recorded in the unthinned control and the stand thinned to 550 trees ha ${ }^{-1}$, so that within-plot variation in tree performance could be related to competition with neighbouring trees. Competitors were selected using a prism, 8-10 trees around each target tree being measured for $d b h$ and proximity.

The $d b h$ and height of trees in a portion of the unthinned control plot were measured annually. It was therefore possible to relate early performance to performance at age 17 years. Height at age 6 (when canopy closed) was considered to be a suitable basis for comparison because competitive effects would have been minimal up to that time.

Susceptibility to a needle-cast fungus, Cyclaneusma minus (Butin) DiCosmo et al. reduced needle retention in the lower crown, leading to a rise in the height to the base of the green crown ( $h t b g c)$. Htbgc, which was defined as the point of attachment of the lowest live branch above which no dead major whorl occurs, was measured by clone and stocking level to indicate relative susceptibility of clones to $C$. minus. In addition, canopy closure was followed by increased branch mortality at the base of the crown owing to low light levels.

\section{Calculations and statistical analysis}

The clonal tree data were analyzed as single tree plots, with ramets of a clone as replicates. Twoway analyses of variance were performed to test for clone, stocking, and interaction effects on $d b h$, height $(h t)$, and $h t b g c$ at age 17 years. Each sum of squares for stocking was partitioned into that representing a linear contrast in $\log$ (stocking), and that representing deviation from the linear relationship. A similar partition was applied to the interactions. A further analysis was run to determine the effect of $C$. minus on $d b h$. In the analysis, $h t b g c$ was fitted as a covariate after removal of the clone and stocking effects but prior to consideration of the interaction effect. No test for block effects was possible in this study. Competition from neighbouring trees was calculated using a modification of Spurr's index (Spurr, 1962). A competition index was calculated by summing $(d b h / \text { distance })^{2}$ for all competing trees around the target tree.

Because the trial contained clones and seedlings growing in mixture, it was possible to separate the phenotypic variance in $d b h\left(V_{\mathrm{P}}\right)$ into its two components of genotypic variance $\left(V_{\mathrm{G}}\right)$ and environmental variance $\left(V_{E}\right)$. For each stocking, $V_{\mathrm{P}}$ was estimated by the variance of seedling origin trees, $V_{\mathrm{E}}$ by the within clone variance, and $V_{\mathrm{G}}$ by subtracting $V_{\mathrm{E}}$ from $V_{\mathrm{P}}$ (Falconer, 1960). No variance component between clones was calculated, so the low replication and unbalanced nature of the dataset were not of concern.

\section{Results}

\section{Diameter, height, and height to base of the green crown}

Means of size traits at age 17 years are given in Table 2, and the results of analysis of variance in Table 3. The mean $d b h$ of clones at the lowest stocking was approximately twice that found at the highest stocking, with two clones attaining $50 \mathrm{~cm} d b h$ at the lowest stocking. Tree mean height was largest at the lowest stocking and approached $30 \mathrm{~m}$ in some clones. Height was much reduced at the highest stocking, where tree mortality was evident in all clones except 451. Height to the base of the green crown increased with stocking from 4 to $15 \mathrm{~m}$, depending on the clone. Large differences in live crown ratio ( green crown length / tree height) were evident, ranging from $25 \%$ for clone 448 at the highest stocking to $85 \%$ for clone 451 at the lowest stocking.

The $d b h$ of clones 448,451 and 454 , which were better represented at the extreme stockings than the other clones, is compared with seedlingorigin trees in Fig. 1. Clone 451 was significantly larger than seedling-origin trees at the two highest stockings, but not significantly different at the lowest stocking. Clone 454 tended to be smaller than the seedling-origin trees, but the difference was not significant at the lowest stocking. Clone 448 also tended to be smaller than seedling-origin trees, but significantly so only at the lowest stocking level. 
Table 2. Number of ramets and means of size traits (diameter at breast height (dbh), total height and height to base of green crown (htbgc)) are given by clone and stocking level. Number of seedling-origin trees and means of size traits are also given (Stocking $1=60,2=180,3=550,4=2200$ trees ha $^{-1}$ nominal)

\begin{tabular}{|c|c|c|c|c|c|c|c|c|c|c|c|c|c|c|c|c|}
\hline \multirow[b]{2}{*}{ Stocking } & \multicolumn{4}{|c|}{$\begin{array}{l}\text { Number of } \\
\text { ramets }\end{array}$} & \multicolumn{4}{|c|}{$\begin{array}{l}\mathrm{dbh} \\
(\mathrm{cm})\end{array}$} & \multicolumn{4}{|c|}{$\begin{array}{l}\text { Height } \\
\text { (m) }\end{array}$} & \multicolumn{4}{|c|}{$\begin{array}{l}\text { htbgc } \\
\text { (m) }\end{array}$} \\
\hline & 1 & 2 & 3 & 4 & 1 & 2 & 3 & 4 & 1 & 2 & 3 & 4 & 1 & 2 & 3 & 4 \\
\hline \multirow{7}{*}{$\begin{array}{l}\text { Clone } \\
448 \\
450 \\
451 \\
454 \\
455 \\
456 \\
\text { Seedling }\end{array}$} & 2 & 0 & 6 & 2 & 41 & $\ldots$ & 33 & 21 & 23 & - & 25 & 20 & 4 & - & 14 & \\
\hline & 3 & 0 & 3 & 0 & 38 & - & 25 & -1 & 26 & - & 25 & - & 6 & - & 13 & - \\
\hline & 5 & 0 & 8 & 5 & 51 & - & 41 & 31 & 29 & - & 27 & 26 & 4 & - & 10 & 11 \\
\hline & 10 & 9 & 9 & 6 & 50 & 41 & 30 & 22 & 27 & 27 & 26 & 24 & 4 & 8 & 13 & 15 \\
\hline & 2 & 6 & 0 & 0 & 44 & 27 & - & - & 26 & 24 & - & - & 5 & 10 & - & - \\
\hline & 0 & 3 & 2 & 4 & - & 45 & 36 & 19 & - & 27 & 26 & 18 & - & 6 & 10 & 10 \\
\hline & 12 & 35 & 190 & 173 & 56 & 45 & 34 & 26 & 27 & 24 & 25 & - & 3 & 5 & 10 & 14 \\
\hline
\end{tabular}

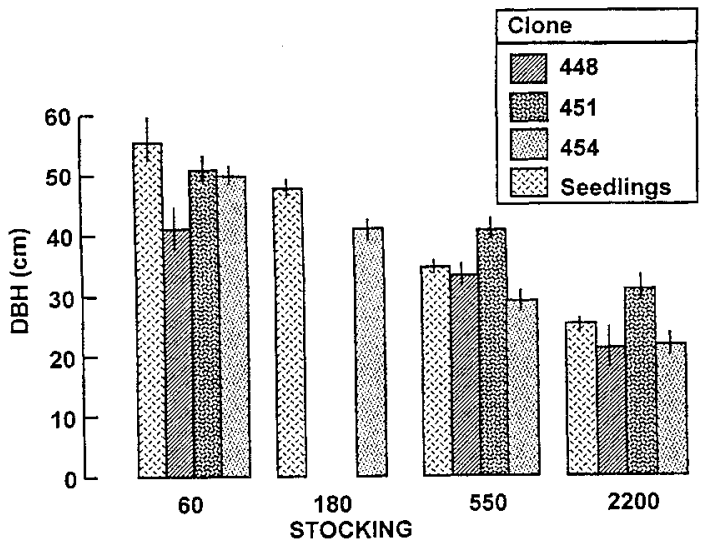

Fig. 1. Mean $d b h$ of three clones and seedling-origin trees at four stockings (trees ha ${ }^{-1}$ ). Error bars indicate standard error of the mean. Significant clone, stocking and genotype $\mathrm{x}$ stocking interactions were found.

\section{Genotype $x$ stocking interactions}

The significant clone effects found for $d b h$ and $h t b g c$ interacted with stocking (Table 3 ). Clone 451 tended to be the largest clone in height, $d b h$, and green crown length, with $d b h$ significantly larger than the other clones at the two highest stocking levels, but not significantly different from 454 at the lowest stocking. The large $d b h$ of clones 454 and 456 at the lower stocking levels tested is in marked contrast to their small $d b h$ at the two highest stocking levels tested. Clones 448, 450 and 455 performed poorly, in terms of $d b h$, at each stocking level tested. Within a stocking level, $C$. minus was primarily responsible for differences in $h t b g c$ among clones; clones 448,450 , and 454 were the most susceptible clones. Greater defoliation was recorded in seedling-origin trees growing at the higher stocking level examined (Table 4).

The effect of stocking in the interaction between clone and stocking found for $d b h$ and htbgc (Table 3 ) can be accounted for by the linear contrast in $\log$ (stocking). This indicates that deviations by individual clones from the overall relationship with stocking were linear, but with different slopes for each clone.

Table 3. Analysis of genotype and stocking effects on size traits in Pinus radiata on a fertile site. The effect of stocking was partitioned into a linear contrast in log (stocking), and into a contrast representing the deviations from a linear relationship

\begin{tabular}{|c|c|c|c|c|c|c|}
\hline \multirow[b]{3}{*}{ Trait } & \multicolumn{5}{|c|}{ Mean squares } & \multirow[b]{3}{*}{ Error } \\
\hline & \multirow[b]{2}{*}{ Clone } & \multicolumn{2}{|l|}{ Stocking } & \multicolumn{2}{|c|}{ Clone $\times$ stocking } & \\
\hline & & Linear & Non-linear & Linear & Non-linear & \\
\hline $\mathrm{dbh}(\mathrm{cm})$ & $220^{* * *}$ & $6358 * *$ & $40^{*}$ & $89^{* * *}$ & 41 & 26 \\
\hline height (m) & 33.9 ** & $106.6^{* *}$ & $29.0^{* * *}$ & 9.5 & 13.0 & 4.9 \\
\hline htbgc (m) & $11.3^{*}$ & $907.7 * *$ & $22.7^{* *}$ & $5.7^{*}$ & 0.2 & 1.7 \\
\hline d.f. & 5 & 1 & 2 & 5 & 3 & 68 \\
\hline
\end{tabular}

* significant at $5 \%$ level, ** significant at $1 \%$ level. 
Table 4. The percentage of $\mathrm{P}$. radiata trees with different levels of needle retention, given in relation to stocking at Puruki. Susceptibility to the effects of $\mathrm{C}$. minus is considered to be high when needle retention in the lower crown is low $(0$ years), and low when needle retention is high $(3+$ years). Needle retention was recorded in spring 1992, in randomly located assessment plots described by Beets and Brownlie (1987)

\begin{tabular}{llllr}
\hline \multirow{2}{*}{$\begin{array}{l}\text { Stocking } \\
\text { (trees ha }\end{array}$} & \multicolumn{4}{l}{ Needle retention (years) } \\
\cline { 2 - 5 } & $3+$ & 2 & 1 & 0 \\
\hline 550 & 29 & 19 & 17 & 33 \\
60 & 51 & 14 & 26 & 9 \\
\hline
\end{tabular}

When the $d b h$ of clones 448,451 and 454 was analyzed using $h t b g c$ as a covariate, the covariate was significant ( F 1,45=5.92) and the interaction effect was reduced but still significant ( $F$ $2,45=3.24)$.

\section{Competitive relationships in stands}

Tree $d b h$ was weakly related to competition index. The competition index explained 18.8\% of the environmental variance in $d b h$ in the stand at 550 trees $\mathrm{ha}^{-1}$ (Fig. 2), and 15.3\% in the stand at 2200 trees $\mathrm{ha}^{-1}$. No significant interaction occurred between clone effects and competition index. Height at age 6 years, measured for a small number of trees in the stand at 2200 trees $\mathrm{ha}^{-1}$ (Fig. 3), explained $58 \%$ of the environmental variance in $d b h$ for those trees.

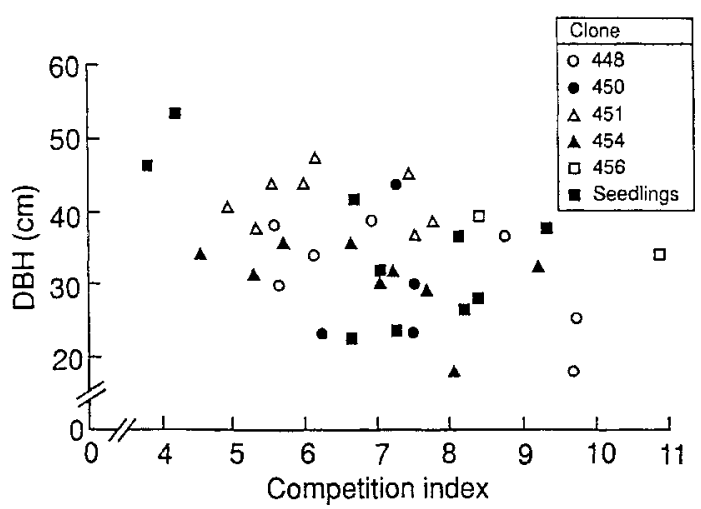

Fig. 2. The relationship between $d b h$ and the competition index at age 17 years. The competition index was derived from the $d b h$ and distance of selected trees surrounding the target tree. The stand was stocked at 550 trees ha ${ }^{-1}$.

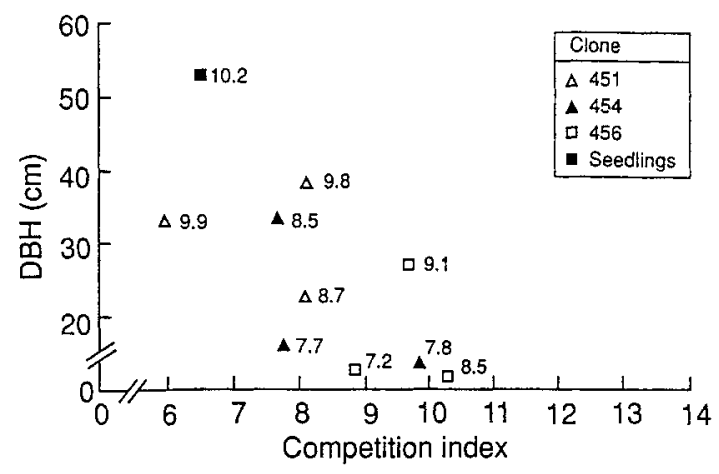

Fig. 3. The relationship between $d b h$, and competition index at age 17 years, and tree height at age 6 years (indicated adjacent to each plotted point) for ten trees in the unthinned control plot.

\section{Source of variation in $d b h$}

Phenotypic variance in $d b h$ did not vary greatly with stocking in absolute terms, but when expressed as a coefficient of variation $(\mathrm{CV})$ it increased from $14 \%$ at the lowest stocking to $29 \%$ at the highest stocking (Table 4). Genotypic variance decreased at the higher stockings (although when expressed as a $C V$, it remained approximately constant). Conversely, environmental variance increased at higher stockings. The ratio of all genotypic to phenotypic variance (i.e. broad-sense heritability; Zobel \& Talbert, 1984) was, therefore, greatly affected by stocking, decreasing from 0.79 at the lowest stocking to 0.23 at the highest stocking (Table 5).

\section{Discussion}

Because of deficiencies in the design of this trial, some qualifications regarding these data are necessary. Caution is required when considering the effects of thinning on height because (except in the unthinned control stands where suppression was occurring) at Puruki mean height is

Table 5. Components of variance of $d b h$, and heritability estimates $\left(V_{\mathrm{G}} / V_{\mathrm{P}}\right)$ at four stocking levels. (Seedlings)

\begin{tabular}{rlllll}
\hline $\begin{array}{l}\text { Stocking } \\
\text { (trees ha }^{-1} \text { ) }\end{array}$ & $\mathrm{CV}$ & $\mathrm{V}_{\mathrm{P}}$ & $\mathrm{V}_{\mathrm{E}}$ & $\mathrm{V}_{\mathrm{G}}$ & $\mathrm{V}_{\mathrm{G}} / \mathrm{V}_{\mathrm{P}}$ \\
\hline 60 & 13.6 & 58.5 & 12.3 & 46.2 & 0.79 \\
180 & 16.9 & 58.0 & 19.4 & 38.6 & 0.66 \\
550 & 24.4 & 68.5 & 30.3 & 38.2 & 0.56 \\
2200 & 28.8 & 54.4 & 42.0 & 12.4 & 0.23 \\
\hline
\end{tabular}


known to be less affected by stocking and more by site and establishment factors (Beets \& Pollock, 1987). Furthermore, the large choice of potential crop trees at the lowest stocking could have allowed the selection of seedling-origin trees of good form without sacrificing tree size. Stocking and site effects were confounded because of the lack of true replication. However, the large differences observed in. $d b h$ and $h t b g_{c}$ were clearly associated with stocking effects. In terms of variance components, because the variance between seedlings and within clones (no between clone variance was calculated) were based on a large number of trees, the unbalanced nature of the design did not cause problems in the analysis. Clonal effects include those of physiological aging, with implications for estimation of variance components (Burdon \& Shelbourne, 1974). We assume that physiological aging was negligible in our material.

Competitive relationships in pine plantations are receiving increased attention, with implications both for tree improvement and silvicultural management. Family differences in competitive ability are expected (Ford, 1975; Hara, 1984; Magnussen, 1989; von Euler, Baradat \& Lemoine, 1991). The consequences of competition for estimating genetic parameters and variances in progeny trials using single-tree plots are difficult to deal with, and a genotype $\mathrm{x}$ stocking interaction, as demonstrated in our study, further complicates the estimation of genetic parameters (Magnussen, 1989). Our finding, that most of the increase in variation in diameter at high levels of competition was environmental rather than genetic in origin, is consistent with that of Cotterill \& Zed (1980) who showed that the heritability of $d b h$ in $P$. radiata was generally low to moderate. However, the ratio $V_{G} / V_{P}$ increased with thinning intensity (Table 5), suggesting that the heritability estimate for $d b h$ is very sensitive to competitive conditions in the testing environment. Our results indicate that statistically superior performance is more apparent under open-grown conditions, as also found by Cannell (1982).

Stability in growth performance over a range of growing conditions is considered desirable (Zobel \& Talbert, 1984). Our results demonstrate the importance of rapid early growth rate on stability over a wide range of stockings. The selection of plus trees in unmanaged stands es- tablished at high stockings, and subsequent testing of progeny at a young age and a high stocking, will tend to favour genotypes with rapid early height growth rates. However, during the initial development of intensively pruned and thinned $P$. radiata stands, competition for light is minimal, and therefore rapid early height growth is relatively less important than traits influencing log quality (e.g. branch size, stem straightness, stem taper) and health. In terms of quality traits, clone 454 had better form (straighter stem, smaller branches, and less taper) than the most competitive clone, 451. Branchiness traits have already been documented for these and other clones (Madgwick, 1983).

Variation in performance of our clones also depended on a number of interacting environmental (biotic and abiotic) and management factors related to the health of the trees. Clone 451 had a rapid early growth rate and a low susceptibility to $C$. minus and therefore derived less benefit from thinning than clones 454 and 456 . While comparatively resistant to $C$. minus, clone 456 did not grow rapidly in height, which resulted in poor performance at the highest stocking level where competition for light was intense. At Puruki clones 448, 450, and 454 were the most susceptible to $C$. mimus. This fungus is known to cause low needle retention and poor growth of susceptible genotypes from around age 6 years onwards, particularly under mild and wet climatic conditions (van der Pas, SlaterHayes, Gadgil \& Bulman, 1984; Gadgil, 1984). Repeated thinning improved stand health by (1) allowing the identification and selective thinning of seedling-origin trees exhibiting ill-health at older ages, and (2) improving stand aeration and drying of tree crowns, and thereby apparently reducing susceptibility to $C$. minus. The decrease in genotype $x$ stocking interaction for $d b h$ found after $h t b g c$ was fitted as a covariate suggests that at least some of the interaction effect can be ascribed to $C$. minus, but additional factors that affect growth are also involved. For example, reduced needle retention is becoming increasingly evident in parts of Puruki catchment (a condition known locally as Upper MidCrown Yellowing), but the effect of this source of needle loss on growth has not been quantified. Current research indicates that the severity of the condition differs among clones and that 
magnesium nutrition is implicated. Information on interactions among physiological processes and stocking is not available but these may also be implicated in the genotype $x$ stocking interaction.

It has been suggested that testing should be conducted under conditions similar to those used in practice (Tauer, 1975). Our results indicate that a reliance on rapid early growth rate can disadvantage genotypes that (i) perform more than adequately at low stocking levels, (ii) have desirable $\log$ quality traits, and (iii) are resistant to disease and perhaps other disorders. As a selection criterion, intra-specific competitive ability is not an issue of importance when intensive pruning and thinning is the normal management practice. Based on progeny tests planted in family blocks, Cannell (1982) found that selection for performance in open-grown conditions did not result in a reduction in productivity per hectare under conditions of intense competition, suggesting that selection under open-grown conditions may still be appropriate regardless of the stocking regime adopted.

\section{References}

Beets, P.N. \& Brownlie, R.K. 1987. Puruki Experimental Catchment: Site, climate, management, and research. New Zealand Journal of Forestry Science 17, 137-160.

Beets, P.N. \& Pollock, D.S. 1987. Accumulation and partitioning of dry matter in Pinus radiata as related to stand age and thinning. New Zealand Journal of Forestry Science 17, 246-271.

Bolstad, P.V. \& Libby, W.J. 1982. Comparison of radiata cuttings of hedge and tree-form origin after seven growing seasons. Silvae Genetica 31, 9-13.

Burdon, R.D. \& Shelbourne, C.J.A. 1974. Use of vegetative propagules for obtaining genetic information. New Zealand Journal of Forestry Science 4, 418-425.

Campbell, R.K. \& Wilson, B.C. 1973. Spacing-genotype interaction in Douglas-fir. Silvae Genetica 22, 15-20.

Cannell, M.G.R. 1982. 'Crop' and 'Isolation' ideotypes: Evidence for progeny differences in nursery-grown Picea sitchensis. Silvae Genetica 31, 60-66.

Cotterill, P.P. \& Zed, P.G. 1980. Estimates of genetic parameters for growth and form traits in four Pinus radiata D Don progeny tests in South Australia. Australian Forest Research 10, 155-167.

Dixon, R.K. 1990. Physiological processes and tree growth. In Process Modeling of Forest Growth response to Environmental Stress (ed. R.K. Dixon, R.S. Meldahl, G.A. Ruark \& W.G. Warren). Portland, OR, USA: Timber Press.

Falconer, D.S. 1960. Introduction to Quantitative Genetics. New York: The Ronald Press Co.. 365 pp.
A broader and far-reaching implication for tree breeders is that traditional methods of performance testing, reliant on phenotypic selection and progeny testing, are becoming less appropriate. Interest is developing in an increasing number of traits. In addition, changes in climate, site, and atmospheric conditions require that testing be undertaken over a wider range of conditions than was previously considered necessary (Ledig \& Kitzmiller, 1992). Some, such as elevated atmospheric $\mathrm{CO}_{2}$, may currently be non-existent. Comprehensive field testing is both slow and costly. Conventional methods need long time intervals to be reliable, and our results suggest that wider spacings would avoid some of the complications introduced by early competition among genotypes. The need for alternative, quantitative approaches based on an understanding of the underlying processes is increasingly being emphasized, and will require more integration of research across a number of disciplines (Dixon, 1990).

Ford, E.D. 1975. Competition and stand structure in some even aged plant monocultures. Journal of Ecology 63, 311-333.

Fries, A. 1984. Spacing interaction with genotype and with genetic variation for production and quality traits in a trial of seedlings and grafted clones of Scots pine (Pinus sylvestris L.) Silvae Genetica 33, 145-152.

Gadgil, P.D. 1984. Cyclaneusma (Naemacyclus) needlecast of Pinus radiata in New Zealand. 1: Biology of Cyclaneusma minus. New Zealand Journal of Forestry Science 14, 179-196.

Hara, T. 1984. A stochastic model and the moment dynamics of the growth and size distribution in plant populations. Journal of Theoretical Biology 109, $173-90$.

Hattemer, H.H., Andersson, E. \& Tamm, C.O. 1977. Effects of spacing and fertilization on four grafted clones of Scots pine. Studia Forestalia Suecica 141, $1-31$.

Jackson, D.S., Gifford, H.H. \& Hobbs, I.W. 1973. Daily transpiration rates of radiata pine. New Zealand Journal of Forestry Science 3, 70-81.

Knight, P.J. 1978. Foliar concentrations of ten mineral nutrients in nine Pinus radiata clones during a 15-month period. New Zealand Journal of Forestry Science 8, 351-368.

Ledig, F.T. \& Kitzmiller, J.H. 1992. Genetic strategies for reforestation in the face of global climate change. Forest Ecology and Management 50, 153-169. 
Madgwick, H.A.I. 1983. Differences in growth and weight of genotypes of pine with special reference to clones of Pinus radiata. New Zealand Journal of Forestry Science 13, 115-124.

Magnussen, S. 1989. Effects and adjustments of competition bias in progeny trials with single-tree plots. Forest Science 35, 532-547.

Morgenstern, E.K. 1982. Interactions between Genotype, Site and Silvicultural Treatment. Information Report PI-X-14. Petawawa National Forestry Institute, Canadian Forestry Service. 18 pp.

Pawsey, C.K. 1971. Comparison of vegetativelypropagated and seedling trees of Pinus radiata Australian Forest Research 5, 47-57.

Spurr, S.H. 1962. A measure of point density. Forest Science 8, 85-95.

Sziklai, O. 1974. Juvenile-mature correlation. In Proceedings IUFRO, Joint meeting of working parties on propagation and ecological genetics, breeding theory and progeny testing. Department of Forest Genetics, The Royal College of Forestry, Stockholm, Sweden, $217-235$
Tauer, C.G. 1975. Competition between selected black cottonwood genotypes. Silvae Genetica 24, 44-49.

van der Pas, J.B., Slater-Hayes, J.D., Gadgil, P. D. \& Bulman, L. 1984. Cyclaneusma (Naemacyclus) needlecast of Pinus radiata in New Zealand. 2. Reduction in growth of the host, and its economic impact. New Zealand Journal of Forestry Science 14, 197-209.

von Euler, F., Baradat, P. \& Lemoine, B. 1992. Effects of plantation density and spacing on competitive interactions among half-sib families of maritime pine. Canadian Journal of Forest Research 22, 482-9.

Zobel, B. \& Talbert, J. 1984. Applied Forest Tree Improvement. New York: John Wiley \& Sons.

\section{Acknowledgements}

We thank Dr D. S. Jackson for his early involvement in establishing the research site, and for ensuring that clonal material was represented at Puruki. 



\title{
Growth of Betula and Abies trees and their productivity at different altitudes in the subalpine zone
}

\author{
OSAMU SHIBATA and YUKIKO ANDO
}

Department of Biology, Shinshu University, Japan

\begin{abstract}
Shibata, O. \& Ando, Y. 1993. Growth of Betula and Abies trees and their productivity at different altitudes in the subalpine zone. In Management of structure and productivity of boreal and subalpine forests (ed. S. Linder \& S. Kellomäki). Studia Forestalia Suecica 191. 94 pp. ISSN 0039-3150, ISBN 91-576-4822-0.

Trees of Betula ermanii and Abies mariesii in the subalpine zone became shorter with increase in altitude of their habitat. Radial growth of Betula increased with altitude, while that of Abies was suppressed. Annual productivity of Betula was about the same among trees in different altitudinal habitats, but that of $A$ bies was reduced when altitude increased. Such contrasting growth between Betula and Abies species seems to have been caused by their different response to climatic stresses.
\end{abstract}

Key words: Abies mariesii, Betula ermanii, production, altitude, subalpine, Japan.

Osamu Shibata and Yukiko Ando, Department of Biology, Faculty of Science, Shinshu University, Matsumoto, 390 Japan.

MS. received 4 November 1992

MS. accepted 23 January 1993

\section{Introduction}

It is well known that plant life is largely altered by temperature as a climatic stress. In mountain areas, the temperature gradients often influence the vertical zonation of vegetation. Some temperature effects have been studied concerning photosynthesis (Mooney, Marrison \& Morrow, 1975; Bunce, Chabot \& Miller, 1979). For photosynthesis and growth of subalpine tree species, many studies (e.g., Tranquillini \& Havranek, 1985; Schönenberger \& Frey, 1988; Graumlich, 1991) have reported on the interrelation of various environmental factors. The annual growth of tree species is shown in the increment of the annual ring and of tree height, and the former is often used as an indicator of their production. The width of the annual ring roughly synchronizes with environmental temperature, and the relationships have been refined to analyze paleoclimate (Cropper, 1982; Henry, Andrews \& Short, 1989; Villalba, Leiva, Rubulls \& Lenanzo, 1990).

The Japanese subalpine zone (1 500-2 $500 \mathrm{~m}$ above sea level (a.s.1.)) is characterized by $T$ suga diversifolia and Abies veitchii at low altitudes and Abies mariesii at high altitudes. Betula ermanii grows in the gaps of coniferous forest in the subalpine zone. With increasing altitude of habitat, the standing density of $B$. ermanii increases while that of $A$. mariesii decreases. At timber-line, about $2500 \mathrm{~m}$, a pure forest of $B$. ermanii exists in a narrow zone, and here the species branches laterally more often than at lower altitudes.

This paper describes altitudinal differences in some of the productive characteristics of $B$. ermanii and $A$. mariesii.

\section{Materials and methods}

The experimental site was located in the subalpine zone of the eastward slope of $\mathrm{Mt}$. Norikura (3 $026 \mathrm{~m}$ a.s.1., $36^{\circ} 06^{\prime} \mathrm{N}, 137^{\circ} 33^{\prime} \mathrm{E}$ ) in the central mountain region of Japan. Abies mariesii (abbreviated to Abies) and Betula ermanii (abbreviated to Betula) growing at $2000 \mathrm{~m}$, 
$2350 \mathrm{~m}$, and $2500 \mathrm{~m}$ a.s.l. at the site were used as materials for researching the productivity of subalpine forest.

Annual wood production of Betula and Abies was calculated fron volumes produced by mature trees in 1989 and 1990 on the basis of the pipe model theory of plant form (Shinozaki, Yoda, Hozumi \& Kira, 1964a), a useful method for estimating wood production without felling trees. These volumes were evaluated from a conical form with the width of annual ring, the diameter of annual ring at ground level, and tree height. To estimate these tree growth factors, five mature trees of both species, with standard height and diameter, were chosen at altitudes of $2000 \mathrm{~m}, 2350 \mathrm{~m}$, and $2500 \mathrm{~m}$. The width of the annual ring was measured on wood samples cut off from the east side of trunks at around ground level, and the diameter of the annual ring was calculated on the basis of the tree's diameter at ground level.

To estimate altitudinal temperature gradients, air temperature at different altitudes was calculated using a lapse rate of $0.65^{\circ} \mathrm{C}$ per $100 \mathrm{~m}$ for this mountain area, based on temperature data observed at $1000 \mathrm{~m}$ altitude (Nagano Center of Japanese Meteorological Society, 1984-1991). The lapse rate was obtained from temperatures observed at $1000 \mathrm{~m}, 1500 \mathrm{~m}$, $2200 \mathrm{~m}$, and $2700 \mathrm{~m}$ (Miyazaki, 1974; Shibata, Kato, Arai \& Kinoshita, 1976). The air temperatures estimated in the subalpine zone were based on data from June to August, because Betula leaves in that area began to open in early June and change their colour in early September.

\section{Results}

At $2500 \mathrm{~m}$ on Mt. Norikura, the average air temperature from June to August in 1983-1990 was lowest $\left(7.9^{\circ} \mathrm{C}\right)$ in 1989 and highest $\left(9.6^{\circ} \mathrm{C}\right)$ in 1990 (Fig. 1). The temperature variation over several years was synchronized with the annual variation of the width of annual rings of Betula at $2500 \mathrm{~m}$, but this synchronization was not found in Abies and Betula at lower altitudes. The width of the annual ring of Abies was greater in 1990 than in the other years, although the temperature in 1990 was about the same as that in 1984. Despite the significant temperature

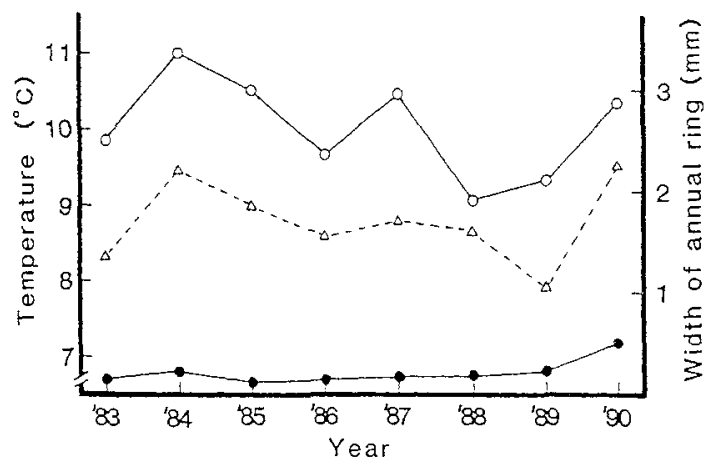

Fig. 1. Yearly changes in average air temperature $(\triangle)$ from June to August in 1983-1990 and the width of the annual ring of Betula ermanii (o) and Abies mariesii at an altitude of $2500 \mathrm{~m}$.

difference between 1984 and 1989, the ringwidths were the same in both years.

Annual radial growth of Betula increased greatly with increase in the altitude of its habitat in 1989 and 1990, while Abies decreased gradually $(p<0.05$ in 1989 and $p<0.01$ in 1990; Fig. 2). Radial growth of both species in 1989 was less than in 1990 at all altitudes. For Betula, the difference between the two years was significantly larger $(p<0.01)$ at $2500 \mathrm{~m}$, while for Abies the difference was significantly larger $(p<0.05)$ at $2000 \mathrm{~m}$ and $2350 \mathrm{~m}$.

Trees chosen for estimating wood production were $20-30 \mathrm{~cm}$ in diameter, with heights of ca. $19 \mathrm{~m}$ at $2000 \mathrm{~m}$, ca. $9 \mathrm{~m}$ at $2350 \mathrm{~m}$, and ca. 5 $\mathrm{m}$ at $2500 \mathrm{~m}$, but the ages of these trees, judged from the number of annual rings, varied between

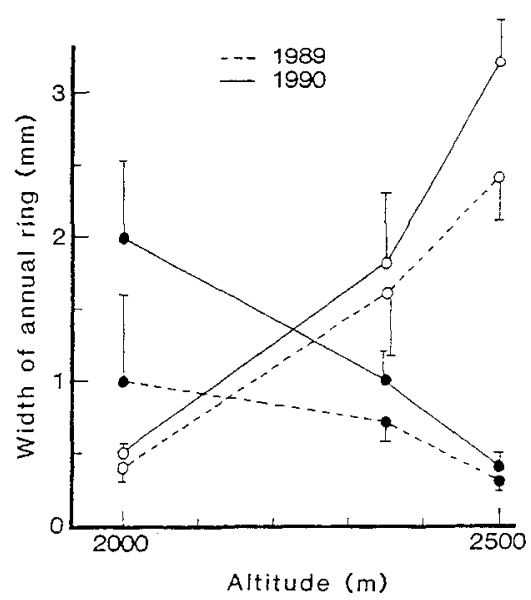

Fig. 2. Changes with altitude in the width of the annual ring of Betula ermanii (o) and Abies mariesii (O) in 1989 and 1990 . Vertical bars show the standard deviation. 
ca. 60 years to ca. 150 years for Betula and from ca. 100 to ca. 250 years for Abies at the same altitudes. The relation between wood production and altitude of habitat of Abies and Betula in 1989 and 1990, is shown in Fig. 3. In 1990, production of Abies decreased with increasing altitude, especially from $2000 \mathrm{~m}$ to $2350 \mathrm{~m}$, but that of Betula decreased little. As a result, Betula at $2000 \mathrm{~m}$ produced only about $30 \%$ of that in Abies. However, because of the small decrease of production in Betula with increasing elevation, production at $2350 \mathrm{~m}$ and at $2500 \mathrm{~m}$ was larger in Betula than in Abies, especially at $2500 \mathrm{~m}(p<0.01)$. In 1989 , the production of Abies at $2000 \mathrm{~m}$ was about half that in 1990, whereas the production of Betula was about $70 \%$ that in 1990 .

\section{Discussion}

The radial growth of Abies in 1990 was more vigorous than in 1984, although the temperature was about the same in both years. This suggests an influence of factors other than temperature upon the vigorous growth in 1990. One such factor may be nitrogen deposition from cloud water, because of recent air pollution. However, this is not clear at present, since the nitrogen analysis has not yet been completed. Radial growth of Betula seemed to be affected by temperature alone during these eight years.

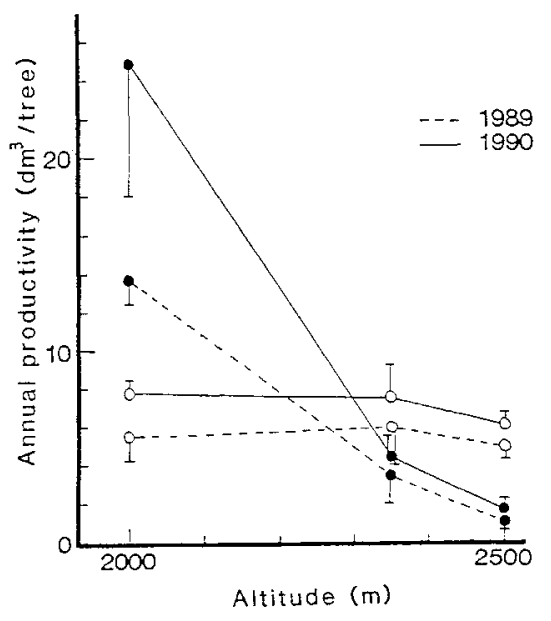

Fig. 3. Changes with altitude in the productivity of Betula ermanii (o) and Abies mariesii (0) in 1989 and 1990. Vertical bars show the standard deviation.
The radial growth of Abies, shown as the width of the annual ring, decreased with increasing altitude, and was less in cool summers than in hot summers. The radial growth of Betula, however, increased with altitude, although like Abies, it was reduced in the year with a cool summer. Some of the reasons for their contrasting growth patterns may be related to differences in their light-requirements and in their freezing resistance level (Sakai, 1975; Sakai \& Kurahashi, 1975). Grace \& Norton (1990) have reported more vigorous radial growth of Pinus sylvestris at the tree-line than at lower altitudes, as a result of higher temperature in its terminal meristems. As regards Betula, however, its vigorous radial growth at the timber-line may be related to photosynthesis in Betula bark, which contains chlorophyll, like that of Populus tremuloides (Schaedle \& Foote, 1971; Convington, 1975). The interior of the Betula forest is lighter than that of the coniferous forest, and is warmer on sunny days, because direct solar radiation often reaches the forest floor. Such conditions are favourable for photosynthesis in Betula bark.

It has been reported by Shinozaki et al. (1964b) that the theoretical wood production of a tree of conical form is about the same as its actual production. The pipe model theory has been applied to estimate the production of deciduous trees in recent papers (Chiba, 1990, 1991). Shortened Betula trees near the timberline are transformed to cluster canopies as they grow into multi-stemmed forms. For this form of Betula the theoretically calculated wood production must be smaller than actual production, whereas wood production of Betula in the lower area seems nearly equal to its theoretical production, because the species grows rather straight, with relatively few lateral branches. This interpretation makes the contrasting altitudinal wood production of the two species clearer. With increasing altitude, the production of Abies markedly decreased, while no such decrease was found for Betula. Such differences between the species seem to have resulted from their contrasting responses to climatic stresses.

The potential productivity of Betula is larger than that of Abies in the upper subalpine zone. The wood production of Betula at lower altitudes, where Betula trees grow sparsely in Abies forest, seems to be smaller than that of Abies 
and is probably due to insufficient light under the coniferous canopy. These results suggest that forest productivity at intermediate altitudes in the subalpine zone would be increased through the colonisation by Abies of gaps in coniferous forest. In the more severe climate of the upper subalpine zone, with very low temperatures and heavy snow in winter, Betula colonisation would increase forest production.

\section{References}

Bunce, J.A., Chabot, B.E. \& Miller, L.N. 1979. Role of annual carbon balance in the distribution of plant species along an elevational gradient. Botanical Gazette 140, 288-294.

Chiba, Y. 1990. Plant form based on the pipe model theory. I. Statical model in the crown. Ecological Research 5, 207-220.

Chiba, Y. 1991. Plant form based on the pipe model theory. II. Quantitative analysis of ramification in morphology. Ecological Research 6, 21-28.

Convington, W.W. 1975. Altitudinal variation of chlorophyll concentration and reflectance of the bark of Populus tremuloides. Ecology 56, 715-720.

Cropper, J.P. 1982. Climatic reconstructions (1801 to 1938) inferred fron tree-ring width chronologies of the north American arctic. Arctic and Alpine Research $14,223-241$.

Grace, J. \& Morton, A. 1990. Climate and growth of Pinus sylvestris at its upper altitudinal limit in Scotland. Evidence from tree growth-rings. Journal of Ecology 78, 601-610.

Graumlich, L.J. 1991. Subalpine tree growth, climate, and increasing $\mathrm{CO}_{2}$ : An assessment of recent growth trends. Ecology 72, 1-11.

Henry, F.D., Andrews, J.T. \& Short, S.K. 1989. Climate variations in northern north America (6 $000 \mathrm{BP}$ to present) reconstructed fron pollen and tree-ring data. Arctic and Alpine Research 21,45-59.

Miyazaki, T. 1974. Alpine and subalpine climate of the eastern region in Mt. Norikura (Japanese). In Fundamental studies on destruction of the biotic environment and its reclamation in the central region of Japan, No. 2 (ed. T. Shimizu), 57-60. Shinshu Univ., Japan.

Mooney, H.A., Marrison, A.T., Morrow, P.A. 1975. Environmental limitation of photosynthesis on a California evergreen shrub. Oecologia 19, 293-301.

Nagano Center of Japanese Meteorological Society
1984-1991. Yearly reports of meteorology of Nagano Prefecture in 1983-1990. Nagano, Japan. (In Japanese.)

Sakai, A. 1975. Freezing resistance of evergreen and deciduous broad-leaf trees in Japan with special reference to their distribution. Japanese Journal of Ecology 25, 101-111. (In Japanese with English summary.)

Sakai, A., \& Kurahashi, A. 1975. Freezing resistance of conifers in Japan with special reference to their distribution. Japanese Journal of Ecology 25, 192-200. (In Japanese with English summary.)

Schaedle, M. \& Foote, K.C. 1971. Seasonal changes in the photosynthetic capacity of Populus tremuloides bark. Forest Science 17, 308-313.

Schönenberger, W. \& Frey, W. 1988. Untersuchungen zur Ökologie und Technik der Hochlagenaufforstung. Schweizerische Zeitschrift für Forstwesen 139, 735-820.

Shibata, O., Kato, K., Arai, T. \& Kinoshita, T. 1976. On the microenvironment in Mt. Norikura, the central mountain region of Japan. Journal of the Faculty of Science, Shinshu Univ. 11, 15-39. (In Japanese with English summary.)

Shinozaki, K., Yoda, K., Hozumi, K. \& Kira, T. 1964a. A quantitative analysis of plant form - the pipe model theory. I. Basic analysis. Japanese Journal of Ecology 14, 97-105.

Shinozaki, K., Yoda, K., Hozumi, K. \& Kira, T. $1964 b$. A quantitative analysis of plant form - the pipe model theory. II. Further evidence of the theory and its application in forest ecology. Japanese Journal of Ecology 14, 133-139.

Tranquillini, W. \& Havranek, W.M. 1985. Influence of temperature on photosynthesis in spruce provenance from different altitudes. Mitteilungen/Eidgenössische Anstalt für forstliche Versuchswesen 270, 41-51.

Villalba, R., Leiva, J.C., Rubulls, S. \& Lenzano, L. 1990. Climate, tree-ring, and glacial fluctuations in the Rio Frias valley, Rio Nigro, Argentina. Arctic and Alpine Research 22, 215-231. 


\title{
Low temperature as an ecological factor in the cool-climate eucalypt forests
}

\author{
J.C.G. BANKS \\ Department of Forestry, Australian National University, Canberra \\ D.M. PATON \\ Department of Chemistry, Australian National University, Canberra
}

\begin{abstract}
Banks, J.C.G. \& Paton, D.M. 1993. Low temperature as an ecological factor in the coolclimate eucalypt forests. In Management of structure and productivity of boreal and subalpine forests (ed. S. Linder \& S. Kellomäki). Studia Forestalia Suecica 191. 94 pp. ISSN 0039-3150, ISBN 91-576-4822-0.
\end{abstract}

Severe valley frosts which occur once every 10 to 20 years and extreme frosts every 100 years or so are major disturbance factors in the cool-climate eucalypt forest ecosystems of southeastern Australia. These winter frosts, resulting from strong nocturnal temperature inversion and cold air drainage, maintain inverted treelines and influence species patterns and forest productivity in lower slope valley forests. Examples of inverted treelines, related to low temperature, are described for subalpine, montane, tableland, and coastal escarpment forests. An infrequent extreme frost in 1982 in the Bonang Valley, Gippsland, destroyed the crowns of eucalypts lying wholly or partly within the freezing air layer and disrupted tree growth by modifying crown morphology. Tree-ring analysis of Bonang trees indicates that frost-damaged trees took five growing seasons to recover, although in that time other environmental factors were probably also important. An analysis of the dynamics of lignotuberous seedlings in a fully stocked valley treeline forest demonstrates the capacity of these seedlings to recover rapidly and re-establish an equilibrium following severe frost and other damage.

Key words: cool mountain eucalypt forests, inverted treelines, frost damage, tree rings, seedling dynamics.

J.C.G. Banks, Department of Forestry, Australian National University, P.O. Box 4, Canberra A.C.T. 2601, Australia.

D.M. Paton, Department of Chemistry, Australian National University, P.O. Box 4, Canberra A.C.T. 2601, Australia.

MS, received 4 November 1992

MS. accepted 7 January 1993

\section{Introduction}

Both subalpine and inverted (or valley) treelines are found in the cool mountain forests of southeastern Australia in certain topographic situations. Each treeline type tends to be contourrelated for a particular aspect, and each clearly results from the adverse environmental conditions for tree growth at that altitude. Low winter temperatures are usually involved in these adverse conditions and combined with the relatively low cold tolerance of eucalypts, give dramatic contour-related changes at the treeline.

The subalpine treeline is restricted to high altitude areas which include an alpine zone. In Tasmania this treeline occurs around the 1200 $\mathrm{m}$ contour and is dominated by the Tasmanian snow gum, Eucalyptus coccifera J.D. Hook. On the mainland, in the Australian Alps and Snowy Mountains, the subalpine treeline occurs at 1830 to $2000 \mathrm{~m}$ and is dominated by snow gum, E. pauciflora Sieber ex Sprengel (Costin, 1981). These treelines are related to both winter and summer temperature regimes, and in agreement with northern hemisphere treelines, are largely delineated by a mean summer temperature of about $10.0^{\circ} \mathrm{C}$ in the warmest month, (Daubenmire, 1954; Tranquillini, 1979; Slatyer, 1988). In this respect eucalypt subalpine treelines are in broad agreement with world-wide 
subalpine treelines, indicating that the evergreen eucalypts are ecologically equivalent to the subalpine trees of the northern hemisphere, although $E$. pauciflora, the most hardy treeline eucalypt, has maximum twig cold resistance between $-20^{\circ} \mathrm{C}$ and $-23^{\circ} \mathrm{C}$ compared with $-30^{\circ} \mathrm{C}$ and below for many subalpine trees of the northern hemisphere (Sakai, Paton \& Wardle, 1981). The small and variable photoperiodic responses in eucalypts (Paton, 1978) appear related to their evergreen habit, and help explain the absence of short-day, low temperature-induced winter dormancy that is so commonly found in cold-resistant plants of the northern hemisphere (Sakai et al., 1981).

The less common inverted treelines in the cool eucalypt forests occur over an altitudinal range extending from the subalpine zone to the coastal plain. They appear as sharp, contourrelated forest-grassland boundaries, as shown in Fig. 1.

The grassland, which is often called a frost hollow, is characterised by the periodic occurrence of lethal winter temperatures, preventing tree establishment. Inverted treelines are confined to valleys subject to strong nocturnal winter temperature inversions, involving downslope cold air drainage and the pooling of very cold air masses in valley bottoms. The classic European example is the Gstettneralm Sinkhole near Lunz in Austria, where the temperature inversion in winter is reported to range from $-1.8^{\circ} \mathrm{C}$ at the sinkhole rim to $-28.8^{\circ} \mathrm{C}$ some $150 \mathrm{~m}$ below at the sinkhole bottom, (Geiger, 1966). This temperature gradient is associated with fir trees being replaced downslope by the

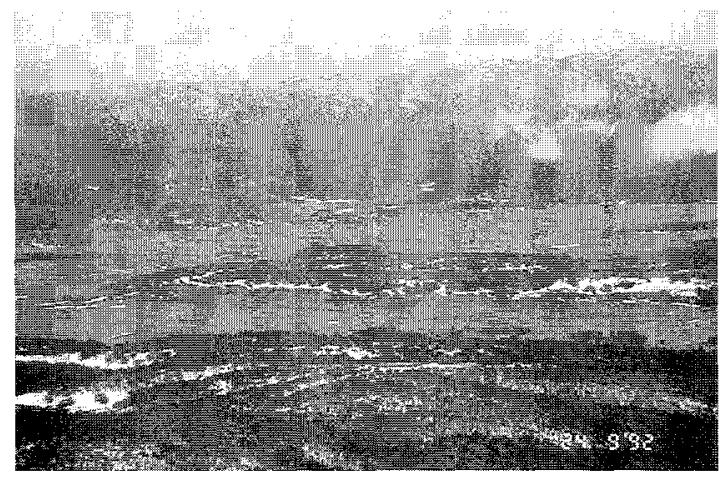

Fig. 1. Aerial photograph showing a typical subalpine frost hollow valley with a sharp grassland-forest boundary which forms the contour-related, inverted treeline. more cold-tolerant dwarf pines, and these in turn by grass at the bottom of the sinkhole. As other ecological factors can be involved, it should be emphasised that lower-slope valley treelines are not always associated with downslope temperature inversions that lead to temperature's limiting conditions for tree growth. For example, the "double timberlines" reported in North America as described by Arno \& Hammerly (1984), occur where the lower treeline delineates the forest limit under declining moisture conditions. Similarly, in Australia, along the escarpment in the southeast, some inverted treelines can be attributed to periodic flooding in flat valleys, as seen in the Buddawang National Park on the Central tablelands. Other apparent inverted treelines are often the result of past land clearing of fertile valleys for agriculture, (Rowe, 1987).

Moore \& Williams (1976) first suggested that low temperature is the primary cause of the absence of trees on grassland below inverted treelines at about $1300 \mathrm{~m}$ in southeast Australia, as illustrated in Fig. 2a. More recent reports of these subalpine, inverted treelines have been made by Harwood (1980), Costin (1981) and Slatyer (1988). The role of a rare killing frost in generating and maintaining an inverted treeline at $660 \mathrm{~m}$ (Fig. 2b) has been described by Paton (1988). Several authors (e.g. Burbridge \& Gray, 1970; Pryor \& Banks, 1991) have considered frost hollows below inverted treelines at $600 \mathrm{~m}$ (Fig. 2c) in the Canberra region. The remnants of an inverted treeline at $80 \mathrm{~m}$ (Fig. 2d), remaining after agricultural development on the coastal plain below the tableland escarpment southeast of Canberra, have not been noted previously. However, the provenance of E. pauciflora at this low-altitude location revealed marked tolerance to high growing temperatures, not shown by provenances of this species near Canberra and at subalpine altitudes (Paton, 1980).

While E. pauciflora is common to inverted treelines at all four altitudes (Fig. 2), other component eucalypt species vary widely. The present study compares these differences in species composition that have not been previously reported. Such differences in species patterns are attributed to the effects of low temperature regimes in the cool-climate eucalypt forest. Long-lasting effects of low temperature are evident also in the slow recovery of surviving trees that sus- 
tained major crown damage after the rare killling frost described by Paton (1988). A third low-temperature effect involves the dynamics of tree seedlings below and near the canopy of a subalpine inverted treeline.

All three low temperature effects involve new observations, but none is capable of direct experimentation at this stage. Accordingly, the usual detail given under Materials and Methods is replaced by relevant information considered essential for interpretation of the observed results. The same procedure was followed when the effects of the rare killing frost were reported and interpreted (Paton, 1988).

\section{Inverted treelines in cool climate eucalypt forests}

The cool-climate eucalypt forests of southeastern Australia are found on the New England, Central, and Monaro Tablelands in New South Wales, much of Gippsland in eastern Victoria, and Tasmania. These forests are dominated by more than 100 tree species from the broadleaf evergreen genus Eucalyptus (Beadle, 1981), and occur as subalpine, montane, tableland, and coastal forests. Three species, E. pauciflora, E. rubida Deane \& Maiden and E. viminalis Labill., are widely distributed throughout these forests and are typically associated with inverted treelines. Associated species include E. mannifera Mudie and E. stellulata Sieber ex DC, which occur only on the mainland; E. delegatensis R. Baker and E. lacrimans Johnston extend from the Snowy Mountains south into Tasmania, while E. johnstonii Maiden occurs only in Tasmania. Other species associated with these treelines are considered to be relict species, as they typically have severely restricted and often highly fragmented occurrences, e.g. E. camphora R. Baker.

The often remarkably predictable species patterns in the eucalypt forest reflect the high level of species-site specificity in the genus, (Florence, 1981). These patterns are expressed in the forest as complex mosaics, which can be explained in simple terms as species replacement series along environmental gradients. Each replacement series comprises species from one eucalypt subgenus, and where two or more subgenera are present together in the forest, the replacement series overlap one another. The most important subgenera in these cool forests are Symphyomyrtus and Monocalyptus.

Within any one climatic zone, edaphic factors tend to dominate environment gradients, although in certain topographic situations, localised low temperature regimes are the major environmental factor controlling species patterns. In valley systems where down-slope cold air drainage and the pooling of cold air masses occurs in valley bottoms, the expected replacement series related to altitude are interrupted by the appearance of cold-tolerant species. The replacement interruptions that occur at inverted treelines in the subalpine, montane, tableland, and coastal forests in southern New South Wales and adjacent Victoria, are described in the present study.

The subalpine forests' frost hollows and their inverted treelines are typically found in wide, shallow valleys. At the highest elevations E. pauciflora from the subalpine treeline, may merge directly into the inverted treeline stands with no change in tree species composition. With longer sheltered slopes, other species such as $E$. delegatensis may occur on the mid-slope, sandwiched between upper and lower stands of $E$. pauciflora (Fig. 2a). The composition of these inverted treeline stands varies with local site conditions, but E. pauciflora usually dominates, except on locally drier sites where it is replaced by E. rubida, or on wetter sites by $E$. stellulata or-on the most exposed sites-by E. lacrimans. The last two species are closely related to $E$. pauciflora. The width of these inverted treeline stands is slope-dependent, as on steep slopes they are mostly narrow while on gentle slopes they may be up to several hundred metres wide. Some of the best examples of these subalpine inverted treelines are located in the Kosciusko National Park in the Snowy Mountains of New South Wales, where one of the most extensive inverted treelines occurs at Long Plain, a gently sloping valley about $16 \mathrm{~km}$ long by 0.5 to $2.5 \mathrm{~km}$ wide, which ranges in elevation from 1380-1 300 $\mathrm{m}$, with an average gradient of 1:200. Although the integrity of some of the treeline stands in this valley has been disrupted by past grazing and burning practices, which ceased as late as the 1960s, the original contour-related treeline can be readily identified. It consists predomi- 

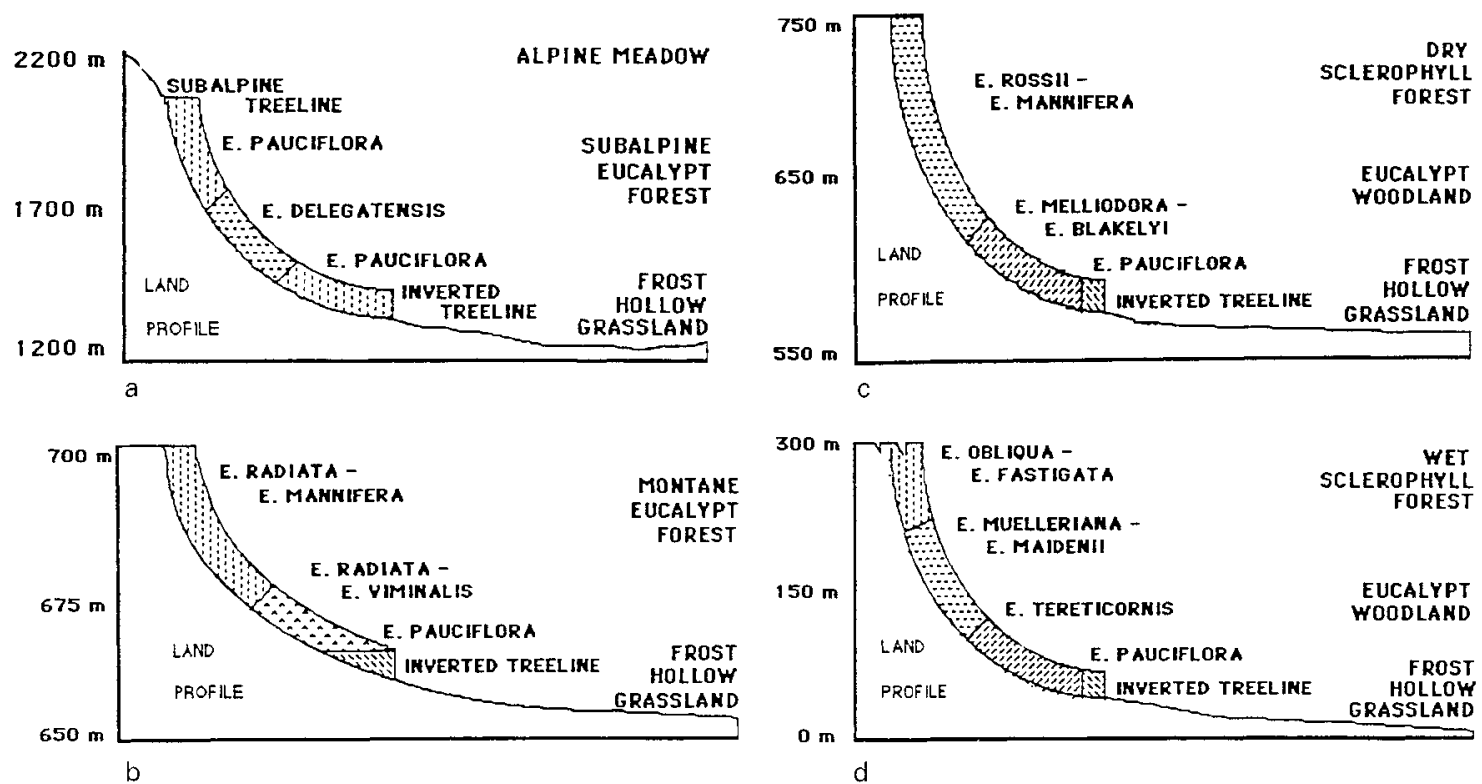

Fig. 2 a. Species pattern in subalpine eucalypt forest, showing $E$. pauciflora comprising the treeline forest and the abrupt forest-alpine meadow and grassland boundaries. Snowy Mountains, N.S.W. $b$. Species pattern in a lowerslope montane forest, showing an inverted treeline comprising E. paucifolia, E. viminalis. c. Species pattern in a footslope dry sclerophyll forest-woodland, with E. pauciflora comprising the inverted treeline at the abrupt woodlandgrassland boundary. Black Mountain, A.C.T. d. Species pattern in a coastal plain eucalypt forest, showing E. pauciflora comprising the inverted treeline at the abrupt woodland-grassland boundary. Bega Valley, N.S.W.

nantly of $E$. pauciflora, with $E$. stellulata in wetter sites (Fig. 2a), and some isolated patches of E. lacrimans.

In the montane forest, inverted treelines are found in both wide and narrow valley systems, where a cold air pool forms on the valley floor and up the lower slopes. Evidence for this is seen in lower valley slope species replacement patterns, where cold-tolerant species re-appear either in the valley floor itself (incipent frost hollow), or at some distance upslope, forming a distinct inverted treeline above a grassdominated frost hollow. The example from the Bonang River valley in East Gippsland Victoria (Fig. 2b), shows the down-slope series of Symphyomyrtus species E. mannifera-E. viminalis, overlapped by the Monocalyptus species E. radiata-E. pauciflora. That the inverted treeline is comprised of either E. viminalis (nongranite) or E. pauciflora (granite), with E. stellulata and $E$. camphora locally dominant in wet sites, illustrates the sensitivity of these treeline species to water regimes and geology. Also within these footslope forest stands, the lower limits of other species can be influenced by cold temperatures. For example, the replacement zone of E. mannifera by E. viminalis at Bonang was found to be contour-related, indicating that the lower limits of $E$. mannifera are influenced by low temperature (Paton 1988).

Inverted treelines around frost hollows also occur in the eucalypt woodlands, and characteristically E. pauciflora is again the treeline species. On the Monaro Tableland, woodlands typically replace the dry sclerophyll forest on the lower slopes and plains. Within these woodlands of $E$. melliodora Cunn. ex Schauer and E. blakelyi Maiden, frost hollows are found in low-lying topography, where in winter, lethal cold air temperatures occur from time to time. In the example from Black Mountain (Fig. 2c), the species pattern is related in part to the low winter temperature regime, and in part to soil fertility. Here E. mannifera is confined to skeletal soils well above the treeline contour, and the woodland species are confined to sites having deeper soils. These in turn are replaced on colder sites by $E$. pauciflora at the boundary of the treeless frost hollow, especially on granitic soils. A similar situation occurs in the coastal forests at Bega Valley (Fig. 2d), where the upper slope forest consists of E. obliqua L'Hert. and E. fasti- 
gata Deane \& Maiden, which are replaced by E. muelleriana A. Howitt and E. maidenii F. Muell. on the lower slopes and by E. tereticornis Smith woodland in the valley above frost hollows, with E. pauciflora forming an inverted treeline around frost hollows, again where granitic soils occur.

\section{The recovery of severely frost-damaged mature eucalypts}

In the winter of 1982, an unusually severe frost occurred in the Bonang Valley in East Gippsland. This was a rare event, as indicated by the frost damage to large eucalypt trees well above the established inverted treeline. It was probably the most severe frost for at least 100 years, as it killed several large Acacia melanoxylon $\mathrm{R}$. Br. trees in the valley, which were known by local landholders to be about 100 years old. Resultant tree crown damage caused by this frost has been reported by Paton (1988), who examined the frost damage to individual species at different contour levels above the valley floor. He also demonstrated, by tracing down-slope smoke movement patterns, that this killing frost was caused by cold air drainage into the natural frost hollow, combined with severe radiation cooling during clear-sky conditions on a winter night, resulting in a temperature of about $-20^{\circ} \mathrm{C}$. Surviving trees of $E$. radiata Sieber ex $\mathrm{DC}$ and E. viminalis, which were wholly within the killing frost zone, had their crown branches killed back, often to the main bole, while those partly within the lethal frost lost only the lower portion of their crowns. Crown recovery was initiated in the following spring, with branch replacement arising from previously dormant epicormic buds. After eight years trees with the severe crown damage had yet to regain apical dominance, their crowns retaining deep narrow columnar silhouettes strikingly similar to those of fire-damaged "chimney" trees.

Given the severity of damage and the apparently slow crown recovery of frost-damaged trees at the Bonang site, bole increments were compared between frost-affected and unaffected trees for the period before and after the frost, to establish whether bole increment had also been checked by this severe frost. For this purpose bole samples were taken for tree ring analysis in autumn 1991, from three trees of $E$. viminalis and $E$. radiata having respectively severe, mod- erate and zero crown frost damage. Useful data were obtained from E. viminalis, tree rings of the other species were too indistinct for analyses. Tree ring indices for the 11 growing seasons (1980/1-1990/1) were derived for each tree, to remove the effect of diameter differences. These showed that bole diameter increments of the frost-damaged trees were suppressed for five growing seasons immediately following the killing frost in the winter of 1982. Compared with the undamaged tree, the severely frost-damaged tree lost an average radial increment of 35\% and the moderately damaged trees $25 \%$ over the five growing seasons.

\section{Tree seedling dynamics in a subalpine inverted treeline forest}

In most eucalypt forests and woodlands, tree replacement usually arises from two types of seedlings; those derived directly from seed and those which have repeatedly resprouted from the lignotuber of an older seedling. As these lignotuberous plants remain small, they are equivalent to the true seedlings in many respects, and for this reason, are treated as seedlings in this report. This lignotuberous seedling pool builds up over many years by opportunistic seedling establishment, the seedlings being suppressed by the overwood until loss or weakening of one or more trees allows them to advance into saplings and finally trees. The long-term persistence of these seedlings is assured by the presence of numerous dormant buds in the lignotuber, a swollen woody structure at the base of the seedling, that ensures survival should the aerial parts the seedling be lost to environmental stresses such as frost, drought, fire, animal grazing or mechanical damage. Nothing is known of the dynamics of this lignotuberous seedling pool in a forest which has a fully stocked overwood. To answer questions of biomass turnover, seedling longevity and replacement, a long-term study was established at Long Plain in 1989 and preliminary results are now presented.

The study site is in an inverted treeline stand of mature E. pauciflora on the eastern edge of the large subalpine frost hollow known as Long Plain in the Snowy Mountains, N.S.W. The site provides an ideal opportunity to study the dynamics of a lignotuberous seedling pool under natural conditions, including a severe frost regime with minimal anthroprogenic influence. 
It was chosen after one of the authors (Paton, 1988), had noted the effects of a severe frost on Long Plain in the winter of 1987. This frost, which had a minimum temperature of at least $-15^{\circ} \mathrm{C}$, extended well into the E. pauciflora stands at the inverted treeline zone, killing the lower crowns of mature trees and the aerial parts of lignotuberous seedlings which had long been established under the forest overwood. Lignotuberous seedling numbers and heights, new seedlings, and seedling losses have been recorded annually for three years (1989-1991), from a $10 \times 30 \mathrm{~m}$ plot within the mature forest. The plot forms part of a longer transect that extends through the treeline into the open grassland of the frost hollow.

The results show mean seedling height and yearly changes in seedling numbers (Table 1). For the three years involved, the mean seedling height did not change significantly, remaining essentially stable at about $35 \mathrm{~cm}$. Taken as an index of biomass, this stability indicates that the aboveground seedling biomass has also remained essentially constant over the study period. Seedling numbers increased from 346 to 385 or by an average of $11 \%$, with gains exceeding losses in both periods. As a result, average seedling densities increased slightly, from 1.15 to 1.28 seedlings $\mathrm{m}^{-2}$. A small number of lignotuberous seedlings "disappeared" at the second scoring, only to re-appear at the third scoring. This was unexpected, and we have designated these as quiescent seedlings, to distinguish them from new seedlings derived from seed in the season of measurement. In the absence of any significant change in the overwood, no seedling attained sapling status during the three-year-period.

Table 1. Eucalypt seedling dynamics for the period 1989-1991. Data from a $300 \mathrm{~m}^{2}$ plot under a fully stocked snow gum (Eucalyptus pauciflora) stand, at Long Plain, Snowy Mountains, N.S.W.

\begin{tabular}{|c|c|c|c|}
\hline \multirow[b]{2}{*}{ Component } & \multicolumn{3}{|l|}{ Year } \\
\hline & 1989 & 1990 & 1991 \\
\hline $\begin{array}{l}\text { Seedling mean height, cm } \\
\text { SE }\end{array}$ & $\begin{array}{r}35.2 \\
1.8\end{array}$ & $\begin{array}{r}34.2 \\
2.1\end{array}$ & $\begin{array}{r}35.0 \\
2.0\end{array}$ \\
\hline Seedling number & 346 & 367 & 385 \\
\hline New seedlings & - & 64 & 48 \\
\hline Seedling losses & - & 44 & 47 \\
\hline Quiescent seedlings & - & - & 21 \\
\hline
\end{tabular}

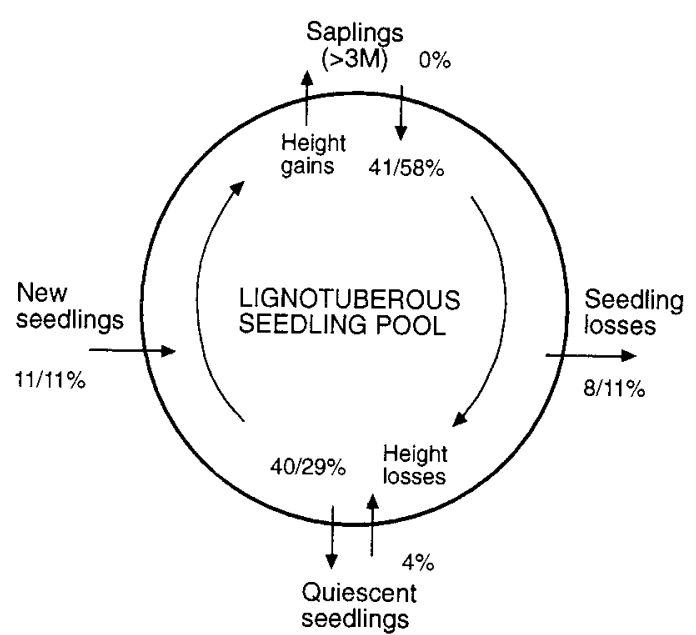

Fig. 3. Flow diagram illustrating lignotuberous seedling dynamics under a fully stocked stand. Percentage values indicate annual changes in seedling status for 1989 to 1990 and 1990 to 1991. Data from Long Plain, Snowy Mountains, N.S.W.

Values for seedling numbers and mean height values in Table 1 can be generalised in the form of a flow diagram (Fig. 3). This diagram allows several aspects of the dynamic nature of the seedling population to be clearly illustrated using percentage values for changes in different seeding categories with time. Consideration of annual inputs and outputs affecting the lignotuberous seedling pool (Fig. 3) lead to two important results. Firstly, whilst mean seedling height of the lignotuberous seedling pool remained constant, there were major changes in the heights of individual seedlings, with an average of $40 \%$ of all seedlings either gaining or losing height in each year, indicating that there is considerable biomass loss and replacement within the seedling pool. Secondly, numerical changes to the seedling pool are represented by the input of new seedlings, and an output of seedlings advancing to saplings, by seedling losses, and by quiescent seedlings that have taken more than one year to recover after dying back to the lignotuber.

\section{Discussion}

These observations show that frost hollows with their attendant treelines of E. pauciflora, occur over a wide altitudinal range in the cool eucalypt 
forests of southeastern Australia, with their greatest frequency at higher elevations. In the subalpine zone $E$. pauciflora is the major forest and woodland species and is the dominant treeline species, with localised occurrences of E. stellulata and E. rubida on wet and dry sites respectively, and E. lacrimans on dry, exposed sites. At the lower elevations in the tableland woodlands and coastal forests, E. pauciflora has a more relict-type occurrence, being increasingly restricted to granitic soils. Nevertheless, the consistent occurrence of $E$. pauciflora as a treeline species over these lower altitudes, indicates that of those species available, E. pauciflora is best adapted to the environmental conditions prevailing at frost-hollow inverted treelines. These conditions are likely to be site-specific, resulting in the development of distinct $E$. pauciflora ecotypes. In support of this, Pryor (1957) has reported considerable within-species morphological and physiological variation, and he suggested that individual populations are responding to local site conditions. Evidence for adaption to prevailing temperature regimes is fragmentary, but with respect to low temperatures, Paton (1971) has found a graded frost resistance in $E$. pauciflora over an altitudinal range of $1200-1480 \mathrm{~m}$ in the Brindabella Range, frost resistance above and below this altitudinal range not being strongly linked to temperature trends associated with altitude. Clearly, other environmental factors, such as the local topography and possibly soil water and nutrient regimes, are involved in such ecotypic selection. Similar observations have been made for E. viminalis (Paton, 1971) and for E. regnans (Eldridge, 1968). Furthermore, Harwood (1980) has found differing frost resistance in inverted treeline populations of E. pauciflora at Seventeen Flat and Currango Plain, near our Long Plain study site, thus indicating that local temperature regimes in these frost hollows are an important selection factor. This was further supported by Harwood's observation of a marked decrease in frost resistance in upslope populations at Currango Plain, but not at Seventeen Flat. These observations, while important, need to be treated cautiously when dealing with treeline populations around cold-air drainage valleys, as active selection for low temperature tolerance occurs at infrequent and irregular intervals, such as the extreme 100-year-event freeze reported for Bonang. Additionally, summer maximum temperatures may also be an important selection criteron in these treeline populations, especially at high altitudes. For example, seedling growth studies of E. pauciflora (Paton, 1988) have shown that seedlings from Bega $(80 \mathrm{~m})$ respond favourably to high temperatures of $36^{\circ} / 28^{\circ} \mathrm{C}$, (day/night) in contrast to seedlings from altitudes above $606 \mathrm{~m}$, that either died or displayed severe growth abnormalities at this high temperature regime.

The long-term effect of a rare killing frost on the subsequent growth of crown-damaged trees was shown by the results from Bonang, where crown recovery of frost damaged trees is still incomplete 10 years after the frost event. Radial increment was also suppressed, but for a shorter period of five years. This slow recovery is in contrast to that reported by Banks (1982) for E. pauciflora crown-damaged by fire, where recovery is rapid and is often accompanied by a surge in radial increment, attributed to the enhanced availability of nutrients and reduced competition. Neither of these factors is evident with the killing frost.

The establishment of the lignotuberous seedling pool beneath a fully stocked stand is a continuous process, with new seedlings establishing as seed becomes available and suitable environmental conditions prevail. These include an initial period of freedom from pathogens and a reduction in competition from surrounding vegetation. Thus seedling establishment is largely dependant on ground surface disturbance, although in the absence of fire, seedling recruitment is low, as showm by the Long Plain study. Once established, the lignotuberous seedlings will persist indefinitely, with their advancement to saplings being restrained by the overwood. Under periodic stresses such as frost, fire, drought, and insect damage, lignotuberous seedlings repeatedly regress, recovering under favourable environmental conditions. The results from Long Plain show that almost half the seedlings in the period of observation declined in height and recovered to the same mean height, emphasising the point that seedling supression in a fully stocked stand most likely involves competition for resources between large established trees and their small offspring. Such competition is presumably reduced when the fully stocked overstorey is disrupted by individ- 
ual tree deaths or periodic severe crown damage from wildfire, storm, insect grazing, etc. When the aerial portion of the seedling dies back to the lignotuber, recovery is dependent on resources available and on the nature of the extreme event. Recovery after fire is usually instantaneous and rapid, due in part to reduction in competition and to stimulus from ash nutrients. In the case of severe frost damage, recovery of aerial growth from the lignotuber is delayed. Observations at Bonang indicate that this delay may be as long as one to three years. At Long Plain, recovery of seedlings that had died back to the lignotuber was delayed a year, and whilst the causes of the initial dieback were undetermined, this lagged recovery is typical of sites undisturbed by fire.

\section{References}

Arno, S.F. \& Hammerly, R.P. 1984. Timberline: Mountain and Arctic Forest Frontiers. Seattle: The Mountaineers.

Banks, J.C.G. 1982. The use of dendrochronology in the interpretation of the dynamics of the snow gum forest. PhD Thesis, Dept. Forestry, Australian National University, Canberra.

Beadle, N.C.W. 1981. The Vegetation of Australia. Cambridge: Cambridge University Press.

Burbridge, N.T. \& Gray, M. 1970. Flora of the A.C.T. A.N.U. Press Canberra, 5.

Costin, A.B. 1981. Alpine and subalpine vegetation. In Australian Vegetation, Cap. 16 (ed. R.H. Groves). Cambridge University Press.

Daubenmire, R. 1954. Alpine timberlines in the Americas and their interpretation. Butler University Botanical Studies 11, 119-136.

Eldridge, K.G. 1968. Physiological studies of altitudinal variation in Eucalyptus regnans. Proceedings of the Ecological Society of Australia 3, 70-76.

Florence, R.F. 1981. The Biology of the Eucalypt Forest. In The Biology of Australian Plants, Cap.6 (ed. J.S. Spate \& A.J. McComb). University of Western Australia Press.

Geiger, R. 1966. The climate near the ground, 393-403. Harvard University Press, Cambridge, Mass., USA.

Harwood C.E. 1980. Frost resistance of subalpine Eucalyptus species. 1. Experiments using a radiation frost room. Australian Journal of Botany 28, 587-599.

Moore, R.M. \& Williams, J.D. 1976. A study of subalpine woodland-grassland boundary. Australian Journal of Ecology 1, 145-153.

Paton, D.M. 1971. Frost resistance in Eucalyptus: A new method for assessment of frost injury in altitudinal provenances of E. viminalis. Australian Journal of Botany 20, 127-139.
Paton, D.M. 1978. Eucalyptus physiology. I. Photoperiodic responses. Australian Journal of Botany 26, 633-642.

Paton, D.M. 1980. Eucalyptus Physiology: II Temperature responses. Australian Journal of Botany $28,555-566$.

Paton, D.M. 1988. Genesis of an inverted treeline associated with a frost hollow in south-eastern Australia. Australian Journal of Botany 36, 655-663.

Pryor, L.D. 1957. Variation in snow gum (Eucalyptus pauciflora). Proceedings of the Linnean Society of N.S.W. 81, 299-305.

Pryor, L.D. \& Banks, J.C.G. 1991. Trees and Shrubs in Canberra, 13-14. Little Hills Press in co-operation and assistance of the A.C.T. Government. Sydney,

Rowe, R. 1987. A climatological study of an inverted treeline in the Orroral Valley, A.C.T. Honours Thesis, Dept. Geography, Australian National University, Canberra.

Slatyer, R.O. 1988. Alpine and valley bottom treelines. In The Scientific Significance of the Australian Alps, Cap. 10 (ed. R. Good). The Australian Alps National Parks Liason Committee and the Australian Academy of Science. Canberra.

Sakai, A., Paton, D.M. \& Wardle, P. 1981. Freezing resistance of trees of the south temperate zone, especially subalpine species of Australia. Ecology 62:3, $563-570$.

Tranquillini, W. 1979. Physiological ecology of the alpine timberline. Tree existence in high altitudes with special reference to the European Alps. Ecological Studies 31, 137 pp. Berlin: Springer-Verlag. 


\title{
Developing remote sensing techniques to estimate photosynthesis and annual forest growth across a steep climatic gradient in western Oregon, USA
}

\author{
R.H. WARING, J. RUNYON, S.N. GOWARD ${ }^{1}$, R. McCREIGHT, \\ B. YODER and M.G. RYAN ${ }^{2}$ \\ College of Forestry, Oregon State University, Corvallis \\ ${ }^{1}$ Department of Geography, University of Maryland \\ ${ }^{2}$ U.S. Forest Service, Rocky Mountain Forest and Range Experiment Station, \\ Fort Collins
}

\section{Abstract}

Waring, R.H., Runyon, J., McCreight, R.,Yoder, B., Goward, S.N. \& Ryan, M. 1993. Developing remote sensing techniques to estimate photosynthesis and annual forest growth across a steep climatic gradient in western Oregon, USA. In: Management of structure and productivity of boreal and subalpine forests (ed. S. Linder \&S. Kellomäki). Studia Forestalia Suecica 191. 94 pp. ISSN 0039-3150, ISBN 91-576-4822-0.

The upper limits to photosynthesis are set by the amount of light intercepted daily and annually by green foliage. Freezing temperatures, drought, and humidity deficits further constrain photosynthesis. The visible light intercepted and that utilized by forests distributed across an environmental gradient in western Oregon were assessed from ground-based meteorological and physiological measurements. Utilized light was converted into biomass increment and showed an annual efficiency of $1 \mathrm{~g} \mathrm{MJ}^{-1}$ for forests with aboveground production from $<2$ to $17 \mathrm{Mg} \mathrm{ha}^{-1} \mathrm{yr}^{-1}\left(r^{2}=0.98\right)$. We present analogues in remote sensing for all of the ground-based measurements. We illustrate how various sensors estimate: (1) solar radiation, (2) temperature, (3) drought, (4) atmospheric water vapor deficits and (5) key properties of the vegetation. Combined, these remotely sensed techniques offer a means of estimating forest growth in the Pacific Northwest and possibly, globally.

Key words: light interception, photosynthesis, respiration, remote sensing, climate change, net primary production.

R.H. Waring, J. Runyon, R. McCreight \& B. Yoder College of Forestry, Oregon State University, Corvallis, Oregon 97331 , USA.

S.N. Goward, Department of Geography, University of Maryland, College Park, MD 30742, USA.

M.G. Ryan, U.S. Forest Service, Rocky Mountain Forest and Range Experiment Station, Fort Collins, Colo. 80523, USA.

MS. received 4 November 1992

MS. accepted 13 January 1993

\section{Introduction}

Large changes in climate are predicted in the next century as a result of increasing production of greenhouse gases. Natural systems of the future are expected to differ structurally from those observed today. Given these uncertainties, by what means are we to evaluate the potential effects of climate change on vegetation? One benchmark for measuring change came in 1972 with the launching of the first in a series of Landsat satellites. Much greater coverage is planned from a variety of satellites near the end of the present decade. With improvements in calibration, spectral sensitivity, spatial coverage, and data processing, new satellite sensors offer the potential to follow subtle changes in the biophysical characteristics of landscapes. We had the opportunity, as part of a NASA sponsored research project (Oregon Transect Ecosystem Research, OTTER), to investigate whether current remote sensing techniques 
might be used to assess constraints on photosynthesis, transpiration, decomposition, and other related ecosystem processes. We assert that changes in essential ecosystem processes are potential forecasters of impending change in ecosystem structure.

In this paper we focus on estimating photosynthesis and growth. Current process models use detailed information on the physiological status and local environment to evaluate these variables daily, seasonally, and yearly (Rumning \& Coughlan, 1988). In this study we seek to generalize for a wide range of species and to minimize the information required for seasonal integration. From ground measurements, we estimate the visible fraction of solar radiation intercepted by forest canopies and the constraints on utilizing the intercepted radiation due to freezing temperatures, drought, and high atmospheric vapor pressure deficits. We compare annual estimates of utilized radiation against measured growth as a validation of the concept. We also consider the need for additional information in estimating growth of very old forests. We then consider remote sensing analogues for all of the ground-based measurements, with the goal of using remote sensing alone to predict photosynthesis and growth at regional and global scales.

\section{Study area and measurements}

The transect in Oregon (Fig. 1), is located near that established and described in detail by Gholz (1982). In June, 1989, we installed meteorological stations near the sites along the transect. The stations automatically recorded at hourly intervals: incoming short-wave solar radiation, air temperature, relative humidity, and precipitation. Descriptions of the vegetation and soils appear in Gholz (1982) and in Franklin \& Dyrness (1973). We estimated standing woody biomass of trees from diameter measurements made within $20-50$ circular plots $\left(50 \mathrm{~m}^{2}\right)$ using equations developed by Gholz, Grier, Campbell \& Brown (1979). Annual aboveground growth was derived using the same biomass equations with diameter as the independent variable (Table 1). Diameter growth was measured on increment cores extracted from the 1st, 5th, and 10 th tree of each species on each plot.

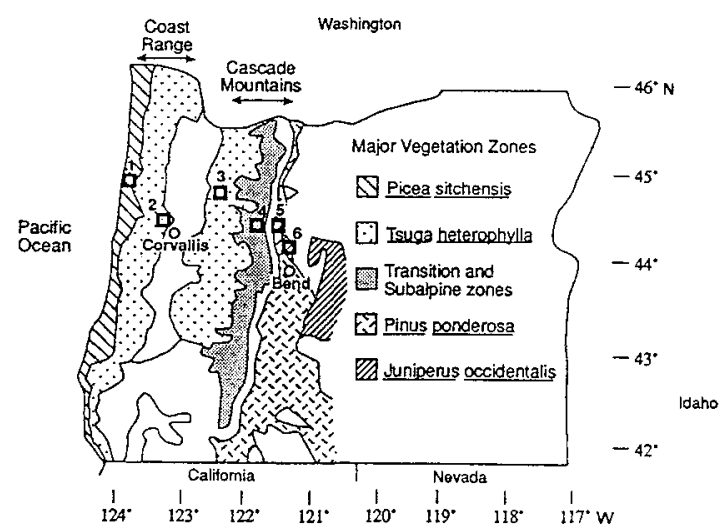

Fig. 1. Map of the study area in Oregon showing the location of meteorological stations (numbers 1-6) and major vegetation zones designated by the dominant tree species (after Gholz, 1982; Franklin \& Dyrness, 1973).

At the time of maximum canopy development in July we measured intercepted photosynthetically active radiation (IPAR) with a Sunfleck Ceptometer as described by Pierce \& Running (1988), (Table 1). The fraction of incident solar radiation intercepted by the coniferdominated forests remained nearly constant throughout the year. The deciduous forest of alder (Alnus rubra Bong.) initiated new leaves in April and dropped most foliage by late October. Soil drought, as it limits water uptake and stomatal conductance, was assessed by measuring predawn water potentials of trees periodically throughout the dry season (Table 2). In addition, we periodically collected data on photosynthetic rates and stomatal conductance at sites 1,2, 3 and 5 to confirm previous studies reported by Running (1976), Emmingham \& Waring (1977) and Waring \& Franklin (1979).

\section{Physiological analysis of climatic data}

The upper limits on growth are established by the amount of photosynthate accumulated throughout the year, or carried over from the previous year (Hunt, Martin \& Running, 1991). In many areas, intercepted photosyntheticallyactive radiation (IPAR) relates directly to photosynthesis (Charles-Edwards, 1979) and to growth (Monteith 1981; Cannell, 1989). In Oregon, the estimated annual IPAR did not 
Table 1. Characteristics of the study sites across the transect

\begin{tabular}{|c|c|c|c|c|c|c|c|}
\hline \multirow[b]{2}{*}{ Feature } & \multicolumn{7}{|l|}{ Site } \\
\hline & 1 & $1 \mathrm{~A}$ & 2 & 3 & 4 & $5^{*}$ & 6 \\
\hline Site Name & $\begin{array}{l}\text { Cascade head } \\
\text { (Old-Growth) }\end{array}$ & $\begin{array}{l}\text { Cascade Hcad } \\
\text { (Alder) }\end{array}$ & Warings Woods & Scio & Santiam Pass & Metolius & Juniper \\
\hline $\begin{array}{l}\text { Physiographic } \\
\text { Province }^{1}\end{array}$ & $\begin{array}{l}\text { Western coast } \\
\text { range }\end{array}$ & $\begin{array}{l}\text { Western coast } \\
\text { range }\end{array}$ & Interior valley & $\begin{array}{l}\text { Low-elevation } \\
\text { west } \\
\text { Cascades }\end{array}$ & $\begin{array}{l}\text { High Cascades } \\
\text { summit }\end{array}$ & $\begin{array}{l}\text { Eastern high } \\
\text { Cascades }\end{array}$ & $\begin{array}{l}\text { High lava } \\
\text { plain }\end{array}$ \\
\hline Dominant species & $\begin{array}{l}\text { Picea } \\
\text { sitchensis, } \\
\text { Tsuga } \\
\text { heterophylla }\end{array}$ & Alnus rubra & $\begin{array}{l}\text { Pseudotsuga } \\
\text { menziesii }\end{array}$ & $\begin{array}{l}\text { Tsuga } \\
\text { heterophylla, } \\
\text { Pseudotsuga } \\
\text { menziesii }\end{array}$ & $\begin{array}{l}\text { Tsuga } \\
\text { mertensiana }\end{array}$ & $\begin{array}{l}\text { Pinus } \\
\text { ponderosa }\end{array}$ & $\begin{array}{l}\text { Juniperus } \\
\text { occidentalis }\end{array}$ \\
\hline Elevation (m) & 240 & 200 & 170 & 800 & 1460 & 1030 & 930 \\
\hline Slope $(\%)$ & 12 & 0 & 13 & 12 & 0 & 0 & 0 \\
\hline Aspect & $130^{\circ}$ & $\cdots-$ & $160^{\circ}$ & $325^{\circ}$ & - & - & -- \\
\hline $\begin{array}{l}\text { Stem density } \\
(\text { no.ha } \\
-1)>5 \mathrm{~cm}\end{array}$ & 385 & 1793 & 226 & 870 & 1740 & 600 & 141 \\
\hline Basal area $\left(\mathrm{m}^{2} h a^{-1}\right)$ & 98.2 & 35 & 51.3 & 67 & 83.3 & 6.8 & 9.3 \\
\hline Percent IPAR & 96.4 & 93.7 & 94.1 & 99.5 & 61.4 & 28.6 & 22.0 \\
\hline
\end{tabular}

${ }^{1}$ Physiographic provinces from Franklin and Dyrness (1973). 
Table 2. Minimum monthly predawn water potentials (MPa) for sites along the Oregon Transect, 1990-1991

\begin{tabular}{lllllll}
\hline & \multicolumn{1}{l}{ Site } \\
\cline { 2 - 7 } Month & 1 & 2 & 3 & 4 & 5 & 6 \\
\hline May & - & -0.55 & -0.55 & - & -0.53 & -1.08 \\
June & -0.37 & -0.75 & -0.55 & -0.58 & -0.53 & -0.95 \\
July & - & -1.08 & - & -0.72 & -0.72 & -2.20 \\
Aug. & - & -1.76 & - & -0.61 & -0.76 & -2.20 \\
Sept. & - & -1.70 & -0.65 & - & -1.53 & - \\
Oct. & -0.70 & -1.96 & -0.65 & -0.69 & -1.82 & -2.50 \\
\hline
\end{tabular}

relate well to growth (Fig. 2). From previous research, we recognize that much of the radiation intercepted during drought, frost, or high humidity deficits cannot be utilized due to stomatal closure. To take these physiological constraints into account, we developed some simple algorithms to calculate the amount of intercepted radiation actually utilized each day (Table 3 ). We have purposely defined broad thresholds and responses as these are more likely to apply to the wide range of species found across Oregon and can be derived from standard weather data (Running, Nemani \& Hungerford, 1987).

The difference between IPAR and Utilized PAR represents the restrictions that climatic variables place on photosynthesis throughout the year. In our study, the climatic constraints ranged from less than $10 \%$ for the coastal rainforest to $>75 \%$ where juniper (Juniperus occi-

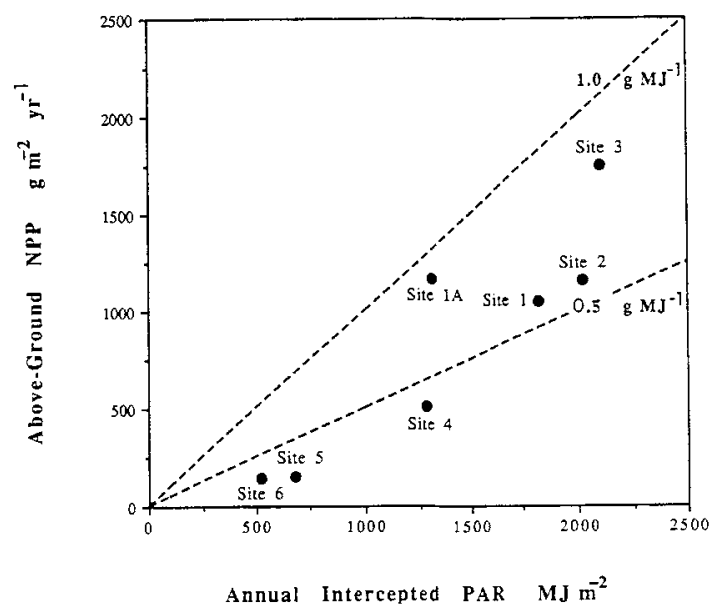

Fig. 2. Estimates of aboveground net primary production from annual intercepted PAR. Dashed lines express production rates ( $g$ of dry matter accumulated per MJ of PAR intercepted). Linear $r^{2}=0.84$.
Table 3. Criteria for reducing intercepted PAR, based on physiological thresholds applicable to all major tree species in Oregon

Freezing temperatures

- If less than $-2^{\circ} \mathrm{C}$, assume no radiation utilized for 24-hour period

Soil drought

- If predawn water potential less than $-1.5 \mathrm{MPa}$, assume no radiation utilized

- If predawn water potential is between -1.0 to $-1.5 \mathrm{MPa}$, assume half radiation utilized

Vapour pressure deficits (VPD)

- If VPD exceeds $25 \mathrm{mb}$, assume no radiation utilized - If VPD is between 15 to $25 \mathrm{mb}$, assume half radiation utilized

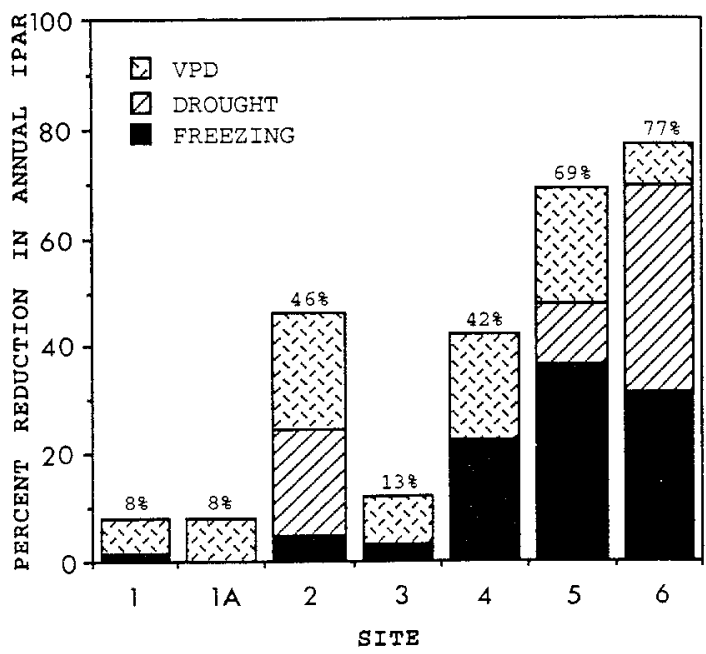

Fig. 3. The fraction of intercepted radiation not utilized by the various forests is shown as a function of freezing temperatures, drought, and excessive vapor pressure deficits (VPD). The total reduction in IPAR that could be utilized ranged from less than $10 \%$ at the coastal hemlock forest (Site 1) to $77 \%$ at the juniper woodland (Site 6). After Runyon (unpublished).

dentalis Hook) occurs (Fig. 3). Utilized PAR correlated closely with measured aboveground net primary production (NPP), with an aboveground efficiency of $1.0 \mathrm{~g}$ of biomass $\mathrm{MJ}^{-1}$ (Fig. 4). Only one plot, an old-growth Sitka spruce (Picea sitchensis (Bong.) Carr.)/Western hemlock (Tsuga heterophylla (Raf.) Sarg.) forest, showed demonstrably less growth than predicted. Although old-growth forests are rare today, they are important because they bear witness to historical changes in climate and may be more susceptible to future changes than younger forests. Their physiology is different from younger forests in at least two important 


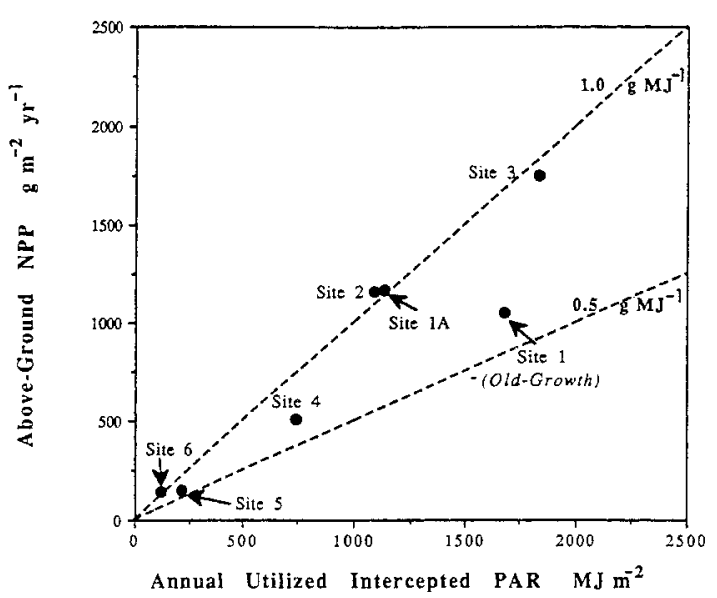

Fig. 4. Estimated aboveground Net Primary Production (NPP) compared to utilized PAR. This explains $98 \%$ of the variance in NPP for the range of forest stands across the Oregon transect. The old-growth stand was excluded from the regression. It effectively utilized $30 \%$ less PAR than indicated. Deducting an additional $100 \mathrm{MJ} \mathrm{m}^{-2}$ for increased maintenance respiration compared to an adjacent 120 -year-old stand brings the calculated NPP in line with that observed. After Ryan (unpublished).

ways. First, they maintain old branches that have progressively less ability to conduct water efficiently as they grow in length (Tyree \& Sperry, 1988). Secondly, they have more living cells in their biomass than younger forests. These extra cells require carbohydrates for maintenance that could otherwise go toward growth (Ryan, 1990).

In old-growth Douglas-fir (Pseudotsuga menziesii (Mirb.) Franco), Lodgepole pine (Pinus contorta Dougl. ex Loud.), and Ponderosa pine (Pinus ponderosa Doug. ex Loud.) forests it has been estimated that stomatal conductance and photosynthesis are reduced about $30 \%$ below that observed in forests where trees still grow in height (Kline, Reed, Waring \& Stewart, 1976; Ryan, 1991; Yoder, 1992). The additional increase in maintenance respiration associated with increasing biomass was estimated using formulas outlined by Ryan (1990) that take into account sapwood volume, appropriately weighed mean annual temperature and maintenance respiration rates measured on western hemlock trees in Oregon (Ryan, unpublished). Maintenance respiration by the old-growth forest at site 1 was estimated at $230 \mathrm{~g} \mathrm{C} \mathrm{m}^{-2}$ $\mathrm{yr}^{-1}$, only $60 \mathrm{~g} \mathrm{C} \mathrm{m}^{-2} \mathrm{yr}^{-1}$ more than in an adjacent 120-year-old stand (Ryan, unpublished). Assuming dry matter contains 50\% carbon, this translates into about $100 \mathrm{~g} \mathrm{C} \mathrm{m}^{-2}$ $\mathrm{yr}^{-1}$ of biomass, taking into account the respiration cost of growth.

Reduced photosynthesis by old-growth forests, not maintenance respiration, appeared to be the major constraint on growth. We calculated the NPP of the old-growth stand, assuming first a $30 \%$ reduction in utilized PAR (1 $640 \mathrm{MJ} \mathrm{m}^{-2}$ reduced to $1150 \mathrm{MJ} \mathrm{m}^{-2}$ ). We further reduced this estimate by $100 \mathrm{MJ} \mathrm{m}^{-2}$ to account for the increase in maintenance respiration. With a conversion efficiency of $1.0 \mathrm{~g}$ $\mathrm{MJ}^{-1}$, the predicted and measured NPP were essentially the same ( $1050 \mathrm{~g} \mathrm{~m}^{-2} \mathrm{yr}^{-1}$ compared to $1030 \mathrm{~g} \mathrm{~m}^{-2} \mathrm{yr}^{-1}$ as noted in Table 1 ).

\section{Selecting remote sensing techniques to predict photosynthesis and growth}

The above empirical analysis of the OTTER field measurements suggests that a relatively robust estimate of aboveground primary production may be evaluated from a limited number of canopy and environmental variables. These include:

1. incident PAR radiation

2. fraction of PAR intercepted by the canopy

3. air temperature

4. atmospheric vapor pressure deficit

5. environmental drought, as defined by predawn leaf water potential

6. presence of "old-growth" stands.

Remotely sensed measurements of reflected solar and emitted terrestrial radiation have the potential for fulfilling these measurement requirements (Goward, 1989). In the Oregon transect study we collected remotely sensed measurements which address these biophysical variables. The measurements include standardized laboratory and field studies, aircraftbased observations and satellite data. These data have been compiled in a computer Pilot Land Data Base at NASA Ames Research Center. Data processing and analysis are now underway.

The principles for derivation of these biophysical measurements from remotely sensed observations have developed over the last quarter century. In general, the measured spectral radiant fluxes are diagnostic of surface and atmos- 
pheric phenomena because the molecular composition of terrestrial materials alters the spectral radiant flux through selective absorption and scattering. The magnitude of the observed alteration is diagnostic of the presence and magnitude of the terrestrial phenomenon.

\section{Incident PAR solar radiation}

The maximum daily insolation possible at any given location can be calculated from earth-sun relations. However, the solar radiation which reaches the biosphere is attenuated by cloud reflectance, scattering by molecules and aerosols and absorption by water vapor, carbon dioxide and ozone. Estimates of these atmospheric reductions in incident solar radiation may be derived from a number of satellite sensors. The most precise estimates may be acquired from geostationary orbits, where sensors "stare" at the earth. From these satellites, half-hourly updates of atmospheric conditions are possible (Tarpley, 1979). However, the data handling and processing demands with this approach are exceptionally large. A simpler approach is to use a one-time-per-day observatory in a sunsynchronous, polar orbit (Pinker, 1990). One of the most novel approaches developed to date to estimate the incident PAR flux uses noon-time ultraviolet measurements from the Total Ozone Mapping Spectrometer (TOMS; Eck \& Dye, 1991). When daily estimates of radiation from the TOMS satellite are integrated for each month, good agreement with ground measurements results (Fig. 5).

\section{Canopy-intercepted PAR}

Combinations of visible and near-infrared spectral reflectance from the earth are related to fractional capacity of vegetation canopies to absorb PAR radiation (Kumar \& Monteith, 1981; Asrar, Fuchs, Kanemasu \& Hatfield, 1984; Sellers, 1985; Gallo, Daughtry \& Bauer, 1985; Goward \& Huemmrich, 1992). One such combination is the normalized difference vegetation index (NDVI), which is the difference of these spectral measurements divided by their sum. Laboratory studies conducted on Douglas-fir canopies demonstrated that both chlorophyll concentrations and leaf structure affect this NDVI signal (Yoder, 1992). As a result, photo-

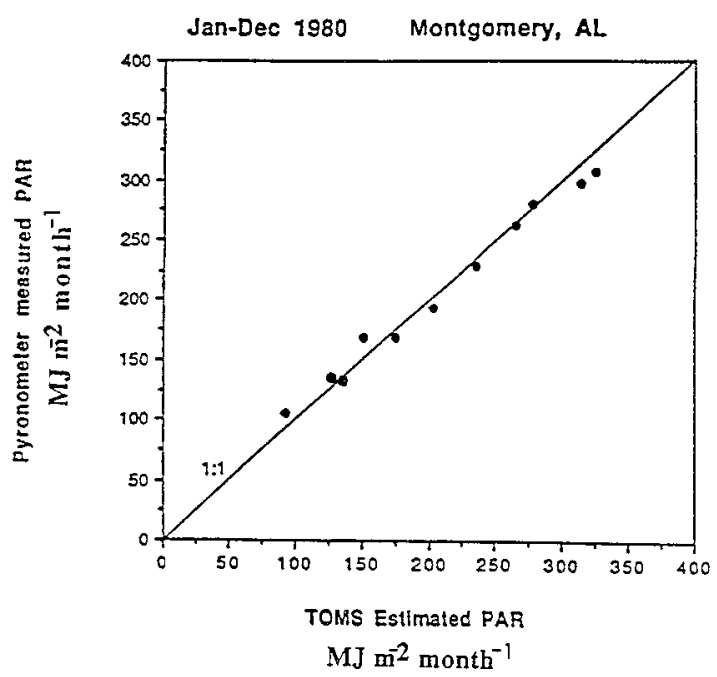

Fig. 5. Daily satellite measurements of cloud cover determined by ultra-violet reflectance allows monthly estimates of incident PAR radiation to match those measured at ground stations; $r^{2}=0.98$. (Eck \& Dye, 1991).

synthesis, measured under near optimal conditions, was closely correlated to NDVI values (Hatfield, Asrar \& Kanemasu, 1984; Yoder, 1992). In the field we found a good relationship between NDVI determined at $300 \mathrm{~m}$ above each stand and intercepted PAR measured beneath (Fig. 6). Differences in chlorophyll concentrations which exist in foliage across the transect have not yet been examined relative to the remotely sensed measurements (P. Matson and

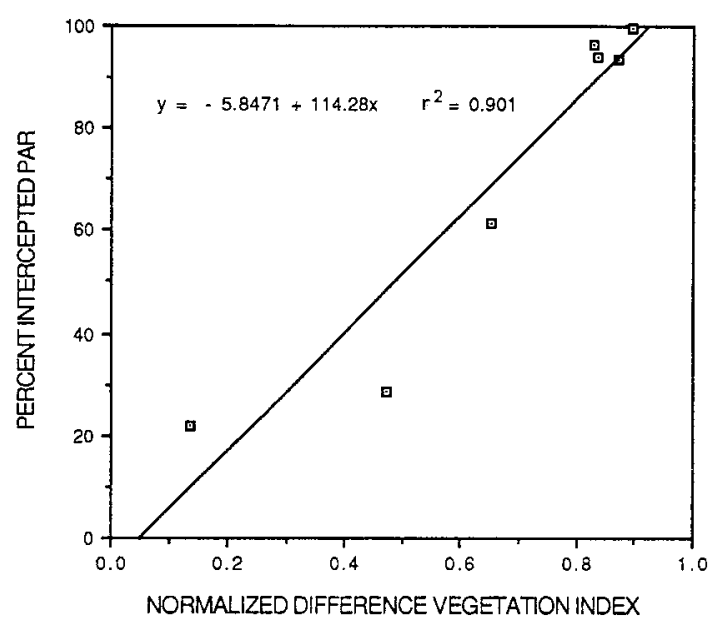

Fig. 6. The normalized difference vegetation index (NDVI) determined from $300 \mathrm{~m}$ altitude related closely to IPAR measured beneath the forest canopy ( $\mathrm{McCreight}$ \& Runyon, unpublished). 
C. Billow, unpublished data from NASA Ames

Research Center, Moffet Field, CA).

Derivation of these spectral measurements from spacecraft is also possible, at least at intervals between 10 days and a month (Goward, Markham, Dye, Dulaney \& Yang, 1991). Fortunately, these periodic measurements provide an estimate of fractional PAR absorptance that is robust through overcast periods, which allows for interpolation of photosynthetic activity between successive measurements (Goward \& Huemmrich, 1992). For the Oregon study NOAA satellite data, when corrected for variation in atmospheric clarity, provided regular updates to NDVI patterns across the entire transect (Spanner, unpublished, NASA Ames Research Center, Moffet Field, CA). These observations in general agree well with the aircraft and ground measurements with the exception of the winter period where deviations of uncertain origin are observed.

\section{Air temperature, drought and vapor pressure deficit}

In logical order, those days with temperatures below freezing, with evidence of drought, and (or) extreme humidity deficits will reduce the IPAR utilized (Table 3). Temperature is a critical variable in calculating all three of these constraining factors and is important for its control on other ecosystem processes as well.

Measurement of terrestrial thermal infrared (TIR) emissions provide an estimate of the surface temperature. For non-desert regions of the earth the emissivity factor in Planck's equation is approximately 0.98 . Atmospheric attenuation, predominately resulting from water vapor $a b$ sorptance, may be reasonably addressed using two or more spectral measurements in the $8-14 \mu \mathrm{m}$ region (Price, 1984). It is therefore possible to estimate surface kinetic temperatures from spectral TIR observations. Such observations are acquired by the NASA TIMS (Thermal Infrared Multispectral Scanner) aircraft instrument and the satellite-based NOAA Advanced Very High Resolution Radiometer (AVHRR).

The thermal IR signal can be used to estimate air temperature because closed-canopy forests are within a few degrees of ambient air temperatures (Luvall \& Holbo, 1989). A combination of the NDVI from the visible and near-infrared measurements and the TIR measurements permits assessment of closed-canopy conditions and the temperature estimated for this condition typically is within $2^{\circ} \mathrm{C}$ of air temperature with an $r^{2}>0.95$ (McCreight, unpublished).

Drought stops transpiration. A rise in leaf temperature above that of ambient air occurs, and is associated with a drying and warming of background litter and soils (Aston \& van Bavel, 1972). The drying is closely correlated with increasing drought stress, as measured by predawn water potential (Fogel \& Cromack, 1977). We can interpret drought-induced temperature responses in a scene if a range in vegetation density is present (Goward \& Hope, 1989; Nemani \& Running 1989; Price, 1990). Along the transect, those sites where drought occurred (Table 2) were characterized by large differences in the surface temperature over a range in NDVI values (Fig. 7). Under conditions where soil water was not limiting, the complex of ecosystems showed less than a $5^{\circ} \mathrm{C}$ difference in surface temperature, across the same range of NDVI measurements.

The atmospheric humidity deficit, expressed as vapor pressure deficit, affects stomatal aperture, even when soil water is not limiting. To estimate the vapor pressure deficit of the air requires, in addition to ambient temperature estimates, some measure of the water vapor content. Water vapor is the primary attenuator of TIR radiance but its impact is wavelengthdependent. It is therefore possible to estimate the amount of water vapor in the atmospheric column between the sensor and the ground by collecting dual-band spectral TIR observations (Justice, Eck, Tanre \& Holben, 1991). Because the majority of water vapor in the column is near the surface an estimate of surface vapor pressure deficit can be computed with this measurement and the estimated ambient air temperature (Fig. 8).

\section{Old-growth forests}

Standing biomass is important in estimating maintenance respiration. An accurate estimate of height is desirable to recognize when growth has stopped, and photosynthetic rates, defined in our model as a $30 \%$ reduction in utilized PAR, are applied. Conventional stereo images 


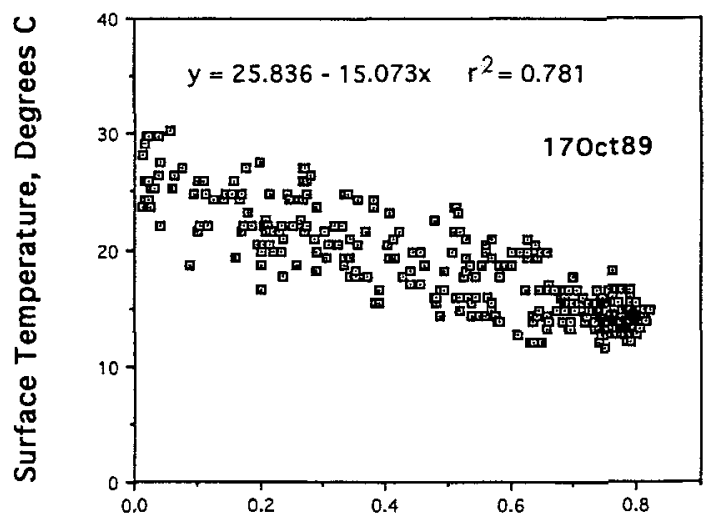

Normalized Difference Vegetation Index

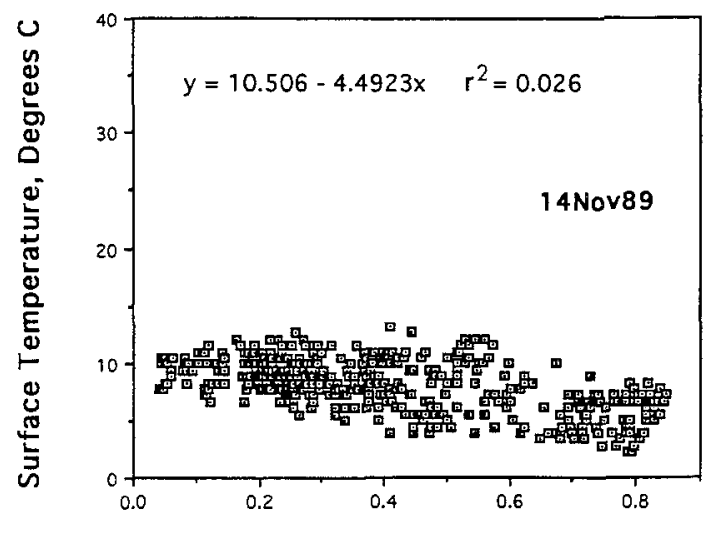

Normalized Difference Vegetation Index

Fig. 7. Remotely sensed evidence of seasonal drought. Slope of surface temperature/NDVI steepens with drought. Near site 2, the end of the dry period in October revealed surface temperature variations in excess of $20^{\circ} \mathrm{C}$, indicative of extreme drought stress on all vegetation (Goward, McCreight \& Waring, unpublished).

are useful for estimating tree heights and standing biomass but images from satellites generally cover too much area in a scene to provide the desired resolution for estimating canopy height. As an alternative, variation in near-infrared and short-wave-infrared reflectance have been used in the Pacific Northwest region to distinguish old-growth forests from mature, and other age classes (Cohen \& Spies, 1992). The local variation observed in temperature over a scene during the day may also provide an indirect measure of forest structure (Luvall \& Holbo, 1989). Tree size can also be assessed by analyzing spectral differences in shadow observed at

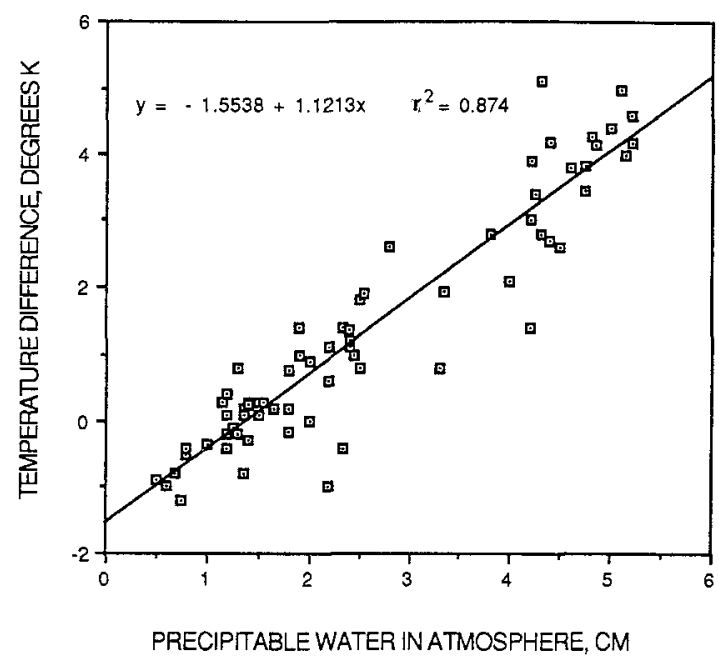

Fig. 8. Estimation of atmospheric water vapor content from two spectral wave lengths of thermal infrared radiance (after Justice et al., 1991).

varying sun angles ( $\mathrm{Li} \&$ Strahler, 1985; Franklin \& Hiernaux, 1991).

In summary, currently available satelliteborne sensors offer the potential to obtain key biophysical measurements with which to characterize photosynthetic activity in the biosphere. Combinations of spectral observations from the ultraviolet, visible, near-infrared, shortwave infrared and thermal infrared provide critical information on energy availability in conjunction with physiological and environmental constraints which determine current rates of photosynthetic activity. The great advantage of satellite observations is that they provide consistant global coverage and fine spatial resolutions. The most serious current limitation is that most of these satellites provide only periodic measurements at intervals between 10 days and a month. This level of temporal precision may miss some critical events needed to monitor biospheric photosynthetic activity accurately. Within the Oregon Transect study we are now working toward a test of this methodology which will provide at least one critical evaluation of this approach.

\section{Conclusions}

Research being carried out under the NASA OTTER project is exploring the potential for 
monitoring biospheric activity with satellitebased remote sensing observations. A generalized model of biospheric activity is being investigated which considers photosynthetic activity as a balance between intercepted solar radiation and factors which limit the capacity of vegetation to utilize this energy. Results from field measurements indicate that the effects of air temperature, drought and atmospheric vapor pressure deficit explain much of the variance in rates of aboveground production per unit inter- cepted PAR radiation. The effects of stand age and nutrient status are also being considered. Remotely sensed measurement procedures to consider each of these environmental and physiological factors are under investigation. Preliminary results indicate that these methods provide the needed information to characterize biospheric activity across the Oregon Transect. Generalization to global scales will depend on successful execution of similar studies in other biospheric regions of the globe.

\section{References}

Asrar, G., Fuchs, M., Kanemasu, E.T. \& Hatfield, J.L. 1984. Estimating absorbed photosynthetic radiation and leaf area index from spectral reflectance in wheat. Agronomy Journal 76, 300-314.

Aston, A.R. \& van Bavel, C.H.M. 1972. Soil surface water depletion and leaf temperature. Agronomy Journal 64, 368-373.

Cannell, M.G.R. 1989. Physiological basis of wood production: a review. Scandinavian Journal of Forest Research 4, 459-490.

Charles-Edwards, D.A. 1979. Photosynthesis and crop growth. In Photosynthesis and plant development (ed. R. Marcelle, H. Clijsters \& M. van Pouke), 111-124. The Hague: Junk.

Eck, T. \& Dye, D. 1991. Satellite estimation of photosynthetically active radiation at the Earth's surface. Remote Sensing of Environment 38, 135-146.

Cohen, W.B. \& Spies, T.A. 1992. Estimating structural attributes of Douglas-fir/western hemlock forest stands from LANDSAT and SPOT imagery. Remote Sensing of Environment 41, 1-18.

Emmingham, W.H. \& Waring, R.H. 1977. An index of photosynthesis for comparing sites in western Oregon. Canadian Journal of Forest Research 7, 165-174.

Fogel, R. \& Cromack Jr., K. 1977. Effect of habitat and substrate quality on Douglas-fir litter decomposition in western Oregon. Canadian Journal of Botany 55, 1632-1640.

Franklin, J. \& Hiernaux, P.H.Y. 1991. Estimating foliage and woody biomass in Sahelian and Sudanian woodlands using a remote sensing model. International Journal of Remote Sensing 12, 1387-1404.

Franklin, J.F. \& Dyrness, C.T. 1973. Natural vegetation of Oregon and Washington. Corvallis, Oregon, USA: Oregon State University Press.

Gallo, K.P., Daughtry, C.S.T. \& Bauer, M.E. 1985. Spectral estimation of absorbed photosynthetically active radiation in corn canopies. Remote Sensing of Environment 17, 221-232.

Gholz, H.L. 1982. Environmental limits on aboveground net primary production, leaf area, and biomass in vegetation zones of the Pacific Northwest. Ecology $63,461-481$

Gholz, H.L., Grier, C.C., Campbell, A.G. \& Brown, A.T. 1979. Equations for estimating biomass and leaf area of plants in the Pacific Northwest. Forest Research
Laboratory, Oregon State University, Corvallis, Oreg. Research Paper 41.

Goward, S.N. 1989. Satellite bioclimatology. Journal of Climate 7, 710-720.

Goward, S.N. \& Huemmrich, K.F. 1992. Vegetation canopy PAR absorptance and the normalized difference vegetation index: An assessment using the SAIL model. Remote Sensing of Environment 39, 119-140.

Goward, S.N. \& Hope, A.S. 1989. Evapotranspiration from combined reflected solar and emitted terrestrial radiation: Preliminary FIFE results from AVHRR data. Advances in Space Research 9, 239-249.

Goward, S.N., Markham, B., Dye, D.G., Dulaney, W. \& Yang, J. 1991. Normalized difference vegetation index measurements from the advanced very high resolution radiometer. Remote Sensing of Enironment 35, $257-277$.

Hatfield, J.L., Asrar, G. \& Kanemasu, E.T. 1984. Intercepted photosynthetic active radiation estimated by spectral reflectance. Remote Sensing of Environment $14,65-75$.

Hunt Jr, E.R., Martin, F.C. \& Running, S.W. 1991. Simulating the effects of climatic variation on stem carbon accumulation of a ponderosa pine stand: comparison with annual growth incremental data. Tree Physiology 9, 161-171.

Justice, C.O., Eck, T., Tanre, D. \& Holben, B.N. 1991. Effect of water vapor on the normalized difference vegetation index derived for the Sahelian Region from NOAA AVHRR data. International Journal of Remote Sensing 12, 1165-1188.

Kline, J.R, Reed, K.L., Waring, R.H. \& Stewart, M.L. 1976. Field measurements of transpiration in Douglasfir. Journal of applied Ecology 13, 273-283.

Kumar, M. \& Monteith, J.L. 1981. In Remote sensing of crop growth. Plants in the Daylight Spectrum (ed. $\mathrm{H}$. Smith), 134-144. New York: Academic Press.

Li, X. \& Strahler, A.H. 1985. Geometric-optical modeling of a conifer forest canopy. I.E.E.E. Transactions on Geoscience and Remote Sensing 23, 703-721.

Luvall, J.C. \& Holbo, H.R. 1989. Measurements of shortterm thermal responses of coniferous forest canopies using thermal scanner data. Remote Sensing of Environment 27, 1-10.

Monteith, J.L. 1981. Climatic variation and the growth 
of crops. Quarterly Journal of the Royal Meteorological Society 107, 749-774.

Nemani, R.R. \& Running, S.W. 1989. Estimation of surface resistance to evapotranspiration from NDVI and thermal-IR AVHRR data. Journal of Climate and Applied Meteorology 28, 276-294.

Pierce, L.L. \& Running, S.W. 1988. Rapid estimation of coniferous forest leaf area using a portable integrating radiometer. Ecology 69, 1762-1767.

Pinker, R.T. 1990. Satellites and our understanding of the surface energy balance. Palaeogeography, Palaeoclimatology, Palaeoecology 82, 321-342.

Price, J.C. 1984. Land surface temperature measurements from the split window channels of the NOAA 7 advanced very high resolution radiometer. Journal of Geophysical Research 89 D5, 7231-7237.

Price, J.C. 1990. Using spatial context in satellite data to infer regional scale evapotranspiration. IEEE Transactions on Geoscience and Remote Sensing 28, 940-948.

Running, S.W. 1976. Environmental control of leaf water conductance in conifers. Canadian Journal of Forest Research 6, 104-112.

Running, S.W. \& Coughlan, J.C. 1988. A general model of forest ecosystem processes for regional applications. I. Hydrologic balance, canopy gas exchange and primary production processes. Ecological Modelling 42, 125-154.

Running, S.W., Nemani, R.R. \& Hungerford, R.D. 1987. Extrapolation of synoptic meteorological data in mountainous terrain, and its use for simulating forest evapotranspiration. Canadian Journal of Forest Research 17, 472-483.

Ryan, M.G. 1990. Growth and maintenance respiration in stems of Pinus contorta and Picea engelmanni. Canadian Journal of Forest Research 20, 48-57.
Ryan, M.G. 1991. A simple method for estimating gross carbon budgets for vegetation in forest ecosystems. Tree Physiology 9, 255-266.

Sellers, P.J. 1985. Canopy reflectance, photosynthesis, and transpiration. International Journal of Remote Sensing 6, 1335-1372.

Tarpley, J.D. 1979. Estimating incident solar radiation at the surface from geostationary satellite data. Journal of Applied Meteorology 18, 1172-1181.

Tyree, M.T. \& Sperry, J.S. 1988. Do woody plants operate near the point of catastrophic xylem dysfunction caused by dynamic water stress? Plant Physiology $88,574-580$.

Waring, R.H. \& Franklin, J.F. 1979. Evergreen coniferous forests of the Pacific Northwest. Science 204, $1380-1386$.

Yoder, B.J. 1992. Photosynthesis of conifers: influential factors and potential for remote sensing. Ph.D. thesis, Oregon State University, Corvallis, OR.

\section{Acknowledgements}

Many scientists involved in the Oregon Transect Ecosystem Project shared unpublished findings to permit this synthesis. To all we are grateful. Jeanne Panek and Beverly Law made helpful suggestions on earlier drafts of the manuscript. David Peterson, Branch Chief at NASA Ames Research Center, deserves special recognition for initiating the project. Support from Maurice Averner, Diane Wickland and Anthony Janetos at NASA Headquarters was essential, as was coordination of the NASA research planes under the direction of James Huning. Work supported here was under NASA grant NAGW-1717. 


\title{
Description of crown structure for light interception models: angular and spatial distribution of shoots in young Scots pine
}

\author{
PAULINE STENBERG \\ Department of Forest Ecology, University of Helsinki, Finland
}

HEIKKI SMOLANDER

The Finnish Forest Research Institute, Suonenjoki Research Station, Finland

SEPPO KELLOMÄKI

University of Joensuu, Faculty of Forestry, Joensuu, Finland

\begin{abstract}
Stenberg, P., Smolander, H. \& Kellomäki, S. 1993. Description of crown structure for light interception models: Angular and spatial distribution of shoots in young Scots pine. In: Management of structure and productivity of boreal and subalpine forests (eds S. Linder \& S. Kellomäki). Studia Forestalia Suecica 191. 94 pp. ISSN 0039-3150, ISBN 91-576-4822-0.

The angular and spatial distributions of shoots in nine young Scots pine (Pinus sylvestris L.) stands are described. For determining these distributions the azimuth, zenith angle and spatial coordinates of shoots in 25 sample trees were measured. The sample trees were $7-19$ years old, and 1-7 $\mathrm{m}$ tall.

No preferred azimuth of shoots was observed. In larger trees the spherical distribution provided a reasonably good approximation to the shoot orientation but in smaller trees the shoot inclination was closer to the horizontal than is implied by the spherical distribution. The frequency distribution of shoot inclination varied with relative depth in the crown; in the upper crown a more vertical inclination of shoots dominated whereas in the lower crown shoots were more horizontal. The number density of shoots in different horizontal layers varied with distance from the stem.

Observed distributions of shoot zenith angle and vertical and horizontal position of shoots were successfully approximated by the beta distribution, specified by measured mean and variance and a fixed range. This implies that in describing the structure of a Scots pine crown, the angular and spatial distribution of shoots can be determined by measuring the mean and variance of these distributions as a function of crown depth.
\end{abstract}

Key words: Pinus sylvestris, crown architecture, light penetration, shoot orientation, STAR, clumping, beta distribution, spherical distribution.

P. Stenberg, Department of Forest Ecology, P.O. Box 24, SF-00014 University of Helsinki, Finland.

H. Smolander, The Finnish Forest Research Institute, Suonenjoki Research Station, SF-77600 Suonenjoki, Finland.

S. Kellomäki, University of Joensuu, Faculty of Forestry, P.O. Box 111, SF-80101 Joensuu, Finland.

MS. received 4 November 1992

MS. accepted 30 January 1993

\section{Introduction}

Operational descriptions of crown structure are needed for models of light interception. In light interception models a statistical approach is commonly used to describe the spatial distribution of leaf area in the crown, and the penetra- tion of direct radiation is expressed as the probability of a gap in the specified direction. This approach is based on the assumption that the locations of some chosen foliage elements (e.g. leaves or shoots) are statistically indepen- 
dent random variables with a specified probability density function in the crown envelope. Light penetration through the crown can then be expressed as an exponential function of projected foliage area density along the solar beam (Mann, Curry, Hartfield \& Demichele, 1977). In addition to the spatial probability density function of foliage elements, the total area of foliage projections is required as input to the model. The projected area of a foliage element depends on its size, shape and orientation. Thus, crown structure may be defined in terms of the geometrical structure and the angular and spatial distribution of foliage elements.

The spatial density function of foliage elements is usually derived by dividing the crown envelope into subvolumes (cells) and determining the amount of foliage in each of them. A statistical distribution is then fitted to the data, assuming that within a cell, foliage elements are uniformly and independently located. Coniferous crowns are characterised by a very discontinuous spatial density of needle area. For example, Whitehead, Grace \& Godfrey (1990) described needle area density in six young Monterey pine (Pinus radiata D. Don) trees by dividing the crowns into cells of $10 \mathrm{~cm}^{3}$, and found that the proportion of empty cells was $77-92 \%$. They calculated that the assumption of a uniform needle area density throughout the crown would overestimate light interception by $20-30 \%$.

However, the clumping of needles makes it difficult to describe accurately the spatial distribution of needle area in a coniferous crown. For example, if the crown is divided into subvolumes which are larger than the size of a shoot, the clustering of needles into shoots (resulting in a non-uniform needle area density within a cell) will not be reflected in the obtained density function. As a result, the penetration of light through the cells may be underestimated, and light interception by the crown would consequently be overestimated.

To avoid the problem involved in deriving the spatial density function of needle area for the purpose of estimating light interception, it is proposed that the shoot could be a more appropriate unit in describing crown structure in conifers. In the approach taken in this study, the annual shoot constitutes the basic foliage ele- ment in modelling light interception by Scots pine crowns. Crown structure is described in terms of shoot geometry, and the statistical distributions of the location and orientation of shoots. The spatial and angular distributions of annual shoots in young Scots pine crowns were derived, on the basis of empirical measurements of azimuth, zenith angle and spatial coordinates of shoots in 25 sample trees from 9 stands.

\section{Definitions}

Given the directional distribution of incident radiation and the areas of crown projection (crown shadows) in all directions, the amount of light (PAR) intercepted by a crown can be calculated. The crown shadow area equals the projection of the crown envelope reduced by the area of gaps (the sunlit area). In light interception models, therefore, the key problem is to derive an expression for the probability of a gap through a crown in any given direction. For this purpose a mathematical description of crown structure is needed. The theoretical background to the measurements made in this study is presented briefly below.

\section{Theory for direct sunlight penetration}

The statistical approach to describing foliage position is based on the assumption that "the crown consists of a number $(n)$ of foliage elements the locations of which are identically and independently distributed random variables with density function $(f)^{\prime \prime}$. Considering the shoots as the basic foliage elements, the density function is thus defined so that $f(x, y, z) d x d y d z$ denotes the probability of a shoot to be located in the elementary volume $d x d y d z$. The probability of a gap $\left(P_{\mathrm{g}}\right)$ through the crown in the direction of the sun is then given by:

$$
P_{g}=\exp \left[-\int_{s} n \bar{a} f(x, y, z) d s\right]
$$

where $n \bar{a}$ denotes the total projected area (silhouette area) of the shoots ( $\bar{a}=$ mean silhouette area of the shoots), and $S$ denotes the path of the solar beam through the crown. The quantity $n \bar{a} f(x, y, z)$ expresses the density of projected shoot area in the crown (sum of shoot silhouette areas per unit volume). The projected (silhouette) area of a shoot depends on shoot struc- 
ture and shoot orientation relative to the beam direction.

The total needle surface area of the crown is $n \bar{l}_{\mathrm{s}}$, where $\bar{l}_{\mathrm{s}}$ denotes the mean total needle surface area per shoot, and the total needle surface area density is consequently $f_{\mathrm{L}}(x, y, z)=$ $n \bar{l}_{\mathrm{s}} f(x, y, z)$. Let $G_{\mathrm{s}}=a / \bar{l}_{\mathrm{s}}$ denote the mean shoot silhouette area (in the sun's direction) divided by the mean needle surface area of a shoot. The projected shoot area density may thus be written as $n \bar{a} f(x, y, z)=G_{\mathrm{s}} f_{\mathrm{L}}(x, y, z)$, and Eq. 1 transforms into:

$$
P_{g}=\exp \left[-\int_{s} G_{s} f_{L}(x, y, z) d s\right]
$$

Equations (1) and (2) were derived on the assumption that the mean shoot silhouette area $(\bar{a})$ and mean needle area per shoot $\left(\bar{l}_{s}\right)$ are statistically independent of location in the crown, and must be modified when this is not true. Formally this is done by replacing them with location-dependent variables, $a(x, y, z)$ and $l_{\mathrm{s}}(x, y, z)$. In Eq. 2, accordingly, $G_{s}$ should be replaced by $G_{s}(x, y, z)=a(x, y, z) / l_{s}(x, y, z)$, the mean ratio of shoot silhouette area to total needle area around the location $(x, y, z)$.

\section{Spatial density of shoots}

The spatial density of shoots in the tree crowns will be described assuming that: (i) the crowns are symmetrical with respect to azimuth (i.e. the horizontal cross-section is a disc), and (ii) the density of shoots in the horizontal is independent of azimuth but depends on the relative depth in the crown.

Let $Z$ and $z$ denote the absolute and the relative depth in the crown and let $R$ and $r$ denote the absolute and relative distance from the stem. We have thus $z=Z / H$ and $r=R / R(Z)$, where $H$ is crown length and $R(Z)$ is the crown radius at depth $Z$.

Let $f_{v}(z)$ denote the normalized vertical density of shoots and let $f_{h}(r \mid z)$ denote the normalized horizontal density of shoots at the relative depth $z$. These functions are defined so that they satisfy the equations:

$$
\int_{0}^{1} f_{v}(z) d z=1
$$

and

$$
2 \pi \int_{0}^{1} f_{h}(r \mid z) r d r=1
$$

Note that $f_{v}(z) d z$ denotes the proportion of shoots situated vertically between $z-d z / 2$ and $z+d z / 2$, and $2 \pi f_{h}(r \mid z) r d r$ is the proportion of shoots (in a horizontal layer at the relative depth $z$ ) situated between the relative distances $r-d r / 2$ and $r+d r / 2$ from the stem.

Substituting $d z=d Z / H, r=R / R(Z)$ and $d r=$ $d R / R(Z)$, the denormalized density of shoots in the crown can now be expressed by the function:

$$
f(Z, R)=\frac{f_{v}(z) f_{h}(r \mid z)}{H R(Z)^{2}}
$$

satisfying the conditions $f(Z, R) d Z d R=f_{v}(z) d z$ $f_{h}(r \mid z) r d r$, and

$$
2 \pi \int_{0}^{H} \int_{0}^{R(Z)} f(Z, R) R d Z d R=1
$$

\section{Angular distribution of shoots}

The angular distribution of shoots is defined by the joint density function $g(\theta, \phi)$ of the zenith angle $(\theta)$ and the azimuth $(\phi)$ of the shoot axes. The shoot zenith angle will be defined as belonging to the range $[0, \pi / 2]$, i.e. the shoot axis is considered to be pointing toward the upper hemisphere. If $\theta$ and $\phi$ are independent, as will be assumed in the following, we may write $g(\theta, \phi)=g_{i}(\theta) g_{a}(\phi)$, where $g_{i}$ is the density function of shoot zenith angle and $g_{a}$ the density function of shoot azimuth. These functions satisfy the equations:

$$
\int_{0}^{\pi / 2} g_{i}(\theta) \mathrm{d} \theta=1
$$

and

$$
\int_{0}^{2 \pi} g_{a}(\phi) d \phi=1
$$

A special case is the spherical distribution for which $g_{i}(\theta)=\sin \theta$ and $g_{a}(\phi)=1 /(2 \pi)$. For this distribution we have $g(\theta, \phi) d \theta d \phi=\sin \theta /(2 \pi) d \theta d \phi$, i.e. the number of shoot directions belonging to a given solid angle is proportional to the corre- 
sponding area on the unit sphere. Thus, the spherical distribution implies that the shoot axes have no preferred direction in space.

\section{Materials and methods}

The material consisted of 25 sample trees in nine young Scots pine stands in Eastern Finland $\left(62^{\circ} 47^{\prime} \mathrm{N}, 30^{\circ} 58^{\prime} \mathrm{E}, 140 \mathrm{~m}\right.$ a.s.1.), previously described in detail by Kurttio \& Kellomäki (1990). The nine stands were divided into four groups according to tree size (Table 1). In groups I-III, the orientation (zenith angle and azimuth) and position (height and distance from stem) of each shoot in the crowns were measured. In group IV, the orientation and position of shoots were measured in three branches (the longest, shortest and median branch) of every whorl. The material included measurements of shoot characteristics and (projected) needle area for a subsample of shoots from each crown. In this study only foliated shoots were considered. Shoots older than five years or with needles covering less than $20 \%$ of the length of the shoot axis, or both, were excluded.

The frequency distributions of shoot zenith angle and azimuth were determined separately for each group. In one group (III), the frequency distributions of shoot zenith angle were determined separately for each vertical quartile of the crowns, to analyze the effect of depth in the crown on shoot inclination.

As shown in Eq. 5, the density of shoots (proportion of shoots per unit volume) in a crown can be expressed in terms of crown dimensions and the normalized vertical and horizontal density functions $\left(f_{v}(z)\right.$ and $\left.f_{h}(r \mid z)\right)$. These functions were determined on the basis of measurements

Table 1. Characteristics of the study stands

\begin{tabular}{lcccccc}
\hline Group & $\begin{array}{c}\text { No. of } \\
\text { shoots }\end{array}$ & Stand & $\begin{array}{l}\text { Density } \\
\text { ha }\end{array}$ & $\begin{array}{l}\text { Height, } \\
\mathrm{m}\end{array}$ & $\begin{array}{l}\text { Age, } \\
\text { yrs }\end{array}$ & $\begin{array}{l}\text { No. of } \\
\text { trees }\end{array}$ \\
\hline I & 838 & 1 & 1800 & 1.2 & 7 & 3 \\
II & 3540 & 2 & 3800 & 1.1 & 7 & 3 \\
& & 3 & 2200 & 2.1 & 9 & 3 \\
III & & 4 & 1400 & 1.8 & 11 & 4 \\
& & 5 & 3500 & 2.4 & 13 & 3 \\
IV & 7213 & 6 & 1500 & 3.8 & 13 & 3 \\
& & 7 & 2400 & 3.6 & 15 & 2 \\
& & 9 & 1400 & 4.8 & 17 & 3 \\
& & 9 & 2200 & 7.4 & 19 & 1 \\
\hline
\end{tabular}

of shoot coordinates in group III (Table 1), consisting of five trees of approximately the same height $(3.6-3.8 \mathrm{~m})$.

The normalized vertical density function $\left(f_{v}(z)\right.$, Eq. 3$)$ represents the proportion of shoots as a function of relative depth in the crown. It was obtained by normalizing the crown length to 1 for each tree in group III, dividing the crowns into 8 layers of relative depth 0.125 , summing the number of shoots found in the corresponding layers of each tree and, finally, dividing by the total number of shoots.

The normalized horizontal density function $\left(f_{h}(r \mid z)\right.$, Eq. 4$)$ at relative depth (z) represents the proportion of shoots per unit of normalized horizontal crown cross-sectional area at a radial distance $(r)$ from the stem. The normalized horizontal densities were determined separately for the vertical quartiles of group III, i.e., the layers between the relative depths of $0-0.25,0.25-0.5$, $0.5-0.75$ and $0.75-1$. The procedure was as follows: in each layer the (maximum) radius of the crown (=the maximum distance between stem and shoot) was normalized to 1 and the layer (a cylinder) was divided into ten "rings" of relative width 0.1 . The numbers of shoots belonging to corresponding rings of each tree were summed and divided by the horizontal area of that ring. Finally, the number density in each ring was divided by the total number of shoots.

The beta distribution was used to approximate both the measured frequency distributions of shoot zenith angle and the normalized vertical and horizontal densities of shoots. The density function for the beta distribution is defined by:

$$
f(x)=c\left(x-x_{\min }\right)^{p-1}\left(x_{\max }-x\right)^{q-1}
$$

The shape parameters $p$ and $q$ were calculated using the measured mean and variance $(\bar{X})$ as follows (Swindel, Smith \& Grosenbaugh, 1987):

$$
\hat{p}=\frac{\left(\bar{x}-x_{\min }\right)\left[\left(x_{\max }-\bar{x}\right)\left(\bar{x}-x_{\min }\right)-s^{2}\right]}{s^{2}\left(x_{\max }-x_{\min }\right)}
$$

and

$$
\hat{q}=\frac{\left(x_{\max }-\bar{x}\right)\left[\left(x_{\max }-\bar{x}\right)\left(\bar{x}-x_{\min }\right)-s^{2}\right]}{s^{2}\left(x_{\max }-x_{\min }\right)}
$$

The scaling parameter $c$ (Eq. 9) was estimated numerically. 


\section{Results}

The frequency distributions of shoot azimuth in the four different groups (I-IV) are shown in Fig. 1. The result indicates that the shoot azimuth may well be described by a uniform distribution.

The frequency distributions for the shoot zenith angle varied with tree size (groups I-IV) so that there was a small shift toward more horizontal inclinations in smaller trees (Fig. 2). Beta distributions specified by the mean, standard deviation, and fixed range $[0, \theta / 2]$ were fitted to the data. The mean zenith angle varied between $63^{\circ}$ and $73^{\circ}$, and its standard deviation between $17^{\circ}$ and $21^{\circ}$. The density function representing a spherical shoot orientation (dotted line) is shown for comparison. In all groups shoot inclination was more horizontal than is implied by the spherical distribution; however, the spherical distribution provided a reasonably good approximation for the largest trees (group IV).

In group III, crowns were divided into four layers and the variation in shoot zenith angle with relative depth in the crown was analyzed (Fig. 3). A clear tendency toward more horizontally inclined shoots in the lower crown was observed. The mean shoot zenith angle changed

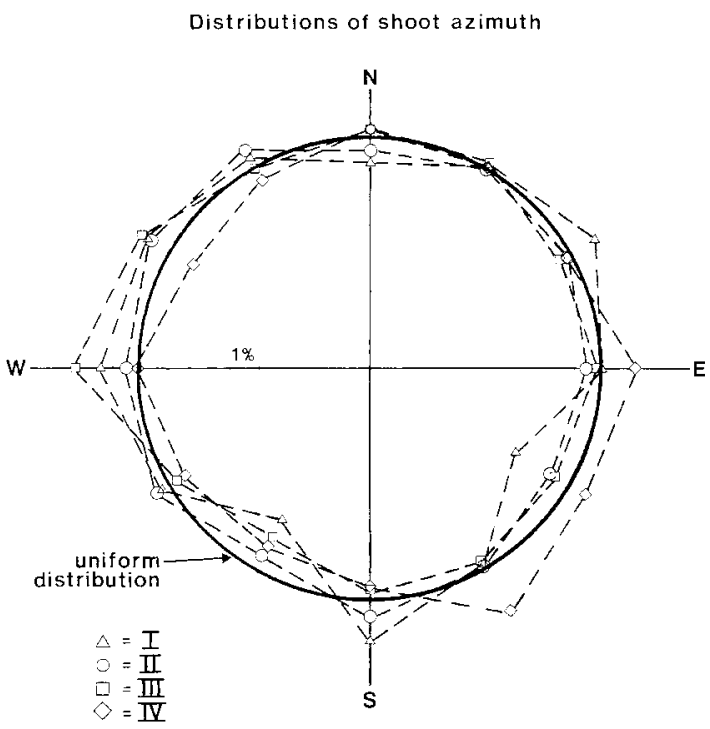

Fig. 1. Frequency distributions of shoot azimuth (groups I-IV).

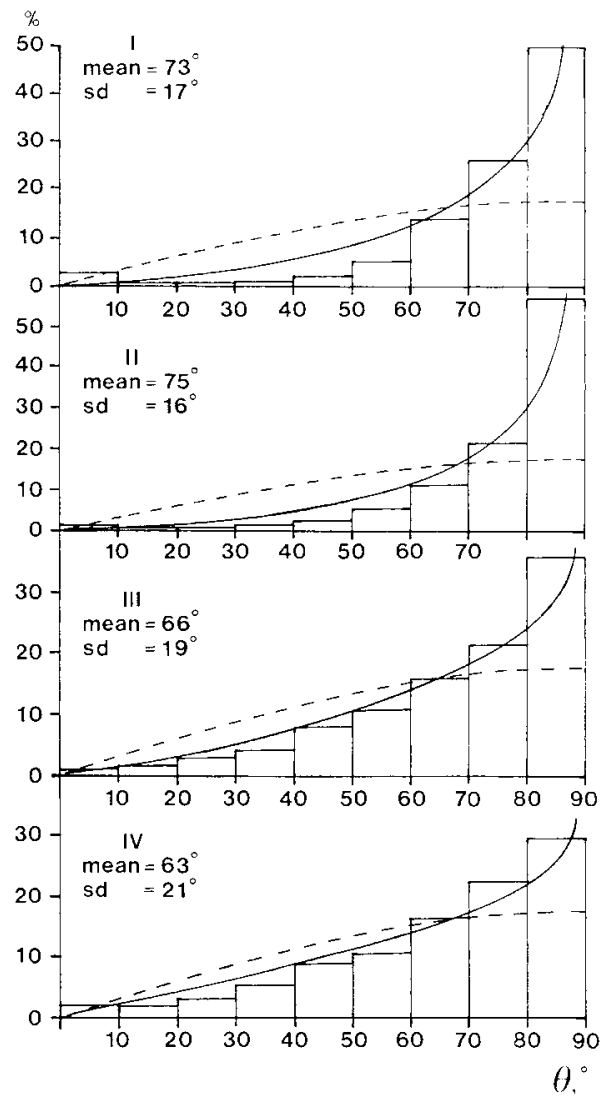

Fig. 2. Frequency distributions of shoot zenith angle $(\theta)$ in trees of different size (groups I-IV), together with the fitted beta distributions (continuous line) and the spherical distribution (dashed line).

from $44^{\circ}$ in the upper crown to $71^{\circ}$ in the lowest quartile of the crown.

The spatial density function $(f)$ (Eq. 1) of shoots at a given location is obtained as the denormalized product (Eq. 5) of the vertical density and the horizontal density at the given height. Spatial densities were derived for the crowns in group III.

The normalized vertical density of shoots in group III is shown in Fig. 4, together with the fitted beta distribution. The mean and standard deviation were 0.67 and 0.20 , respectively. The beta distribution had a maximum at the relative depth of 0.77 .

The normalized horizontal densities of shoots in the four quartiles of the trees in group III, and fitted beta distributions, are shown in Fig. 5. The density of shoots varied with relative distance from the stem, i.e. in any layer the number of shoots per unit of horizontal area was far 


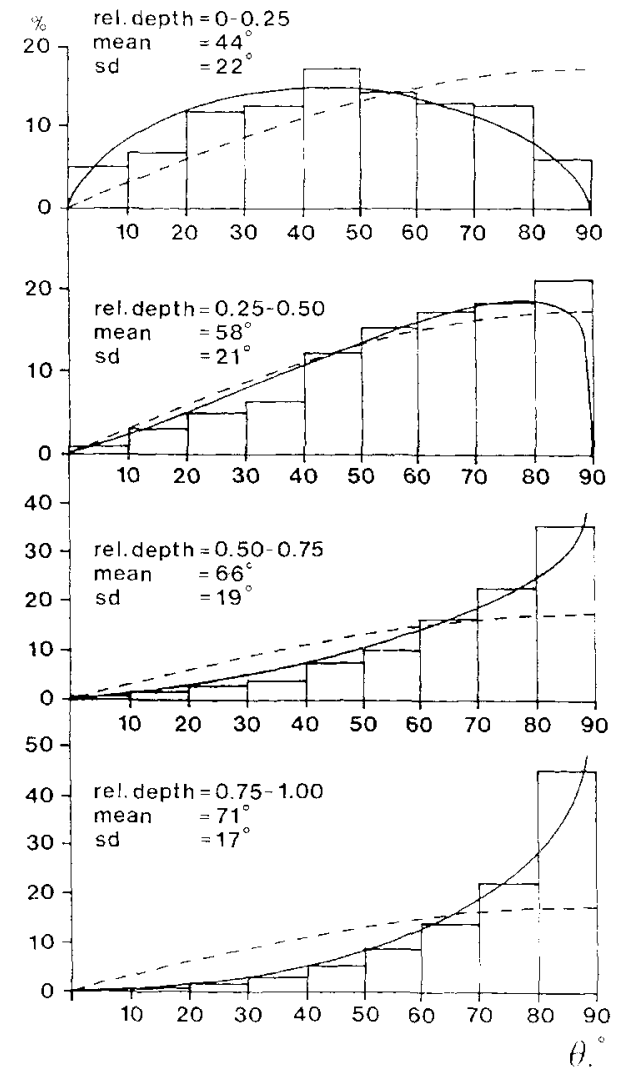

Fig. 3. Frequency distributions of shoot zenith angle $(\theta)$ at different relative depths in the crowns of group III, together with the fitted beta distributions (continuous line) and the spherical distribution (dashed line).

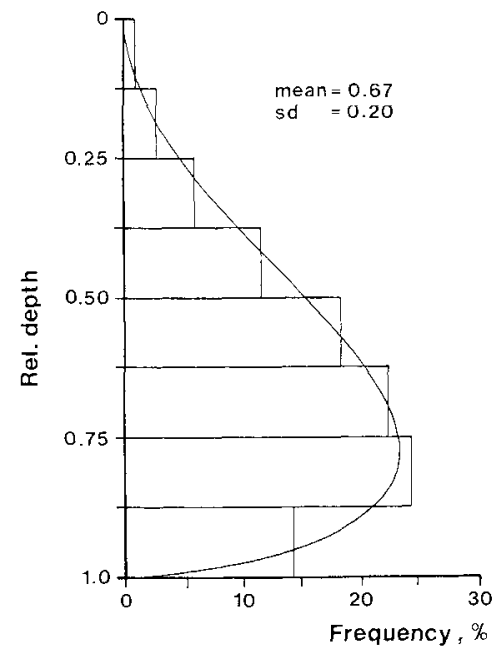

Fig. 4. Normalized vertical density of shoots (group III), together with the fitted beta distribution.

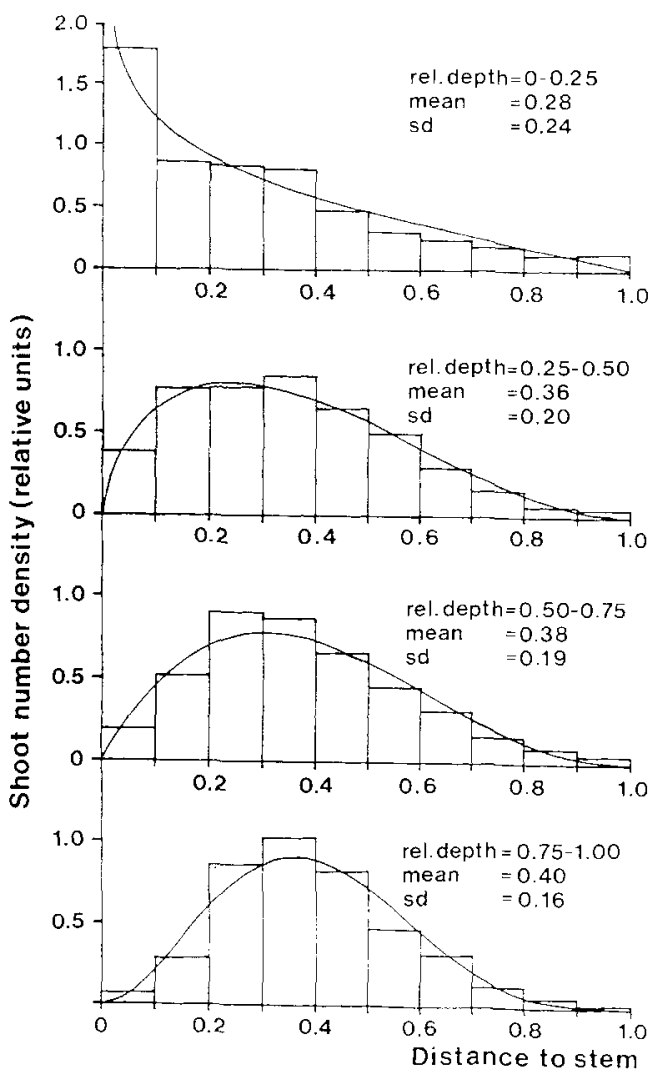

Fig. 5. Normalized horizontal density of shoots in different layers (group III), and the fitted beta distributions.

from constant. With increasing depth in the crown a slight shift of the density outwards from the stem could be observed. The mean increased from 0.28 to 0.40 . In the upper crown the maximum density of shoots occurred close to the stem, while in the two lower quartiles the maximum occurred at a relative distance of 0.3-0.4 from the stem. The sharp peak in density closest to the stem in the uppermost quarter may, however, partly be due to the calculation method, whereby the maximum crown radius in each quartile was used as a reference instead of the actual (but unknown) crown radius at different vertical positions in each layer.

\section{Discussion}

In the simple equation for direct sunlight penetration (gap probability) (Eq. 1) it is implicitly assumed that the mean shoot silhouette area $(a)$ 
is statistically independent of location in the crown. The silhouette area of a shoot when projected in a specified direction is, by definition, equal to the product of its total needle surface area $\left(\bar{l}_{s}\right)$ and the ratio of silhouette to total needle area, commonly referred to as "STAR" (see Oker-Blom \& Smolander, 1988). The mean silhouette area can subsequently be expressed as the mean needle area $\left(\bar{l}_{s}\right)$ of shoots multiplied by a mean STAR weighted by needle area $\left(G_{S}\right)$, and variation in either or both of these parameters can cause $\bar{a}$ to vary with location in the crown.

The mean (projected) needle area per shoot, measured for a subsample of shoots in group III, was found to decrease monotonically as a function of relative depth in the crown (Fig. 6) and increased with distance from the stem, except for the large shoots occurring close to the stem in the upper crown (Fig. 7). This implies that the needle area density $\left(f_{L}\right)(\mathrm{Eq} .2)$ is not proportional to the shoot number density $(f)$ but is shifted upwards and further out from the stem.

The STAR depends on several shoot characteristics, some of which are age-dependent (e.g. needle angle and density). It also varies with the direction of the shoot relative to the direction of projection (Oker-Blom \& Smolander, 1988). Because shoot orientation and age distribution vary with location in the crown, the same is therefore true for the STAR and for $G_{s}$, which represents a mean STAR with respect to shoot orientation and weighted by needle area. In ad-

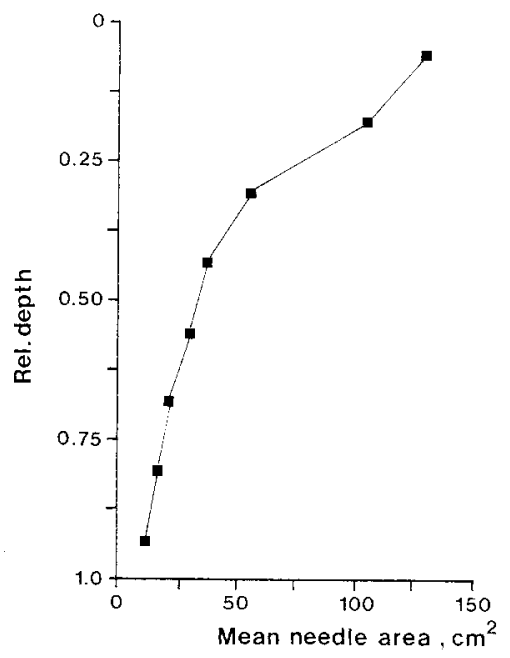

Fig. 6. Mean projected needle area per shoot as a function of relative depth in the crown (group III).

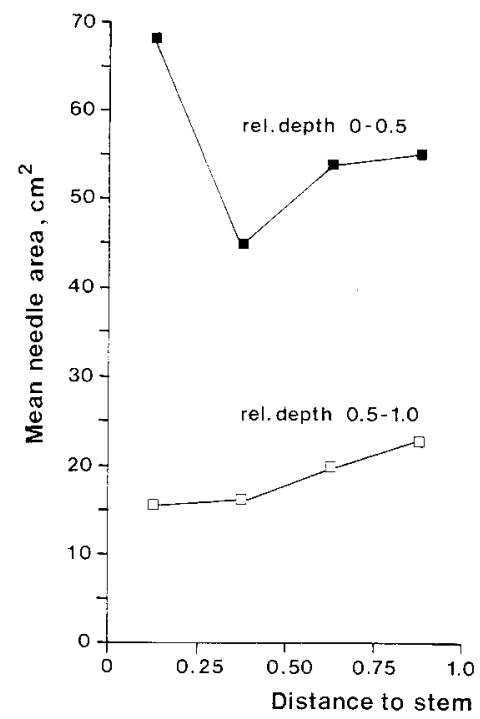

Fig. 7. Mean projected needle area per shoot in the upper and lower crown (group III), as a function of relative distance from the stem.

dition, the deviation of shoot angular distribution from the spherical (Fig. 2) implies that $G_{s}$ varies with direction (sun position) as well.

These considerations suggest that the mean silhouette area $(\bar{a})$, the mean needle area $\left(\bar{l}_{s}\right)$, and the silhouette to total needle area ratio $\left(G_{s}\right)$ of shoots all vary with location in the crown. The variation in shoot size (mean needle area per shoot) with location can be incorporated by applying Eq. 2 instead of Eq. 1, however, the variation in $G_{s}$ should still be considered. Shoot silhouette areas were not measured in this study: to determine the variation in $G_{s}$ with location in the crown will therefore require further investigation.

In this study, the shoot was taken as the basic foliage element in describing crown structure. Most models have used the individual leaf or needle as the basic foliage element (e.g. Wang, Jarvis \& Benson, 1990; Whitehead et al., 1990). The theoretical implication of the choice of unit (needle or shoot) used in defining the spatial density of foliage follows from the assumption in statistical models of light penetration, that the foliage elements are located independently of each other ("randomly"). If, instead of shoots, the locations (spatial coordinates) of individual needles were assumed to be statistically independent random variables, the model (Eqs. 1 and 2) would remain formally the same; however, 
the interpretation of the variables involved would be different. For example, the parameters $(\bar{a})$ and $\left(G_{s}\right)$ would in that case refer to the mean projected area of single needles and the ratio between projected and total needle area, respectively. The ratio of projected and total area of a shoot is much smaller than for a needle, because of needle overlap within a shoot (Oker-Blom \& Smolander, 1988). Consequently, at a given foliage area density ( $f_{L}$ in Eq. 2 ), the projected foliage area density $\left(G_{s} f_{L}\right)$ is smaller if shoots rather than needles are assumed to be statistically independent. In practice, therefore, the choice of foliage element can have a considerable influence on estimated light interception.

In conclusion, the clumped distribution of needle area typical of coniferous crowns can be incorporated in statistical models of light penetration by means of non-uniform spatial density functions, by choosing "clumped" units (shoots,

\section{References}

Kurttio, O. \& Kellomäki, S. 1990. Structure of young Pinus sylvestris: branching and its dependence on tree size. Scandinavian Journal of Forest Research 5, $169-176$.

Mann, J.E., Curry, G.L., Hartfield, D.J. \& Demichele, D.W. 1977. A general law for direct sunlight penetration. Mathematical Biosciences 34, 63-78.

Oker-Blom, P. \& Smolander, H. 1988. The ratio of shoot silhouette area to total needle area in Scots pine. Forest Science 34, 894-906.

Swindel, B.F., Smith, H.D. \& Grosenbaugh, L.R. 1987. in this case) as the basic foliage elements, or both. The theoretically critical question, regarding statistical light penetration models in general, is at what hierarchical level and which scale, if any, may the distribution of foliage elements be assumed to be random as opposed to regular or clumped ? The fact that the locations of needles are positively correlated (clustered in shoots), while the locations of shoots obviously are negatively correlated, makes the assumption of randomness theoretically unjustified in either case. For practical purposes, however, the usefulness of these models and the appropriate choice of unit must be judged by their ability to predict accurately light interception, and by the possibility to determine empirically the required input variables. A clear advantage in using the shoot as a basic unit is that the angular and spatial density functions can be determined in a rather operational way.

Fitting diameter distributions with a hand-held, programmable calculator. Scandinavian Journal of Forest Research 2, 325-334.

Wang, Y.P., Jarvis, P.G. \& Benson, M.L. 1990. Twodimensional needle area density distribution within the crowns of Pinus radiata trees. Forest Ecology and Management 32, 217-237.

Whitehead, D., Grace, J. C. \& Godfrey, M.J.S. 1990. Architectural distribution of foliage in individual Pinus radiata $\mathrm{D}$. Don crowns and the effects of clumping on radiation interception. Tree Physiology 7, 135-155. 


\title{
Dry-matter allocation in Norway spruce branches: a demographic approach
}

\author{
J.G.K. FLOWER-ELLIS
}

\author{
Department of Ecology \& Environmental Research, Swedish University of \\ Agricultural Sciences, Uppsala
}

\section{Abstract}

Flower-Ellis, J.G.K. 1993. Dry-matter allocation in Norway spruce branches: a demographic approach. In Management of structure and productivity of boreal and subalpine forests (eds S. Linder \& S. Kellomäki). Studia Forestalia Suecica 191. 94 pp. ISSN 0039-3150, ISBN 91-576-4822-0.

The initial stages of the response to fertilisation $(F)$ and combined irrigation + fertilisation (IL) of developing whorl 4 branches of 25 -year-old Norway spruces in northern Sweden, were investigated. Trees were sampled seven times from May to mid-September in the first year of treatment (year 1) and in the following year (year 2). The needle and shoot contents of starch and soluble carbohydrates (glucose, fructose, sucrose, maltodextrins) were analysed. Numbers, lengths and dry weights were determined for needles and axes, by orders and age classes. The response was divided into four main components: (1) accumulation and movement of reserves, (2) development of new structures, (3) increment of existing structures and (4) loss of structures. Residual dry mass (RDM; dry weight minus analysed carbohydrates) was calculated as a base for estimating growth.

Starch began to accumulate in late winter. Changes in the starch and sugar content strongly affected needle and shoot weights, consequently also growth estimates. With RDM as base, the increment of existing needles and shoots in control, $F$ and IL respectively, was ca. 19,12 and $13 \%$ of total increment in year 2 . Needle and shoot mortality was $8 \%$ of branch dry weight in year 2. Increases in needle RDM with age were significant, and were supported by clear increases in RDM during the growing season.

The combination of the demographic approach with gravimetric and analytical data improved understanding of the pattern and time-course of dry-matter allocation. The increase in RDM of needles with age may be a significant carbon sink in boreal forests. The uses, and limitations, of RDM as a base for estimates of growth, are discussed. The origin of increases in needle RDM with age is discussed.

When differences in the carbohydrate content at the beginning and end of the season were not taken into account, growth could be underestimated by $15-25 \%$. The size of the error depends on the timing of the first sampling relative to the phenology of the starch cycle.

Keywords: module, mortality, carbohydrate, Picea abies, growth, Sweden, boreal forest, dynamics

J.G.K. Flower-Ellis, Section for Production Ecology, Dept. of Ecology \& Environmental Research, Swedish University of Agricultural Sciences, P.O. Box 7072, S-750 07 Uppsala, Sweden.

MS. received 18 February 1993

MS. accepted 20 December 1993

\section{Introduction}

Estimation of dry-matter increment of branches in woody perennials remains one of the less tractable tasks of growth analysis. Where conifers such as Norway spruce (Picea abies (L.) Karst.) with evergreen needle leaves are concerned, the difficulty is compounded by the presence of several or many living age-classes of needle. Estimates of increment essentially depend on difference methods (Whittaker, 1965;
Newbould, 1967; Madgwick, 1970; Evans, 1972). Simplifying assumptions, e.g. that steady-state conditions obtain, must often be made. Such assumptions are not readily testable, and where trees are at the stage of crown expansion, or are reacting to experimental manipulation, are not valid (Madgwick \& Tamm, 1987).

In situations in which steady-state conditions cannot be assumed, combination of structural 
concepts systematised by Hallé \& Oldeman (1970) with the demographic approach of e.g., Harper \& White (1974) and White $(1979,1984)$, may be more fruitful. The tree crown may be regarded as an assemblage ("metapopulation" sensu White, 1979) of individual branches (cf. Sprugel, Hinckley \& Schaap, 1991), assorted by age and position. Branches themselves may be regarded as assemblages of structural elements, "modules" (Harper \& White, 1974; Hallé, Oldeman \& Tomlinson, 1987), assorted primarily by order and age. In Norway spruce, a species with determinate growth, the module may be considered identical with the woody axis formed in a single season, bearing needles and buds (here: organs), cf. White (1984).

The number of live branches in the crown as a whole may increase or decrease in response to experimental manipulation, but primary responses occur at branch level, within modules. The numbers, dimensions and unit mass of modules and organs are affected; and both natality and mortality may change markedly. In analysing the response to manipulation, changes in the number of modules and organs must be distinguished from changes in their dimensions and unit mass. Demographic concepts thus serve as a book-keeping device (Flower-Ellis \& Persson, 1980).

A further distinction must be made between reversible and notionally irreversible changes in mass. For example, Ericsson (1979) showed for Scots pine (Pinus sylvestris L.) how starch reserves accumulate in previous year's $(\mathrm{C}+1)$ and older needles before bud-break, and are utilised as shoot extension proceeds (also Rutter, 1957; Clausen \& Kozlowski, 1967; Little, 1974; Fischer \& Höll, 1991). A similar cycle of accumulation and depletion occurs in evergreen species other than conifers ( Reader, 1978; Flower-Ellis, 1980), and is associated with substantial variations in mass. The unit dry mass of organs minus their analysed carbohydrate content is here termed residual dry mass ( $R D M$ ), and is considered to approximate structural mass. The increase in the RDM of an organ, module or branch during a period of time - e.g. a growing season should be a more appropriate measure of growth than is the change in dry mass alone, which confuses several fundamentally different processes.

Change is thus partitioned into three main components: change in number, in RDM and in the mass of carbohydrate reserves, which may be treated as pools, subdivided by age classes, orders or both. But change may have a negative or a positive sign. By considering all three components of change, a better understanding of the time course and distribution of growth may be obtained than is possible using dry matter alone.

If changes affecting structure only are considered, the following steps in the response might be proposed: in the first growing season of nutrient input, an increase (1) in the length of current needles pre-formed in the previous year's bud, (2) in the number of needle primordia per bud formed in the current season and (3) in the number of vegetative lateral buds. In the second growing season, further steps in the response may be expected: an increase (4) in the length of current shoots, (5) in the length of current needles and (6) in the proportion of buds formed in the previous season, which develop into shoots. From the interaction between these processes, and nutrient supply and weather, comes the expansion of the tree's assimilating area, which results in increased stem increment.

This paper deals with the structure and drymatter dynamics of developing fourth-whorl branches of Norway spruce in the early stages of the response to increased mineral nutrient supply. The analysis considers the interaction of four processes: (1) the accumulation and movement of reserves, (2) the development of new structures, (3) the increment of existing structures, and (4) the loss of structures. It is to be noted that growth is regarded here as being synonymous with the accretion of structural units. The paper has two main aims:

First, to demonstrate the application of demographic concepts to the analysis of the initial response of a single branch whorl to increased, balanced nutrient supply.

Secondly, to show the effect of seasonal variation of the starch and sugar content of needles and shoots on estimates of branch growth.

\section{Materials and methods}

\section{Site and climate}

The source of the material was Flakaliden, a "nutrient optimisation experiment" (Linder, 
1990) laid out in a Norway spruce stand planted in 1963 after clear-felling, followed by prescribed burning and scarification. Stand density is 2033 stems $\mathrm{ha}^{-1}$. The stand is situated in northern Sweden (lat. $64^{\circ} 7^{\prime} \mathrm{N}$, long. $19^{\circ} 45^{\prime} \mathrm{E}$ ), 310-320 m above sea-level. The site is of the low-herb type, with dwarf shrubs, mainly bilberry (Vaccinium myrtillus L.). The soil is a thin, sandy glacial till with many boulders, overlying gneiss.

Flakaliden is situated in the boreal forest climatic zone, according to Köppen's system. The growing season is short, and there is a snow cover every year. The growing season at the Svartberget field station (ca. $20 \mathrm{~km}$ north-east of Flakaliden, $225 \mathrm{~m}$ a.s.1.) in 1987 lasted from 18 May-25 September; in 1988, from 11 May-8 October (threshold $+5^{\circ} \mathrm{C}$ ). The $1986 / 87$ winter was very cold. A snow cover was established by 3 December 1986, and remained until 26 April 1987. The ground was frozen at a depth of $10 \mathrm{~cm}$ by mid-December 1986, and was still partly frozen at that level (the ice-water stage) until 5 May 1987. The 1987/88 winter, by contrast, was mild. A deep snow cover was established by 20 November 1987, and did not thaw completely until mid-May 1988. The ground remained unfrozen at $10 \mathrm{~cm}$ depth until late December 1987, and was free of ice by 5 April 1988 (Degermark, 1988, 1989).

\section{Treatments}

The aim of the nutrient optimisation experiments is to eliminate water and mineral nutrients as growth-limiting factors. At the same time, leaching of nutrients to the groundwater is to be avoided.

The treatments in the main experiment, which started in 1987, are as follows: irrigation (I), irrigation combined with fertilisation (IL) and annually applied solid fertiliser $(\mathrm{F})$, in addition to the control $(\mathrm{C})$. This paper deals only with the control, F and IL treatments.

Treatments are replicated four times on double plots, dimensions $50 \times 100 \mathrm{~m}$, consisting of two net plots, each of $1000 \mathrm{~m}^{2}$, surrounded by a buffer zone. Destructive sampling is permitted in the buffer zone only.

In 1987 and 1988, the annual dose of nitrogen was $100 \mathrm{~kg} \mathrm{~N} \mathrm{ha}^{-1}$, other nutrients being supplied in proportion to nitrogen (Table 1). Combined irrigation and fertilisation began on
Table 1. Summary of macronutrients $(N, P, K, S$, Ca, Mg), $\mathrm{kg} / \mathrm{ha}$, supplied to the $F$ and IL treatments in 1987 and 1988

\begin{tabular}{lrrrr}
\hline \multicolumn{1}{c}{ Treatment... } & IL & F & \multicolumn{1}{c}{ IL } & F \\
\multicolumn{1}{c}{ Year... } & 1987 & & 1988 & \\
\hline Nitrogen & 100 & 100 & 100 & 100 \\
Potassium & 48 & 48 & 48 & 48 \\
Phosphorus & 17 & 17 & 17 & 17 \\
Calcium & 53 & 9 & 0 & 9 \\
Sulphur & 18 & 12 & 8 & 12 \\
Magnesium & 6 & 6 & 6 & 6 \\
\hline
\end{tabular}

27 June and continued until 21 August 1987. In 1988, it began on 16 June and ended on 12 August.

\section{Sample trees}

Following a complete inventory, and detailed structural analysis of 32 trees in six height classes in October 1986, four height classes of tree were selected for serial branch sampling (Table 2). The sample trees, chosen from lists of all trees of those height classes in the buffer zones, were distributed over all replicate plots of the C, F and IL treatments, so that every plot had approximately the same number. Within these three treatments, seven groups of ten trees each were chosen, one group for each of the seven sampling occasions (210 trees in all). Sampling dates were chosen to cover the phenological development of Norway spruce on the site (Table 3 ).

Trees of any height class were assigned at random to a particular sampling occasion. The sampling cycle returned to the same group of trees once a year only, at about the same time. Groups of reserve trees, closely resembling those in the main series, were also selected. Trees from these groups replaced any tree which died or was damaged (e.g. by snowbreak).

This procedure gives comparable groups of

Table 2. Tree height classes in sampling groups, based on the initial height distribution in the stand in autumn 1986. SD - standard deviation of the mean

\begin{tabular}{lllll}
\hline & \multicolumn{4}{l}{ Stratum, SD } \\
\cline { 2 - 5 } & -1.0 & Mean & +1.0 & +1.5 \\
\hline Height class, $m$ & 1.65 & 2.59 & 3.52 & 3.99 \\
Trees/group & 2 & 4 & 2 & 2 \\
\hline
\end{tabular}


Table 3. Sampling dates for occasions $T 2-T 7$, 1987 and T2-T7 1988, Flakaliden. At T2, the developing fourth, seventh and tenth whorls were sampled. The same whorls were sampled at T1 as at $T 7$

\begin{tabular}{lcccccc}
\hline Occasion & T2 & T3 & T4 & T5 & T6 & T7 \\
\cline { 1 - 5 } 1987 & $3 / 6$ & $15 / 6$ & $29 / 6$ & $13 / 7$ & $17 / 8$ & $22 / 9$ \\
1988 & $31 / 5$ & $14 / 6$ & $5 / 7$ & $20 / 7$ & $16 / 8$ & $19 / 9$ \\
Whorls & 3 & 4 & 4 & 4 & 4 & 2 \\
& 6 & 7 & 7 & 7 & 7 & 4 \\
& 9 & 10 & 10 & 10 & 10 & 7 \\
& & & & & & 10 \\
& & & & & & 13 \\
\hline
\end{tabular}

sample trees on every occasion, while making it possible to separate, by occasions or annually, the growth response of trees representing different height strata in the stand at the start of the experiment. The spread of tree size ensures a corresponding spread, e.g. in shoot length, facilitating use of regression estimates in which shoot length is estimator variable (Cochran, 1977). If grouping is successful, chance variation, e.g. in branch structure, related to variation in tree size on different sampling occasions, should be minimised.

\section{Branch sampling}

\section{Terminology}

Structural terminology is based on Flower-Ellis, Albrektson \& Olsson, (1976, Fig. 2; for age notation, see also Flower-Ellis, 1971), whereby the uppermost branch whorl is whorl 1 and the main axis of a branch is order 1 . Current shoots are designated $\mathrm{C}$, the year of origin being added where necessary for distinction, thus: C87. According to the above system, shoot age is counted from the current shoot, and is designated $\mathrm{C}+1 \ldots \mathrm{C}+\mathrm{n}$. Modules are referred to as shoots, qualified by order and age: thus 'firstorder current shoots', etc.

Branch whorls were sampled so as to give a profile down the crown (Table 3), a single branch being cut from each of the sampled whorls. Branches were normally sampled from mid-May to mid-September, intervals between samplings being shortest during the period of most active growth (Table 3 ).

\section{Subsampling for analysis}

Subsamples (needles only in 1987, axes + needles from 1988) for carbohydrate and min- eral nutrient analysis were immediately removed from each branch, separated by age-classes, bagged, and immersed in liquid nitrogen $\left(-196^{\circ} \mathrm{C}\right)$. They were stored at $-20^{\circ} \mathrm{C}$ until analysed. Branches were stored individually at $4^{\circ} \mathrm{C}$, before separation into age-classes and branching orders (order 1, order $>1$ ). Branch fractions were stored individually in polythene bags at $-20^{\circ} \mathrm{C}$, to await detailed processing.

Only material from the developing fourth branch whorl of control, F and IL in 1987 and 1988, respectively, is considered here. This whorl was chosen for comparability (needle samples for diagnostic mineral nutrient analysis are customarily taken from it, e.g. Aronsson \& Elowsson, 1980). Needle subsamples from this whorl in 1987 were too small for it to be possible to separate treatments in the carbohydrate analyses in that year. From 1988 onward, the size of subsamples was increased.

\section{Processing and analysis}

The subsamples were dried in a ventilated oven $\left(85^{\circ} \mathrm{C}, 48 \mathrm{~h}\right)$, then separated into the fractions (a) needles and (b) shoot axes, which were counted and measured. The fractions were pooled by age-classes within treatments. After milling to pass a $0.12 \mathrm{~mm}$ sieve, the material was dried under vacuum. Starch and soluble sugars (fructose, sucrose, maltodextrins and fructan) were analysed enzymatically, according to Steen \& Larsson (1986), slightly modified (50 $\mathrm{mg}$ sample extracted $40 \mathrm{~min}$ at $60^{\circ} \mathrm{C}$, Thermamyl 120L).

\section{Growth analysis}

The branch fractions were dried in a ventilated oven $\left(85^{\circ} \mathrm{C}, 24 \mathrm{~h}\right)$, to aid separation into needles and shoot axes. After further drying $\left(85^{\circ} \mathrm{C}, 24\right.$ h) they were weighed. The number of needles and shoot axes on each sample branch was counted, and lengths were measured, by orders and age-classes. On first-order axes, needle scars were also counted, for estimating mortality. In what follows, shoots of order 3 and above are not distinguished from second-order shoots, nor are second-order nodal and internodal shoots treated separately.

Since subsamples were treated individually until they were pooled, the number and dry mass of shoot and needle subsamples could be added to the total for each branch. 


\section{Calculations}

\section{Needles}

The relationship between the dry mass and length of single needles was calculated by ageclasses for every sampling occasion, for orders 1 and $>1$ separately. From previous studies (Flower-Ellis \& Yang, unpublished) it is known that this relationship is adequately represented for individual Norway spruce needles by the linear model

$$
X 2=\alpha+\beta \cdot X 1+\varepsilon,
$$

where $X 1$ is length ( $\mathrm{mm}), X 2$ is dry mass $(\mathrm{mg})$ including carbohydrates and $\varepsilon$ is the error term.

Since the length and number of needles is known, mean needle length $l$ is readily calculated for a given age-class and occasion. From the above relationships, the mass $w$ of a needle of length $l$ can be estimated for any age-class and occasion. If mean needle length varies, whether systematically or randomly, estimates of $w$ will be correspondingly affected.

Individual sampling occasions provide independent estimates of $l$ in an age-class. Where there are no significant differences in length between occasions in needle age-classes $\mathrm{C}+1$ and older (see Results), a common mean length $L$ can be calculated. For $L$ or for any convenient integer value $l_{s}$ (standard needle length), the mass of single needles was estimated for occasions (1) ... (7), free from the effects of variation in length. Differences in mass were thus obtained directly. Changes in the mass of single needles with age may also be quantified by the above procedure (but see below).

Successive estimates of the mass of developing current needles must be made using observed mean length on each occasion, until length growth is complete. Needle length in any ageclass is taken as constant after the end of the first growing-season (Meissner, 1894, 1897).

The mean number of living needles $n_{i}$ in an age-class $i$ on a given occasion is also known. The total mass of needles in that age-class may thus be estimated directly or as $\left(n_{i} \cdot w_{i}\right)$, to give the dry-matter pool size. If no needles die in the interval $T_{i} \ldots T_{i+1}$, total change in mass in an age-class will depend principally on the change in $w_{i}$ in that interval. This makes it possible to calculate change in mass in two ways: (1) with a constant needle population, (2) with the effects of needle mortality explicitly included. This facilitates comparison of treatments, by separating primary growth processes, i.e. those which directly affect increase in mass at organ level, from those which indirectly affect the overall change in mass of the branch.

The size of the current needle population was taken as being the mean number of needles present on current shoots, after shoot extension was complete. Since current needles usually were too fragile to handle until mid-July, calculations of dry-matter and carbohydrate pool sizes for these needles were not feasible until after that time.

Needle mass calculated as above includes both starch, which exhibits marked seasonal variation, and sugars, which vary over a narrower range. The results of the carbohydrate analyses were used for calculating residual dry mass (RDM: needle mass minus the equivalent of the analysed carbohydrate content; considered to approximate the needle's structural mass). The momentary carbohydrate pool size for a needle age-class was obtained by multiplying the dry-matter equivalent of the carbohydrate content of single needles by the number of live needles present on that occasion. 'Total carbohydrates' refers to the sum of starch + analysed sugars, while 'total sugars' refers to the sum of the analysed sugars only.

\section{Shoot axes}

Shoot axes were dealt with similarly. The mass of individual shoots older than the current year also varies, partly as a result of the carbohydrate cycle, partly because radial increment occurs. The relationship between shoot length and mass becomes increasingly non-linear with age in first-order shoots. If, however, mass per unit length ( $q, \mathrm{mg} \mathrm{mm}^{-1}$ ) is substituted for mass, the relationship can be expressed by a linear model (cf. (1) above), which reflects both (a) the increase in the cross-sectional area of the shoot axis with age or with time during the growing season, and (b) variations in mass associated with changes in carbohydrate content.

As with needles, the length of shoots was taken as constant after the end of the first growing season. Shoot mass as given here includes bark.

\section{Statistical usage}

Statistical terminology follows Snedecor \& Cochran (1980). Significance levels, e.g. for com- 
parisons, are referred to as follows: * - significant at $5 \%$ level but not at $1 \%$ level; ** significant at $1 \%$ level but not at $0.1 \%$ level; *** _ significant at $0.1 \%$ level; NS not significant.

\section{Results}

\section{Initial branch structure}

At the stage of stand development in question, the size (length, mass, number of organs) of a branch in a certain whorl, e.g. developing whorl 4 , is proportionate to the overall size of the tree (Table 4). In the present paper, however, different size classes of tree are not distinguished. The structure of the mean branch for the group is used, i.e. the structure common to a group of trees composed as in Table 2, before irrigation and nutrient treatments started. Each year, the new whorl 4 will grow on successively taller trees; branch size therefore tends to increase, irrespective of treatment.

\section{Stability of estimates of existing branch structure}

'Existing branch structure' is made up of the shoots present on the developing whorl 4 branch at the beginning of the growing season. Existing structures increase in mass through the radial increment of axes and the increase in mass of individual needles, and may lose mass through the death of shoots and needles. Unless such losses can be demonstrated, existing structure may be regarded as a fixed entity for purposes of calculation.

Any significant trend on time during the sampling series, e.g. in mean shoot length or in the number of living needles in any age-class, must be taken into account in estimating change in mass in that age-class. Such trends originate mainly (a) in sampling error affecting one or more characters, (b) in biological causes. Successful grouping should result in stable values for the main structural elements, e.g. the length of shoot axes existing at the beginning of the sampling series. Decreases, for instance in the number of live needles, may then be considered to reflect mortality.

In the sample branches of 1987 , there was no trend on time between 3 June and 22 September, in first-order or $>1$ order shoot axis length in age-classes $\mathrm{C}+1, \mathrm{C}+2$ and $\mathrm{C}+3$; nor was there a trend in the number of living needles in these age-classes (Table 5).

In the 1988 material, first-order shoot axis length in age-classes $\mathrm{C}+1, \mathrm{C}+2$ and $\mathrm{C}+3$ showed no trend on time during the corresponding period; nor did the number of living needles in age-classes $\mathrm{C}+2$ and $\mathrm{C}+3$ do so. However, the number of living $\mathrm{C}+1$ needles on first-order axes increased significantly during this interval (from $125.6 \pm 7.1$ to $141.2 \pm 8.6$ needles per shoot ( $\pm 95 \%$ confidence limits; cf. Table 5 ).

However, for order $>1$ in 1988, the situation was otherwise. For $\mathrm{C}+1$ shoots, there was a weak, non-significant downward trend with time in the number of shoots, a significant downward trend in total shoot length, and a weak, nonsignificant downward trend in the number of live needles. For the $\mathrm{C}+2$ shoots, there were significant, downward trends in all three characters (Table 5).

The lack of significance of two of the slope coefficients in the $\mathrm{C}+1$ age-class must be set against the negative sign of all three. Taken together with (a) the downward trends in the $\mathrm{C}+2$ age-class, and (b) the presence of attached

Table 4. Mean and standard deviation of dry mass, $g$, of branches by six classes of tree height, in whorl 3 of Norway spruce trees at Flakaliden, as determined by destructive sampling in October 1986. Represents the initial condition of developing whorl 4 in 1987 (See also Table 2)

\begin{tabular}{lcccccc}
\hline & \multicolumn{2}{l}{ Stratum, SD } & & & \\
\cline { 2 - 7 } \multicolumn{1}{c}{ Height class, m... } & -1.5 & -1.0 & Mean & +1.0 & +1.5 & +2.0 \\
\cline { 2 - 7 } \multicolumn{1}{c}{} & 1.18 & 1.65 & 2.59 & 3.52 & 3.99 & 4.46 \\
\hline Branch mass, g & 15.09 & 24.78 & 41.35 & 56.65 & 73.34 & 82.25 \\
SD & 5.44 & 11.51 & 16.19 & 25.46 & 45.03 & 24.21 \\
No. trees & 5 & 5 & 7 & 5 & 5 & 5 \\
\hline
\end{tabular}


dead second-order laterals on the sample branches, these results suggest that some $\mathrm{C}+1$ shoots and needles died in the interval between 31 May and 19 September 1988.

\section{Accumulation and movement of reserves}

The starch content of needles (per cent of dry mass) reached a maximum in June in both 1987 and 1988. It began to decrease with the onset of growth in current shoots, and was less than $1 \%$ by mid-September 1987. In 1988, however, needles in the F and IL treatments contained less than $1 \%$ of starch by mid-August 1988, in contrast to those in the control, which still contained $5-6 \%$ of starch. Some starch was still present in control needles on 19 September (Fig. 1c). The total sugar content of the needles varied over a narrower range during the period late May-September (Fig. 1b, d).

The starch content of shoot axes (per cent of dry mass) was lower than that of needles of the same age-class at all samplings (Fig. 1e). The total sugar content was also lower in shoot axes than in needles of the same age-class (Fig. 1f). The seasonal course of variation in the total carbohydrate content of shoots was otherwise similar to that in needles.

\section{New structures: current growth}

Growth of new shoots and needles begins by mid-June and is normally completed by midAugust. The phase of most rapid growth coincides with the decline in the starch pool in the needles, cf. Fig. 1a, c.

Table 5. Observed mean and standard deviation (SD) for shoot length ( $\mathrm{mm}$ ), number of shoots and number of living needles in existing structure (age-classes $C+1, C+2$ and $C+3$, orders 1 and $>1)$ in developing whorl 4 branches of Norway spruce in 1987 and 1988 (T2-T7 inclusive). The slope coefficient (b) for the regression of the values for individual sampling occasions on time (week no.) is also shown. If the t-test $\left(b / s_{b}\right)$ shows that $b$ is not significantly different from zero, and if the sign of the coefficients shows no bias, the regressions on time are considered to show no trend. No. observations for Order 1: 179 in 1987, 178 in 1988; order >1, 179 in 1987, 173 in 1988

\begin{tabular}{|c|c|c|c|}
\hline $\begin{array}{l}\text { Item, year } \\
\text { Age-class }\end{array}$ & $\begin{array}{l}\text { Mean } \\
\text { SD }\end{array}$ & $\begin{array}{l}\text { Slope } \\
\text { coeff. }\end{array}$ & Signif. \\
\hline \multicolumn{4}{|c|}{ Order 1} \\
\hline \multicolumn{4}{|c|}{ Shoot length, 1987} \\
\hline $\mathrm{C}+1(\mathrm{C} 86)$ & $\begin{array}{l}75.0 \\
16.7\end{array}$ & 1.099 & NS \\
\hline$C+2(C 85)$ & $\begin{array}{c}109.0 \\
31.7\end{array}$ & -0.859 & NS \\
\hline$C+3(C 84)$ & $\begin{array}{r}108.6 \\
46.2\end{array}$ & -0.814 & NS \\
\hline \multicolumn{4}{|c|}{ No. live needles, 1987} \\
\hline $\mathrm{C}+1(\mathrm{C} 86)$ & $\begin{array}{r}160.8 \\
32.2\end{array}$ & 0.690 & NS \\
\hline$C+2(C 85)$ & $\begin{array}{r}210.4 \\
49.2\end{array}$ & -1.280 & NS \\
\hline$C+3(C 84)$ & $\begin{array}{r}145.4 \\
44.5\end{array}$ & -1.990 & NS \\
\hline \multicolumn{4}{|c|}{ Shoot length, 1988} \\
\hline $\mathrm{C}+1(\mathrm{C} 87)$ & $\begin{array}{l}58.6 \\
16.1\end{array}$ & 0.829 & NS \\
\hline$C+2(C 86)$ & $\begin{array}{l}88.5 \\
24.6\end{array}$ & 0.488 & NS \\
\hline $\mathrm{C}+3(\mathrm{C} 85)$ & $\begin{array}{r}125.1 \\
47.3\end{array}$ & -0.461 & NS \\
\hline \multicolumn{4}{|c|}{ No. live needles, 1988} \\
\hline $\mathrm{C}+1(\mathrm{C} 87)$ & $\begin{array}{r}132.2 \\
30.3\end{array}$ & 2.351 & $*$ \\
\hline $\mathrm{C}+2(\mathrm{C} 86)$ & $\begin{array}{r}173.1 \\
39.2\end{array}$ & 1.392 & NS \\
\hline$C+3(C 85)$ & $\begin{array}{r}172.6 \\
45.7\end{array}$ & -0.926 & NS \\
\hline \multicolumn{4}{|c|}{ Order $>1$} \\
\hline $\mathrm{C}+1(\mathrm{C} 86)$ & $\begin{array}{l}645.6 \\
356.2\end{array}$ & -0.610 & NS \\
\hline $\mathrm{C}+2(\mathrm{C} 85)$ & $\begin{array}{l}318.2 \\
182.2\end{array}$ & -0.910 & NS \\
\hline \multicolumn{4}{|c|}{ No. shoots, 1987} \\
\hline $\mathrm{C}+1(\mathrm{C} 86)$ & $\begin{array}{r}18.7 \\
9.2\end{array}$ & -0.668 & NS \\
\hline$C+2(C 85)$ & $\begin{array}{l}6.8 \\
3.2\end{array}$ & -0.220 & NS \\
\hline \multicolumn{4}{|c|}{ No. live needles, 1987} \\
\hline $\mathrm{C}+1(\mathrm{C} 86)$ & $\begin{array}{r}1199.2 \\
677.3\end{array}$ & -0.739 & NS \\
\hline$C+2(C 85)$ & $\begin{array}{l}651.4 \\
380.8\end{array}$ & -1.245 & NS \\
\hline \multicolumn{4}{|c|}{$\Sigma$ Shoot length, 1988} \\
\hline $\mathrm{C}+1(\mathrm{C} 87)$ & $\begin{array}{l}469.6 \\
255.3\end{array}$ & -2.023 & $*$ \\
\hline$C+2(C 86)$ & $\begin{array}{l}253.8 \\
140.1\end{array}$ & -2.947 & $* *$ \\
\hline No. shoots, 1 & & & \\
\hline $\mathrm{C}+1(\mathrm{C} 87)$ & $\begin{array}{r}17.1 \\
7.9\end{array}$ & -0.858 & NS \\
\hline$C+2(C 86)$ & $\begin{array}{l}6.4 \\
2.9\end{array}$ & -2.042 & * \\
\hline No. live need & 988 & & \\
\hline $\mathrm{C}+1(\mathrm{C} 87)$ & $\begin{array}{l}874.4 \\
466.4\end{array}$ & -0.686 & NS \\
\hline $\mathrm{C}+2(\mathrm{C} 86)$ & $\begin{array}{l}491.3 \\
269.4\end{array}$ & -2.110 & * \\
\hline
\end{tabular}


In 1987, after the first season's treatment, the $\mathrm{F}$ and IL treatments did not differ significantly from the control in any of the following structural characters: number of second-order laterals per branch; number, mean length and total length of current shoots (C87); number, mean length and total length of current needles (Linder \& Flower-Ellis, 1992). Treatments were therefore not distinguished in that year.

By September 1988, after the second season's nutrient supply, branches in whorl 4 of trees in the $\mathrm{F}$ and IL treatments were clearly larger than those of the control, while differences between the two treatments receiving fertiliser were not marked and were rarely significant (Table 6). On first-order shoots, the current year's increment (C88) was longer in the F and IL treatments than in the control $(* * *)$. When the unadjusted means were compared, there were also more live needles on shoots in the $\mathrm{F}$ and IL treatments; when the comparison was made at a common length, differences were not significant. The current shoots of control trees had more needles per unit length than those in the two fertilised treatments ( $\mathrm{F} * * *, \mathrm{IL} * *$ ). Mean needle length was greater in the F and IL treatments than in the control ( $\mathrm{F} * *$, IL *). The total length of live needles was also greater on shoots of $F$ and IL trees before adjustment to a common shoot length (***). After adjustment, differences were not significant.

Mean values for characters on shoots of order $>1$ in the $\mathrm{F}$ and $\mathrm{IL}$ treatments were generally larger than those in the control (Table 6), although differences were not always clear-cut. Mean shoot length was greater in $\mathrm{F}$ and IL treatments than in the control (***), but differences in the number of current shoots and in the number of live needles were not significant. Mean needle length was greater than in the control $\left(\mathrm{F}^{* *}, \mathrm{IL} *\right)$ ). Differences in the total length of shoots of orders $>1$ were not significant. The number of needles per unit length did not differ significantly, but total needle length was greater in F and IL than in the control (*). After adjustment to a common length, the IL treatment alone had a significantly greater total needle length on shoots of order $>1(* *)$.

$A$ feature of the response not evident from the tables, was an increase in the number of current shoots arising directly from shoots older than $\mathrm{C}+1$ in the $\mathrm{F}$ and IL treatments, i.e. from dor- mant buds. Shoots of order $>1$, which had not produced terminal or lateral shoots in 1987 , began to do so in 1988. There are few $\mathrm{C}+2$ shoots of order $>1$ on whorl 4 branches (cf. Table 5), therefore a limited population of dormant buds from which new shoots can arise.

\section{Increment of current needles and shoot axes}

The mass of single needles, by age-classes, was estimated for every sampling occasion from its relationship with length (cf. Fig. 2). Since there was no difference between treatments, in slope or intercept, in the relationship within any ageclass on any sampling occasion, treatments were not separated. For comparing age classes, a standard needle length $\left(l_{s}=10 \mathrm{~mm}\right)$ was used, $\mathrm{cf}$. Fig. 3 a, b. For estimating pool size, the mean needle length in each age class was used.

The mass of single, current needles continued to increase after they had reached their final length. As is indicated by the development of mass per unit length, the radial increment of current shoot axes also continued after growth in length was complete. Although part of the increase in mass was attributable to accumulation of starch and sugars in both needles and shoot axes, their RDM also increased.

\section{Existing structures: dry-matter dynamics}

Needles

Changes in mass, at constant length, of the $\mathrm{C}+1$, $\mathrm{C}+2$ and $\mathrm{C}+3$ needles during the sampling period largely reflected the changes in their total carbohydrate content (compare Fig. 1 a, c and $3 \mathrm{a}, \mathrm{b})$. The mass of single needles at peak starch content, e.g. in 1988, was 125,127 and $130 \%$ of that in mid-August $(\mathrm{C}+1, \mathrm{C}+2$ and $\mathrm{C}+3$ needles, respectively; Fig. $3 \mathrm{~b}$ ).

Mass was significantly greater in old than in younger needles (Fig. 2 b, 3 a, b). In the autumn of 1987, for example, the ranking was as follows:$\mathrm{C}<\mathrm{C}+1<=\mathrm{C}+2<\mathrm{C}+3$ (Table 7). The difference extended to RDM. Taking the RDM of the current needle in September as datum, the difference between the RDM of the C87 needle and that of the $\mathrm{C}+3(\mathrm{C} 84)$ needle at fixed length, was $1.96 \mathrm{mg}(\mathrm{C}+3: \mathrm{C} 87: 1.63: 1)$. The difference in RDM between the $\mathrm{C} 88$ and $\mathrm{C}+3$ (C85) needle was $0.65 \mathrm{mg}(\mathrm{C}+3: \mathrm{C} 88: 1.20: 1)$. As appears from Fig. 3 (a) and (b), the difference 


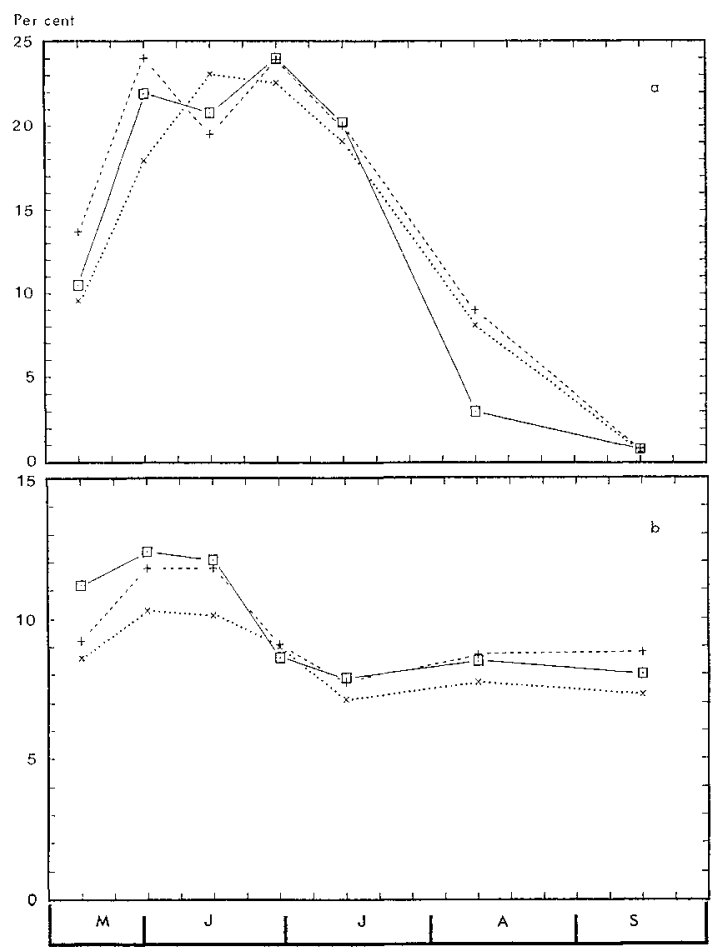

Fig. 1(a-f). Seasonal variation in starch and total sugar content of needles and shoot axes (\%), in 1987 and 1988. (a) 20 May to 22 Sept. 1987, starch content of needles in age classes $\mathrm{C}+1(+), \mathrm{C}+2(\square)$ and $\mathrm{C}+3(\mathrm{x})$ without distinction as to treatment. (b) 1987 , total sugars in needles (occasions and symbols as in (a)). (c) 31 May to 19 Sept. 1988, starch content of C +1 needles by treatments (+ control, $\square$ F and x IL). (d) 1988, total sugars in $\mathrm{C}+1$ needles (occasions and symbols as in (c)). (e) 1988 , starch content of $C+1$ shoot axes by treatments (symbols as in (c)). (f) 1988, sugars in shoot axes (symbols as in (c)). Contrast the pattern of change in sugars in needles in 1987 and 1988 (b, d).

increased most between age classes $\mathrm{C}+2$ and $\mathrm{C}+3$.

\section{Shoot axes}

The increase in mean length and total length of current needles in the $F$ and IL treatments
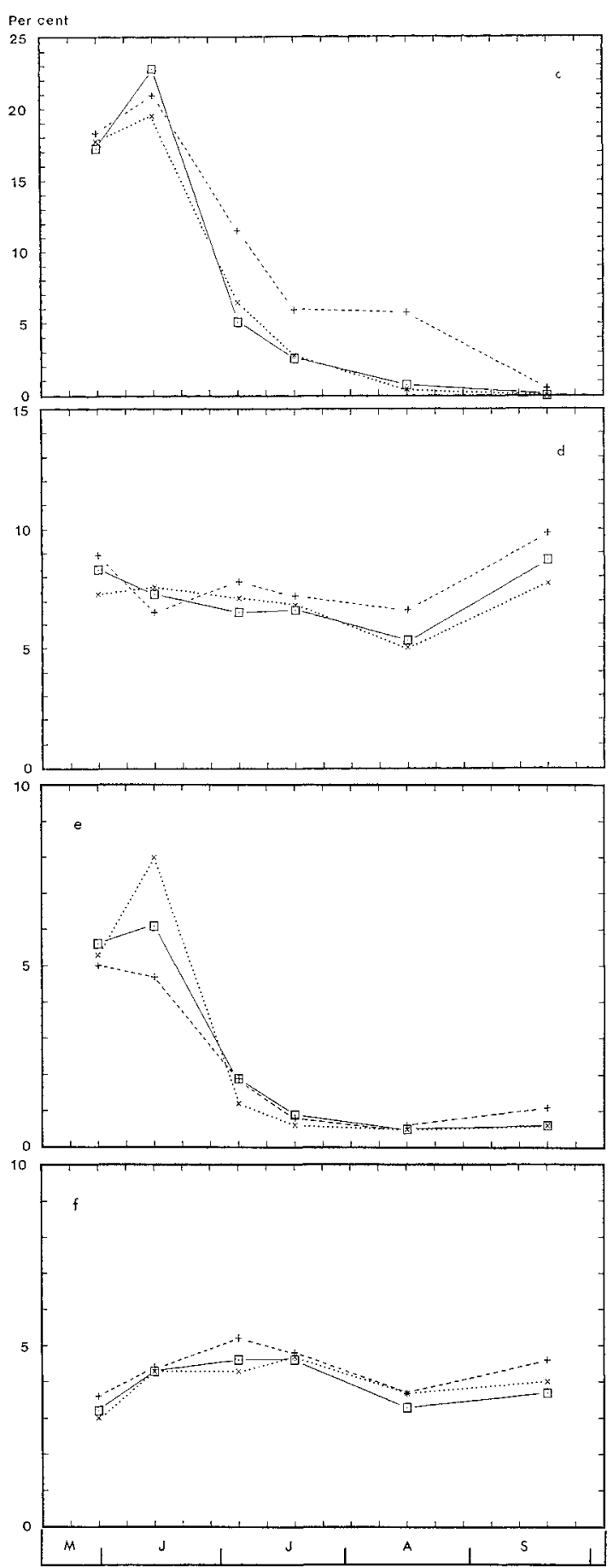

(Table 6) should be associated with increased radial increment of both first- and second-order $\mathrm{C}+1, \mathrm{C}+2$ and $\mathrm{C}+3$ shoot axes of branches in those treatments, as compared with the control. However, within any age-class, there were no differences in slope or intercept between 
Table 6. Means and standard deviations for current production (C88), by treatments and orders, in whorl 4 branches of a joint material from the last two sampling occasions in 1988 (no significant differences between the means for any character on the two occasions; t-test). Adjusted comparisons were made analogously on values estimated from regressions, e.g. between needle number and shoot length. Internode length on C88 shoots is equivalent to the reciprocal of No. needles $\mathrm{mm}^{-1}$

\begin{tabular}{|c|c|c|c|}
\hline \multirow[b]{2}{*}{ Item } & \multicolumn{3}{|c|}{ Treatment } \\
\hline & $\mathrm{F}$ & IL & Control \\
\hline \multicolumn{4}{|l|}{ Order 1} \\
\hline Shoot length $\mathrm{mm}$ & 117.4 & 115.6 & 69.1 \\
\hline SD & 34.4 & 37.8 & 19.0 \\
\hline No. live needles & 149.0 & 153.7 & 122.5 \\
\hline SD & 26.5 & 24.7 & 24.9 \\
\hline Needle length $\mathrm{mm}$ & 12.8 & 12.6 & 11.2 \\
\hline SD & 2.0 & 2.1 & 1.5 \\
\hline Live needles. $\mathrm{mm}^{-1}$ & 1.34 & 1.43 & 1.82 \\
\hline $\mathrm{SD}$ & 0.36 & 0.37 & 0.34 \\
\hline Tot. needle length $\mathrm{cm}$ & 191.3 & 196.5 & 136.6 \\
\hline $\mathrm{SD}$ & 45.0 & 52.6 & 30.7 \\
\hline No. samples & 20 & 20 & 20 \\
\hline \multicolumn{4}{|l|}{ Order $>1$} \\
\hline Mean shoot length $\mathrm{mm}$ & 35.1 & 32.7 & 25.4 \\
\hline SD & 5.2 & 5.5 & 4.5 \\
\hline No. shoots & 55.7 & 58.5 & 52.6 \\
\hline $\mathrm{SD}$ & 28.0 & 28.1 & 22.0 \\
\hline No. live needles & 1822.0 & 1804.3 & 1321.2 \\
\hline SD & 922.1 & 884.1 & 796.5 \\
\hline Needle length $\mathrm{mm}$ & 12.5 & 12.0 & 10.6 \\
\hline SD & 2.2 & 2.0 & 1.3 \\
\hline Live needles. $\mathrm{mm}^{-1}$ & 1.60 & 1.61 & 1.68 \\
\hline $\mathrm{SD}$ & 0.30 & 0.16 & 0.13 \\
\hline Tot. shoot length $\mathrm{cm}$ & 183.7 & 178.8 & 144.0 \\
\hline SD & 99.3 & 88.6 & 74.3 \\
\hline Tot. needle length $\mathrm{cm}$ & 2276.1 & 2232.6 & 1390.3 \\
\hline SD & 1185.7 & 1208.1 & 836.3 \\
\hline No. samples & 19 & 20 & 20 \\
\hline
\end{tabular}

regressions for individual treatments, and common relationships between $q$ and length were therefore calculated.

Using these, and the observed mean lengths (cf. Table 5), the time-course of change in $q$ was estimated (Fig. 4a). Thus the first-order $\mathrm{C}+1$ shoot axis of mean length increased in mass by $0.137 \mathrm{~g}$ between 31 May and 19 September 1988, the $\mathrm{C}+2$ shoot axis by $0.357 \mathrm{~g}$ and the $\mathrm{C}+3$ shoot axis by $1.075 \mathrm{~g}$, i.e. an increase of $1.569 \mathrm{~g}$ for existing shoot axes of the first order (Fig. 4 b).

In this general trend of increase, decreases in the mass of second-order shoot axes were also observed. Between 31 May and 14 June 1988, q
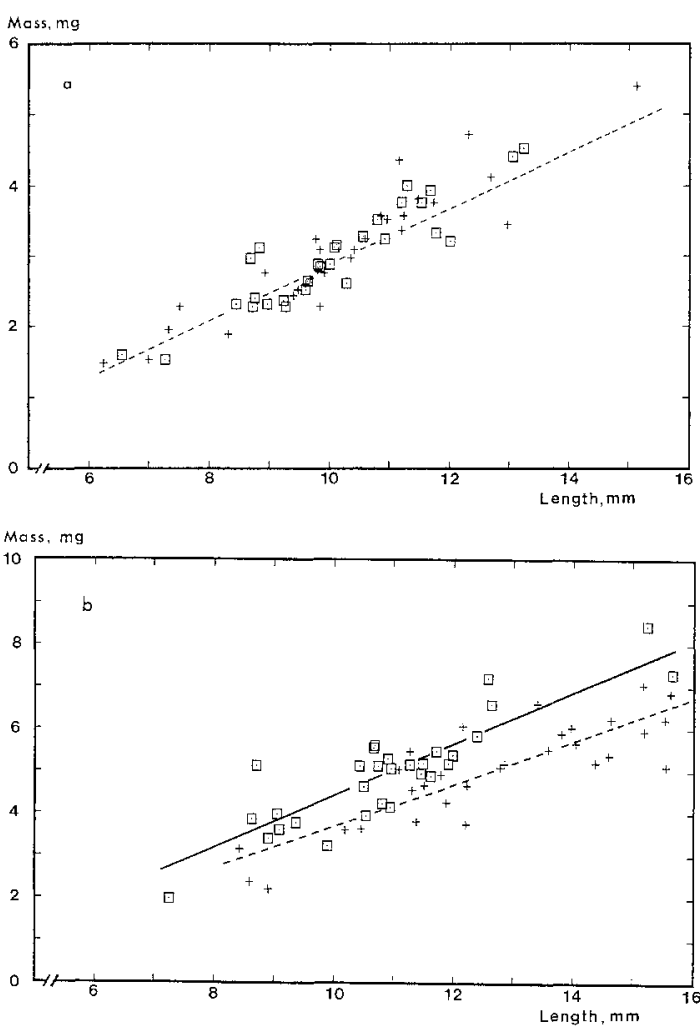

Fig. 2(a, b). Relationships between single-needle length (mm) and dry mass (mg). (a) Within an age-class in different years: $C+1$ needles in September $1987(+)$ and September 1988 (ㄱ) , without distinction as to treatment (common regression line). (b) Between age-classes on the same occasion: current $(\mathrm{C} 88,+)$ and $\mathrm{C}+3(\square)$ needles in September $19888^{* *}$.

decreased in both $\mathrm{C}+1$ and $\mathrm{C}+2$ axes (Fig. 4 c; Table 5). After correction for the carbohydrate content, the RDM of second-order axes also decreased. In the corresponding age-classes in 1987 , similar decreases in $q$ were observed, that in the $\mathrm{C}+1$ (C86) shoot axis being just significant (*; $-0.071 \mathrm{~g}, t=2.558,58$ d.f.).

While in terms of length, shoots of orders $>1$ dominate branch structure (compare Tables 5, 6 and 8 ), individual shoots are, on average, short and of small diameter. A large proportion of the transverse section consists of parenchymatous cells and phloem, and wood increment is limited; the movement of reserves is therefore clearly mirrored by dry-matter variations.

\section{Existing structures: mortality}

By 3 June 1987, some needle loss had already occurred in all three age-classes on the first- 

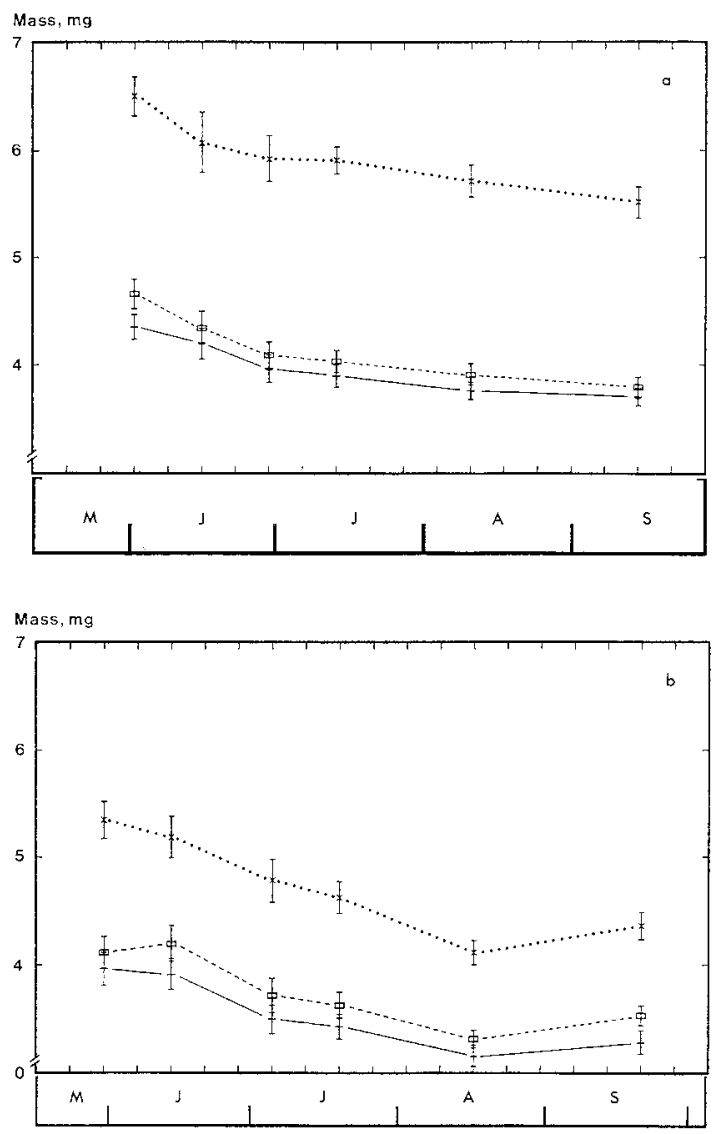

Fig. 3(a, b). Seasonal variation in dry mass \pm 1 SEE, of the standard needle $(10 \mathrm{~mm})$ in 1987 and 1988. (a) 1987, (b) 1988, for age-classes $\mathrm{C}+1(+), \mathrm{C}+2(\neg)$ and $\mathrm{C}+3(\mathrm{x})$. Means and SEEs calculated from regressions (compare Fig. 2).

Table 7. Ranking of single needle mass by ageclasses in September 1987 (compare Fig. 3). Student's t, 58 degrees of freedom

\begin{tabular}{llll}
\hline Age-class & C86 & C85 & C84 \\
\hline C87 & 2.255 & 2.591 & 12.553 \\
C86 & $*$ & 0.678 & 11.309 \\
C85 & - & NS & $* * * *$ \\
& - & - & 9.944 \\
& & & $* * * *$ \\
\hline
\end{tabular}

order shoots. From a comparison of the number of needle scars with the number of live needles, needle survivorship was estimated at 964, 936 and $925 \% / 00$ in age-classes $\mathrm{C}+1, \mathrm{C}+2$ and $\mathrm{C}+3$, respectively. The corresponding figures for 31 May 1988 were 988,981 and $928 \mathrm{o} / \mathrm{oo}$.

The absence of significant, negative trends in needle number on first-order shoots between the third and the seventh samplings in 1987 and 1988 (Table 3), implies that no shoots or needles died during that period. The dry-matter and carbohydrate dynamics of existing needles on first-order shoots during this period may therefore be calculated under the assumption of a constant population size (at least as regards $\mathrm{C}+2$ and $\mathrm{C}+3$ needles; cf. Table 5). The same assumption may also be applied to first-order shoots in each of the two years, and to shoots and needles of order $>1$ in age-classes $\mathrm{C}+1$ and $\mathrm{C}+2$ in 1987. For order $>1$ shoots and needles in 1988, the negative trends observed mean that the assumption does not apply.

In terms of actual numbers and lengths of needles and shoots at the beginning and end of the sampling period, the observed trends in axes of order $>1$ translate as shown in Table 8 .

For age-class $\mathrm{C}+1$ on shoots of order $>1$, subsequent calculations must be made under two separate sets of assumptions: (a) that needle and shoot mortality occurred (cf. Table 8) and (b) that no mortality occurred. For age-class $\mathrm{C}+2$, needle and shoot mortality will be assumed to have occurred as in Table 8 .

\section{Growth and dry-matter allocation}

Carbohydrate pool: needles

As no significant differences between treatments, with respect to structure, were found in 1987, pool sizes for needles were calculated for the joint material (Control $+\mathrm{F}+\mathrm{IL}$ ), using a common needle length.

The carbohydrate pool in existing needles (combined order 1 and $>1$, Fig. 5a) reached its maximum size by 3 June (3.241 g), then began to decrease. By 22 September it contained 0.717 g, made up almost entirely of sugars (compare Fig. 1 a, b). The carbohydrate pool was distributed between the existing age-classes in the proportions 55.9, 35.3 and $8.8 \%(\mathrm{C}+1, \mathrm{C}+2$ and $\mathrm{C}+3$, respectively), i.e. in about the same proportions as needle numbers (Table 5). Until mid-August 1987, too little current needle was available for carbohydrate analysis.

By far the greater part of the total carbohydrate pool in existing needles was in needles of age $\mathrm{C}+1$ (Fig. 5 b), reflecting their numerical dominance (Table 5).

In 1988, the carbohydrate content of existing needles reached its maximum about ten days 

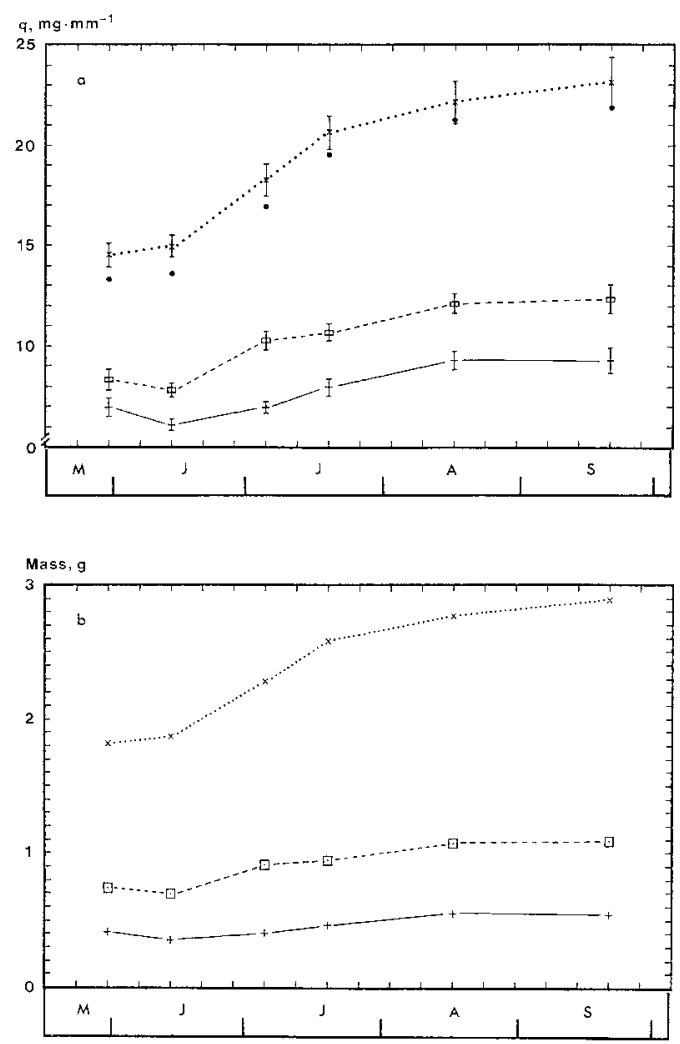

Table 8. Estimates of mean number and length of $C+1$ and $C+2$ shoot axes and needles in the spring and autumn of 1988, for order $>1$ axes on whorl 4 branches of Norway spruce trees. It is inferred that mortality corresponds to the difference between the estimates for May and September.

\begin{tabular}{|c|c|c|c|}
\hline \multirow[b]{2}{*}{ Item } & \multirow[b]{2}{*}{ Date } & \multicolumn{2}{|c|}{ Age-class } \\
\hline & & $\begin{array}{l}\mathrm{C}+1 \\
(\mathrm{C} 87)\end{array}$ & $\begin{array}{l}\mathrm{C}+2 \\
(\mathrm{C} 86)\end{array}$ \\
\hline \multirow[t]{2}{*}{ No. shoots } & 31 May & 17.7 & 7.0 \\
\hline & 19 Sept. & 16.0 & 5.5 \\
\hline \multirow{2}{*}{$\Sigma$ Shoot length, $\mathrm{cm}$} & 31 May & 51.9 & 29.2 \\
\hline & 19 Sept. & 38.9 & 19.0 \\
\hline \multirow[t]{2}{*}{ No. live needles } & 31 May & 905.3 & 545.8 \\
\hline & $19 \mathrm{Sept}$ & 824.3 & 403.3 \\
\hline
\end{tabular}

later than in 1987 (ca. 14 June; Fig. 1 c, d). On that date, the $\mathrm{F}$ needles contained the largest carbohydrate pool (Fig. 6a). In the subsequent decline, both the carbohydrate content (principally starch) and the pool size in the needles of the control continued to exceed those in the $\mathrm{F}$ and IL treatments. The most notable difference occurred on 16 August, which was also the point at which pool size reached its lowest level. The

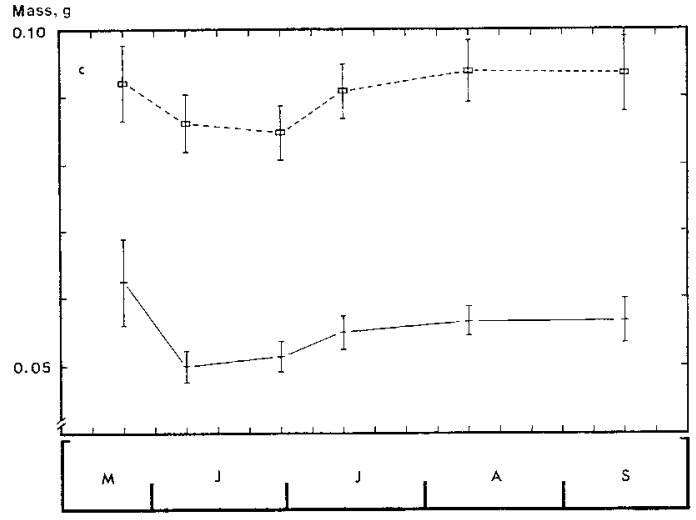

Fig. 4(a-c). Seasonal development of existing shoot axes in 1988. (a) Expressed per unit length $\left(\mathrm{mg} \cdot \mathrm{mm}^{-1}\right)$ for first-order $\mathrm{C}+1(+), \mathrm{C}+2(\square)$ and $\mathrm{C}+3(\mathrm{x})$ shoots ( denotes RDM of $\mathrm{C}+3$ axis); (b) for the corresponding first-order axis of mean length (g); (c) for the secondorder shoot of mean length $(\mathrm{g})$. Bars - 1 SEE. Note the marked decrease in mass of second-order shoots between 31 May and 14 June (Fig. 4 c).

pool increased again by 19 September (Fig. 6; mainly sugars), in contrast to 1987 , when there was no end-of-season increase.

The carbohydrate pool at its peak was substantially smaller in 1988 than in $1987(1.950 \mathrm{~g}$ in the control; but compare needle numbers in Table 5). When needle mortality (ca. 223 needles, cf. Table 8) is not taken into account, the carbohydrate pool was smaller absolutely at the end of the 1988 growing season, than at the equivalent time in 1987 (e.g. control $0.587 \mathrm{~g}$ ).

If needle mortality is taken into account (Table 8), the carbohydrate pool in existing needles in the control, at the end of the growing season of 1988 , was ca. $23 \%$ larger than in 1987 , and ca. 16 and $25 \%$ larger than that in the $F$ and IL treatments, respectively, in 1988.

The largest proportion of the needle carbohydrate pool at the end of the 1988 season was in the current (C88) needles $(48.8,59.6$ and $58.6 \%$ in control, $\mathrm{F}$ and IL, respectively; cf. Fig. 6 d), i.e. rather more than the share of current needles in the total number of needles on the branch (compare Tables 5 and 6). Most of this was in needles of order $>1$. 


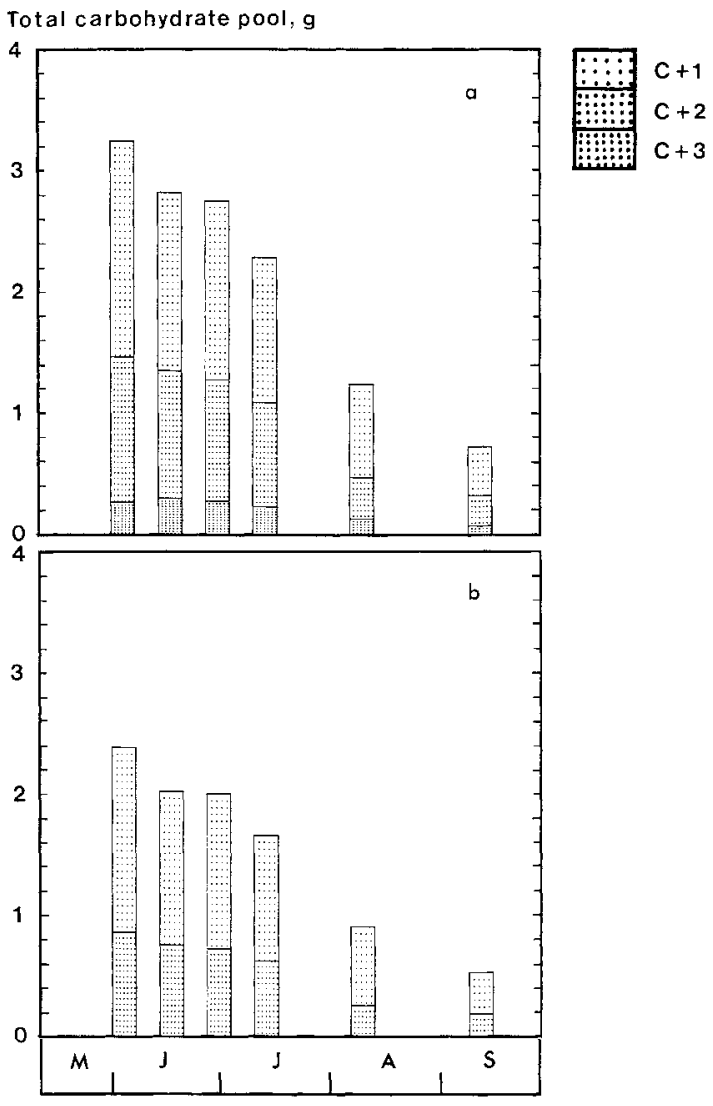

Fig. 5(a,b). Seasonal variation in the total carbohydrate pool in existing needles in 1987 , by age classes (g). (a) Order 1, (b) order $>1$. Compare Fig. 6.

\section{Carbohydrate pool: shoot axes}

In existing shoot axes in 1988, the range of variation in the carbohydrate pool was narrower than that in needles (Fig. 6 b). The decline in starch content was masked by the increase in mass resulting from radial growth. The carbohydrate pool in shoot axes reached its lowest level in mid-August 1988, after which there was a small increase.

\section{Carbohydrate pool: rates of accumulation and mobilisation}

Between 31 May and 14 June, the carbohydrate pool in existing structures of $F$ and IL branches increased more rapidly than that in the control (equivalent to +24 and $+20 \mathrm{mg} \mathrm{day}^{-1}$, respectively; compare control, $+10 \mathrm{mg}$ day $^{-1}$ ), although the final pool sizes did not differ greatly. The subsequent rate of mobilisation in the control was clearly lower than in the F and IL treatments (compare Fig. $1 \mathrm{c}$ ) and its maximum occurred later. Thus in the F and IL branches, mobilisation was most rapid between 14 June and 5 July ( -48 and $-43 \mathrm{mg}$ day $^{-1}$; compare control, $-25 \mathrm{mg} \mathrm{day}^{-1}$ ), whereas in the control, the highest rate occurred between 5 and 20 July, and did not exceed $-28 \mathrm{mg} \mathrm{day}^{-1}$.

The net total flux of carbohydrates through existing structures between 31 May and 19 September 1988, was estimated by summing changes in pool size. The flux was as follows: control, $-1.265 \mathrm{~g} ; \mathrm{F},-1.438 \mathrm{~g}$; IL $-1.424 \mathrm{~g}$, i.e. average turnover was ca. $13 \%$ higher in the $\mathrm{F}$ and IL treatments than in the control. When fluxes in C88 structures between 5 July and 19 September were taken into account, the average difference in turnover increased slightly, to $18 \%$ (control $-1.310 \mathrm{~g}, \mathrm{~F}-1.522 \mathrm{~g}$, IL $-1.581 \mathrm{~g}$ ).

Three main points are to be noted. First, that the carbohydrate pool at its peak may make up about one-fifth of the total mass of existing branch structure, irrespective of treatment. Secondly, that the rate of mobilisation of the carbohydrate pool in the F and IL branches early in the season, was 1.88 and 1.69 times that of the control. Thirdly, that the average total net flux of carbohydrates through existing structures of $\mathrm{F}$ and IL branches was ca. 1.13 times that in the control.

The effects of the observed differences in the size and duration of the carbohydrate pool on estimated growth, are considered below.

\section{Estimates of growth: dry-matter and RDM}

Variation in the carbohydrate content evidently underlies much of the variation in the drymatter content of both needles and shoot axes. What effect has it on estimates of growth?

The consequences may be illustrated by estimating growth in terms (a) of dry matter (including carbohydrates), and (b) of RDM. It will be assumed that existing structure is common to the control, F and IL treatments and constant throughout, i.e. the effects of mortality will be eliminated. Current growth, in terms of numbers, lengths, etc., is that actually observed.

\section{Common existing structure}

The carbohydrate content of shoot axes was not measured in 1987. The analysis of allocation in that year must therefore deal mainly with dry matter (Table 9). Dry-matter and needle RDM 

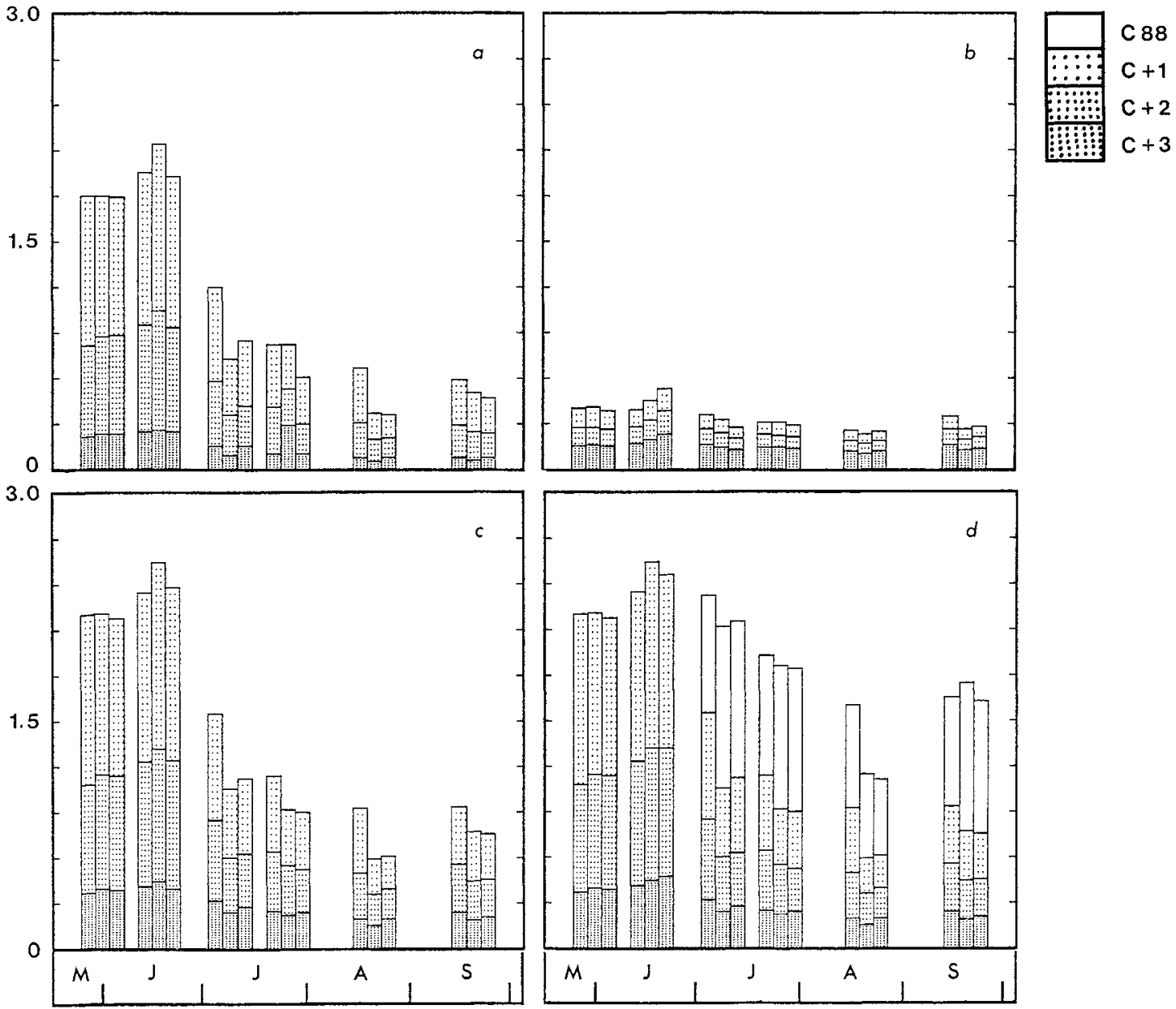

Fig. 6(a-d). Seasonal variation in the total carbohydrate pool in needles and shoot axes (orders 1 plus $>1$ ), by treatments and age-classes, in 1988 (g). (a) Existing needles, (b) existing shoot axes, (c) existing needles plus shoot axes $(a+b)$, (d) all needles and shoot axes (C88 from 5 July). Each group of three bars is in the order control, F, IL.

values in the table are based on constant numbers and lengths for existing structures.

On 3 June 1987, before outward signs of growth appeared (but cf. Fig. 1), the mass of existing structures was $12.829 \mathrm{~g}$. Between 3 June and 22 September, a total of $5.440 \mathrm{~g}$ of current shoot was produced (4.265 g of needles, $1.175 \mathrm{~g}$ of axes). During this period, the net increase in mass of existing structures was $0.343 \mathrm{~g}$, consisting of an increase of $0.694 \mathrm{~g}$ in axes and a decrease of $-0.351 \mathrm{~g}$ in needles. The total increase in mass was therefore $5.783 \mathrm{~g}$ (Table 9, cols. (3) and (5)). The final branch mass on 22 September was $18.612 \mathrm{~g}$.

When the needles only are considered, growth estimated in terms of RDM gives a different picture. Production of current needles was 3.771 g, while the RDM of existing needles increased by $2.066 \mathrm{~g}$; in sum, $5.837 \mathrm{~g}$ (Table 9, col. (7)). The increase in the RDM of the needles alone was thus larger than the sum of the dry-matter increase of both needles and shoot axes, as estimated above.

On 31 May 1988, there were no outward signs of growth (but cf. Fig. 1). On that date, the sum of the dry-matter pools in needles and shoots, i.e. the initial mass of the branch, was $11.785 \mathrm{~g}$. By 19 September, it had increased to $12.186 \mathrm{~g}$ (Fig. 7 a). The increase (0.401 g) was not significant.

Differences in carbohydrate content (Fig. 1) between the control, F and IL treatments re- 
Table 9. Distribution by orders and age-classes of the increment ( $m g$ ) of needles and shoot axes in whorl 4 branches of the control trees between 3 June and 22 September 1987 (RDM increment shown for needles only). Numbers ( $n$ ) and lengths ( $l$ ) of all structures set to standard values (observed length and number for shoots, observed number and standard length $(10 \mathrm{~mm})$ for needles). Minus signs denote decreases

\begin{tabular}{|c|c|c|c|c|c|c|}
\hline \multirow[b]{2}{*}{$\begin{array}{l}\text { Age-class } \\
\text { Col.(1) }\end{array}$} & \multicolumn{4}{|l|}{ Dry-matter } & \multicolumn{2}{|l|}{ RDM } \\
\hline & $\begin{array}{l}\text { Shoots } \\
\delta m \\
\mathrm{mg} \cdot \mathrm{cm}^{-1} \\
(2)\end{array}$ & $\begin{array}{l}\delta m \cdot l \cdot n \\
\mathrm{mg} \\
(3)\end{array}$ & $\begin{array}{l}\text { Needles } \\
\delta m / \text { needle } \\
\mathrm{mg} \\
(4)\end{array}$ & $\begin{array}{l}\delta m \cdot n \\
m g \\
(5)\end{array}$ & $\begin{array}{l}\text { Needles } \\
\dot{\delta} m / \text { needle } \\
\mathrm{mg} \\
(6)\end{array}$ & $\begin{array}{l}\delta m \cdot n \\
\mathrm{mg} \\
(7)\end{array}$ \\
\hline \multicolumn{7}{|l|}{$\begin{array}{l}\text { Current } \\
\text { C87 }\end{array}$} \\
\hline $\begin{array}{l}\text { Order } 1 \\
\quad>1 \\
\text { Sum C } 87 \\
\text { Existing } \\
C-1 \text { (C86) }\end{array}$ & $\begin{array}{l}40.64 \\
13.63\end{array}$ & $\begin{array}{r}203.2 \\
971.8 \\
1175.0\end{array}$ & $\begin{array}{l}3.442 \\
2.695\end{array}$ & $\begin{array}{r}454.3 \\
3810.7 \\
4265.0\end{array}$ & $\begin{array}{l}2.436 \\
2.439\end{array}$ & $\begin{array}{r}321.6 \\
3449.0 \\
3770.6\end{array}$ \\
\hline $\begin{array}{l}\text { Order } 1 \\
\quad>1 \\
\text { Sum } C+1 \\
C+2(C 85)\end{array}$ & $\begin{array}{l}2.57 \\
0.99\end{array}$ & $\begin{array}{l}19.3 \\
63.6 \\
82.9\end{array}$ & $\begin{array}{l}-0.656 \\
-0.577\end{array}$ & $\begin{array}{l}-104.3 \\
-691.8 \\
-796.1\end{array}$ & $\begin{array}{l}0.547 \\
1.316\end{array}$ & $\begin{array}{r}87.0 \\
1578.6 \\
1665.7\end{array}$ \\
\hline $\begin{array}{l}\text { Order } 1 \\
\quad>1 \\
\text { Sum } C+2 \\
C+3(C 84)\end{array}$ & $\begin{array}{r}22.04 \\
1.18\end{array}$ & $\begin{array}{r}242.4 \\
37.3 \\
279.7\end{array}$ & $\begin{array}{l}-0.875 \\
-0.640\end{array}$ & $\begin{array}{l}-182.0 \\
-416.6 \\
-598.6\end{array}$ & $\begin{array}{l}0.390 \\
0.397\end{array}$ & $\begin{array}{r}81.2 \\
258.6 \\
339.7\end{array}$ \\
\hline $\begin{array}{c}\text { Order } 1 \\
\quad>1 \\
\text { Sum } C+3\end{array}$ & $\begin{array}{l}30.08 \\
-\end{array}$ & $\begin{array}{r}330.9 \\
-\quad 330.9\end{array}$ & $\begin{array}{l}-0.989 \\
-\end{array}$ & $\begin{array}{l}-149.3 \\
- \\
-149.3\end{array}$ & $\underline{0.402}^{-}$ & $\begin{array}{l}\frac{60.8}{60.8} \\
\frac{-}{6}\end{array}$ \\
\hline $\begin{array}{l}\text { Sum } C+3 \\
\text { Total } \\
C-C+3\end{array}$ & & 1868.5 & & -149.3 & 2721.0 & \\
\hline
\end{tabular}

sulted in small differences in the RDM of existing structures. If these are disregarded, the average values for the RDM of existing structures on 31 May and 19 September 1988 were $9.587 \mathrm{~g}$ and $11.282 \mathrm{~g}$. The average increase in the 'structural' mass of the branch was therefore 1.695 g, i.e. 4.2 times greater than that estimated from the difference in the dry matter pools.

The RDM of both needles and shoot axes decreased between 31 May and 14 June 1988, i.e. to the time at which current shoot growth began (Fig. 7).

Clear differences in the growth of current shoots in the control, as compared with the $\mathrm{F}$ and IL treatments, appeared by midsummer and were maintained. By 19 September, the drymatter pool for current needles and shoot axes in the control was $7.841 \mathrm{~g}$, in the $\mathrm{F}$ treatment $13.120 \mathrm{~g}$ and in the IL treatment $12.363 \mathrm{~g}$ (Fig. 7 b). Current growth was greater in the treatments receiving fertiliser than in the control, but they did not themselves differ significantly.

On 19 September, the RDM pool in current growth was $7.121 \mathrm{~g}$ in the control, $12.145 \mathrm{~g}$ in
$\mathrm{F}$ and $11.491 \mathrm{~g}$ in IL, i.e. $91-93 \%$ of the drymatter pool, cf. Fig. 1.

The sum of the dry-matter pools of existing plus current structures, i.e. final branch mass, on 19 September 1988 was $19.307 \mathrm{~g}$ for the control, 24.331 g for $F$ and $23.667 \mathrm{~g}$ for IL. Assuming that the increase in mass of existing structures was $0.401 \mathrm{~g}$, as above, the total drymatter increase in the whorl 4 branch of the control, F and IL treatments may be estimated at $8.242,13.521$ and $12.764 \mathrm{~g}$, respectively.

Since, however, the increase of $0.401 \mathrm{~g}$ in existing structures was not significant, an estimate of dry-matter increase must be limited to current growth, i.e. $7.841,13.120$ and $12.363 \mathrm{~g}$. The corresponding $\mathrm{RDM}$ values, including a common increase of $1.695 \mathrm{~g}$, would be $8.816,13.840$ and $13.186 \mathrm{~g}$.

\section{Observed initial structure}

The assumption of a common initial base is not essential to the above comparison. Taking existing structure in the control, $F$ and IL treatments to be that actually observed on 31 May 1988 , 

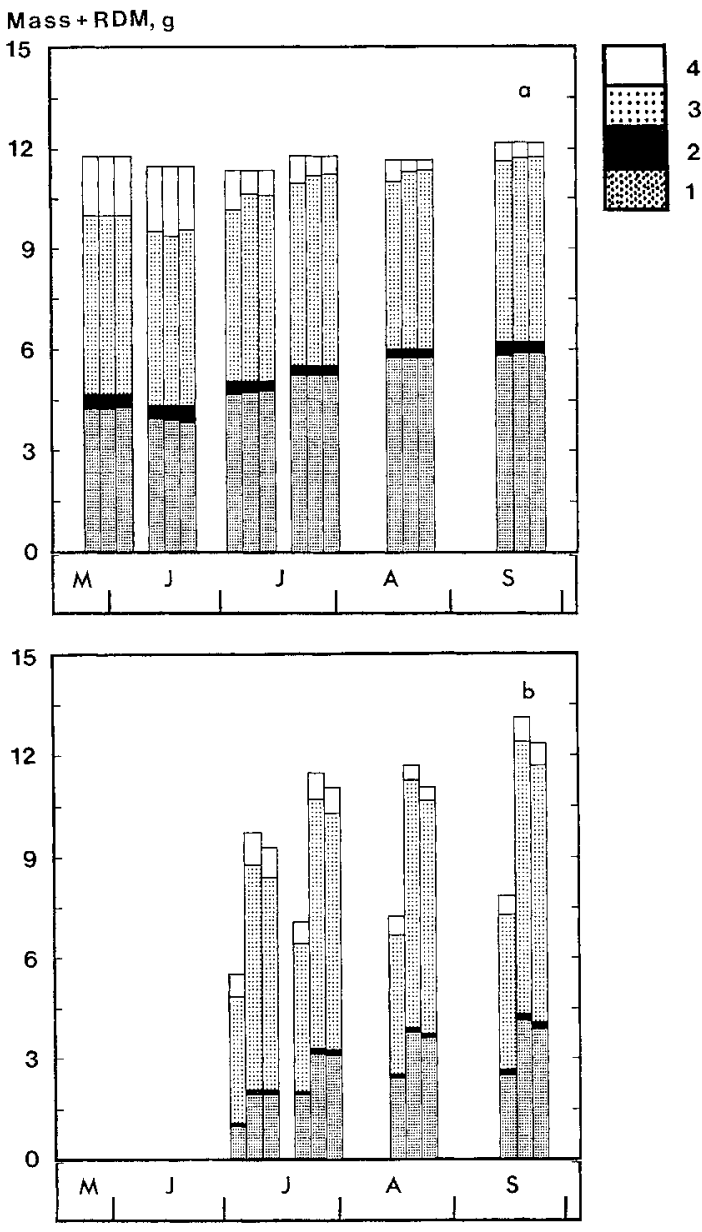

Fig. 7(a,b). Seasonal variation in the total dry-matter pool by components, in needles and shoots in 1988, by treatments (g). (a) Existing shoots: from the base (1) RDM, (2) total carbohydrates; existing needles, (3) RDM and (4) total carbohydrates. (b) Current shoot axes (C88): from the base, (1) RDM, (2) total carbohydrates; current needles (C88), (3) RDM, (4) total carbohydrates. Current production from 5 July 1988. The total height of each bar represents total dry mass. For existing needles and shoots, a common structures was used. For C88 needles and shoots, observed mean values for individual treatments were used. Needle mortality not included.

and constant throughout, dry-matter increment in existing structures may be estimated at 0.603 , 0.905 and $0.523 \mathrm{~g}$, respectively. The corresponding total dry-matter increase (current + existing) was $7.189,11.175$ and $13.240 \mathrm{~g}$ in control, $\mathrm{F}$ and IL.

On the same assumptions, the increases in the RDM of existing structures were $1.831,1.821$ and $2.020 \mathrm{~g}$ in the control, F and IL treatments.
For total increment, the corresponding values for RDM were $7.786,11.354$ and $13.833 \mathrm{~g}$.

The distribution of change in RDM is shown by age classes in Fig. 8. With the exception of the $\mathrm{C}+3$ needles, the RDM of both existing needles and shoot axes generally increased between 31 May and 19 September. Most of the increase in needle $\mathrm{RDM}$ was in order $>1$ needles (more numerous than those of order 1; cf. Tables 5 and 9), while the $\mathrm{C}+3$ shoot axis of order 1 showed the largest increase among existing shoot axes in all treatments. The overall increases within an age class may, however, conceal differences between treatments and orders. Thus the RDM of existing needle age classes of order 1 in the control decreased $(-67 \mathrm{mg})$, whereas it increased in needles of order $>1$ $(+226 \mathrm{mg})$. In the F and IL treatments, there were only small decreases in the RDM of firstorder $\mathrm{C}+3$ needles.

\section{Effects of mortality}

Between 31 May and 19 September 1988, 81 $\mathrm{C}+1$ needles and $143 \mathrm{C}+2$ needles died and were shed from order $>1$ shoots (Table 8 ). During the same period, shoots were lost, equivalent to $13.0 \mathrm{~cm}$ of $\mathrm{C}+1$ and $10.2 \mathrm{~cm}$ of $\mathrm{C}+2$ shoot axes (Table 8). Assuming the unit mass of these needles and axes on 19 September, to have been that of the needles and axes then present, dry-matter losses by mortality were $0.699 \mathrm{~g}$ of needle and $0.311 \mathrm{~g}$ of shoot axes. This is equivalent to a decrease of $8.3 \%$ in the end-of-season dry-matter pool of existing structures.

\section{Discussion}

\section{Pattern of response}

The structural response to an increased nutrient supply consists of a series of linked changes in allocation, which initially take place at the level of the module. The response will be modified by other factors, e.g. temperature, during the growing season.

Weather conditions in 1987 and 1988 contrasted strongly. The 1987 growing season began with cold weather in May, followed by a cool, wet summer. The diurnal mean air temperature in June and July was lower by ca. $2^{\circ} \mathrm{C}$, and in August by $4^{\circ} \mathrm{C}$, as compared with the period 


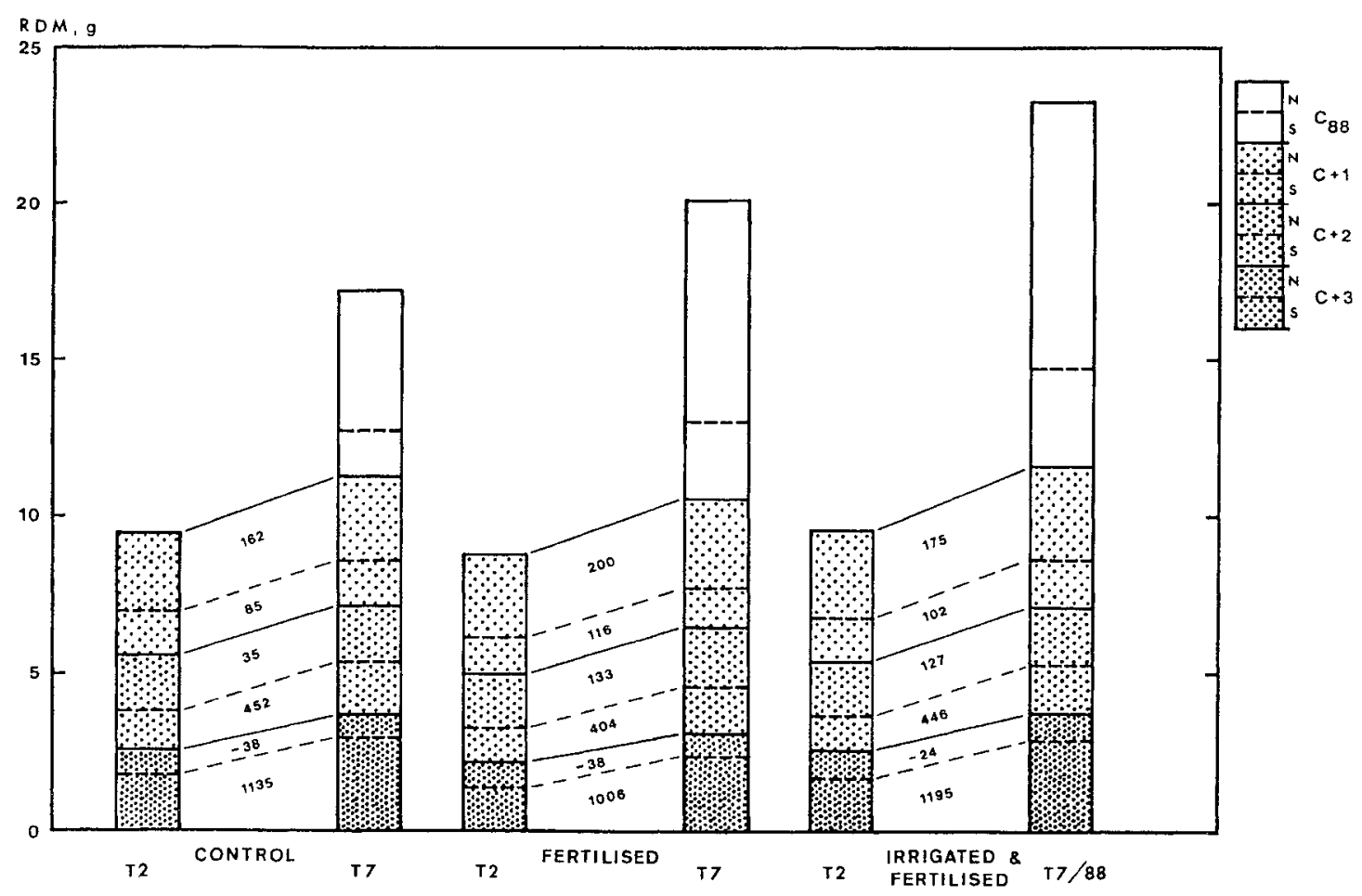

Fig. 8. RDM of existing structures on 31 May (T2) and of existing structures + current production, by age-classes, on 19 September 1988 (T7), for control, F and IL branches. The observed value for each treatment is shown for both existing structure and current production. Existing structure is constant between T2 and T7. Increment of existing structure (mg) is shown for needles (N) and shoot axes (S) by age-classes. Minus signs denote decreases. Mortality is not included.

1951-80 (Degermark, 1988). Tree growth was poor. Almost all structural characters investigated showed no response to increased nutrient supply. A small increase in the mean length of current $(\mathrm{C} 87)$ needles in the $\mathrm{F}$ treatment was the exception, but was not significant. It suggests, nonetheless, increased nutrient uptake in the $F$ treatment in the first growing season, and is supported by the higher $\mathrm{N}$ concentration in C87 needles (Linder \& Flower-Ellis, in prep.). The higher rates of carbohydrate accumulation in $\mathrm{F}$ and IL at the beginning of the 1988 growing season point in the same direction.

In 1988, warm weather in early May led to a rapid thaw. This was followed by an unusually warm, dry June and July and a normally warm, but rainy August (Degermark, 1989). The course of starch accumulation at the beginning of the 1988 growing season was similar in the control, $\mathrm{F}$ and IL treatments. Although the accumulation rate between 31 May and 14 June was higher in F and IL than in the control, there was little difference in the peak size of the carbo- hydrate pool in existing structures. However, starch reserves were mobilised earlier, and more rapidly, in the F and IL treatments (cf. Ericsson, 1979; Fig. 5(a)), and the total turnover was larger. Current growth in F and IL, respectively, was 1.67 and 1.58 times that in the control.

Differences in the rate of carbohydrate mobilisation were associated with differences in phenology; budbreak and flushing occurred earlier in the F and IL treatments (cf. also Pinus sylvestris; Flower-Ellis, 1982). Phenological differences between treatments recurred at Flakaliden after 1988 (Nylander, unpublished).

By the end of the 1988 growing season, whorl 4 branch structure in treatments receiving fertiliser clearly differed from that in the control. How did the differences arise?

The current shoot of order 1 was longer in the $\mathrm{F}$ and IL treatments than in the control. The number of needles per current shoot also increased (Table 6). The larger number of needles on first-order shoots appears rather to have resulted from an increase in mean shoot 
length in 1988, than from an increase in the number of needle primordia formed in 1987. Comparison at a common axis length eliminated a prima facie significant difference, and confirmed that current needles were more widely spaced on $\mathrm{F}$ and IL trees than on control trees, i.e. internodes were ca. 39\% longer (compare Cannell \& Willett, 1975).

Although current needle length also increased, differences among treatments in needle length density $\left(\mathrm{cm} \mathrm{cm}^{-1}\right.$ axis, cf. needle area density; Wang, Jarvis \& Benson, 1990) on first-order current shoots were consequently small in the 1988 growing season (cf. Table 6; control 19.7, F 16.2, IL $17.0 \mathrm{~cm} \mathrm{~cm}^{-1}$ ).

In order $>1$, the number of current shoots on the whorl 4 branch did not increase in the F and IL treatments in 1988. The number of current needles did so, but this increase was mainly accounted for by increased mean length of current shoots. With a concomitant increase in current needle length, the total length of C88 needles in the $\mathrm{F}$ and IL treatments also increased. As in the case of first-order shoots, this resulted in small differences among treatments in needle length density on current shoots (cf. Table 6).

When the steps in the response pattern (see Introduction) are considered, the present material provided no evidence for an effect of increased nutrient supply on the length of needles in the first season (step 1). It suggests that there was no increase in the number of needle primordia (step 2). For whorl 4 branches, any increase in nutrient uptake in the first season did not lead to an increase in the number of current shoots in the second season (step 3), but did lead to an increase in shoot length (step 4) and needle length (step 5). There was no evidence for a difference between treatments with respect to step (6).

Thus, whorl 4 branches responded to nutrient addition by a co-related increase in current shoot length and needle number, and an increase in needle length. The result, for the F and IL treatments, was a ca. $60 \%$ increase in the total length of current needles, and a ca. $28 \%$ increase in the total length of current shoots, by the end of the second season. The greater shoot length alone should suffice to account for any subsequent increase in the number of current shoots, by way of the relationship between parent shoot length and the number and length of laterals (compare Cannell, 1974; Cochrane \& Ford, 1978; Flower-Ellis \& Persson, 1980). The response in 1987 was most probably limited by poor growing conditions (e.g. as regards step 1). Through their effect on predetermined structures in the bud, the poor conditions in 1987 probably also limited the capacity of branches to respond to favourable weather in 1988.

This clearly illustrates the difficulty of analysing, in a field experiment, the initial stages of a response to treatment. Replicate sets of years (1) and (2) will be required, if an adequate 'sample' of the response mechanism is to be obtained. This would normally imply the use of seedlings in growth chambers. However, since the response mechanism in juvenile material may be other than that in older material, this might lead to difficulty in applying the results. A modified 'single-tree plot' approach, using established trees, might provide a means of replicating the initial stages under field conditions. Varying weather conditions in years (1) and (2) might then be turned to advantage in determining the 'mean response' and its variability.

\section{Carbohydrate and dry-matter dynamics}

An important aspect of the response was the difference in the rate and timing of mobilisation of carbohydrate reserves in existing structures of $F$ and IL branches, and their larger total turnover of carbohydrates. Any one of these factors is sufficient to account for the observed difference in growth. Reserve carbohydrate mobilised in the control in the latter part of the growing season, could have made little contribution to shoot growth, and may have been translocated to other sinks, e.g. roots (Ericsson \& Persson, 1980; Àgren, Axelsson, Flower-Ellis, Linder, Persson, Staaf \& Troeng, 1980).

The accumulation of starch, which began early in May in both 1987 and 1988, was associated with an increase in the dry mass of needles and shoot axes. Mobilisation of the reserves led initially to a sharp decrease in the RDM of both needles and shoot axes, followed by a gradual increase.

While an increase in the RDM of axes can mainly be ascribed to radial increment, the decrease in the RDM of both needles and axes, and the subsequent increase in needles, are less 
readily explained. It may be that the carbohydrates analysed did not account for all constituents of the reserves. Norway spruce needles contain substances other than those analysed in the present study, e.g., raffinose, stachyose, verbascose (Jeremias, 1969), which may also occur in shoot axes. Individually, these substances are present in far smaller amounts than is starch, and than are some of the sugars analysed here. Needle RDM may, however, be measurably affected by the simultaneous mobilisation of several of them. Since these substances were not included in the present analyses, and since their seasonal variation under the conditions at Flakaliden is unknown (but compare Jeremias, 1969), the dynamics of RDM cannot, at present, be accounted for in this way.

A further possibility is that both the decrease, and subsequent increase, of RDM may be connected with nitrogen metabolism. A decrease in the concentration of $\mathrm{N}$ in the needles at the relevant time has been observed in both Scots pine and Norway spruce (Aronsson \& Elowson, 1980; Linder \& Flower-Ellis, 1992). A decrease in RDM, unaccompanied by a change in needle $\mathrm{N}$ content, would have the opposite effect. This lends some support to the existence of the decreases in RDM, in needles at least. Since, however, data on mineral nutrients are not reported here (Linder \& Flower-Ellis in prep.), this explanation must also remain tentative.

\section{Increase in needle mass with age}

Old needles (e.g. $C+3$ ), when compared at fixed length, had a larger mass and RDM than younger needles. Was the difference the result (a) of the confounding of an age effect with a position effect or (b) of the secondary incorporation of carbon into the needles?

In support of the first of these, the following may be adduced: Proximal increments tend to be longer than more distal increments on an axis (e.g. Renvall, 1914; Flower-Ellis et al., 1976; $\mathrm{Fu} \&$ Tamm, 1985). The length of needles tends to be correlated with the length of the shoot on which they are borne. Needle length should therefore tend to decrease from the proximal towards the distal end of an axis of any order, and with it, other needle dimensions which affect mass. However, correlation frequently is weak, because other factors (in northern regions, mainly temperature: e.g. Hustich, 1948; Junttila \& Heide, 1981), exert an overriding influence on needle length. On balance, there appears to be no firm evidence for the existence of a trend in needle length with position, such that it would decisively affect needle mass.

Evidence from other sources suggests that the second possibility is the more probable. Three origins for the greater mass of old needles present themselves, viz. an increase in length, in thickness or in density.

Length increment can probably be ruled out. Notwithstanding early debate (Kraus, 1885; Meissner, 1894, 1897), it has not been convincingly demonstrated that individual conifer needles increase in length after the end of the first growing season. Age-classes $\mathrm{C}+1$ to $\mathrm{C}+3$ were repeatedly sampled in the present study. There was no evidence of a significant trend in needle length with time in any one of them.

Evidence for increasing needle thickness with age was provided over a century ago (e.g. Strasburger, 1891). This will increase the transverse-sectional area of the needle, therefore its mass, but will not necessarily affect its density.

Madgwick \& Tamm (1987) discuss evidence for mass increase in Norway spruce needles with age; they found an increase of ca. $20 \%$ between the first and fifth growing seasons. Increases of similar magnitude in Norway spruce have been reported by van Laar (1976); compare also Morrow \& Timmer (1981). Further evidence is provided by studies of specific leaf area (SLA) in Norway spruce and Scots pine. SLA in Norway spruce was shown to decrease approximately linearly on age over six age classes, which, in the absence e.g. of a trend in needle length, would suggest an increase in needle density with age (Perterer \& Körner, 1990; Fig. 7, and Fig. 8 , Scots pine.).

Indirect evidence is also available from nutrient analyses of conifer needles. These frequently show a decrease in the concentration of several nutrient elements with needle age, such as nitrogen (e.g. Mälkönen, 1974; Lim and Cousens, 1986), suggesting a "dilution effect" brought about by increasing needle density. Against this interpretation, however, observed increases in concentration of other elements (e.g. Ca) must be set.

A possible origin for the increase in needle thickness was early suggested by Meissner 
(1894), among others, as being the growth of phloem cells in the vascular tissue of the needle. This suggestion was pursued by Ewers, who demonstrated secondary production of phloem cells in mature needles of 11 conifer taxa, during needle life-cycles of more than 30 years in some species (Ewers, 1982). This may lie behind the observed increases in mass of Norway spruce needles, although the relationship between the increase in number of phloem cells, and the increase in needle mass, remains to be explicitly quantified. The secondary incorporation of carbon in this way could also cause an increase in density, resulting in the observed decreases in the concentration of certain nutrients with age (but compare $\mathrm{Ca}$ ).

If increases in needle mass with age in Norway spruce are maintained during the lifespan of needles (19 years or more, e.g. Flower-Ellis \& Yang (1987)), the implications for the carbon and nutrient economy of that species are considerable. Taken together with the seasonal variations in dry-matter content and RDM, such increases are a potential source of error, e.g. when nutrient status is determined (Tamm, 1955), when mineral nutrient and carbon budgets are calculated, and when needle area distribution within the canopy is indirectly estimated by way of SLA.

\section{Effects of carbohydrate content on growth estimates}

Extrapolation of the curve for needle starch content in 1987 suggests that starch had begun to accumulate early in May; the starting-point was similar in 1988 . In both years, $25-36 \%$ of the dry-matter content of needles was starch and sugars by mid-May, before trees showed outward signs of activity after the winter. By 22 September, the needles contained ca. $10 \%$ of carbohydrates (mainly sugars, but some starch in the control). These may be regarded as typical values for the beginning and end of the growing season. It is important to note that starch began to accumulate several weeks before the start of the growing season (as defined by the air temperature), while a snow cover existed and while the soil may still have been frozen.

The first-order $\mathrm{C}+1$ needles will serve to illustrate the effects of carbohydrate content on growth estimates. On 3 June (T1) and 22
September 1987 (T2) respectively, their total carbohydrate content was $35.8 \%$ (starch $24.0 \%$ ) and $9.6 \%$ (starch $0.8 \%$ ).

The mass of the single needle, including carbohydrates, on those dates was 4.35 and $3.69 \mathrm{mg}$; expressed as RDM, 2.79 and $3.34 \mathrm{mg}$. By difference, a single needle is found to have lost $0.66 \mathrm{mg}$ (dry matter base) or gained $0.55 \mathrm{mg}$ (RDM base) during the interval T1 ... T2. For a first-order $\mathrm{C}+1$ population of 161 needles, the total dry-matter decrease was $106 \mathrm{mg}$, as compared with an increase of $88 \mathrm{mg}$ in RDM; similar discrepancies occur for other needle age classes, and for shoots.

Sugars are present in needles before starch accumulation begins (ca. $10 \%$ of dry matter; unpublished data, Flakaliden). If the increase in carbohydrate content between 1 May and 3 June is approximated by a straight line, samples taken between those dates would contain between ca. 10 and ca. $36 \%$ of carbohydrate. Use of any such sample for calculating growth as above, would result in a series of discrepancies, comparable to those illustrated.

Similar uncertainty in estimation will occur if treatments result in differences in the rate or seasonal pattern of mobilisation (as in the present study), which affect the carbohydrate content on the second sampling occasion. Use of RDM as a base resulted, in general, in higher estimates of growth than those obtained when total dry-matter was used. The difference between the estimates mirrored the difference in the carbohydrate content at $\mathrm{T} 1$ and $\mathrm{T} 2$.

For eliminating such uncertainty, two alternative courses of action are open: To attempt to avoid the problem, by taking samples when there is no starch present; or to analyse for carbohydrates.

Adoption of the first course presupposes that a 'safe' date can be identified for a particular locality. This seems unlikely, when differences in the dynamics of carbohydrates between years and between treatments, are considered (Ericsson, 1979; Linder \& Flower-Ellis, 1992). It may therefore be necessary to determine the carbohydrate content, when estimating growth in conifers with evergreen leaves, so that it can be expressed in terms of RDM. But is the present definition of RDM adequate?

RDM has been regarded as equivalent to structural dry mass. As a first approximation, 
RDM was defined as "dry mass minus starch" (compare Aronsson \& Elowsson, 1980). As it became clear that variations in dry mass were also associated with seasonal change in other carbohydrates (cf. Fig. 1), the definition of RDM was modified to that used in the present paper. Some variation still remains (cf. Fig. 7): its source has yet to be identified. The analysis of other organic constituents (cf. Jeremias, 1969) may further reduce residual variation, until an operative definition of RDM is reached. This process of successive approximation may make it necessary to question the status of substances conventionally regarded as structural (e.g. hemicellulose). The analysis of dry-matter allocation in woody plants, such as Norway spruce, will not have a firm base until this question has been resolved. There are also important consequences for the interpretation of mineral nutrient concentrations and their seasonal variation. In this respect, only limited progress has been made since this question was originally raised by Tamm (1955).

\section{Demography and growth analysis}

The main aim of this paper was to show how demographic concepts may be used to distinguish processes which normally are confused, thereby increasing understanding of the response to an experimental manipulation. This has been illustrated for a simple, well-defined system, viz. the developing fourth-whorl branch of Norway spruce.

By combining data on the number of organs and their dimensions, with mass and carbohydrate content, a greater insight into processes is obtained, than is possible when information on mass only, or mass and carbohydrate content, are used. The increase in understanding is considerable (compare Fig. 8, Table 9). Thus the ability to maintain a constant structure makes it possible to examine, e.g., the effect of increased nutrient supply on the size and dynamics of the carbohydrate pool, and to treat mortality as a discrete process. By extension, the approach should permit precise, quantitative assessments to be made of the consequences of other experimental manipulations, such as defoliation, on the size and turnover rate of resource pools in general (Ericsson, Larsson \& Tenow, 1980). Properly applied, the combination of demographic, dimensional, gravimetric and analytical information may fulfil many of the requirements outlined by Åren (1981), and should provide modellers with a biologically relevant means of integrating information on structure and function.

\section{References}

Ågren, G.I. 1981. Problems involved in modelling tree growth. In: Understanding and predicting tree growth (ed. S. Linder). Studia Forestalia Suecica 160, 7-18.

Ågren, G., Axelsson, B., Flower-Ellis, J.G.K., Linder, S., Persson, H., Staaf, H. \& Troeng, E. 1980. Annual carbon budget for a young Scots pine. In: Structure and function of northern coniferous forests - an ecosystem study (ed. T. Persson). Ecological Bulletins (Stockholm) 32, 307-313.

Aronsson, A. \& Elowsson, S. 1980. Effects of irrigation and fertilization on mineral nutrients in Scots pine needles. In: Structure and function of northern coniferous forests-an ecosystem study (ed. T. Persson). Ecological Bulletins (Stockholm) 32, 219-228.

Cannell, M.G.R. 1974. Production of branches and foliage by young trees of Pinus contorta and Picea sitchensis: provenance differences and their simulation. Journal of Applied Ecology 11, 1091-1115.

Cannell, M.G.R. \& Willett, S.C. 1975. Rates and times at which needles are initiated in buds on different provenances of Pinus contorta and Picea sitchensis in Scotland. Canadian Journal of Forest Research 5, $367-380$.
Clausen, J.J. \& Kozlowski, K.K. 1967. Food sources for growth of Pinus resinosa shoots. Advancing Frontiers of Plant Sciences 18, 23-32.

Cochran, W.G. 1977. Sampling techniques. (3rd ed.). New York: Wiley. $428 \mathrm{pp}$.

Cochrane, L.A. \& Ford, E.D. 1978. Growth of a Sitka spruce plantation: analysis and stochastic description of the development of the branching structure. Journal of Applied Ecology 15, 227-244.

Degermark, C. 1988. Klimat och vattenkemi vid Svartberget. Referensmätning 1987. (Climate and chemistry of water at Svartberget. Reference measurements 1987.) Swedish University of Agricultural Sciences, Vindeln Experimental Forest Station. $61 \mathrm{pp}$.

Degermark, C. 1989. Klimat och vattenkemi vid Svartberget. Referensmätning 1988. (Climate and chemistry of water at Svartberget. Reference measurements 1988.) Swedish University of Agricultural Sciences, Vindeln Experimental Forest Station. 61 pp.

Ericsson, A. 1979. Effects of fertilization and irrigation on the seasonal changes of carbohydrate reserves in different age-classes of needle on 20-year-old Scots pine trees (Pinus silvestris). Physiologia plantarum 45, $270-280$. 
Ericsson, A., Larsson, S. \& Tenow, O. 1980. Effects of early and late season defoliation on growth and carbohydrate dynamics in Scots pine. Journal of Applied Ecology 17, 747-769.

Ericsson, A. \& Persson, H. 1980. Seasonal changes in starch reserves and growth of fine roots of 20 -yearold Scots pines. In: Structure and function of northern coniferous forests - an ecosystem study (ed. T. Persson). Ecological Bulletins (Stockholm) 32, 239 250 .

Evans, G.C. 1972. The quantitative analysis of plant growth. Oxford: Blackwell. 734 pp.

Ewers, F.W. 1982. Secondary growth in needle leaves of Pinus longaeva (Bristlecone pine) and other conifers: quantitative data. American Joumal of Botany 69 , 1552-1559

Fischer, C. \& Höll, W. 1991. Food reserves of Scots pine (Pinus sylvestris L.).I. Seasonal changes in the carbohydrate and fat reserves of pine needles. Trees 5, $187-195$

Flower-Ellis, J.G.K. 1971. Age structure and dynamics in stands of bilberry (Vaccinium myrtillus L.). Royal College of Forestry, Department of Forest Ecology and Forest Soils, Research Notes 9, $108 \mathrm{pp}$.

Flower-Ellis, J.G.K. 1980. Diurnal dry weight variation and dry matter allocation of some tundra plants. 1. Andromeda polifolia L. In: Ecology of a subarctic mire (ed. M. Sonesson). Ecological Bulletins (Stockholm) $30,139-162$.

Flower-Ellis, J.G.K. 1982. Structure and growth of some young Scots pine stands. (2) Effects of irrigation and fertilisation on the amount, rate and duration of leading shoot growth. Swedish Coniferous Forest Project Technical Report $30.46 \mathrm{pp}$.

Flower-Ellis, J.G.K., Albrektson, A. \& Olsson, L. 1976. Structure and growth of some young Scots pine stands. (1) Dimensional and numerical relationships. Swedish Coniferous Forest Project Technical Report 3, 98 pp.

Flower-Ellis, J.G.K. \& Persson, H. 1980. Investigation of structural properties and dynamics of Scots pine stands. In: Structure and function of northern coniferous forests - an ecosystem study (ed. T. Persson). Ecological Bulletins (Stockholm) 32, 125-138.

Flower-Ellis, J.G.K. \& Yang, M.S. 1987. Vertical and cohort life-tables for needles of Norway spruce from northern Sweden. Swedish University of Agricultural Sciences. Reports in Forest Ecology and Forest Soils $57.24 \mathrm{pp}$.

Fu, M.Y. \& Tamm, C.O. 1985. Predicting branch and needle growth of spruce (Picea abies (L.) Karst.) from easily measurable tree parameters. Acta oecologica 6, 347-363

Hallé, F. \& Oldeman, R.A.A. 1970. Essai sûr l'architecture et la dynamique de croissance des arbres tropicaux. Paris: Masson. $178 \mathrm{pp}$.

Hallé, F., Oldeman, R.A.A. \& Tomlinson, P.B. 1978. Tropical trees and forests: an architectural analysis. Berlin: Springer. 441 pp.

Harper, J.L. \& White, J. 1974. The demography of plants. Anmual Review of Ecology and Systematics $5,419-463$.

Hustich, I. 1948. The Scotch pine in northernmost Finland and its dependence on the climate in the last decades. Acta botanica fennica 42, 1-75.
Jeremias, K. 1969. Speicherungsphysiologische Untersuchungen bei Picea abies und Sequoiadendron giganteum. Mitteilungen des Vereins für Forstliche standortskunde und. Forstpflanzenzüchting 19, 58-66.

Junttila, O. \& Heide, O.M. 1981. Shoot and needle growth in Pinus silvestris as related to temperature in northern Fennoscandia. Forest Science 27, 423-430.

Kraus, G. 1885. Mehrjähriges Wachsthum der Kiefernadeln und allgemeine Bemerkungen über Blattgrösse. Abhandl. d. Naturf. gesells. zu Halle 16, $363-368$.

Laar, A. van 1976. Single-tree parameters of Norway spruce (Picea abies (L.) Karst.) in relation to site and environment. Forschungsberichte, Forstliche Forschungsanstalt München, 30.

Lim, M.T. \& Cousens, J.E. 1986. The internal transfer of nutrients in a Scots pine stand. 1. Biomass components, current growth and their nutrient content Forestry 59, 1-27.

Linder, S. 1990. Nutritional control of forest yield. In: Nutrition in trees. The Marcus Wallenberg Foundation Symposia Proceedings 6, 62-87.

Linder, S. \& Flower-Ellis, J.G.K. 1992. Environmental and physiological constraints to forest yield. In Responses of forest ecosystems to environmental changes (ed. A. Teller, P. Mathy \& J.N.R. Jeffers). London \& New York: Elsevier, 149-164.

Little, C.H.A. 1974. Relationship between the starch level at budbreak and current shoot growth in Abies balsamea L. Canadian Journal of Forest Research 4, 268-273.

Madgwick, H.A.L. 1970. Biomass and productivity models of forest canopies. Ecological studies. Analysis and synthesis 1, 47-54.

Madgwick, H.A.L. \& Tamm, C.O. 1987. Allocation of dry weight increment in crowns of Picea abies as affected by stand nutrition. Oikos 48, 99-105.

Mälkönen, E. 1974. Annual primary production and nutrient cycle in some Scots pine stands. Communicationes instituti forestalis fenniae 84, 1-87.

Meissner, R. 1894. Studien über das mehrjährige Wachsen der Kiefernadeln. Zur Kritik der Kraus'schen Mittheilung über den gleichen Gegenstand. Botanische Zeitung 52, 55-82

Meissner, R. 1897. Studien über das mehrjährige Wachsen der Kiefernadeln. Zur Kritik der Kraus'schen Mittheilung über den gleichen Gegenstand. Theil II. Botanische Zeitung 55, 203-218.

Morrow, L.D. \& Timmer, V.R. 1981. Intraseasonal growth and nutrient composition of jack pine needles following fertilisation. Canadian Joumal of Forest Research 11, 696-702.

Newbould, P.J. 1967. Methods for estimating the primary production of forests. IBP Handbook No. 2. Oxford \& Edinburgh: Blackwell. 62 pp.

Perterer, J. \& Körner, Ch. 1990. Das Problem der Bezugsgröße bei physiologisch-ökologischen Untersuchungen an Koniferennadeln. Forstwissenschaftliches Centralblatt / Zeitschr. für das gesamte Forstwesen für Umweltforschung und Naturschütz 109 , 220-241.

Reader, R.J. 1978. Contribution of overwintering leaves to the growth of three broad-leaved, evergreen shrubs belonging to the Ericaceae family. Canadian Journal of Botany 56, 1248-1261. 
Renvall, A. 1914. Ein Beitrag zur Kenntnis der sog. partiellen Variabilität der Kiefer. Acta forestalia fennica 3, 1-172.

Rutter, A.J. 1957. Studies in the growth of young plants of Pinus silvestris $\mathbf{L}$. 1. The annual cycle of assimilation and growth. Annals of Botany (N.S.) 21, 399-426.

Snedecor, G.W. \& Cochran, W.G. 1980. Statistical methods. (7th ed.) Ames, Iowa, USA: Iowa State University Press. 507 pp.

Sprugel, D.G., Hinckley, T.M. \& Schaap, W. 1991. The theory and practice of branch autonomy. Annual Review of Ecology and Systematics 22, 309-334.

Steen, E. \& Larsson, K. 1986 Carbohydrates in roots and rhizomes of perennial grasses. New Phytologist 104, 339-346.

Strasburger, E. 1891. Über den Bau und die Verrichtungen der Leitungsbahnen in den Pflanzen. Histologische Beiträge. Vol. 3. Jena: Gustav Fischer.

Tamm, C.O. 1955. Studies on forest nutrition. 1. Seasonal variation in the nutrient content of conifer needles. Meddelanden frän statens skogsforskningsinstitut 45, $1-34$.

Wang, Y.P., Jarvis, P.G. \& Benson, M.L. 1990. Twodimensional needle-area density distribution within the crowns of Pinus radiata. Forest Ecology and Management 32, 217-237.

White, J. 1979. The plant as a metapopulation. Annual Review of Ecology and Systematics 10, 109-145.

White, J. 1984. Plant metamerism. In: Perspectives on plant population ecology (ed. R. Dirzo \& J. Sarukhan). Mass., USA: Sinauer Associates Inc., Sunderland, 15-47.

Whittaker, R.H. 1965. Branch dimensions and estimates of branch production. Ecology 46, 365-370.

\section{Acknowledgements}

The help of the following persons is gratefully acknowledged: Sune Linder and Aron Aronsson in planning; Leif Olsson, Anita and Peter Flower-Ellis for fieldwork and primary processing; Anita Flower-Ellis for carbohydrate analyses. Detailed processing was done at Jädraas Ecological Station, mainly by Lena Ramström and Siv Sjögren. The study was supported by the Swedish Council of Forestry and Agricultural Research. 



\title{
Above-ground biomass, productivity, and nutrients in 15-year-old stands of Ponderosa pine, Corsican pine, Douglas fir, and European larch in the Craigieburn Range, New Zealand
}

\author{
A.H. NORDMEYER and N.J. LEDGARD \\ N.Z. Forest Research Institute, Rangiora, New Zealand
}

\begin{abstract}
Nordmeyer, A.H. \& Ledgard, N.J. 1993. Above-ground biomass, productivity and nutrients in 15-year-old stands of Ponderosa pine, Corsican pine, Douglas fir and European larch in the Craigieburn Range, New Zealand. In Management of structure and productivity of boreal and subalpine forests (ed. S. Linder \& S. Kellomäki). Studia Forestalia Suecica 191. 94 pp. ISSN 0039-3150, ISBN 91-576-4822-0.

A degraded site at $1040 \mathrm{~m}$ elevation in the Craigieburn Range, New Zealand, was planted in adjacent stands of Ponderosa pine, Corsican pine, Douglas fir, and European larch. After 15 years trees were harvested, and estimates were made of biomass, current production in components, and nutrient contents.

Total above-ground biomass was $97-109 \mathrm{Mg} \mathrm{ha}^{-1}$ in the pines and Douglas fir, and 66 $\mathrm{Mg} \mathrm{ha}^{-1}$ in larch. Needle biomass declined in the order: Douglas fir $\left(16.2 \mathrm{Mg} \mathrm{ha}^{-1}\right)>$ Corsican pine $\left(13.7 \mathrm{Mg} \mathrm{ha}^{-1}\right)>$ Ponderosa pine $\left(9.8 \mathrm{Mg} \mathrm{ha}^{-1}\right)>\operatorname{larch}\left(4.3 \mathrm{Mg} \mathrm{ha}^{-1}\right)$. Current annual production also declined in the same species order $(24.4,20.7,18.3$, and $15.4 \mathrm{Mg} \mathrm{ha}{ }^{-1}$ respectively), and production was closely related to the total amount of needle nitrogen.

The pines and Douglas fir bound a similar amount of nitrogen for current production (240-245 kg dry matter $\left(\mathrm{kg} \mathrm{N}^{-1}\right)$, but larch was less efficient in its nitrogen use $(132 \mathrm{~kg}$ dry matter $\left(\mathrm{kg} \mathrm{N}^{-1}\right)$.

With increasing needle age, concentrations of $\mathrm{N}, \mathrm{P}, \mathrm{K}, \mathrm{Zn}, \mathrm{Cu}$, and $\mathrm{Mg}$ generally declined, whereas $\mathrm{Ca}, \mathrm{Al}$, and $\mathrm{Mn}$ increased. Because Corsican pine and Douglas fir had greater needle retention and higher concentrations, their total contents of $\mathrm{Ca}$ were much greater than those in Ponderosa pine and larch. Phosphorus concentrations and the ratio of monovalent:divalent cations decreased as Al concentrations increased in needles.
\end{abstract}

Key words: Conifers, biomass, productivity, nutrients, montane sites.

A.H. Nordmeyer and N.J. Ledgard, N.Z. Forest Research Institute, P.O. Box 465, Rangiora, New Zealand.

MS, received 4 November 1992

MS. accepted 7 January 1993

\section{Introduction}

Lodgepole pine (Pinus contorta) grows exceptionally well on depleted acid mountain soils in New Zealand in which aluminium is the dominant exchangeable cation (Benecke \& Nordmeyer, 1982), even though it has high concentrations of aluminium in foliage compared with those in introduced legumes and the natural forest species in many mountain areas, mountain beech (Nothofagus solandri var. cliffortioides (Nordmeyer, 1980).

Ponderosa pine (Pinus ponderosa Douglas), Corsican pine (Pinus nigra ssp. laricio (Poiret, Maire)), Douglas fir (Pseudotsuga menziesii (Mirb. Franco)), and European larch (Larix de- cidua Miller) have generally not grown as well as Lodgepole pine on infertile soils, but the underlying reasons have not been elucidated. This study was aimed to develop a better understanding of the nutrient status of the four species on infertile mountain soils in the Craigieburn Range, and of the relationship of above-ground production with tree nutrition in 15-year-old stands on these soils.

\section{Site description}

The study site was at an elevation of $1040 \mathrm{~m}$ on a north-facing slope of $30^{\circ}$ in the Cave 
Stream catchment, Craigieburn Range, Canterbury $\left(43^{\circ} 10^{\prime} \mathrm{S}, 171^{\circ} 45^{\prime} \mathrm{E}\right)$. The soil was a Tekoa high country yellow-brown earth overlying greywacke stones mixed with loess. Stones made up approximately half the soil volume. The surface $20 \mathrm{~cm}$ of these soils have $\mathrm{pH}$ (water) 4.9-5.2, cation exchange capacity $185 \mu \mathrm{eq} \mathrm{g}^{-1}$, exchangeable Al $165 \mu$ eq $\mathrm{g}^{-1}$, and exchangeable bases $20 \mu \mathrm{eq}^{-1}$. Total nitrogen to $60 \mathrm{~cm}$ depth is ca. $6000 \mathrm{~kg} \mathrm{ha}^{-1}$ (Nordmeyer \& Kelland, 1982).

Annual rainfall is $1447 \mathrm{~mm}$ with a spring maximum of $174 \mathrm{~mm}$ month $^{-1}$, and a summer minimum of $69 \mathrm{~mm} \mathrm{month}^{-1}$. The mean annual temperature is $8.0^{\circ} \mathrm{C}$; the mean temperature of the warmest month (February) is $13.9^{\circ} \mathrm{C}$, and of the coldest month (July) $2.0^{\circ} \mathrm{C}$ (McCracken, 1980).

The site was originally forested in mountain beech which had been burnt over 100 years ago. A $50 \%$ vegetation cover of mixed native and exotic grasses had developed at the time the trial was planted.

\section{Methods}

Ponderosa pine, Corsican pine, Douglas fir, and European larch were raised as bare-rooted stock, and 2-year-old seedlings were planted on the site in winter 1965 at 4000 stems ha $^{-1}$. In winter 1978 the stands were thinned to 2000 3000 stems ha ${ }^{-1}$ and pruned to a height of 2 $\mathrm{m}$ above ground level.

\section{Biomass determination}

In late winter 1980 , a plot of 0.01 ha projected area was established in each stand. Each tree in the plot was numbered, and dbh and total height were recorded. Trees were allocated to five $\mathrm{dbh}$ classes, and one random tree was harvested from each class to provide five sample trees for each species.

Ponderosa pine, Corsican pine, and Douglas fir were harvested in August-September 1980, and larch in early December 1980 when its short-shoot needles were well developed. Three additional trees of larch, representing small, medium, and large individuals, were harvested at the end of the growing season (late March) to estimate the biomass of the long shoots.
Selected trees were felled at ground level and their stems were cut at breast height, at the base of the green crown, and at a point midway between the base of the green crown and the top of the tree. All needles and branches in each of the upper (sun) and lower (shade) crowns were dissected into age groups of 1, 2, 3, and $4+$ years. In the upper crown, stem needles were incorporated with branch needles of similar age. For larch, needles were grouped in three classes corresponding with their location on long shoots, 1- and 2-year-old branches, and $3+$ year-old branches.

Discs were cut from each tree stem at the base, breast height, base of green crown, and at $75 \%, 50 \%$, and $25 \%$ of crown depth. Bark thickness and annual diameter growth of wood were measured on each disc. The densities of wood and bark were calculated from oven-dry mass and fresh volumes.

All plant components were oven-dried without sub-sampling to constant weight at $70^{\circ} \mathrm{C}$. Stem wood and bark dry matter of each length of stem were calculated from the proportions of dry wood and bark in the discs at the end of each section, and summed for each stem. Stand biomass of components was estimated by the basal area ratio method (Madgwick, 1983).

\section{Nutrients}

Nitrogen (N), phosphorus (P), potassium (K), magnesium $(\mathrm{Mg})$, and calcium $(\mathrm{Ca})$ concentrations were determined in needles, branches, bark, and wood after digestion in $\mathrm{H}_{2} \mathrm{SO}_{4}-\mathrm{H}_{2} \mathrm{O}_{2}$. $\mathrm{N}$ and $\mathrm{P}$ were determined by colorimetry, and $\mathrm{K}, \mathrm{Mg}$, and $\mathrm{Ca}$ by atomic absorption spectrophotometry (Nicholson, 1984).

Manganese $(\mathrm{Mn})$, aluminium (Al), copper $(\mathrm{Cu})$, and zinc $(\mathrm{Zn})$ were determined in needle components by atomic absorption spectrophotometry after dry ashing and solution in $\mathrm{HCl}$ (Nicholson, 1984). Boron was determined for needle components by the curcumin (colorimetric) method after dry ashing (Nicholson, 1984).

Concentrations of $\mathrm{N}, \mathrm{P}, \mathrm{K}, \mathrm{Mg}$, and Ca were determined in wood and bark samples from the discs taken at the base, at breast height, and at $50 \%$ of crown depth. These were converted into nutrient content for each of the three stem sections (bottom, middle, and upper). Total nutri- 
ent mass in the stemwood and bark was derived from the sum of values for the three sections.

The nutrient content of each stand was estimated by the basal area ratio method (Madgwick, 1983).

\section{Current annual production}

The productivity of each tree was estimated from current needle, branch, and stem production. To determine current branch production, the dry mass of each of the separate branch components up to age 3 years was divided by its age; the $4+$ year component in the sun crown was divided by six (the maximum age of branch in that section) and the $4+$ year component in the shade crown was divided by 12 (the maximum age of branch in that section). The four values were summed for each crown to provide an estimate of total branch production. Current stemwood production was estimated from the current volume production of each stem and its density. Stem bark production was estimated by assuming that the ratio of bark increment:bark biomass was equivalent to wood increment: wood biomass.

The nutrient requirement for current production of needles and branches was estimated in the same way as dry matter. For stemwood and bark production, the nutrient requirement for current growth was estimated from annual production and the relevant wood and bark concentrations at mid-canopy.

\section{Results}

\section{Biomass}

By age 15 basal areas for the two pines and Douglas fir exceeded that of larch (Table 1). Needles were retained for up to 5 years in Ponderosa pine, 7 years in Corsican pine, and 10 years in Douglas fir. The deciduous larch had the least total foliage but had more current foliage production than the other conifers.

The distribution of foliage and branches differed between species (Fig. 1). In Ponderosa pine $61 \%$ of the foliage was in the sun crown, and in larch $49 \%$. In Corsican pine and Douglas fir most of the foliage was in the shade crown, and of that, approximately $4 \mathrm{Mg} \mathrm{ha}^{-1}$ was in older needles. In larch most of the foliage was produced on the short shoots.

The amount of branch biomass in the sun crown was greater in Ponderosa pine and larch than in Corsican pine and Douglas fir, reflecting the distribution of needles (Fig. 1). One-year branch biomass was similar in the pines and Douglas fir at approximately $1.0 \mathrm{Mg} \mathrm{ha}^{-1}$, despite current shoots of Douglas fir being smaller in diameter than those in the pines.

Table 1. Stocking, height, basal area, biomass, and productivity of Ponderosa pine, Corsican pine, Douglas fir, and European larch at age 15 years

\begin{tabular}{|c|c|c|c|c|}
\hline & $\begin{array}{l}\text { Ponderosa } \\
\text { pine }\end{array}$ & $\begin{array}{l}\text { Corsican } \\
\text { pine }\end{array}$ & $\begin{array}{l}\text { Douglas } \\
\text { fir }\end{array}$ & $\begin{array}{l}\text { European } \\
\text { larch }\end{array}$ \\
\hline Stocking, stems ha ${ }^{-1}$ & 2000 & 3100 & 2700 & 2400 \\
\hline Height, m & 6.9 & 6.7 & 7.5 & 7.2 \\
\hline \multirow{2}{*}{\multicolumn{5}{|c|}{$\begin{array}{l}\text { Basal area, } \mathrm{m}^{2} \text { ha }^{-1} \\
\text { Biomass. } \mathrm{Mg} \mathrm{ha} \mathrm{ha}^{-1}+\text { s.d. }\end{array}$}} \\
\hline & & & & \\
\hline Needles & $9.8 \pm 5.4$ & $13.7 \pm 3.8$ & $16.2 \pm 5.6$ & $4.3 \pm 1.8$ \\
\hline Branches & $15.8 \pm 9.5$ & $18.0 \pm 6.8$ & $20.4 \pm 5.4$ & $16.0 \pm 4.2$ \\
\hline Stem wood & $59.6 \pm 9.4$ & $59.4 \pm 6.0$ & $64.0 \pm 4.7$ & $38.5 \pm 2.0$ \\
\hline Stem bark & $12.1 \pm 1.3$ & $13.1 \pm 2.2$ & $8.7 \pm 0.5$ & $7.0 \pm 0.9$ \\
\hline TOTAL & $97 \pm 26$ & $104 \pm 19$ & $109 \pm 16$ & $66 \pm 9$ \\
\hline \multicolumn{5}{|l|}{ Anmual Production, $\mathrm{Mg} \mathrm{ha}^{-1} \pm$ s.d. } \\
\hline Branches & $3.6 \pm 1.9$ & $4.0 \pm 1.9$ & $4.5 \pm 1.5$ & $4.1 \pm 1.4$ \\
\hline Stem wood & $9.8 \pm 1.8$ & $11.2 \pm 1.3$ & $15.0 \pm 2.0$ & $6.0 \pm 1.3$ \\
\hline Stem bark & $2.0 \pm 0.4$ & $2.5 \pm 0.3$ & $2.0 \pm 0.3$ & $1.1 \pm 0.2$ \\
\hline TOTAL & $18.4 \pm 6.0$ & $20.7 \pm 4.6$ & $24.4 \pm 5.2$ & $15.5 \pm 4.7$ \\
\hline \multicolumn{5}{|l|}{ Ratio Production:Biomass } \\
\hline Needles & 0.31 & 0.22 & 0.18 & 1.00 \\
\hline Branches & 0.24 & 0.22 & 0.22 & 0.26 \\
\hline Stemwood & 0.16 & 0.19 & 0.23 & 0.16 \\
\hline TOTAL & 0.19 & 0.20 & 0.22 & 0.24 \\
\hline
\end{tabular}




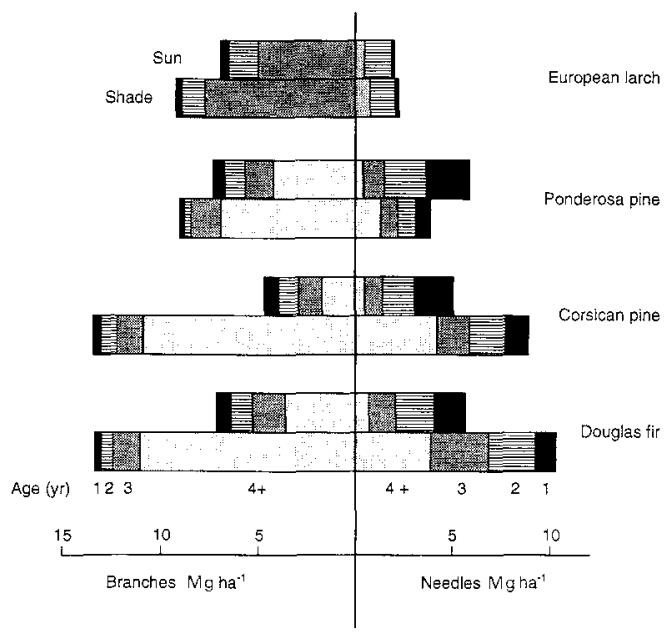

Fig. 1. Distribution of needle and branch biomass by age in sun- and shade-crowns of European larch, Ponderosa pine, Corsican pine, and Douglas fir.

The ratio of current needle biomass : current branch biomass was $2.6,2.7,2.3$, and 0.7 in the sun crown, and 4.3, 3.3, 3.8, and 0.9 in the shade crown of Ponderosa pine, Corsican pine, Douglas fir, and larch, respectively, indicating that the direct structural cost of carrying current foliage was less in the shade than in the sun crown.

There was little difference in the stemwood biomass of the pines and Douglas fir, but all three species had accumulated more stem biomass than larch (Table 1). Wood densities were Ponderosa pine $\left(399 \mathrm{~kg} \mathrm{~m}^{-3}\right)$, Corsican pine $\left(404 \mathrm{~kg} \mathrm{~m}^{-3}\right)$, Douglas fir $\left(442 \mathrm{~kg} \mathrm{~m}^{-3}\right)$, and $\operatorname{larch}\left(457 \mathrm{~kg} \mathrm{~m}^{-3}\right)$.

\section{Annual production}

All stands were at a stage of fast growth, probably as a response to the thinning 2 years earlier and the relatively large amounts of foliage (Table 1). Of the total annual production, the proportion of stemwood made up $39 \%, 53 \%$, $54 \%$, and $61 \%$ in larch, Ponderosa pine, Corsican pine, and Douglas fir, respectively. The modest allocation to current needle production combined with high needle retention in all species but larch, allowed proportionately high allocation of photosynthate to stemwood production.

\section{Nutrients}

In needles, concentrations of $\mathrm{N}, \mathrm{P}, \mathrm{K}, \mathrm{Zn}, \mathrm{Cu}$, and $\mathrm{Mg}$ (generally) declined with age, and $\mathrm{Ca}$, $\mathrm{Mn}$, and $\mathrm{Al}$ increased (Table 2). Calcium, $\mathrm{Mn}$, $\mathrm{B}$, and $\mathrm{Mg}$ (generally) were higher in shade crown needles than in sun crown needles. Variation in mean concentrations was low for $\mathrm{N}, \mathrm{P}, \mathrm{K}$, and $\mathrm{Mg}$ (coefficients of variation $(\mathrm{CV} \%$ ) ranged from $4.3 \%$ to $14.8 \%$ ) but was higher for $\mathrm{Ca}$ in older needles (CV 14\%-26\%).

For all species, nutrient concentrations of current sun crown needles were mostly in the lowmid range of reported values for Ponderosa pine (Clayton \& Kennedy, 1980), Douglas fir (Krueger, 1967; Clayton \& Kennedy, 1980; Cole \& Newton, 1986), and Corsican pine (Wright \& Will, 1958; Miller \& Miller, 1976). A notable difference is that the present results show a consistent rise in $\mathrm{Ca}$ as needles age, and, as a consequence of needle retention, $\mathrm{Ca}$ levels are particularly high in the older needles of Corsican pine and Douglas fir. Also, present $\mathrm{P}$ concentrations in Douglas fir exceeded the levels where a response to fertiliser phosphorus was detected from foliage $\mathbf{P}$ and basal area growth (Belton \& Davis, 1986).

As aluminium concentrations increased in needles there was an associated decline of $\mathrm{P}$ and in the ratio of $\mathrm{K}: \mathrm{Mg}+\mathrm{Ca}$ (Fig. 2). The decline was particularly marked in Ponderosa pine and Douglas fir and least marked in Corsican pine, which accumulated more divalent cations in older needles. Differences between sun and shade needles suggest that relationships between these nutrients were influenced by light as well as age.

In branches concentrations of nutrients declined with increasing tissue age (Table 3). Douglas fir had notably higher concentrations of $\mathrm{N}, \mathrm{P}$, and $\mathrm{K}$ than comparable branch tissues in the other species, whereas Corsican pine, as in its needles, had consistently higher $\mathrm{Mg}$ and $\mathrm{Ca}$ concentrations. Branch $\mathrm{Ca}$ concentrations were higher in the shade than in the sun (Table 3 ).

For stemwood, concentrations of nutrients were higher in the pines than Douglas fir or larch (Table 4). In contrast, the bark of Douglas fir and larch was higher in $\mathrm{N}, \mathrm{P}$, and $\mathrm{K}$ than bark of Corsican pine and Ponderosa pine.

Total above-ground contents of $\mathrm{N}$ and $\mathrm{P}$ declined in the order Douglas fir $>$ Corsican pine $>$ Ponderosa pine $>$ larch. Contents of $\mathrm{Ca}$ in Corsican pine were approximately twice those of Ponderosa pine (Table 5). 
Table 2. Mean mutrient concentrations in the needles of Ponderosa pine (Pp), Corsican pine ( $C p)$, Douglas fir (Df), and European larch (E1)

\begin{tabular}{|c|c|c|c|c|c|c|c|c|c|}
\hline \multirow{2}{*}{$\begin{array}{l}\text { Age (yrs) } \\
\text { Nutrient }\end{array}$} & \multirow[b]{2}{*}{$\mathrm{Sp}$} & \multicolumn{4}{|c|}{ Sun crown needles } & \multicolumn{4}{|c|}{ Shade crown needles } \\
\hline & & 1 & 2 & 3 & 4 & 1 & 2 & 3 & 4 \\
\hline \multirow[t]{4}{*}{$\mathrm{N}, \mathrm{g} \mathrm{kg}^{-1}$} & $\mathrm{Pp}$ & 12.7 & 12.5 & 11.6 & 11.7 & 12.6 & 12.4 & 10.7 & 10.1 \\
\hline & $C_{p}^{r}$ & 12.4 & 12.4 & 11.2 & 10.2 & 10.3 & 10.4 & 9.7 & 8.7 \\
\hline & Df & 14.3 & 14.3 & 13.2 & 11.7 & 13.2 & 12.4 & 12.2 & 11.3 \\
\hline & $\mathrm{El}$ & $19.3^{1}$ & $18.4^{2}$ & $18.3^{3}$ & & 20.3 & 19.4 & 18.8 & \\
\hline \multirow[t]{4}{*}{$\mathrm{P}, \mathrm{g} \mathrm{kg}^{-1}$} & $\mathrm{Pp}$ & 2.1 & 1.6 & 1.4 & 1.3 & 1.8 & 1.5 & 1.3 & 1.3 \\
\hline & $\mathrm{Cp}$ & 1.4 & 1.3 & 1.2 & 1.2 & 1.1 & 1.0 & 1.0 & 0.9 \\
\hline & Df & 1.6 & 1.5 & 1.3 & 1.2 & 1.5 & 1.4 & 1.3 & 1.1 \\
\hline & $\mathrm{El}$ & 2.9 & 2.5 & 2.4 & & 2.7 & 2.6 & 2.4 & \\
\hline \multirow[t]{4}{*}{$\mathrm{K}, \mathrm{g} \mathrm{kg}^{-1}$} & $\mathrm{Pp}$ & 7.8 & 6.6 & 6.3 & 6.1 & 7.7 & 6.9 & 6.4 & 6.0 \\
\hline & $\mathrm{Cp}$ & 5.6 & 6.0 & 5.5 & 5.2 & 5.2 & 5.3 & 5.2 & 4.6 \\
\hline & Df & 7.7 & 6.7 & 6.7 & 6.1 & 8.0 & 6.8 & 6.5 & 5.9 \\
\hline & $\mathrm{El}$ & 11.0 & 9.9 & 9.4 & & 10.6 & 10.3 & 9.6 & \\
\hline \multirow{4}{*}{$\mathrm{Mg}, \mathrm{g} \mathrm{kg}^{-1}$} & $\mathrm{Pp}$ & 0.7 & 0.7 & 0.7 & 0.7 & 0.8 & 0.9 & 0.9 & 0.9 \\
\hline & $\mathrm{Cp}$ & 0.9 & 0.7 & 0.6 & 0.6 & 0.9 & 0.9 & 0.8 & 0.7 \\
\hline & $\mathrm{Df}$ & 1.1 & 1.0 & 0.9 & 1.0 & 1.1 & 1.0 & 1.0 & 0.9 \\
\hline & $\mathrm{El}$ & 1.3 & 1.3 & 1.3 & & 1.4 & 1.5 & 1.4 & \\
\hline \multirow[t]{4}{*}{$\mathrm{Ca}, \mathrm{g} \mathrm{kg}^{-1}$} & $\overrightarrow{P p}$ & 2.2 & 3.8 & 4.1 & 4.6 & 2.1 & 3.3 & 4.8 & 5.9 \\
\hline & $\mathrm{Cp}$ & 4.3 & 6.7 & 7.8 & 9.9 & 6.6 & 10.2 & 12.2 & 15.5 \\
\hline & Df & 5.1 & 6.9 & 7.7 & 8.8 & 6.4 & 8.2 & 10.0 & 10.3 \\
\hline & $\mathrm{El}$ & 2.8 & 3.2 & 3.7 & & 3.3 & 3.8 & 4.0 & \\
\hline \multirow[t]{4}{*}{$\mathrm{Mn}, \mu \mathrm{g} \mathrm{g}^{-1}$} & $\mathrm{Pp}$ & 90 & 130 & 120 & 120 & 110 & 160 & 150 & 160 \\
\hline & $\mathrm{Cp}$ & 140 & 190 & 200 & 240 & 210 & 260 & 270 & 330 \\
\hline & Df & 210 & 230 & 180 & 200 & 220 & 250 & 240 & 220 \\
\hline & $\mathrm{El}$ & & 110 & 110 & & & 130 & 130 & \\
\hline \multirow{4}{*}{$\mathrm{Al}, \mu \mathrm{g} \mathrm{g}^{-1}$} & $\mathrm{Pp}$ & 170 & 270 & 200 & 310 & 250 & 260 & 270 & 270 \\
\hline & $\mathrm{Cp}$ & 750 & 1120 & 1400 & 1430 & 700 & 990 & 1180 & 1360 \\
\hline & Df & 680 & 770 & 740 & 750 & 590 & 610 & 630 & 730 \\
\hline & $\mathrm{El}$ & & 120 & 120 & & & 110 & 130 & \\
\hline \multirow{4}{*}{$\mathrm{Zn}, \mu \mathrm{g} \mathrm{g}^{-1}$} & $\mathrm{Pp}$ & 24 & 15 & 11 & 12 & 18 & 13 & 11 & 12 \\
\hline & $\mathrm{Cp}$ & 22 & 24 & 14 & 11 & 17 & 17 & 9 & 7 \\
\hline & $\mathrm{Df}$ & 12 & 9 & 7 & 7 & 11 & 8 & 6 & 8 \\
\hline & $\mathrm{E} 1$ & & 17 & 16 & & & 17 & 17 & \\
\hline \multirow[t]{4}{*}{$\mathrm{B}, \mu \mathrm{g} \mathrm{g}^{-1}$} & $\mathrm{Pp}$ & 6 & 6 & 6 & 7 & 9 & 8 & 9 & 8 \\
\hline & $\mathrm{Cp}^{\mathrm{p}}$ & 6 & 7 & 8 & 10 & 8 & 9 & 9 & 12 \\
\hline & Df & 9 & 10 & 9 & 11 & 11 & 11 & 11 & 11 \\
\hline & El & & 11 & 10 & & & 11 & 10 & \\
\hline
\end{tabular}

${ }^{1,2,3}$ refer to current branch, $1+2$ year branch, and $3+$ year branch components, respectively.

At the time of harvest all stands had high nutrient requirements for new growth (Table 5). Foliage generally required more $\mathrm{N}$ and $\mathrm{P}$ than other components, but branches had high annual requirements for $\mathrm{Mg}$ and $\mathrm{Ca}$ in all species, and for $\mathrm{K}$ in Corsican pine and Douglas fir. Requirements of nutrients for bark production exceeded those for wood. Total nutrient requirements declined in the order $\mathrm{N}>\mathrm{K}>$ $\mathrm{Ca}>\mathrm{P}>\mathrm{Mg}$.

\section{Productivity and nutrition}

The efficiency of foliage in biomass production declined in the order larch $>$ Ponderosa pine $>$ Corsican pine $>$ Douglas fir (Table 6). For its foliage biomass larch was also the most efficient in producing stemwood.
Over all species annual stemwood production was closely related to the total amount of nitrogen in the needles, reflecting the importance of nitrogen in photosynthesis. On average $77 \mathrm{~kg}$ of stemwood was produced annually for each kilogram of nitrogen in foliage.

The pines and Douglas fir had similar production relative to their annual requirement for nitrogen (ca. $240 \mathrm{~kg}(\mathrm{kgN})^{-1}$ ) and all three were more efficient than larch, which required most nitrogen for its annual needle production.

\section{Discussion}

The amount of foliage in the Craigieburn stands is relatively high for young stands of the species and is probably a consequence of the climate 

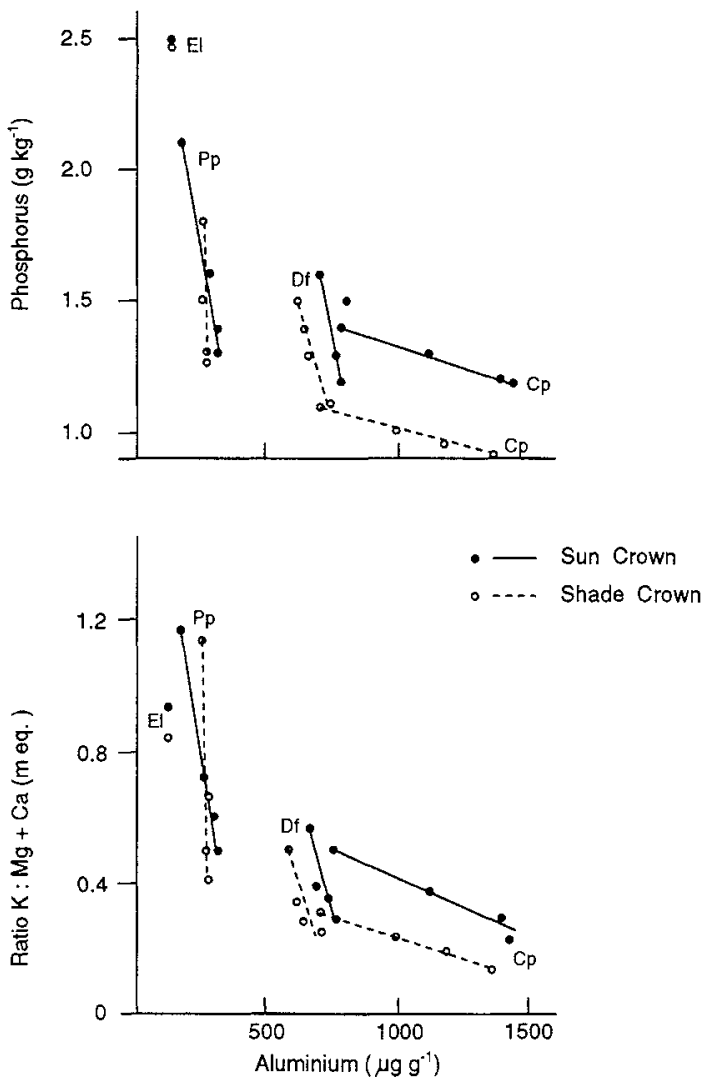

Fig. 2. Relationships of phosphorus concentrations and ratios of monovalent : divalent cations to aluminium in needles of Ponderosa pine, Corsican pine, Douglas fir, and European larch.

and soils. Temperatures of the warmest and coldest months are similar to those at a favourable Tsuga heterophylla site in the USA (Gholz, 1982). Soil $\mathrm{N}$ amounts to ca. $6000 \mathrm{~kg} \mathrm{ha}^{-1}$ at the Craigieburn site (Nordmeyer \& Kelland, 1982), which is in the low range of values reported for the Pacific North-west (Gessel, Cole \& Steinbrenner, 1973), similar to amounts under Ponderosa pine in Arizona (Klemmedson, 1955), and greater than amounts in sands under Corsican pine in Scotland (Miller \& Miller, 1976). Overall it is not surprising that the present stands should have foliage biomass more comparable to fertilised stands of Corsican pine in Europe (Ranger, 1978), and to unfertilised Douglas fir and Ponderosa pine in the USA (Grier, Lee \& Archibald, 1984; Klemmedson, 1955), given the temperature, rainfall, and soil nitrogen at the study site.

For the Craigieburn site, the relatively high foliage-biomass values were largely a conse- quence of needle retention, not of high needle production. Needle retention has benefits in terms of carbon gain (Schulze, Fuchs \& Fuchs, 1977) and of nutrient requirements. A deciduous species such as larch is clearly disadvantaged since it must seasonally restock its carbon and nutrient pools in all its foliage.

The efficiency of foliage in stemwood production here is comparable with Larix leptolepis in Japan (Satoo, 1971), but is higher than $L$. decidua in Germany (Matyssek \& Schulze, 1987) largely because of the longer growing season in New Zealand (Benecke, Schulze, Matyssek \& Havranek, 1981). By comparison with mature stands of Douglas fir in USA (Gholz, 1982) stemwood production here is about twice as high per unit of foliage biomass, and probably reflects growth in young stands with modest respiratory carbon loss in combination with favourable summer rainfall (McCracken, 1980).

Comparisons of nutrient concentrations between stands of similar species growing in different soils and environments are fraught with many problems. Nutrient availability differs between soils, and nutrient demands vary with climate. The trend of decline in concentration of more mobile elements such as $\mathrm{P}, \mathrm{K}$, and $\mathrm{N}$ as foliage ages (Wright \& Will, 1958; Comerford, 1981; Hom \& Oechel, 1983) has been confirmed here. However, for a potentially mobile element such as $\mathrm{K}$, which was at relatively low levels in current needles, the decline with age and with depth in the canopy was comparatively modest. In Douglas fir, $\mathrm{P}$ concentrations decreased with age in the present study, whereas they increased for 3 years after fertilising with urea in a 42-yearold plantation in Oregon (Turner \& Olson, 1976). Nutrient concentrations in the European larch were similar to values for Larix laricina (Tilton, 1977), which also showed patterns of seasonal concentration decrease for $\mathrm{N}, \mathrm{P}, \mathrm{K}$, and $\mathrm{Zn}$, and concentration increase for $\mathrm{Ca}, \mathrm{B}$, and $\mathrm{Al}$ with age, that were consistent with the trends shown for the pines and Douglas fir over longer periods of needle retention. None of the species in this study contained the high concentrations of $\mathrm{Al}$ (up to $3000 \mu \mathrm{g} \mathrm{g}^{-1}$ ) found in Pinus contorta on the same site (Nordmeyer, 1980).

Calcium accumulated in the older needles of Corsican pine to levels of $0.60 \%$ and $0.40 \%$ in 
Table 3. Mean nutrient concentrations in the branches of Ponderosa pine ( $P p)$, Corsican pine $(C p)$, Douglas fir (Df), and European larch (El)

\begin{tabular}{|c|c|c|c|c|c|c|c|c|c|}
\hline \multirow{2}{*}{$\begin{array}{l}\text { Age (yrs) } \\
\text { Nutrient }\end{array}$} & \multirow[b]{2}{*}{$\mathrm{Sp}$} & \multicolumn{4}{|c|}{ Sun crown needles } & \multicolumn{4}{|c|}{ Shade crown needles } \\
\hline & & 1 & 2 & 3 & 4 & 1. & 2 & 3 & 4 \\
\hline \multirow{4}{*}{$\mathrm{N}, \mathrm{g} \mathrm{kg}^{-1}$} & $\mathrm{Pp}$ & 7.1 & 5.0 & 4.1 & 3.2 & 6.9 & 4.7 & 3.9 & 2.8 \\
\hline & $\mathrm{Cp}$ & 9.0 & 5.5 & 4.3 & 3.4 & 8.1 & 5.2 & 4.3 & 3.2 \\
\hline & Df & 12.3 & 7.3 & 5.4 & 3.7 & 11.2 & 7.8 & 5.2 & 3.4 \\
\hline & El & $7.7^{1}$ & $7.7^{2}$ & $4.3^{3}$ & & 7.1 & 7.2 & 4.4 & \\
\hline \multirow{4}{*}{$\mathrm{P}, \mathrm{g} \mathrm{kg}^{-1}$} & $\mathrm{Pp}$ & 1.3 & 0.8 & 0.6 & 0.4 & 1.2 & 0.7 & 0.5 & 0.3 \\
\hline & $\mathrm{Cp}$ & 1.2 & 0.7 & 0.5 & 0.4 & 1.1 & 0.7 & 0.5 & 0.4 \\
\hline & $\mathrm{Df}$ & 1.7 & 1.0 & 0.8 & 0.5 & 1.5 & 1.0 & 0.7 & 0.4 \\
\hline & $\mathrm{El}$ & 0.9 & 1.1 & 0.5 & & 0.9 & 0.9 & 0.5 & \\
\hline \multirow[t]{4}{*}{$\mathrm{K}, \mathrm{g} \mathrm{kg}^{-1}$} & $\mathrm{Pp}$ & 7.4 & 5.0 & 3.8 & 2.3 & 6.7 & 4.8 & 3.8 & 1.9 \\
\hline & $\mathrm{Cp}$ & 5.1 & 4.3 & 3.3 & 2.2 & 4.7 & 3.8 & 3.3 & 2.0 \\
\hline & Df & 7.7 & 5.8 & 4.5 & 2.9 & 6.8 & 5.0 & 4.0 & 2.6 \\
\hline & $\mathrm{El}$ & 6.7 & 6.9 & 2.8 & & 5.5 & 5.6 & 2.8 & \\
\hline \multirow{4}{*}{$\mathrm{Mg}, \mathrm{g} \mathrm{kg}^{-1}$} & $\mathrm{Pp}$ & 0.8 & 0.7 & 0.6 & 0.5 & 0.8 & 0.8 & 0.6 & 0.4 \\
\hline & $\mathrm{Cp}$ & 1.2 & 0.9 & 0.8 & 0.6 & 1.2 & 1.1 & 0.9 & 0.6 \\
\hline & Dff & 0.9 & 0.6 & 0.5 & 0.4 & 0.8 & 0.7 & 0.6 & 0.4 \\
\hline & El & 0.6 & 0.7 & 0.5 & & 0.6 & 0.7 & 0.5 & \\
\hline \multirow[t]{4}{*}{$\mathrm{Ca}, \mathrm{g} \mathrm{kg}^{-1}$} & $\mathrm{Pp}$ & 1.9 & 2.3 & 2.2 & 2.0 & 2.0 & 2.9 & 2.9 & 2.6 \\
\hline & $\mathrm{Cp}$ & 3.9 & 3.7 & 3.4 & 3.2 & 5.2 & 6.2 & 6.0 & 4.3 \\
\hline & Df & 3.3 & 4.3 & 4.0 & 2.8 & 4.6 & 5.9 & 5.4 & 3.0 \\
\hline & $\mathrm{El}$ & 2.8 & 2.7 & 3.3 & & 3.4 & 4.0 & 4.5 & \\
\hline
\end{tabular}

${ }^{1,2,3}$ refer to current branch, $1+2$ year branch, and $3+$ year branch components, respectively.

Table 4. Mean nutrient concentrations $\left(\mathrm{g} \mathrm{kg}^{-1}\right)$ in the stemwood and bark of Ponderosa pine, Corsican pine, Douglas fir, and European larch

\begin{tabular}{|c|c|c|c|c|c|c|}
\hline Species & Location & $\mathrm{N}$ & $\mathrm{P}$ & $\mathrm{K}$ & $\mathrm{Mg}$ & $\mathrm{Ca}$ \\
\hline \multicolumn{7}{|l|}{ WOOD } \\
\hline \multirow[t]{3}{*}{ Ponderosa pine } & mid-crown & 1.4 & 0.3 & 2.4 & 0.4 & 1.0 \\
\hline & breast height & 1.1 & 0.2 & 1.2 & 0.3 & 0.9 \\
\hline & base & 1.0 & 0.2 & 1.0 & 0.4 & 1.0 \\
\hline \multirow[t]{3}{*}{ Corsican pine } & mid-crown & 1.5 & 0.3 & 1.5 & 0.3 & 1.1 \\
\hline & breast height & 1.4 & 0.2 & 1.3 & 0.2 & 1.0 \\
\hline & base & 1.2 & 0.2 & 1.1 & 0.2 & 1.0 \\
\hline \multirow[t]{3}{*}{ Douglas fir } & mid-crown & 1.2 & 0.2 & 1.0 & 0.1 & 0.5 \\
\hline & breast height & 1.2 & 0.3 & 1.6 & 0.1 & 0.5 \\
\hline & base & 1.0 & 0.2 & 0.9 & 0.1 & 0.5 \\
\hline \multirow[t]{3}{*}{ European larch } & mid-crown & 1.2 & 0.2 & 1.0 & 0.2 & 0.7 \\
\hline & breast height & 0.9 & 0.1 & 0.7 & 0.2 & 0.7 \\
\hline & base & 0.9 & 0.1 & 0.7 & 0.1 & 0.7 \\
\hline \multicolumn{7}{|l|}{ BARK } \\
\hline \multirow{3}{*}{ Ponderosa pine } & mid-crown & 4.4 & 0.7 & 3.6 & 0.5 & 2.0 \\
\hline & breast height & 3.0 & 0.4 & 2.4 & 0.3 & 1.8 \\
\hline & base & 2.6 & 0.4 & 1.7 & 0.2 & 2.1 \\
\hline \multirow[t]{3}{*}{ Corsican pine } & mid-crown & 4.6 & 0.7 & 2.1 & 0.8 & 3.9 \\
\hline & breast height & 3.5 & 0.5 & 1.3 & 0.6 & 3.7 \\
\hline & base & 2.4 & 0.3 & 0.8 & 0.3 & 3.1 \\
\hline \multirow[t]{3}{*}{ Douglas fir } & mid-crown & 7.4 & 1.3 & 6.0 & 0.6 & 3.4 \\
\hline & breast height & 5.6 & 1.0 & 4.2 & 0.4 & 2.6 \\
\hline & base & 4.5 & 0.7 & 3.1 & 0.3 & 2.4 \\
\hline \multirow[t]{3}{*}{ European larch } & mid-crown & 6.8 & 1.2 & 5.9 & 0.7 & 3.6 \\
\hline & breast height & 5.4 & 0.9 & 4.9 & 0.6 & 4.1 \\
\hline & base & 4.7 & 0.9 & 3.8 & 0.5 & 4.6 \\
\hline
\end{tabular}

sun and shade crowns of trees in Scotland (Wright and Will, 1958). On a comparative basis Ca concentrations were $0.99 \%$ and $1.55 \%$ in the present study, but needles were retained much longer. Bark and branch concentrations were lower in the Scottish stands than those described here, and probably reflected lower $\mathrm{Ca}$ availability. 
Table 5. Nutrient contents and annual requirements in components of Ponderosa pine (Pp), Corsican pine (Cp), Douglas fir (Df), and European larch (El). Quantities are expressed in $\mathrm{kg}^{-\mathrm{ha}^{-1}}$ except for $\mathrm{Zn}, \mathrm{B}$, and $\mathrm{Cu}$ which are in $\mathrm{g} . \mathrm{ha} \mathrm{a}^{-1}$

\begin{tabular}{|c|c|c|c|c|c|c|c|c|c|}
\hline \multirow[b]{2}{*}{ Nutrient } & \multirow[b]{2}{*}{ Component } & \multicolumn{4}{|c|}{ Content } & \multicolumn{4}{|c|}{ Requirement } \\
\hline & & $\mathrm{Pp}$ & $\mathrm{Cp}$ & Df & $\mathrm{El}$ & $\mathrm{Pp}$ & $\mathrm{Cp}$ & Df & El \\
\hline \multirow[t]{5}{*}{$\mathrm{N}$} & Needles & 116 & 142 & 201 & 78 & 37 & 35 & 40 & 78 \\
\hline & Branches & 53 & 70 & 92 & 78 & 17 & 21 & 30 & 25 \\
\hline & Wood & 68 & 80 & 72 & 37 & 14 & 17 & 18 & 7 \\
\hline & Bark & 41 & 47 & 52 & 40 & 9 & 12 & 15 & 7 \\
\hline & Total & 278 & 339 & 417 & 233 & 77 & 85 & 103 & 117 \\
\hline \multirow[t]{5}{*}{$\mathrm{P}$} & Needles & 15 & 15 & 21 & 10 & 6 & 4 & 4 & 10 \\
\hline & Branches & 7 & 9 & 12 & 10 & 3 & 3 & 4 & 3 \\
\hline & Wood & 12 & 13 & 14 & 6 & 3 & 3 & 4 & 1 \\
\hline & Bark & 6 & 7 & 9 & 7 & 1 & 2 & 3 & 1 \\
\hline & Total & 40 & 44 & 56 & 33 & 13 & 12 & 15 & 15 \\
\hline \multirow[t]{5}{*}{ K } & Needles & 65 & 72 & 106 & 41 & 23 & 16 & 22 & 41 \\
\hline & Branches & 43 & 47 & 67 & 55 & 16 & 14 & 19 & 20 \\
\hline & Wood & 91 & 76 & 73 & 29 & 23 & 17 & 16 & 6 \\
\hline & Bark & 32 & 18 & 39 & 39 & 7 & 5 & 12 & 6 \\
\hline & Total & 233 & 213 & 285 & 164 & 69 & 52 & 69 & 73 \\
\hline \multirow[t]{5}{*}{$\mathrm{Mg}$} & Needles & 7 & 10 & 16 & 6 & 2 & 3 & 3 & 6 \\
\hline & Branches & 7 & 12 & 10 & 9 & 2 & 3 & 3 & 2 \\
\hline & Wood & 20 & 12 & 7 & 6 & 4 & 3 & 2 & 1 \\
\hline & Bark & 5 & 7 & 4 & 4 & 1 & 2 & 1 & 1 \\
\hline & Total & 39 & 41 & 37 & 25 & 9 & $1 \overline{1}$ & 9 & 10 \\
\hline \multirow[t]{5}{*}{$\mathrm{Ca}$} & Needles & 37 & 141 & 139 & 15 & 7 & 15 & 17 & 15 \\
\hline & Branches & 33 & 75 & 70 & 61 & 8 & 17 & 18 & 16 \\
\hline & Wood & 56 & 58 & 34 & 28 & 10 & 12 & 7 & 4 \\
\hline & Bark & 23 & 47 & 24 & 28 & 4 & 10 & 7 & 4 \\
\hline & Total & 149 & 321 & 267 & 132 & 29 & 54 & 49 & 39 \\
\hline $\mathrm{Al}$ & Needles & 2.4 & 15.4 & 11.1 & 0.5 & 0.6 & 2.2 & 1.8 & 0.5 \\
\hline $\mathrm{Mn}$ & Needles & 1.2 & 3.4 & 3.6 & 0.5 & 0.3 & 0.5 & 0.6 & 0.5 \\
\hline $\mathrm{Zn}$ & Needles & 200 & 190 & 140 & 70 & 70 & 60 & 30 & 70 \\
\hline B & Needles & 70 & 120 & 170 & 45 & 21 & 21 & 28 & 45 \\
\hline $\mathrm{Cu}$ & Needles & 27 & 28 & 29 & 15 & 11 & 7 & 8 & 15 \\
\hline
\end{tabular}

Table 6. Ratios of annual production to foliage biomass, and nitrogen content in needles ( $\mathrm{kg} \mathrm{kg}^{-1} \pm$ s.d.)

\begin{tabular}{lcccc}
\hline Component ratios & $\begin{array}{l}\text { Ponderosa } \\
\text { pine }\end{array}$ & $\begin{array}{l}\text { Corsican } \\
\text { pine }\end{array}$ & $\begin{array}{l}\text { Douglas } \\
\text { fir }\end{array}$ & $\begin{array}{c}\text { European } \\
\text { larch }\end{array}$ \\
\hline Total production & 1.8 & 1.5 & 1.5 & 3.8 \\
Total needle biomass & \pm 0.2 & 0.1 & 0.2 & 0.5 \\
Stemwood production & 0.9 & 0.8 & 0.9 & 1.6 \\
Total needle biomass & \pm 0.1 & 0.1 & 0.2 & 0.5 \\
Total production & 148 & 147 & 121 & 199 \\
Total needle nitrogen & \pm 6 & 16 & 12 & 30 \\
Stemwood production & 78 & 81 & 76 & 21 \\
Total needle nitrogen & \pm 7 & 13 & 240 & 132 \\
Total production (i) & 242 & 245 & & 51 \\
Total nitrogen requirement & & & 148 & \\
Stemwood production (i) & 129 & 133 & & \\
Total nitrogen requirement & & & & \\
\hline
\end{tabular}

(i) derived from stand data.

The role of $\mathrm{Ca}$ in tree nutrition is unclear despite large quantities being taken up and accumulated in forest biomass (Cole \& Rapp, 1981). At the cellular level, free Ca levels are strictly regulated, and the activation of
Ca-regulated processes involves calmodulin, which is itself detrimentally affected by increasing Al (Siegel \& Haug, 1983). In this study, foliage Ca:Al ratios (calculated from total nutrient pools) rank larch (33) > Ponderosa pine 
(15) $>$ Douglas fir (12) > Corsican pine (9), so that although concentrations of $\mathrm{Ca}$ were comparatively low in larch and Ponderosa pine, their $\mathrm{Ca}$ : Al ratios were higher than those of Corsican pine and Douglas fir.

The question of root cation-exchange capacity and the ability of the different tree species to take up or exclude $\mathrm{Al}$ has not been thoroughly addressed in the present study. Evidence in Fig. 2 suggests that species with apparently low cation-exchange capacity (a high ratio of $\mathrm{K}: \mathrm{Mg}+\mathrm{Ca}$-Drake, Vengris \& Colby, 1951; Knight, Crooke \& Shepherd, 1972) such as larch and Ponderosa pine have a lower uptake of $\mathrm{Al}$ and higher concentrations of $\mathrm{P}$ than Douglas fir and Corsican pine, which have lower ratios of total $\mathrm{K}: \mathrm{Mg}+\mathrm{Ca}$ in foliage. Such an explanation would be supported by the observation for ryegrass that selections resistant to $\mathrm{Al}$ toxicity were those with lower root CEC (Vose \& Randall, 1962).

Current needle production in the pines and Douglas fir was unexpectedly low considering the stands had been thinned 2 years before the study. The quantities were below $3 \mathrm{Mg}^{-1}$, much less than the $7.2 \mathrm{Mg} \mathrm{ha}^{-1}$ found in Pinus contorta growing alongside these stands (Benecke \& Nordmeyer, 1982). An unusual feature was that current needle production in Corsican pine and Douglas fir was substantially less than the biomass of needles in the 2 and 3 -year age category. For Douglas fir the biomass of 3-year-old needles ( $4.4 \mathrm{Mg} \mathrm{ha}^{-1}$ ) and current needles (2.9 $\mathrm{Mg} \mathrm{ha}^{-1}$ ) might be interpreted as an early needle response to the thinning and the later reduction of current needle production as the canopy closed. Alternatively it might be interpreted as evidence of an increase of dry matter in needles produced in earlier seasons (Madgwick \& Tamm, 1987). The latter explanation is likely since a recent study of Douglas fir needles in this stand found individual needle mass increased up to 3 years of age in all parts of the canopy (C. Maddren, pers. comm.).

The method of estimating branch production involved every branch on each tree. The current shoot branchwood plus bark accounted for $23-29 \%$ of branch production and amounted to approximately $1.0 \mathrm{Mg} \mathrm{ha}^{-1}$ in Ponderosa pine, Corsican pine, and Douglas fir. These quantities alone, which were directly measured, exceeded total branch production estimates for many stands with greater branch biomass (Cole \& Rapp, 1981; Turner, 1981). The estimated current annual branch production in Douglas fir of $4.5 \mathrm{Mg} \mathrm{ha}^{-1}$ for a total branch biomass of $20.4 \mathrm{Mg} \mathrm{ha}^{-1}$ was close to the estimate of Fujimori (1971) of $4.3 \mathrm{Mg} \mathrm{ha}^{-1}$ for a total branch biomass of $20.7 \mathrm{Mg} \mathrm{ha}^{-1}$ in Tsuga heterophylla.

Total nutrient requirements reflected the relatively high current productivity on the site, and for Douglas fir were higher than for the species in its natural habitat (Turner, 1981). Current production $(\mathrm{kg})$ per $\mathrm{kg}$ of nitrogen required was remarkably uniform in Ponderosa pine, Corsican pine, and Douglas fir $(242,245$, and $240 \mathrm{~kg}(\mathrm{kgN})^{-1}$, respectively), but was lower in European larch $\left(132 \mathrm{~kg}(\mathrm{kgN})^{-1}\right)$. This may indicate that larch needles rely more on retranslocated $\mathrm{N}$ for their annual growth than the other species. Since deciduous broadleaved species apparently translocate more $\mathrm{N}$ from old to new tissues than do most conifers (Cole \& Rapp, 1981), it is possible that larch was more similar to deciduous trees in its nutrient requirements and strategies of nutrient retranslocation (Tyrrel \& Boerner, 1987). However, retranslocation of $\mathrm{N}, \mathrm{P}, \mathrm{K}$, and $\mathrm{Zn}$ seems probable in other species as concentrations declined with needle age, and might make a contribution of $>20 \%$ to requirements (Binkley \& Reid, 1985).

The interplay between needle retention and $\mathrm{Ca}$ accumulation may also influence soil properties. Where climate or species favours foliage retention (Corsican pine and Douglas fir) litter$\mathrm{Ca}$ should exceed that where foliage is retained for shorter periods (larch and Ponderosa pine). The prospective changes in $\mathrm{Ca}$ and organic matter could then influence exchangeable $\mathrm{Al}$ in the surface soil. Any external factor such as drought, which lessened needle retention, might have a considerable influence on short- and long-term inputs of $\mathrm{Ca}$ to the soil surface.

This study confirms the high growth potential of Ponderosa pine, Corsican pine, and Douglas fir in the New Zealand high country (Lecigard \& Belton, 1986). Climatic factors appear to favour needle retention, allowing a large quantity of foliage of moderate nutritional status to be maintained. Productivity of these species is related to the total quantity of nitrogen in the foliage. 
Belton, M.C. \& Davis, M.R. 1986. Growth decline and phosphorus response by Douglas fir on a degraded high country yellow-brown earth. New Zealand Journal of Forestry Science 16, 55-68.

Benecke, U., Schulze, E.-D., Maryssek, R. \& Havranek, W.M. 1981. Environmental control of $\mathrm{CO}_{2}$-assimilation and leaf conductance in Larix decidua Mill. 1. A comparison of contrasting natural environments. Oecologia (Berlin) 50, 54-61.

Benecke, U. \& Nordmeyer, A.H. 1982. Carbon uptake and allocation by Nothofagus solandri var. cliffortioides (Hook f.) Poole and Pinus contorta Douglas ex Loudon ssp contorta at montane and subalpine altitudes. In: Carbon uptake and allocation in subalpine ecosystems as a key to management, 9-21 (ed. R.H. Waring). Oregon State University.

Binkley, D. \& Reid, P. 1985. Long-term increase of nitrogen availability from fertilization of Douglas fir. Canadian Journal of Forest Research 15, 723-724.

Clayton, J.L. \& Kennedy, D.A. 1980. A comparison of the nutrient content of Rocky Mountain Douglas fir and ponderosa pine trees. U.S. Forest Service Research Note INT 281.

Cole, D.W. \& Rapp, M. 1981. Elemental cycling in forest ecosystems. In: Dynamic properties of forest ecosystems, 341-490 (ed. D. Reichle). IBP 23, Cambridge University Press.

Cole, E.C. \& Newton, M. 1986. Nutrient, moisture, and light relations in 5-year-old Douglas fir plantations under variable competition. Canadian Journal of Forest Research 16, 727-732.

Comerford, N.B. 1981. Distributional gradients and variability of macroelement concentrations in the crowns of plantation grown Pinus resinosa (Ait.). Plant and Soil 63, 345-353.

Drake, M., Vengris, J. \& Colby, W.G. 1951. Cationexchange capacity of plant roots. Soil Science 72, 139-147.

Fujimori, T. 1971. Primary productivity of a young Tsuga heterophylla stand and some speculations about biomass of forest communities on the Oregon coast. U.S.D.A. Forest Service Research Paper $P N W-123,1-11$.

Gesse1, S.P., Cole, D.W. \& Steinbrenner, E.C. 1973. Nitrogen balances in forest ecosystems of the Pacific North-west. Soil Biology and Biochemistry 5, 19-34.

Gholz, H.L. 1982. Environmental limits on aboveground net primary production, leaf area, and biomass in vegetation zones of the Pacific North-west. Ecology 63, 469-481.

Grier, C.C., Lee, K.M. \& Archibald, R.M. 1984. Effect of urea fertilization on allometric relations in young Douglas fir trees. Canadian Journal of Forest Research $14,900-904$.

Hom, J.L. \& Oechel, W.C. 1983. The photosynthetic capacity, nutrient content, and nutrient use efficiency of different needle age classes of black spruce (Picea mariana) found in interior Alaska. Canadian Journal of Forest Research 13, 834-839.

Klemmedson, J.O. 1955. Nitrogen and carbon regimes in an ecosystem of young dense ponderosa pine in Arizona. Forest Science 21, 163-168.

Knight, A.H., Crooke, W.M. \& Shepherd, H. 1972. Chemical composition of pollen with particular reference to cation exchange capacity and uronic acid content. Journal of Science, Food and Agriculture 23, 263-274.

Krueger, K.W. 1967. Foliar mineral content of forestand nursery-grown Douglas-fir seedlings. U.S. Forest Service Research Paper PNW-45.

Ledgard, N.J. \& Belton, M.C. 1986. Exotic trees in the Canterbury high country. New Zealand Journal of Forestry Science 15, 298-323.

McCracken, I.J. 1980. Mountain climate in the Craigieburn Range, New Zealand. In: Mountain environments and subalpine tree growth (ed. U. Benecke \& M.R. Davis). New Zealand Forest Service, F.R.I. Technical Paper No.70, 41-59.

Madgwick, H.A.I. 1983. Aboveground weight of forest plots - comparison of seven methods of estimation. New Zealand Journal of Forestry Science 13, 100-107.

Madgwick, H.A.I. \& Tamm, C.O. 1987. Allocation of dry weight increment in crowns of Picea abies as affected by stand nutrition. Oikos 48,99-105.

Matyssek, R. \& Schulze, E.-D. 1987. Heterosis in hybrid larch (Larix decidua x leptolepis) II. Growth characteristics. Trees 1, 225-231.

Miller, H.G. \& Miller, J.D. 1976. Effect of nitrogen supply on net primary production in Corsican pine. Journal of Applied Ecology 13, 249-256.

Nicholson, G. 1984. Methods of soil, plant, and water analysis. New Zealand Forest Service, F.R.I. Bulletin No. 70 .

Nordmeyer, A.H. 1980. Tree nutrient concentrations near timberline, Craigieburn Range, New Zealand. In: Mountain environments and subalpine tree growth (ed. U. Benecke \& M.R. Davis). New Zealand Forest Service, F.R.I. Technical Paper No. 70, 111-124.

Nordmeyer, A.H. \& Kelland, C.M. 1982. Nitrogen balance studies in protection forests. In: Nitrogen balances in New Zealand ecosystems, 143-149 (ed. P.W Gander). New Zealand Plant Physiology Division, Department of Scientific and Industrial Research Workshop.

Ranger, J. 1978. Recherches sûr les biomasses comparées de deux plantations de Pin laricio de Corse avec ou sans fertilisation. Annales Science Forestier 35, 93-115.

Satoo, T. 1971. Primary production relations of coniferous forests in Japan. In: Productivity of forest ecosystems, 191-205 (ed. P. Duvigneaud). UNESCO.

Schulze, E.-D., Fuchs, M. \& Fuchs, M.I. 1977. Spacial distribution of photosynthetic capacity and performance in a mountain spruce forest of northern Germany. III. The significance of the evergreen habit. Oecologia (Berlin) 30, 239-248.

Siegel, N. \& Haug, A. 1983. Calmodulin-dependent formation of membrane potential in barley root plasma membrane vesicles : A biochemical model of aluminium toxicity in plants. Physiologia Plantarum 59, 285-291. 
Tilton, D.L. 1977. Seasonal growth and foliar nutrients of Larix laricina in three wetland ecosystems. Canadian Journal of Botany 55, 1291-1298.

Turner, J. 1981. Nutrient cycling in an age sequence of western Washington Douglas fir stands. Annals of Botany 48, 159-169.

Turner, J. \& Olson, P.R. 1976. Nitrogen relations in a Douglas fir plantation. Annals of Botany 40 , 1185-1195.

Tyrrel, L.E. \& Boerner, R.E.J. 1987. Larix laricina and Picea mariana: relationships among leaf life-span, foliar nutrient patterns, nutrient conservation, and growth efficiency. Canadian Joumal of Botany 65 , 1570-1577.

Vose, P.B. \& Randall, P.J. 1962. Resistance of aluminium and manganese toxicities in plants related to variety and cation-exchange capacity. Nature 196, 85-86.
Wright, T.W. \& Wili, G.M. 1958. The nutrient content of Scots and Corsican pines growing on sand dunes. Forestry 31, 13-25.

\section{Acknowledgements}

The authors wish to thank the following people for their assistance in this project: P. McDonald for organising the harvest of trees; M. Lang for nutrient analyses; G. Buckley, J. Wraight, and J. Reid for assistance in harvesting; and J. Orwin and M. Davis for review of the manuscript 



\title{
Nutrient: productivity relations in plantation- grown Sitka spruce in Scotland
}

\author{
D.C. MALCOLM and K.G. IBRAHIM \\ School of Forestry, Institute of Ecology and Resource Management, University \\ of Edinburgh
}

\begin{abstract}
Malcolm, D.C. \& Ibrahim, K.G. 1993. Nutrient : productivity relations in plantation-grown Sitka spruce in Scotland. In Management of structure and productivity of boreal and subalpine forests (ed. S. Linder \& S. Kellomäki). Studia Forestalia Suecica 191. 94 pp. ISSN 0039-3150, ISBN 91-576-4822-0.

The basis of current fertilization practice in seedling and thicket-stage new plantations of Sitka spruce in Scotland is briefly described. The development of such stands is exemplified by an age-series (4, 8 and 12 years) studied on a uniform soil type in one locality. Stand development without $\mathrm{N}$ fertilization showed an increase of above-ground biomass from 0.14 to $38 \mathrm{Mg} \mathrm{ha}^{-1}$ over the three stages while total nitrogen content progressed from 0.98 to $206 \mathrm{~kg} \mathrm{ha}^{-1}$. Analysis of components illustrated increasing allocations of carbon to stem and branches with reductions to foliage so that proportions were about equal at age 12 . Foliage $\mathrm{N}$ still accounted for more than $60 \%$ of the total $\mathrm{N}$ uptake. Growth analyses demonstrated linearity between ages in total and component growth with almost identical relative growth $(0.69)$ and relative $\mathrm{N}$ uptake $(0.66)$ rates. The possibility and desirability of maximising Sitka spruce productivity in forest practice is discussed.
\end{abstract}

Key words: Picea sitchensis, nitrogen, uptake, productivity, biomass, canopy development, growth analysis.

D.C. Malcolm and K.G. Ibrahim, School of Forestry, Institute of Ecology and Resource Management, University of Edinburgh, Edinburgh EH9 3JU, U.K.

MS. received 4 November 1992

MS. accepted 11 January 1993

\section{Introduction}

In the last fifty years Sitka spruce (Picea sitchensis (Bong.) Carr.) has become the main species in Scottish forestry. The predominance of this species is a result of its ease of establishment, the high productivity obtainable (Hamilton \& Christie, 1971) and the versatility of its timber. Of all the exotic species tested, Sitka spruce is clearly the best adapted to the oceanic climate of Scotland with the high precipitation, low vapour pressure deficits and high mean wind speeds encountered over much of the country. In the east and at low elevations soil water deficits may accrue in spring and early summer thereby reducing potential productivity, but generally water supply is not a major limiting factor. The combination of favourable ecological and economic characteristics has thus encouraged the use of Sitka spruce on a wide range of site types of varying inherent fertilities.

The complex geology, glacial geomorphology and topography in Scotland gives rise to a mosaic of site types, which sometimes occur on a small scale pattern, and which ideally require different cultural practices to achieve plantation establishment. Added to this complexity a land use history of early deforestation followed by centuries of extensive pastoralism and its attendant burning of vegetation has meant that some site types have been nutritionally impoverished. The tendency for many sites to accumulate peaty organic matter in the cool wet upland conditions further limits nutrient availability because of low mineralization rates.

Early in the development of afforestation it was recognized that on many of the poorer sites nutrient additions were required to effect satisfactory establishment. Many experiments testing different nutrients, rates and times of application were conducted on a range of sites and species but with an increasing emphasis on the needs 
of Sitka spruce. These experiments demonstrated the overall requirement for phosphorus (P) on almost all upland soils, the need for potassium $(\mathrm{K})$ on organic soils where peat depths exceeded $30 \mathrm{~cm}$ and the benefit of nitrogen $(\mathrm{N})$ additions on only the poorest heathland mineral soils and deep oligotrophic peats and then only if pure stands of Sitka spruce are desired. A complicating feature on the poorer sites was the competition experienced by spruce from ericaceous vegetation which sometimes is difficult to distinguish from low $\mathrm{N}$ availability. Rates of application are now standardised (N-160, P-60, K-100 $\mathrm{kg} \mathrm{ha}^{-1}$ ) and are compromises between cost and growth responses.

The responses of newly planted trees and the need for repeated applications to achieve canopy closure have been shown to vary with soil type, broad vegetation classes and the underlying lithology (Taylor and Worrell, 1991). Essentially the responses are smaller but perhaps of longer duration the more fertile the site in terms of the above factors. Responses to $\mathrm{P}$ and $\mathrm{K}$ last about 6-8 years but only for 3 years with $N$, the need for which is strongly influenced by the lithology (Taylor and Tabbush, 1990).

The aim of much of this applied research, over the last 60 years, has been to achieve canopy closure in the most cost-effective way rather than to maximise productivity within the constraints of climate. Once canopy closure has been attained the possibility of enhanced productivity through continued nutrient inputs is much reduced (Miller, 1981) and this has been the experience in most polestage experiments, where economic responses have been few. With this limited aim much of the research has been reported in terms of relative increases of growth in height or diameter over control values and of correlations between growth rate and upper whorl nutrient concentration. These variables are clearly important in practice but do not offer much explanation of how the desired growth responses are achieved.

The influence of enhanced availability of nutrients on productivity operates through its effect on net photosynthesis and the allocation of fixed carbon to the various parts of the tree. Attention therefore focuses on the effects of nutrient supply on the foliage, its distribution and efficiency through the canopy. The rate of growth in foliage biomass is critically important to productivity through the leaf area available to intercept radiant energy which is strongly affected by nutrient availability. Ingestad (e.g. 1987) and his co-workers have demonstrated in numerous laboratory and field experiments that steady-state nutrition implies that the relative growth rate (RGR) is equal to the relative uptake rate of $\mathrm{N}\left(R_{N}\right)$ and that it is linearly related to the flux density (amount available per unit of soil per unit time) accessible to the root system.

Despite the large areas of Sitka spruce plantations there is almost no published information on the biomass or leaf nutrient distributions in the canopy of young stands prior to canopy closure. This paper describes a study of the increase of foliage area, and mass allocation of above-ground growth in relation to $\mathrm{N}$ uptake in young Sitka spruce stands before canopy closure. The aim was to test the hypothesis that early growth is exponential and that there is close correspondence between above-ground biomass accumulation and $\mathrm{N}$ uptake.

In this work it was not possible to assess allocation to below-ground organs, so that only above-ground development is reported here. Root production data and a measure of nutrient flux density would be required to fully test the Ingestad hypothesis in a field situation.

\section{Materials and methods}

\section{Overall biomass and nutrient distributions}

Three stands of first rotation Sitka spruce (ca. 2500 stems ha ${ }^{-1}$ ) were selected in the valley of the River Tweed $\left(55^{\circ} 38^{\prime} \mathrm{N}, 3^{\circ} 08^{\prime} \mathrm{W}\right)$ some $40 \mathrm{~km}$ south of Edinburgh. The stands at 4,8 and 12 years old were planted on spaced-furrow ploughing on mid to lower colluvial slopes overlying Ordovician sediments. The soils were stony upland brown earths (Code lu; Pyatt, 1982) which are freely drained and on which fertilizer applications are not normally expected although each site did receive $50 \mathrm{~kg} \mathrm{P} \mathrm{ha}^{-1}$ (as rock phosphate) at planting. Precipitation at these sites is about $850-900 \mathrm{~mm} \mathrm{yr}^{-1}$ and they may develop small soil water deficits in early summer.

In 1984 at each age, 3 plots (0.04 ha) were selected and all trees measured for height and 
Table 1. Stand data based on $3 \times 0.04$ ha plots at each stage. Means ( $\pm S E$ where appropriate)

\begin{tabular}{|c|c|c|c|}
\hline & Stage 1 & Stage 2 & Stage 3 \\
\hline Age (yrs) & 4 & 8 & 12 \\
\hline Stem nos & 235 & 281 & 250 \\
\hline Height $(\mathrm{m})$ & $0.67 \pm 0.01$ & $1.77 \pm 0.03$ & $4.30 \pm 0.04$ \\
\hline Basal diameter $(\mathrm{cm})$ & $1.21 \pm 0.02$ & $3.95 \pm 0.15$ & $11.25 \pm 0.33$ \\
\hline Basal area $\left(\mathrm{m}^{2} \times 10^{-4}\right)$ & $1.21 \pm 0.04$ & $14.00 \pm 1.00$ & $98.00 \pm 3.00$ \\
\hline Stand density (nos. ha- ${ }^{-1}$ ) & $1958-0$ & 2342 & 2083 \\
\hline${ }^{1}$ Basal area $\left(\mathrm{m}^{2} \mathrm{ha}^{-1}\right)$ & 0.24 & 4.07 & 20.35 \\
\hline${ }^{2}$ Top whorl N (\% d wt) & 1.26 & 1.53 & 1.20 \\
\hline Top whorl $\mathbf{P}(\% \mathrm{~d}$ wt $)$ & 0.15 & 0.16 & 0.11 \\
\hline Top whorl $\mathrm{K}(\% \mathrm{~d} w t)$ & 0.97 & 0.71 & 0.74 \\
\hline
\end{tabular}

${ }^{1}$ Basal area calculated by summing over the cross-sectional area distributions within each plot.

${ }^{2}$ Nutrient values are means of sampled trees at each stage $(20,10$ and 5 resp.).

basal diameter at ground level. Stand data are in Table 1 and details of field and laboratory sampling and analytical procedures are described by Ibrahim (1990). Sample trees were selected randomly on the basis of the diameter distributions in the 3 plots at each stage. Sample trees, felled between October and March, were divided into components by whorls, weighed fresh (subsampled in older plots), before laboratory determination of dry weight and projected leaf area (LiCor Li-3100). Foliage was separated into $1,2,3$ and $4+$ year age classes. Total dry weight per tree was obtained by addition of components. In all 35 trees were sampled (20, 10 and 5 in ages $4,8,12$ ). Nitrogen, phosphorus and potassium concentrations were determined for each component.

The nutrient values for top whorl foliage (Table 1) were above recognised deficiency levels (Binns, Mayhead \& Mackenzie, 1980) although $\mathrm{P}$ would be considered marginal in age 12 .

\section{Results}

A suite of linear regression equations was developed relating biomass components, leaf area and nutrient contents for each age. Coefficients of determination varied between 0.69 and 0.99 . The variability in the data declined with increasing age despite the lower sample numbers. On the whole, basal diameter was a slightly better predictor of biomass variables than cross-sectional area. A comparison of the values of dry mass derived from either measurement, using a stand table approach or by summing predicted mass for each tree in the plot, or those derived from the mean dry mass of the sampled trees showed them to be very close. The latter method was adopted.

The biomass and nutrient contents of the main components are given on a unit area basis in Table 2. Although the total biomass increases from 139 to $38126 \mathrm{~kg} \mathrm{ha}^{-1}$ from age 4 to 12 the proportion of leaf mass falls from 0.45 to 0.31 as branch and stem weight increases. At age 12, dry weight distribution of these three main components is approximately equal.

The content of nutrients in the foliage expressed as a proportion of the total nutrient of the trees is constant between ages 4 and 8 but then declines between ages 8 and 12. Foliar $\mathrm{N}$ declines from $70 \%$ to $60 \%$, foliar P from $60 \%$ to $50 \%$ and foliar $\mathrm{K}$ from $70 \%$ to $50 \%$. However if nutrient proportions in the leaf mass are examined, the NPK ratios are $8: 1: 6$, $10: 1: 4.5$ and $12: 1: 5.5$ in ages $4-12$ respectively, suggesting that the $\mathrm{P}$ status of age 12 is

Table 2. Total biomass and NPK contents by components (values in $\mathrm{kg} \mathrm{ha}^{-1}$ )

\begin{tabular}{lccc}
\hline Component & Age 4 & Age 8 & Age 12 \\
\hline Total biomass & 139 & 3353 & 38126 \\
$\mathrm{~N}$ & 0.98 & 26.70 & 206.84 \\
$\mathrm{P}$ & 0.15 & 3.04 & 20.83 \\
$\mathrm{~K}$ & 0.81 & 13.12 & 114.77 \\
Stem biomass & 41 & 1039 & 13253 \\
$\mathrm{~N}$ & 0.15 & 2.58 & 33.33 \\
$\mathrm{P}$ & 0.03 & 0.47 & 4.79 \\
$\mathrm{~K}$ & 0.13 & 1.64 & 28.75 \\
Branch biomass & 35 & 1016 & 13008 \\
$\mathrm{~N}$ & 0.14 & 4.68 & 46.65 \\
$\mathrm{P}$ & 0.03 & 0.94 & 5.62 \\
$\mathrm{~K}$ & 0.13 & 3.28 & 28.75 \\
Leaf biomass & 63 & 1298 & 11866 \\
$\mathrm{~N}$ & 0.70 & 19.44 & 127.27 \\
$\mathrm{P}$ & 0.09 & 1.87 & 10.42 \\
$\mathrm{~K}$ & 0.57 & 8.20 & 57.28 \\
\hline
\end{tabular}


marginally low as was noticed in the upper whorl concentrations (Table 1).

Division of the leaf mass into 4 age classes (Table 3) showed the expected decline in weight with increasing needle age and a corresponding reduction in nitrogen content in all stages. Oneyear-old needles accounted for $76 \%$ of total dry mass of needles in age $4,59 \%$ and $38 \%$ in ages 8 and 12 .

\section{Leaf area and nitrogen relations}

Leaf area indices (LAI) were calculated using the relation of total leaf area to cross-sectional area through the stand table approach. The LAI at each age was $0.04,0.61$ and 4.17 respectively.

Because initial plots of leaf area against whorl height revealed irregular distributions, in the as yet unclosed canopies, the distributions were normalized. Internode length was normalized with respect to the length of live crown and the leaf area within an internode with respect to the total leaf area. The vertical distribution of calculated leaf area density ( $\mathrm{LAD} \mathrm{m}^{-1}$ ) was fitted to a beta function for each age class of needles as is shown in Fig. 1. The contribution of each class to LAI is given in Table 4, illustrating the increasing proportion of 2-year-old and older needles with stand canopy development. The height of maximum leaf area in the crown also

Table 3. Leaf mass and $N$ content by leaf age class (values in $\mathrm{kg} \mathrm{ha}^{-1}$ )

\begin{tabular}{|c|c|c|c|c|c|c|}
\hline \multirow{2}{*}{$\begin{array}{l}\text { Leaf } \\
\text { Age } \\
\text { (yr) }\end{array}$} & \multicolumn{2}{|l|}{ Age 4} & \multicolumn{2}{|l|}{ Age 8} & \multicolumn{2}{|c|}{ Age 12} \\
\hline & Mass & $\mathrm{N}$ & Mass & $\mathrm{N}$ & Mass & $\mathrm{N}$ \\
\hline 1 & 48 & 0.56 & 771 & 12.2 & 4463 & 59.2 \\
\hline 2 & 11 & 0.11 & 337 & 4.7 & 3411 & 35.4 \\
\hline 3 & 4 & 0.03 & 138 & 1.6 & 2101 & 18.7 \\
\hline $4+$ & 0 & 0.00 & 52 & 0.7 & 1688 & 13.7 \\
\hline
\end{tabular}

Table 4. Distribution of LAI over needle age class (figures in brackets are \% of total)

\begin{tabular}{clllllll}
\hline \multicolumn{9}{c}{$\begin{array}{l}\text { Needle Age Class } \\
\text { Age }\end{array}$} & 1 & 2 & 3 & 4 & Total & $\begin{array}{l}\text { Crown } \\
\text { depth }\end{array}$ \\
\hline 4 & 0.028 & 0.007 & 0.004 & - & 0.039 & 0.70 \\
& $(72)$ & $(18)$ & $(10)$ & - & & \\
8 & 0.359 & 0.147 & 0.068 & 0.036 & 0.611 & 1.74 \\
& $(59)$ & $(24)$ & $(11)$ & $(6)$ & & \\
12 & 1.589 & 1.203 & 0.735 & 0.641 & 4.168 & 4.12 \\
& $(38)$ & $(29)$ & $(18)$ & $(15)$ & & \\
\hline
\end{tabular}

increases with stand age as canopy closure commences.

It is well-known that soluble nitrogen in tree crowns is translocated from leaves that are approaching senescence. This translocation conserves nitrogen vis à vis further uptake and creates an internal nutrient cycle within the tree (Miller, 1981) that ensures those leaves receiving the higher radiation inputs have the highest leaf $\mathrm{N}$ contents. It would be expected therefore that the distribution of leaf $\mathrm{N}$ would closely follow that of leaf area density. Leaf $\mathrm{N}$ mass density ( $\mathrm{g}$ $\mathrm{m}^{-3}$ ) was derived in the same way as LAD by normalizing in respect of height and whorl and fitted with the same beta function. The vertical distributions of leaf $\mathrm{N}$ mass density had the same trends as leaf area density but with somewhat different parameters. If the relative leaf $\mathrm{N}$ mass for each needle age class is plotted against its corresponding relative leaf area, both accumulated from the top of the canopy downwards, very highly significant linear relationships are found which almost pass through the origin with slopes almost equal to 1.0 $\left(r^{2}>0.97\right)$. The data for all needle ages for each stage is shown in Fig. 2 where it can be seen that there is some suggestion of departure from linearity in the needles at the top of the canopy at age 12. This might be an expression of the tendency for optimal $N$ concentrations to decline as the canopy closes (Miller, 1981).

\section{Growth analyses}

In absolute terms the mean annual growth rate for total above-ground biomass was $4730 \mathrm{~kg}$ $\mathrm{ha}^{-1}$ calculated over the 8 -year age difference between age 4 and 12 . The corresponding annual $\mathrm{N}$ uptake was $25.6 \mathrm{~kg} \mathrm{ha}^{-1}$. In both cases the rates increased by large factors between the two 4-year time intervals $(\times 10$ for biomass, $\times 7$ for $\mathrm{N}$ ). As absolute growth rates are less useful for comparative purposes the mean relative growth rates $(\bar{R})$ and mean relative $\mathrm{N}$ uptake $\left(\bar{R}_{N}\right)$ were calculated for each time interval (ages 4-8, 8-12, 4-12) and for each component. Values for the whole period are equivalent to the mean of the two separate periods and are given in Table 5 . The mean age $4-12$ data can also be derived by plotting the logarithmic values of the variables measured at each age against time. The slope of the straight line plot then gives $R$. These equa- 


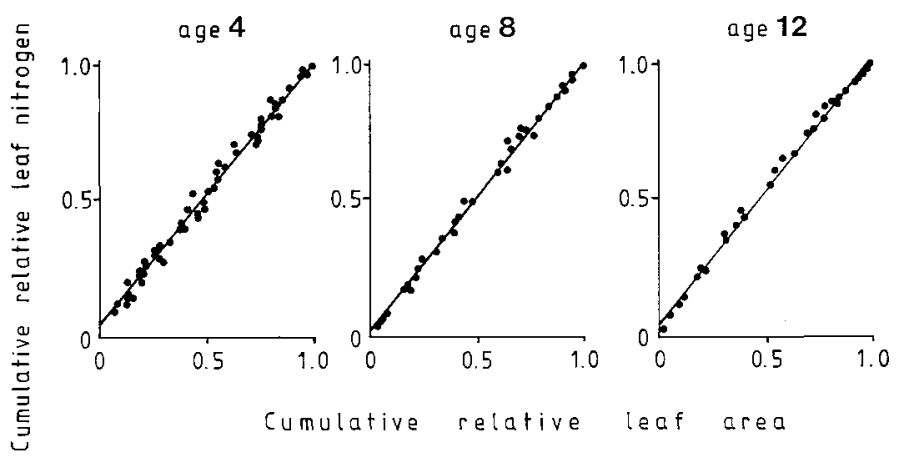

Fig. 1. Distribution of leaf area density $\left(\mathrm{m}^{2} \mathrm{~m}^{-3}\right)$ by age classes at relative heights in the canopy. Canopy heights are $0.70,1.74$ and $4.12 \mathrm{~m}$ in stages 1,2 and 3 .

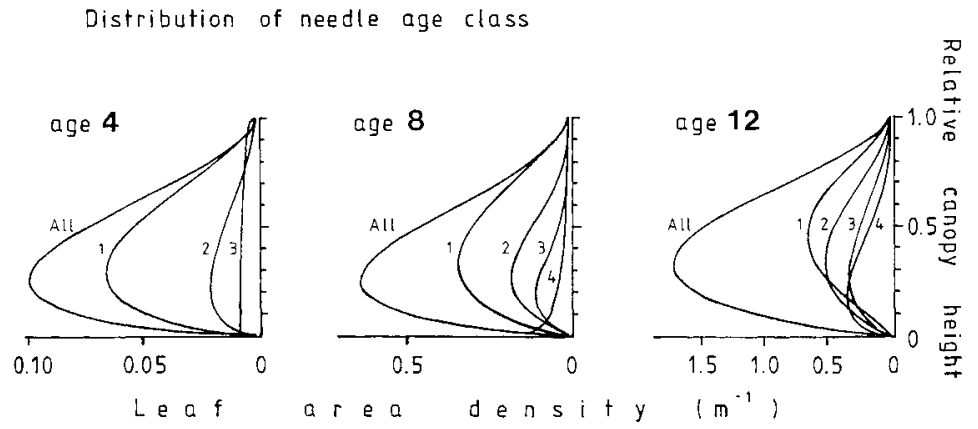

Fig. 2. Relationship between relative needle $\mathrm{N}$ mass and relative leaf area for all needle age classes at each stage. Values are accumulated from the top of the canopy.

tions (Table 5) were highly significant $\left(\mathrm{r}^{2}>0.98\right)$ and showed that the relative growth rate and nitrogen uptake were very close $(R=0.69$ and $R_{N}=0.66$ ), indeed less than $1 \mathrm{SE}$ of the slopes apart.

All $R$ values declined in the second period, except for stem nitrogen. The relative growth rate of branch and stem biomass were higher in both periods than that of foliage which declined from 0.71 to 0.58 in mass but from 0.61 to 0.57 in area between ages $8-12$. That the relative increase in foliage area did not decline so much as that of foliar mass is probably because of changes in specific leaf area lower in the crowns as the canopy began to close (Ibrahim, 1990).

To further investigate the relations between different plant parts and their $\mathrm{N}$ uptake the $\bar{R}$ values were divided according to a procedure recommended by Hunt and Bazzaz (1980). Mean relative growth rate was subdivided according to the $\tilde{R}$ of the component and the ratio of that part to the whole. The quantity $(\bar{J})$ de-

Table 5. Relative growth rates and relative nitrogen uptake rates by components. Periodic values are the slopes (b) of linear regressions. Standard errors and intercepts are for the period 4-12 years

\begin{tabular}{lllllc}
\hline Component & Age 4-8 & $8-12$ & $4-12(\mathrm{~b})$ & SE & Intercept \\
\hline$R$ (Total dry mass) & 0.75 & 0.64 & 0.69 & 0.033 & -5.34 \\
$R_{s}$ (Stem dry mass) & 0.76 & 0.67 & 0.71 & 0.028 & -6.66 \\
$R_{b}$ (Branch dry mass) & 0.79 & 0.67 & 0.73 & 0.038 & -6.88 \\
$R_{l}$ (Leaf dry mass) & 0.71 & 0.58 & 0.65 & 0.037 & -5.93 \\
$R_{A}$ (Leaf area) & 0.61 & 0.57 & 0.59 & 0.014 & -3.88 \\
$R_{N}$ (Total N) & 0.78 & 0.54 & 0.66 & 0.068 & -10.08 \\
$R_{S n}$ (Stem N) & 0.66 & 0.67 & 0.66 & 0.001 & -12.11 \\
$R_{b n}$ (Branch N) & 0.83 & 0.60 & 0.72 & 0.067 & -10.31 \\
$R_{l n}$ (Leaf N) & 0.78 & 0.50 & 0.64 & 0.082 & -10.3 \\
\hline
\end{tabular}

Linear regressions $(\ln W=a+b t)$ where $W=$ weight of component for given period. All $\mathrm{r}^{2}$ values exceed 0.98 . 
rived is termed the component production rate (CPR) and is an index of the allocation in the plant to the production of that component at that time. Assuming a constant $R$ over the whole period the values of $J$ were calculated at each age (Table 6). The results emphasise the proportional increase in the rate of allocation to stems and branches across the period and conversely the reduction in resources allocated to foliage production as the canopy closes. The latter is paralleled by the reduction in the proportion of $\mathrm{N}$ diverted to leaves. In a productive Sitka spruce stand Ford (1982) noted an 11\% reduction in foliage production after maximum basal area increment was attained but his stand was 5 years older than the age 12 stand, which is unlikely to have yet culminated its basal area increment.

Mean net assimilation rates $(E)$ and leaf area ratios $(F)$ were calculated for each time interval (Table 7) and showed a 33\% decrease in $\bar{F}$ in the second period with an increase in $\bar{E}$ from $0.33 \mathrm{~kg} \mathrm{~m}^{-2} \mathrm{yr}^{-1}$ to $0.42 \mathrm{~kg} \mathrm{~m}^{-2} \mathrm{yr}^{-1}$ from the first to the second interval. These values are quite high compared to Ford's (1982) estimate of $0.24 \mathrm{~kg} \mathrm{~m}^{-2} \mathrm{yr}^{-1}$ in his older stand, which had $27 \mathrm{Mg} \mathrm{ha}^{-1}$ foliage compared to the $12 \mathrm{Mg}$ $\mathrm{ha}^{-1}$ at age 12 here.

The concept of nitrogen productivity, $P_{N}$, (Ingestad, 1987) is analogous to that of $\bar{E}$ in that it expresses biomass produced per unit of nitrogen per unit time. $P_{N}$ can be used to explain the strong relationships often found between $R$ and plant nitrogen concentration $\left(N / W=N_{\mathrm{C}}\right)$. $\bar{N}_{\mathrm{C}}$ can be calculated similarly to $\bar{F}$ (Table 7 ). $P_{N}$ was found to be $100 \mathrm{~kg} \mathrm{kgN}^{-1} \mathrm{yr}^{-1}$ in the first period and then declined slightly to $98 \mathrm{~kg} \mathrm{kgN}^{-1} \mathrm{yr}^{-1}$ in the second. Nitrogen productivity would be expected to decrease with increasing foliar biomass because of self-shading or water stress or increased respiration by nonphotosynthetic tissue when the canopy closed (Ingestad, 1981; ̊̊gren, 1983). Nitrogen productivity on a leaf $\mathrm{N}$ basis was $138 \mathrm{~kg} \mathrm{kgN}^{-1}$ $\mathrm{yr}^{-1}$ initially and increased to $147 \mathrm{~kg} \mathrm{kgN}^{-1}$ $\mathrm{yr}^{-1}$ in the second period (age 8-12).

From Table 7 the products of $\bar{E} * \bar{F}$ and $\bar{P}_{N} * \bar{N}_{\mathrm{C}}$ are almost identical and equal to RGR. It can be surmised that the failure to maintain the fraction of $\mathrm{N}$ allocated to the leaf leading to a reduced leaf $N_{C}$ was responsible for the reduced $\bar{R}$ value in the second interval, i.e. between ages 8 and 12. The plant total $\mathrm{N}$ concentration was $7.1 \mathrm{mg} \mathrm{g}^{-1}$ at age $4,8.3 \mathrm{mg} \mathrm{g}^{-1}$ at age 8 and fell to $5.6 \mathrm{mg} \mathrm{g}^{-1}$ at age 12 .

\section{Discussion}

One of the main difficulties in adopting an ageseries approach to a study of this kind is in ensuring that the different sites are comparable.

Table 6. Component production rates $(J)$

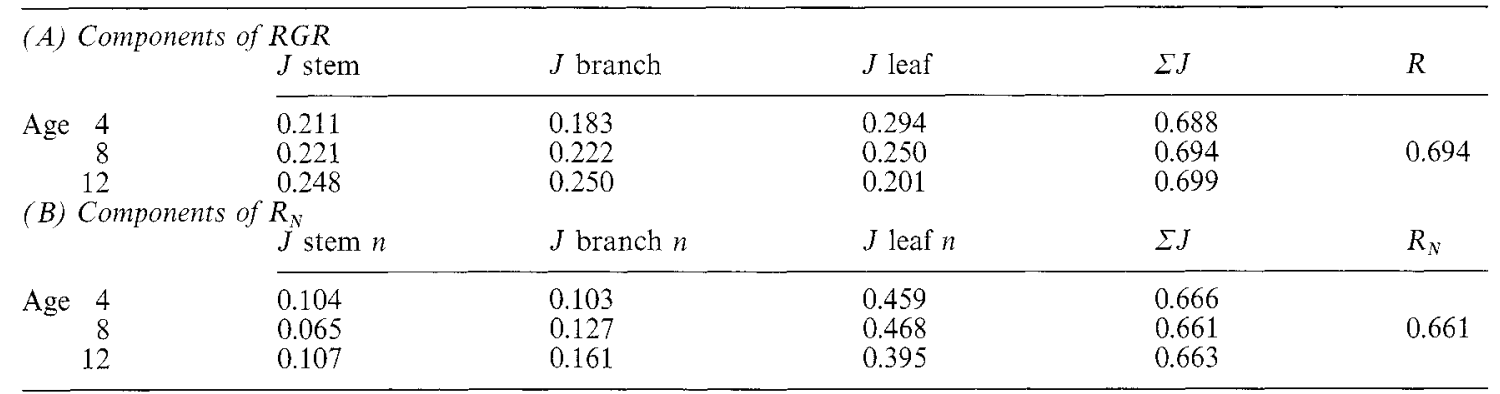

Table 7. Calculated values for leaf, nitrogen and growth rate variables

\begin{tabular}{lllllllll}
\hline Age & $\bar{E}$ & $\bar{F}$ & $\bar{E} \times \bar{F}$ & $P_{N}$ & $\bar{N}_{C}$ & $\bar{P}_{N} \times \bar{N}_{C}$ & $\bar{P}_{l n}$ & $\bar{R}$ \\
\hline $4-8$ & 0.33 & 2.26 & 0.75 & 100 & 7.5 & 0.75 & 138 & 0.75 \\
$8-12$ & 0.42 & 1.51 & 0.63 & 98 & 6.5 & 0.64 & 147 & 0.64 \\
$4-12$ & 0.36 & 1.94 & 0.69 & 112 & 6.2 & 0.69 & 170 & 0.69 \\
\hline
\end{tabular}

$E=$ leaf efficiency $\left(\mathrm{kg} \mathrm{m}^{-2} \mathrm{yr}^{-1}\right) ; F=$ leaf area ratio $\left(\mathrm{m}^{2} \mathrm{~kg}^{-1}\right) ; P_{N}=$ plant nitrogen productivity $\left(\mathrm{kg} \mathrm{kgN}^{-1} \mathrm{yr}^{-1}\right)$; $N_{C}=$ plant $\mathrm{N}$ concentration $\left(\mathrm{mg} \mathrm{N} \mathrm{g} \mathrm{g}^{-1}\right) ; P_{l n}=$ leaf $\mathrm{N}$ productivity $\left(\mathrm{kg} \mathrm{kgN}^{-1} \mathrm{yr}^{-1}\right) ; R=$ relative growth rate $\left(\mathrm{kg} \mathrm{kg}^{-1} \mathrm{yr}^{-1}\right)$. 
Although the sites were selected on the same soil type in similar topographic positions they could not be expected to be identical in every respect that affects stand development. The alternative approach of following the progress of an individual stand was not possible. There are of course many stands for which detailed mensurational data are available but few at this density have been measured in such detail before canopy closure. The aim in this case was to examine the progress of planted stands on a supposedly nutritionally unlimited site and to confirm that exponential growth in biomass occurred in relation to nutrient supply and uptake. The almost identical calculated $\bar{R}$ and $\bar{R}_{N}$ values over the 8-year difference between ages 4 and 12 demonstrate equal exponentiality of growth rate and nitrogen uptake.

Despite the concurrence of $R$ and $R_{N}$, the nutrient supply, as shown by nitrogen, was not optimally available. This is suggested by the top whorl foliar concentrations (Table 1 ) and the reduction in leaf and overall concentrations between ages 8 and 12 . It is difficult to say whether this was a growth effect or a difference between sites. Clearly major changes in the pattern of allocation of carbon and nutrients occur as competition within and between individuals intensifies at canopy closure (Ford, 1984). The change in allocation pattern as the stem becomes an increasingly important sink was paralleled in this case by the lower leaf production at age 12 which may have reflected changes in the radiation regime in the lower canopy where specific leaf area was shown to increase considerably (Ibrahim, 1990). Up to this stage more than $60 \%$ of the production was in leaf and branch which together contain over $75 \%$ of the $\mathrm{N}, \mathrm{P}$ and $\mathrm{K}$ nutrients. Once canopy closure occurs these nutrients will be diverted to upper, more illuminated parts of the canopy and a nutrient cycle involving litter deposition will commence. At age 12 there was as yet negligible litter.

In practical forestry it is considered that these sites do not justify fertilizer inputs, with the possible exception of an initial addition of $P$. Cultivation is only advised to provide a weedfree planting position, the drainage and rooting depths being good. Even the shallow cultivation involved may stimulate some loss of mineral $\mathrm{N}$ in the early years after planting until root systems can spread beyond the furrows. For this reason the youngest age was selected at 4 years. It is apparent however that, to the extent that these stands are not limited by water supply, they would respond to addition of fertilizer before canopy closure. To avoid leaching losses nutrients ideally would have to be provided in relation to the existing mineralization rate (Ingestad, 1988). Constraints on adopting such a practice are both logistical and economic.

It is not certain what the maximal growth rate on these sites might be. For this part of Scotland at these elevations $(250-300 \mathrm{~m})$, Worrell and Malcolm's (1990) model predicts a probable yield class of about 18 (max. m.a.i., $\mathrm{m}^{3}$ $\left.\mathrm{ha}^{-1} \mathrm{yr}^{-1}\right)$. An additional $2 \mathrm{~m}^{3} \mathrm{ha}^{-1} \mathrm{yr}^{-1}$ would be added in respect of the brown earth soil type. The highest growth rate estimated so far in the British Isles for Sitka spruce is for a stand of apparent yield class 36 in County Clare, Eire (Davies, 1982). Interestingly Wang, Jarvis \& Taylor (1991) demonstrated a $\mathrm{N}$ response in polestage Sitka spruce, both thinned and unthinned, and on theoretical grounds of leaf area distribution and absorbed PAR these authors predicted a potential maximum of above-ground biomass production at $36 \mathrm{Mg} \mathrm{ha}^{-1} \mathrm{yr}^{-1}$.

While it is clearly desirable to understand the processes that control productivity and their interaction with site variables, including nutrient flux density, there are several problems in the practical application of the findings of such research. Saw timber is the main market sought by forest management in Britain for the large areas of Sitka spruce forest but unfortunately, fast radial growth in this species results in low average density and poor sawing and drying qualities. A radial growth rate not exceeding that associated with stands of yield class 18 is thought acceptable, in stands established at 2500 stems ha ${ }^{-1}$. Thus attempts to determine maximum productivity, in this species, may not have practical significance.

Finally, the field study of carbon fixation, its subsequent allocation and the influence of nutrient supply on both, provides data on which process models can be further developed or validated. These models may lead to a better appreciation of the influence of silvicultural practices but research findings will not be translated into standard forest or stand treatments unless an economic benefit is demonstrable. With respect to Sitka spruce it is also worth 
noting that at elevations over $250 \mathrm{~m}$ up to the commercial planting limit of about $550 \mathrm{~m}$ a.s.1. some $80 \%$ of the variation in productivity can be accounted for by simple climatic measures,

\section{References}

Ågren, G.I. 1983. Nitrogen productivity of some conifers. Canadian Journal of Forest Research 13, 494-500.

Binns, W.O., Mayhead, G.J. \& Mackenzie, J.M. 1980. Nutrient deficiencies of conifers in British forests. Forestry Commission Leaflet 76. HMSO, London.

Davies, E.J.M. 1982. A pilgrimage to Mount Callan. Scottish Forestry 36, 283-286.

Ford, E.D. 1982. High productivity in a polestage Sitka spruce stand and its relation to canopy structure. Forestry 55, 1-17.

Ford, E.D. 1984. The dynamics of plantation growth. In: Nutrition of plantations (ed. G.W. Bowen \& S. Nambiar), 17-52. London: Academic Press.

Hamilton, G.J. \& Christie, J.M. 1971. Forest Management Tables (Metric). Forestry Commission Booklet 34. HMSO, London.

Hunt, R. \& Bazzaz, F.A. 1980. The biology of Ambrosia trifida L. V. Response to fertilizer, with growth analysis at the organismal and sub- organismal levels. New Phytologist 84, 113-121.

Ibrahim, K.G. 1990. The uptake and dynamics of nitrogen in young stands of Sitka spruce. Unpubl. Ph.D. thesis, University of Edinburgh. $178 \mathrm{pp}$.

Ingestad, T. 1981. Nutrition and growth of birch and grey alder seedlings in low conductivity solutions and at varied relative rate of nutrient additions. Physiologia plantarum 52, 454-466.

Ingestad, T. 1987. New concepts on soil fertility and plant nutrition as illustrated by research on forest trees and stands. Geoderma 40, 237-252.

Ingestad, T. 1988. A fertilization model based on the e.g. accumulated temperature and mean wind speed (Worrell \& Malcolm, 1990). The contribution of soil type and therefore nutrient availability is small by comparison. concepts of nutrient flux density and nutrient productivity. Scandinavian Journal of Forest Research 3, 157-173.

Miller, H.G. 1981. Forest fertilization: some guiding concepts. Forestry 54, 157-167.

Pyatt, D.G. 1982. Soil classification. Forestry Commission Research Information Note $68 / 82 / S S N$. Forestry Commission, Edinburgh.

Taylor, C.M.A. \& Tabbush, P.M. 1990. Nitrogen deficiency in Sitka spruce plantations. Forestry Commission Bulletin 89. HMSO, London.

Taylor, C.M.A. \& Worrell, R. 1991. Influence of site factors on the response of Sitka spruce to fertiliser at planting in Upland Britain. Forestry 64, 13-28.

Wang, Y.P., Jarvis, P.G. \& Taylor, C.M.A. 1991. PAR absorption and its relation to above-ground dry matter production of Sitka spruce. Journal of applied ecology 28, 547-560.

Worrell, R. \& Malcolm, D.C. 1990. Productivity of Sitka spruce in Northern Britain. 1. The effects of elevation and climate. Forestry 63, 105-118.

\section{Acknowledgements}

The Lothian and Borders Forest District, Forestry Commission South Scotland Conservancy kindly permitted destructive sampling. Technical assistance in the field and laboratory was provided by Mr A. Gray. 